\author{
UNIVERSIDADE DE SÃO PAULO \\ FACULDADE DE ARQUITETURA E URBANISMO
}

RICARDO ARENDT STIEBLER COUTO

O USO DE FERRAMENTAS DE GEOPROCESSAMENTO PARA O GERENCIAMENTO DE BENS PATRIMONIAIS E PREDIAIS 
RICARDO ARENDT STIEBLER COUTO

\section{O USO DE FERRAMENTAS DE GEOPROCESSAMENTO PARA O GERENCIAMENTO DE BENS PATRIMONIAIS E PREDIAIS}

Dissertação apresentada a Faculdade de Arquitetura e Urbanismo da Universidade de São Paulo, como requisito para obtenção do titulo de Mestre em Arquitetura e Urbanismo.

Área de Concentração: Tecnologia da Arquitetura Orientador: Prof. Dr. Marcelo Eduardo Giacaglia

São Paulo

2012 


\section{AUTORIZO A REPRODUÇÃO E DIVULGAÇÃO TOTAL OU PARCIAL DESTE TRABALHO, POR QUALQUER MEIO CONVENCIONAL OU ELETRÔNICO, PARA FINS DE ESTUDO E PESQUISA, DESDE QUE CITADA A FONTE.}

E-MAIL AUTOR: ricardocouto@usp.br

Couto, Ricardo Arendt Stiebler
O uso de ferramentas de geoprocessamento para o gerenciamento
de bens patrimoniais e prediais / Ricardo Arendt Stiebler Couto. -São
Paulo, 2012.
153 p. : il.
Dissertação (Mestrado - Área de Concentração: Tecnologia da
Arquitetura) - FAUUSP.
Orientador: Marcelo Eduardo Giacaglia
1.Sistema de informações geográficas 2.Geoprocessamento
3.Gerenciamento de bens patrimoniais e prediais I.Título
CDU 659.2:91




\section{FOLHA DE APROVAÇÃO}

Nome: Couto, Ricardo Arendt Stiebler

Título: O Uso De Ferramentas De Geoprocessamento Para O Gerenciamento De Bens Patrimoniais E Prediais

Dissertação apresentada a Faculdade de Arquitetura e Urbanismo da Universidade de São Paulo, como requisito para obtenção do titulo de Mestre em Arquitetura e Urbanismo.

Aprovado em:

Banca Examinadora

Prof. Dr. Instituição:

Julgamento: Assinatura:

Prof. Dr. Instituição:

Julgamento: Assinatura:

Prof. Dr. Instituição:

Julgamento: Assinatura: 


\section{DEDICATÓRIA}

À maior incentivadora deste trabalho, a Profa. e amiga Marlene Yurgel (in memorian). 


\section{AGRADECIMENTOS}

Primeiramente ao meu orientador, Prof. Dr. Marcelo Eduardo Giacaglia, pela atenção e disponibilidade na orientação, pela confiança depositada e pelo incentivo durante a realização deste trabalho.

À todos os colegas de Labarq, que participaram do desenvolvimento do projeto Atlas e que estão aqui representados.

Aos colegas Anderson Siqueira, Eunice Barbosa e Fabio Gallo Jr. pelo apoio e amizade nesses últimos anos.

À Coordenadora do Espaço Físico da Universidade de São Paulo, em especial nas pessoas de seu diretor Sérgio Assumpção e na arquiteta Barbara Toaliar.

A minha esposa pela paciência e incentivo.

E a todos que me ajudaram, direta ou indiretamente, na realização deste trabalho. 


\section{RESUMO}

O uso dos SIG - Sistemas de Informações Geográficas, no gerenciamento de bens patrimoniais já é uma atividade consolidada, em especial no setor de infraestrutura (saneamento, telecomunicações, eletricidade, transporte), onde os bens são distribuídos ao longo de grandes extensões territoriais. A utilização dos SIG no gerenciamento predial, apesar de ser uma pratica mais recente, vem se desenvolvendo nos últimos anos. Existem alguns casos onde a administração destes dois segmentos - o predial e o patrimonial - estão sob a responsabilidade de um mesmo gestor. A bibliografia o tema é escassa, assim como o relato de experiências práticas. Este trabalho busca estudar a utilização das técnicas de gestão patrimonial e predial baseadas em SIG, especialmente quando integradas, e sua verificação prática no caso de um campus universitário.

Palavras-Chave: Gerenciamento de Bens Patrimoniais, Gerenciamento de Bens Prediais, Geoprocessamento, Sistemas de Informações Geográficas. 


\begin{abstract}
The use of GIS - Geographic Information Systems, in asset management is widespread, especially in the infrastructure sector (utilities and transportation), in which assets are distributed along broad territories. The use of GIS in facility management, although a more recent practice, has been evolving in the last years. There are some cases where, management of, both the infrastructure and the facilities, is the responsibility of a single organization. Literature on the subject is scant, as well as reports on practical experience. This work aims to study the use 0 GIS in infrastructure and facilities management, especially when integrated, and to verify it, in practice, in the case of a university campus.
\end{abstract}

Keywords: Asset Management, Facility Management, Geoprocessing, Geographic Information Systems. 


\section{LISTA DE FIGURAS}

Figura 2.1 - Arquitetura de sistemas de informação geográfica....................... 5

Figura 2.2 - Combinação de Dados em Sistemas de Informação Geográfica .. 6

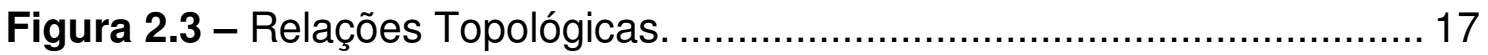

Figura 2.4 - Sobreposição Topológica (overlay). …….................................. 18

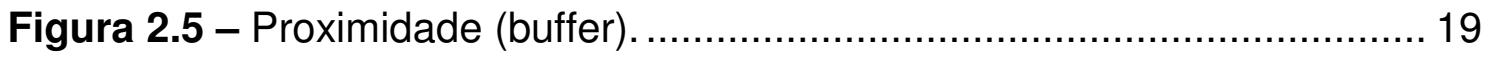

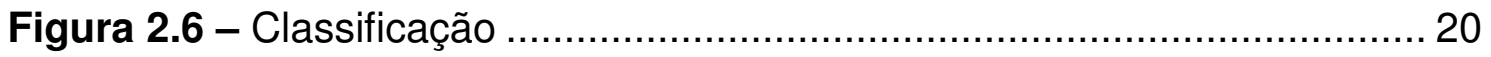

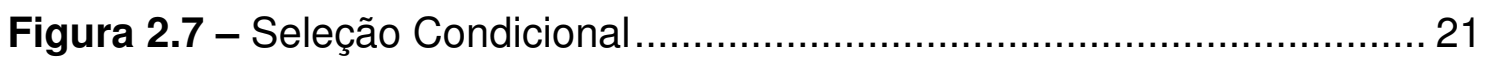

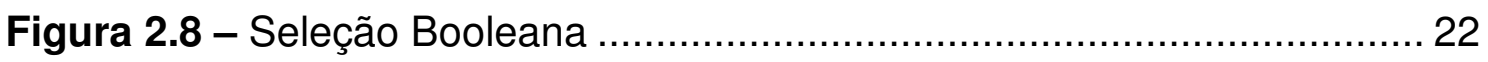

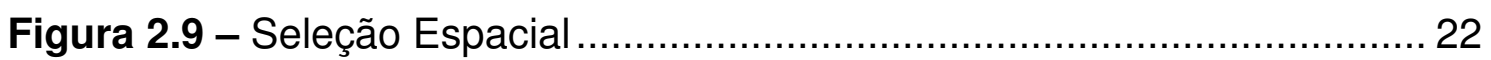

Figura 3.1 - Fotografia orbital do campus da Uni. de New Hampshire .......... 27

Figura 3.2 - Mapa vetorial do campus da Universidade de New Hampshire .. 28

Figura 3.3 - Consulta sobre mapa em SIG ............................................. 29

Figura 3.4 - Analise de distância e tempo de deslocamento........................... 30

Figura 3.5 - Sistema Ferroviário na área da Baía de Guanabara (1854 -1879)

Figura 3.6 - Sistema Ferroviário na área da Baía de Guanabara (2001)........ 36

Figura 3.7 - Exemplo de Ficha de Vistoria de Material Rodante.................... 40

Figura 3.8 - Mapeamento produzido durante o Projeto ................................. 44

Figura 3.9 - Interface Cadastral do SISPAT ………….............................. 45

Figura 3.10 - Manipulação de Anexos no SISPAT ........................................ 46

Figura 3.11 - Interface Geográfica do SISPAT …….................................. 47

Figura 4.1 - Gerenciamento de Facilidades ........................................... 50

Figura 4.2 - Abrangência do Gerenciamento de Facilidades............................52

Figura 4.3 - Dispositivo móvel de levantamento ……….............................. 64

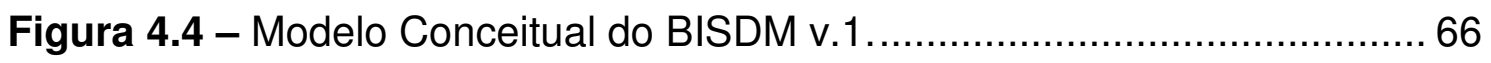

Figura 4.5 - Classificação de ambientes ................................................... 71

Figura 4.6 - Classificação de ambientes por uso, em 3D ………………..... 72

Figura 4.7 - População diurna e noturna em campus. .................................. 73

Figura 4.8 - Rede de transporte dentro de uma edificação............................... 74

Figura 5.1 - Divisão histórica entre o domínio do SIG e do CAD - I................. 78

Figura 5.2 - Divisão histórica entre o domínio do SIG e do CAD - II............... 79

Figura 5.3 - Potencial de abrangência de um SIG ........................................ 81

Figura 5.4 - Contexto Geográfico do Patrimônio........................................... 83 
Figura 5.5 - Exemplo da integração de diferentes bancos de dados. 84

Figura 5.6 - SIG como ferramenta integradora. 85

Figura 5.7 - Mapeamento do aeroporto de Phoenix - vista geral . 88

Figura 5.8 - Mapeamento do aeroporto de Phoenix - ambientes internos ..... 89

Figura 5.9 - Interface do SIG para visualização de espaços do LaRC ........... 91

Figura 5.10 - Exemplo de otimização de espaços no LaRC.......................... 93

Figura 5.11 - Exemplos de diferentes níveis de exibição patrimonial na U.M. 96

Figura 5.12 - Exemplo de classificação, por custo de manutenção na U.M. .. 97

Figura 5.13 - Exemplo de análise espacial na U.M. com o SPACE................ 98

Figura 5.14 - Análise de impactos e interferências na U.M com o SPACE..... 99

Figura 6.1 - Levantamentos planialtimétricos da CUASO, ao final de 2010. 112

Figura 6.2 - Divisão de Trabalho dos Levantamentos (setores) ................... 113

Figura 6.3 - Conferência em campo, sobre o levantamento topográfico. ..... 115

Figura 6.4 - Resultado das etapas de conferência ..................................... 116

Figura 6.5 - Levantamento das áreas externas da CUASO......................... 117

Figura 6.6 - Detalhe do Levantamento das áreas externas da CUASO. ...... 118

Figura 6.7 - Etapas do carregamento de desenhos de um edifício................ 120

Figura 6.8 - Cadastro de um edifício no Atlas........................................... 121

Figura 6.9 - Cadastro Interno de uma Edificação no Atlas. .......................... 122

Figura 6.10 - Cadastro das Redes de Infraestrutura no Atlas....................... 124 


\section{LISTA DE ABREVIATURAS E SIGLAS}

AMV

BIM

BIRD

BISDM

CAD

CAFM

CBTU

CCE

CENTRAL

CIDE

COBIE

COCESP

COESF

CPTM

CUASO

ERP

FFLCH

FLUMITRENS

FM

GML

GPS

IDE

IFC

IFMA

IPP

IPTU

LIDAR
Aparelhos de Mudança de Via

Building Information Models

Banco Internacional para Reconstrução e Desenvolvimento Building Information Spatial Data Model

Computer Aided Design

Computer Aided Facility Management

Companhia Brasileira de Trens Urbanos

Centro de Computação Eletrônica

Companhia Estadual de Engenharia de Transportes e Logística

Centro de Informações e Dados do Estado do Rio de Janeiro

Construction Operations Building Information Exchange Coordenadoria do Campus da Capital

Coordenadoria do Espaço Físico da Universidade de São Paulo

Companhia Paulista de Trens Metropolitanos

Cidade Universitária Armando de Salles Oliveira

Enterprise Resource Planning

Faculdade de Filosofia, Letras e Ciências Humanas

Companhia Fluminense de Trens Urbanos

Facility Managment

Geography Markup Language

Global Positioning System

Integrated Development Environment

Industry Foundation Classes

International Facility Management Association

Instituto Pereira Passos

Imposto sobre a propriedade predial e territorial urbana

Light Detection and Ranging 
MNT

OSCRE

PDA

PET

RFFSA

SAD69

SIG

SIRGAS

SUPERVIA

TI

U.M

USP

WGS84
Modelo Numérico de Terreno

Open Standards Consortium for Real Estate

Personal digital assistant

Programa Estadual de Transporte

Rede Ferroviária Federal S.A.

South American Datum 69

Sistemas de Informações Geográficas

Sistema de Referência Geocêntrico para as Américas

Supervia Concessionária de Transporte Ferroviário S.A.

Tecnologia da Informação

Universidade de Minnesota

Universidade de São Paulo

World Geodetic System 84 
1. INTRODUÇÃO

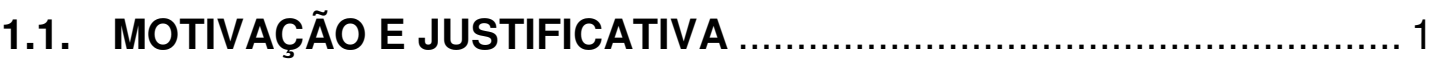

1.2. OBJETIVO

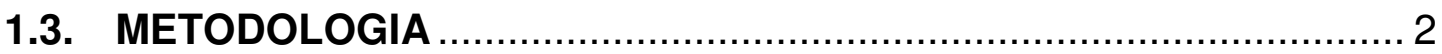

2. GEOPROCESSAMENTO E SISTEMAS DE INFORMAÇÃO GEOGRÁFICA - SIG: TIPOS, FONTES, TRATAMENTOS, CONVERSÃO E ANALISE DE DADOS

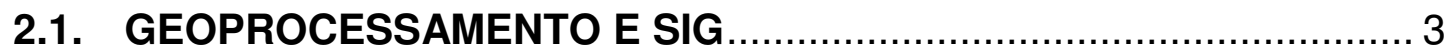

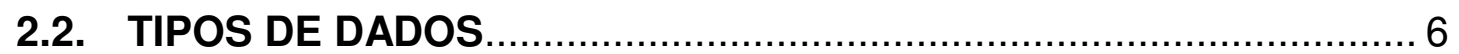

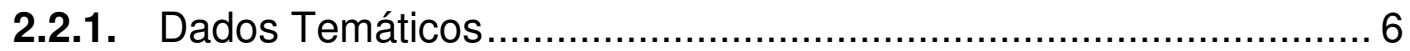

2.2.2. Dados Cadastrais ................................................................... 7

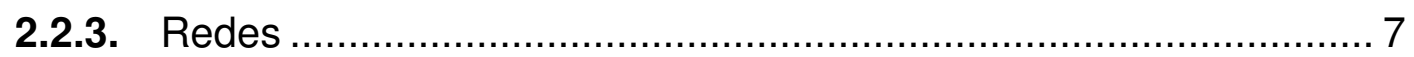

2.2.4. Modelos Numéricos de Terreno..................................................... 7

2.2.5. Imagens de Sensoriamento Remoto ............................................. 8

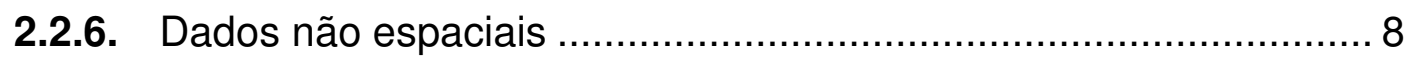

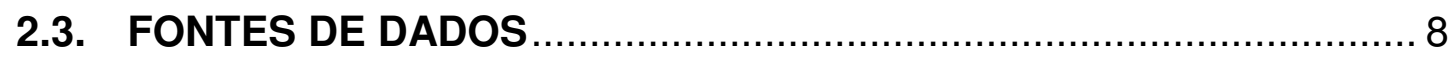

2.3.1. Levantamentos Cartográficos ...................................................... 9

2.3.2. Levantamentos Topográficos …………….............................. 9

2.3.3. Levantamentos Geodésicos ……………….......................... 9

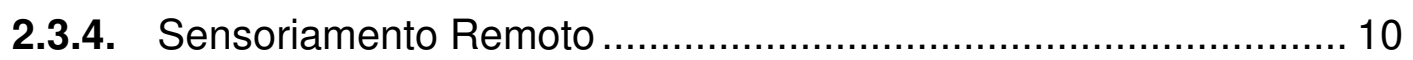

2.3.5. Levantamentos em Campo........................................................ 10

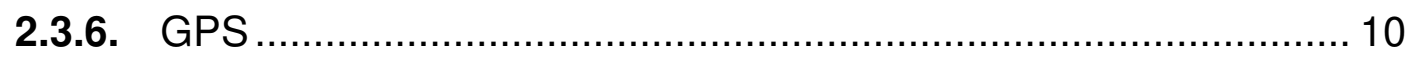

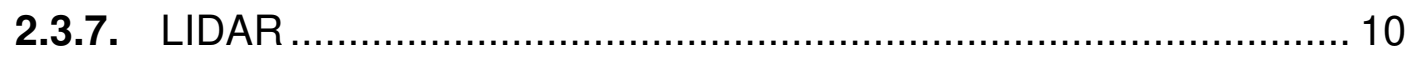

2.3.8. Questionários e Entrevistas ..................................................... 10

2.4. TRATAMENTO E CONVERSÃO DE DADOS ..................................... 11

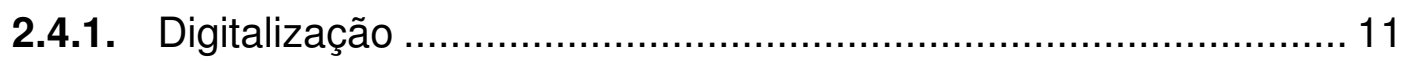

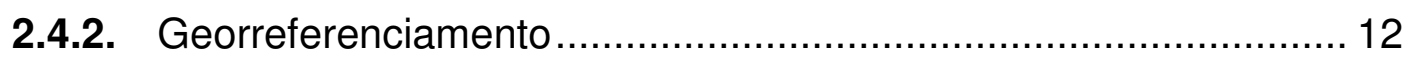

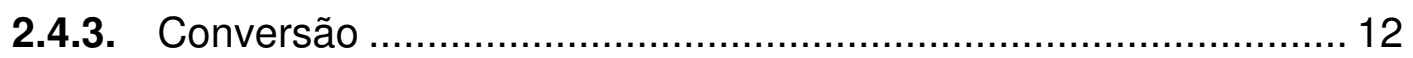

2.4.4. Compatibilização de Sistemas de Referencia ............................. 14

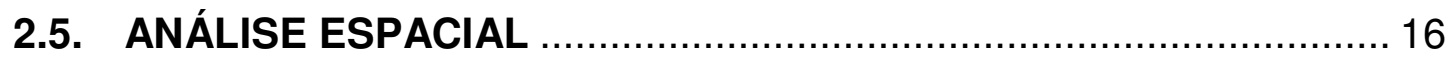

3. GERENCIAMENTO DE BENS PATRIMONIAIS ................................ 23

3.1. O USO DE SISTEMAS DE INFORMAÇÃO GEOGRÁFICA NO GERENCIAMENTO DE BENS PATRIMONIAIS …................................ 25

3.1.1. Levantamento de Dados para um SIG Patrimonial...................... 30 


\subsection{EXEMPLO DE USO DE SIG NO GERENCIAMENTO DE BENS}

PATRIMONIAIS.

3.2.1. Breve histórico da formação do sistema ferroviário Fluminense... 33

3.2.2. A necessidade de um inventário físico ...................................... 36

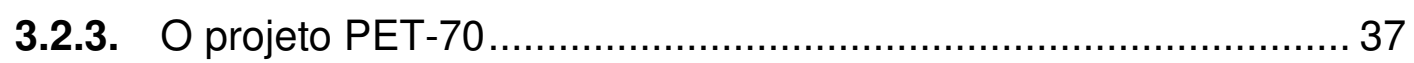

3.2.4. Tratamento Técnico Patrimonial ................................................... 38

3.2.5. Documentação Legal dos Imóveis ............................................. 40

3.2.6. SISPAT - Sistema de Gestão Patrimonial em Base Georreferenciada 41

3.2.7. Produção da base georreferenciada.......................................... 41

3.2.8. Carga das informações............................................................ 43

3.2.9. Desenvolvimento do SISPAT .................................................... 44

3.2.10. Resultados obtidos com a operação do SISPAT .......................... 47

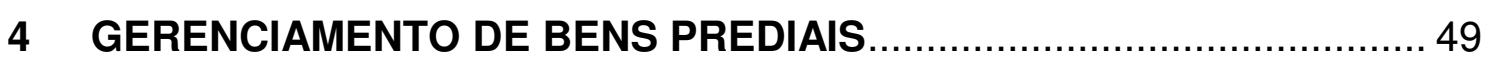

4.1 GERENCIAMENTO DE FACILIDADES …................................. 49

4.1.1 Abrangência do Gerenciamento de Facilidades ......................... 51

4.1.2 Variáveis que influenciam o Gerenciamento de Facilidades ........ 52

4.1.3 Tamanho e localização dos edifícios .......................................... 53

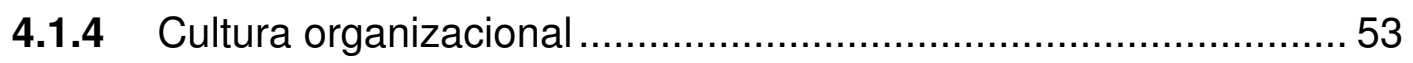

4.1.5 Objetivos do Gerenciamento de Facilidades .............................. 53

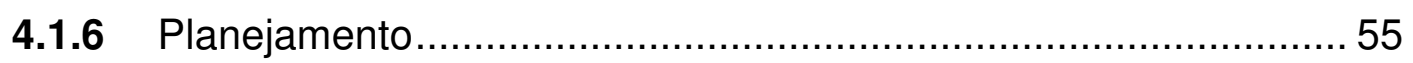

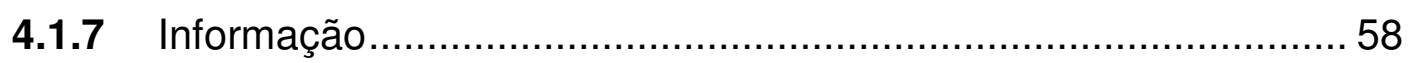

4.1.8 Tecnologias do Gerenciamento de Facilidades ...........................59

4.2 O USO DE SISTEMAS DE INFORMAÇÃO GEOGRÁFICA NO

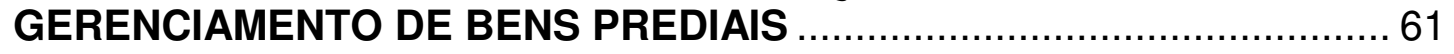

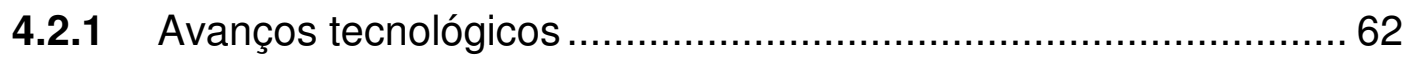

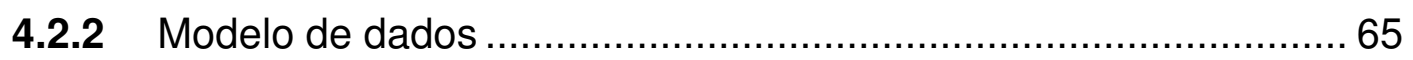

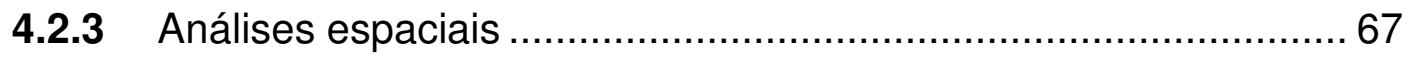

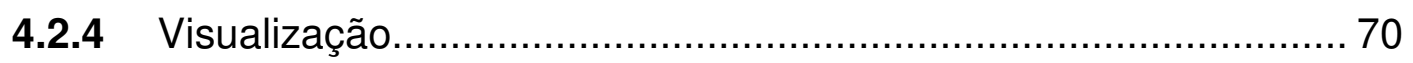

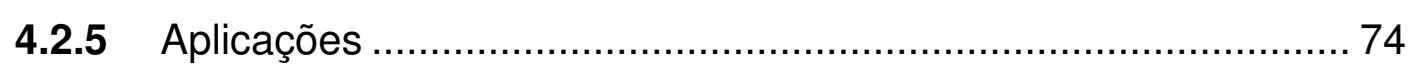

5. GERENCIAMENTO INTEGRADO DE BENS PATRIMONIAIS E PREDIAIS .

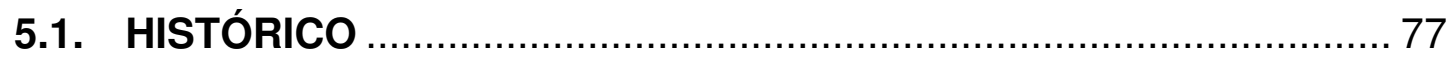

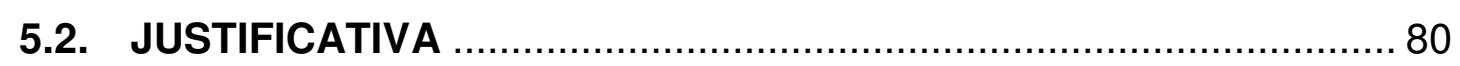

5.3. APLICAÇÃO

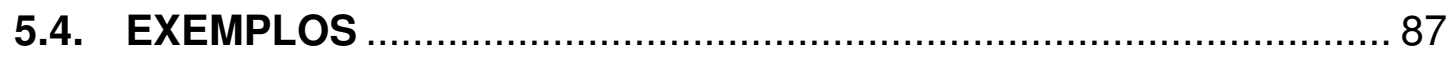

5.4.1. Sky Harbor International Airport............................................... 87 


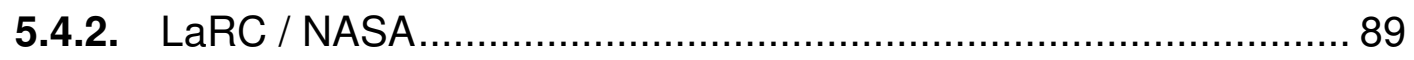

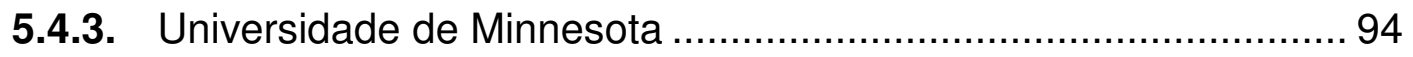

6. ESTUDO DE CASO - PROJETO ATLAS .......................................... 100

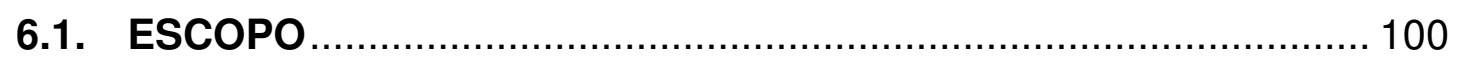

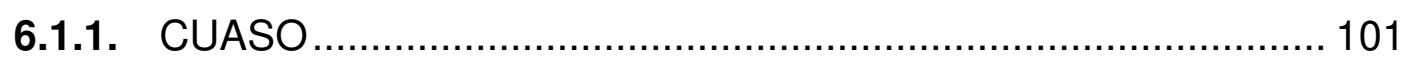

6.1.2. Gestão patrimonial da CUASO ................................................ 102

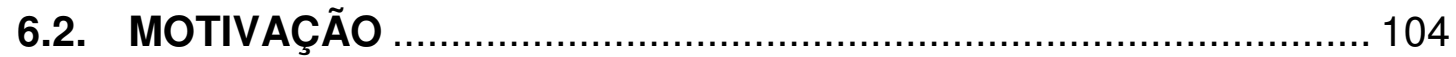

6.2.1. Cadastro das áreas externas............................................... 104

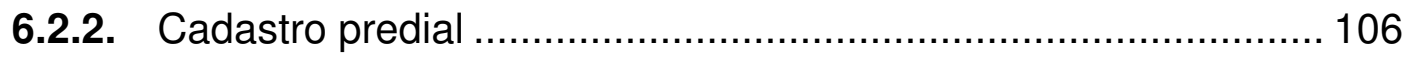

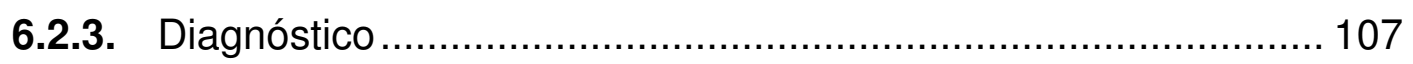

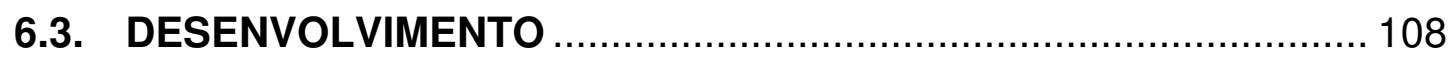

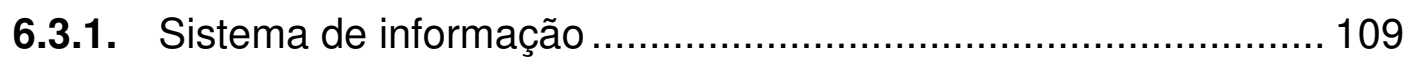

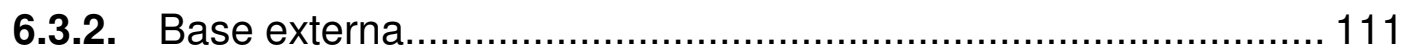

6.3.3. Cadastro predial .............................................................. 118

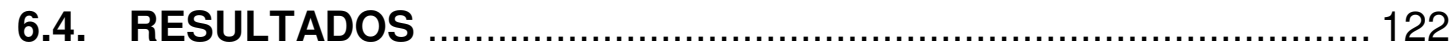

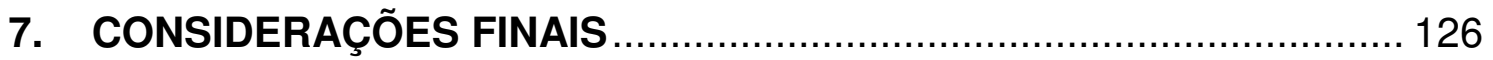

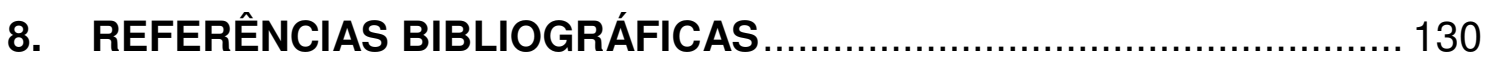

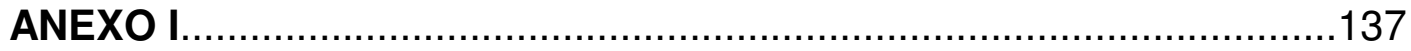

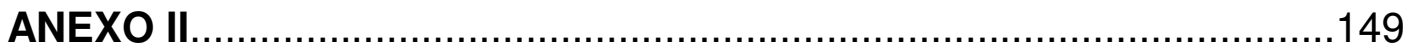




\section{INTRODUÇÃO}

\subsection{MOTIVAÇÃO E JUSTIFICATIVA}

Historicamente sempre houve uma divisão nas tecnologias empregadas no gerenciamento de bens patrimoniais e no gerenciamento de bens prediais.

Os Sistemas de Informações Geográficas - SIG - vem sendo utilizados a muitos anos no gerenciamento de bens patrimoniais, em especial no setor de infra-estrutura (saneamento, telecomunicações, eletricidade e transporte), setor este que tem seus bens distribuídos ao longo de grandes extensões territoriais.

O gerenciamento predial por sua vez é atendido por ferramentas CAD Computer Aided Design - ou por sistemas derivados deste como o CAFM Computer Aided Facility Management. A utilização do SIG no gerenciamento predial, apesar de ser uma pratica mais recente, vem se desenvolvendo nos últimos anos.

Existem, entretanto alguns casos onde a administração destes dois segmentos - o predial e o patrimonial - estão sob responsabilidade de um mesmo gestor. São exemplos deste tipo de ocorrência universidades, instalações militares, hospitais, aeroportos, grandes empresas entre outros. São órgãos ou instituições muitas vezes sediadas ao longo de grandes extensões territoriais, podendo ter instalações em diferentes localidades, servindo a uma grande população de usuários, com demandas de infraestrutura de porte urbano e com um grande acervo predial.

Em uma situação como esta, a integração em um mesmo ambiente gerencial pode ser de grande valia para o gestor, haja vista a grande interrelação entre os elementos tratados. A bibliografia sobre o tema é escassa, assim como o relato de experiências práticas. 


\subsection{OBJETIVO}

Este trabalho tem por objetivo estudar a utilização das técnicas de gestão patrimonial baseadas em SIG, para o gerenciamento integrado de bens patrimoniais e bens prediais.

\subsection{METODOLOGIA}

A pesquisa inicia pelo levantamento bibliográfico sobre geoprocessamento e sistemas de informações geográficas, em especial dos aspectos de interesse do gerenciamento patrimonial.

A pesquisa continua pelo do levantamento dos sistemas de informações geográficas - SIG e dos sistemas de gerenciamento de facilidades - CAFM, utilizados na gestão patrimonial e predial, respectivamente. Os CAFM são em geral extensões de sistemas de projeto com auxílio do computador - CAD. A pesquisa se estende pelo levantamento de casos nos quais um SIG foi utilizado na gestão de facilidades, em substituição aos sistemas CAFM baseados em CAD.

O levantamento bibliográfico termina com o levantamento da bibliografia, ainda escassa, sobre o uso de um SIG na gestão simultânea de bens patrimoniais e prediais, objeto desta pesquisa.

A pesquisa apóia-se também no caso real do desenvolvimento do Projeto "Atlas", da Universidade de São Paulo, do qual o autor possui papel chave. $O$ projeto Atlas é desenvolvido pelo Laboratório de Informatização de Acervo Labarq - FAU /USP, para a Coordenadoria do Espaço Físico da Universidade de São Paulo - COESF, órgão este que tem como finalidade organizar e sistematizar as atividades relacionadas ao espaço físico da USP, sendo responsável pela análise das solicitações e propostas de ocupação dos campi, de construções novas, de ampliação e reformas de edifícios existentes.

Ao final da pesquisa é apresentada uma visão critica da utilização da tecnologia, buscando salientar as vantagens e desvantagens da utilização do SIG no gerenciamento patrimonial e predial em detrimento de outras técnicas. 


\section{GEOPROCESSAMENTO E SISTEMAS DE INFORMAÇÃO GEOGRÁFICA - SIG: TIPOS, FONTES, TRATAMENTOS, CONVERSÃO E ANALISE DE DADOS}

\subsection{GEOPROCESSAMENTO E SIG}

Segundo Davis e Câmara (2004) o geoprocessamento é a disciplina do conhecimento que utiliza técnicas matemáticas e computacionais para 0 tratamento da informação geográfica com influencia em diversas áreas como Cartografia, Análise de Recursos Naturais, Agricultura, Transportes, Comunicações, Energia, Planejamento Urbano e Regional, Concessionárias de Serviços Públicos entre outras. O autor afirma: "Se onde é importante para seu negócio, então Geoprocessamento é sua ferramenta de trabalho".

As ferramentas computacionais para geoprocessamento, chamadas de sistemas de informação geográfica (SIG), permitem realizar análises complexas, ao integrar dados de diversas fontes e ao criar bancos de dados georreferenciados. Sempre que o onde aparece, dentre as questões e problemas que precisam ser resolvidos por um sistema informatizado, haverá uma oportunidade para considerar a adoção de um SIG.

SIG são amplamente utilizados em diversos setores da economia, como Governo, em Planejamento Urbano e Regional, em todo o setor de InfraEstrutura em especial Energia, Saneamento e Telecomunicação, em Transporte e Logística, Negócios, Monitoramento, Meio-Ambiente, Segurança, no setor de Defesa, Agricultura, Recursos Naturais, Inventários, Cartografia, Visualização entre outros.

Rodrigues (1987) define o SIG como um sistema que trata de informações sobre entes de expressão espacial, ou seja, aqueles para os quais localização, forma, posição, conectividade, etc. são relevantes.

Ainda segundo Câmara (1995) as principais características dos SIG são oferecer mecanismos para combinar as várias informações, por meio de algoritmos de manipulação e análise e para consultar, recuperar, visualizar e imprimir o conteúdo da base de dados geocodificados. 
O SIG pode ser visto como uma ferramenta de apoio ao planejamento e a tomada de decisões que envolvam a integração de dados georreferenciados, isto é dados cuja relevância espacial contribui para o entendimento e a solução de determinado problema. Para Rodrigues (1998):

"O porquê da utilização de um SIG se verifica por ser um modelo único; a manutenção de dados é integrada, compacta e barata; o acesso é rápido; realiza análises, especulações, e outras atividades afins, que até então eram inviáveis; promove a incorporação de processos; apresenta melhores projetos, programas, controle, etc.; e fornece um ambiente de integração de informações".

É importante destacar que um SIG não é um aplicativo isolado, mas sim uma tecnologia que envolve diversos componentes como software, hardware, dados, operadores e metodologias.

Software é o conjunto de programas de computador com a finalidade básica de coletar, armazenar, processar e analisar e exibir o conjunto de dados.

Hardware refere-se ao conjunto de equipamentos, necessário para executar o software, basicamente o computador e seus periféricos, como impressoras, plotters, scanners, mesas digitalizadoras, além de equipamentos de coleta de dados como receptores GPS, máquinas fotográficas, computadores de mão (PDA), entre outros.

Os dados podem ser espaciais ou não. Os dados não espaciais, ou tabulares, podem estar ou não associados aos dados espaciais.

Usuários são os operadores do sistema, e elo fundamental para a eficiência e eficácia de sua aplicação. O Geoprocessamento é uma atividade interdisciplinar, assim como os usuários de um SIG.

Metodologias é o conjunto de técnicas de analise utilizadas para a obtenção do resultado desejado.

Segundo Câmara (1995) um SIG tem os seguintes componentes:

- Interface com usuário; 
- Entrada e integração de dados;

- Funções de processamento gráfico e de imagens;

- Visualização e impressão;

- Armazenamento e recuperação de dados (sob a forma de um banco de dados geográfico).

A interface homem-maquina define como o sistema é operado e controlado. Internamente, o sistema deve possuir mecanismos de processamento de dados espaciais (entrada, edição, analise, visualização e saída) e um sistema de gerencia de bancos de dados geográficos, para o armazenamento e recuperação dos dados espaciais e seus atributos.

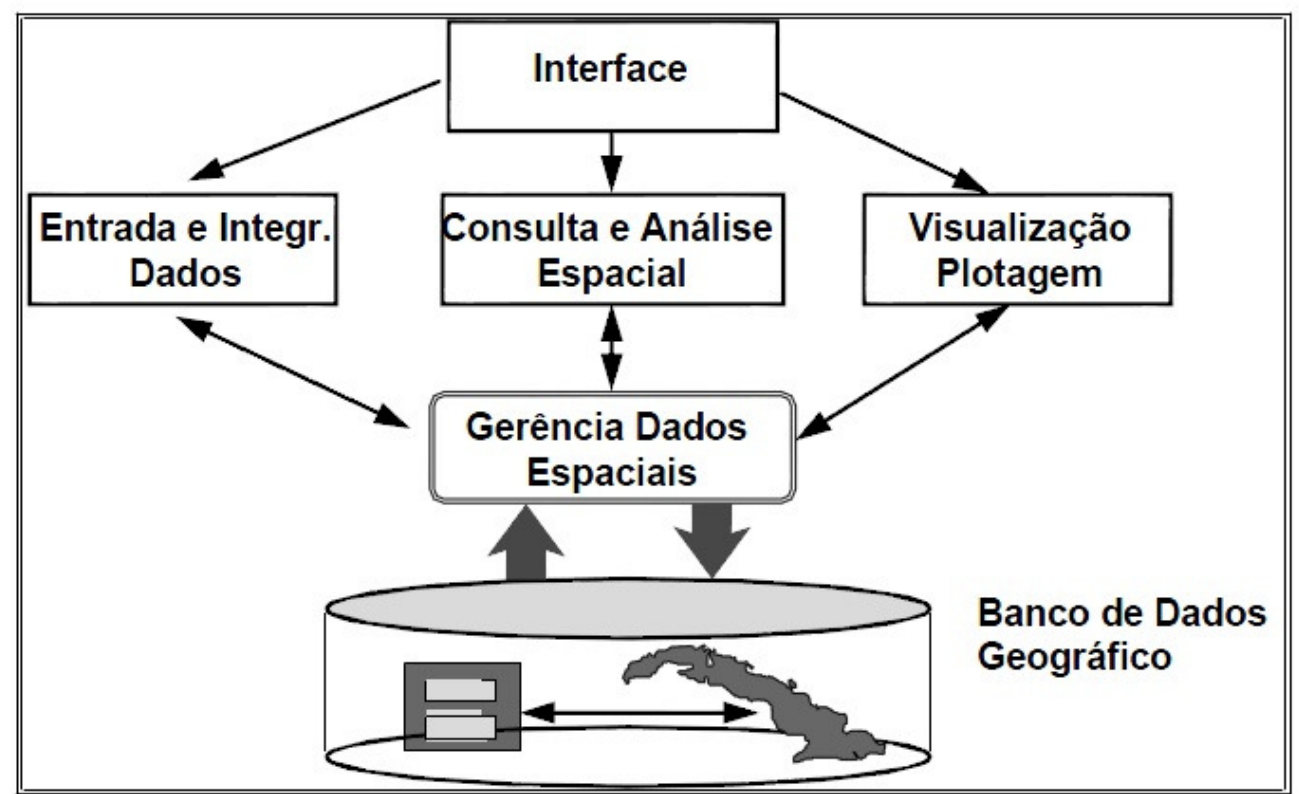

Figura 2.1 - Arquitetura de sistemas de informação geográfica Fonte: Davis e Câmara (2004)

A Figura 2.1 indica relacionamentos entre componentes em um SIG. 


\subsection{TIPOS DE DADOS}

Os SIG têm a capacidade de integrar tipos diferentes de dado, para manipulação, análise, consulta, e visualização dos dados e resultados na forma de mapas, conforme ilustrado na Figura 2.2.

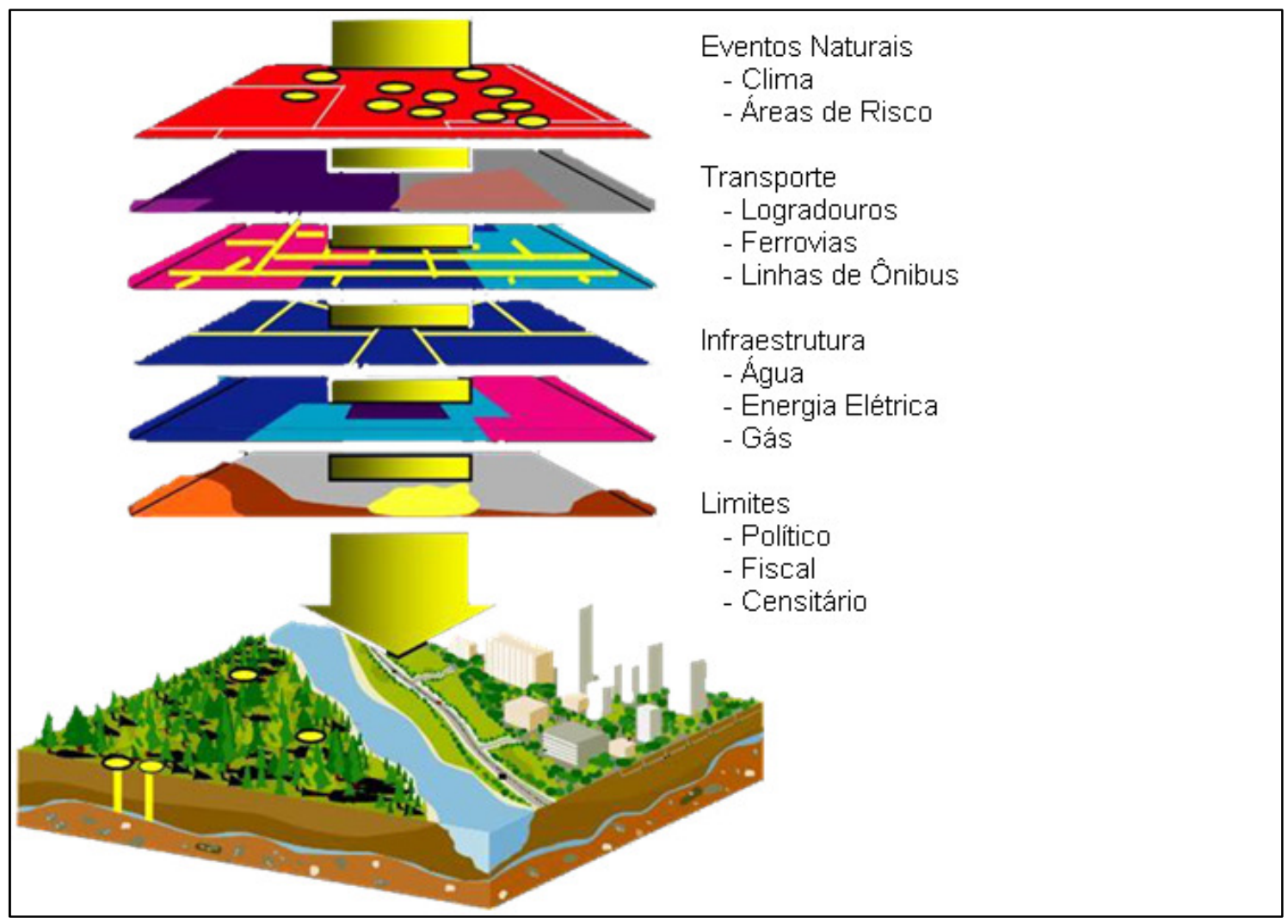

Figura 2.2 - Combinação de Dados em Sistemas de Informação Geográfica Fonte: adaptado de Young (2008)

A seguir são apresentados os tipos de dados utilizados em SIG, adaptado de Câmara e Monteiro (2004).

\subsubsection{Dados Temáticos}

Dados temáticos descrevem a distribuição espacial de uma grandeza geográfica, expressa de forma qualitativa. Um exemplo de dado temático é o tipo de vegetação de certa área. Estes dados são obtidos a 
partir de levantamento de campo, e inseridos no sistema por digitalização ou, a partir de classificação de imagens.

\subsubsection{Dados Cadastrais}

Um dado cadastral distingue-se de um temático, pois cada um de seus elementos é um objeto geográfico, que possui atributos e pode estar associado a várias representações gráficas. Por exemplo, os lotes de uma cidade são elementos do espaço geográfico que possuem atributos (dono, localização, valor venal, IPTU devido, etc.) e que podem ter representações gráficas diferentes em mapas de escalas distintas.

\subsubsection{Redes}

Em Geoprocessamento, o conceito de "rede" denota as informações associadas a:

- Serviços de utilidade pública, como água, luz e telefone;

- Redes de drenagem (bacias hidrográficas);

- Rodovias.

No caso de redes, cada objeto geográfico possui uma localização geográfica e está associado a atributos descritivos em banco de dados. As informações gráficas de redes são armazenadas em coordenadas vetoriais, com topologia arco-nó. A topologia de redes constitui um grafo, que armazena informações sobre as relações espaciais dos objetos (conectividade, sentido de fluxo, etc.).

\subsubsection{Modelos Numéricos de Terreno}

O termo modelo numérico de terreno (MNT) é utilizado para denotar a representação quantitativa de uma grandeza que varia continuamente no espaço. 
Entre os usos mais comuns de modelos numéricos de terreno, podese citar:

- Armazenamento de dados de altimetria para gerar mapas topográficos;

- Análises de corte-aterro para projetos;

- Mapas de declividade;

- Apresentação tridimensional.

\subsubsection{Imagens de Sensoriamento Remoto}

Obtidas por satélites, fotografias aéreas ou "scanners" aerotransportados, as imagens representam formas de captura indireta de informação espacial. Armazenadas como matrizes, cada elemento de imagem (denominado "pixel") tem um valor proporcional à energia eletromagnética refletida ou emitida pela área da superfície terrestre correspondente. Pela natureza do processo de aquisição de imagens, os objetos geográficos estão contidos na imagem, sendo necessário recorrer a técnicas de fotointerpretação e de classificação para individualizá-los.

\subsubsection{Dados não espaciais}

São dados alfanuméricos, sem referencia espacial, armazenados em Bancos de Dados. Esses dados podem ser associados à dados georreferenciados dentro de um ambiente SIG.

\subsection{FONTES DE DADOS}

A etapa de produção ou obtenção dos dados é pré-requisito para a construção de um SIG. A precisão dos mapas e analises gerado por este SIG está diretamente relacionado com dos métodos utilizados no levantamento e tratamento dos dados originais (FORTES, 2007).

Os dados em projetos SIG podem ser divididos em dois tipos de acordo com sua origem: Dados Primários e Dados Secundários (QUINTANILHA, 
2005). Os dados primários são aqueles coletados diretamente de observações e registro para uso no SIG. Já os Dados Secundários são aqueles produzidos por outras instituições ou com outras finalidades e adquiridos para utilização no SIG.

Quintanilha (2005) cita as fontes mais comuns de dados utilizados em SIG:

\subsubsection{Levantamentos Cartográficos}

Mapas ou Cartas Cartográficas, produzidas por operações científicas, técnicas e artísticas, representam de forma gráfica objetos, elementos, fenômenos e ambientes físicos e socioeconômicos.

Levantamentos Cartográficos são exemplos de dados Secundários, normalmente obtidos de fontes governamentais, como IBGE, Exército, Prefeituras, entre outros órgãos.

\subsubsection{Levantamentos Topográficos}

Os levantamentos topográficos são baseados na medição de distâncias e ângulos e a aplicação de relações trigonométricas, por meio de equipamentos analógicos e, mais recentemente, por equipamentos digitais, denominados estações totais. São utilizados em levantamentos com extensão de até aproximadamente $30 \mathrm{~km}$, onde a curvatura da Terra não necessita ser considerada.

\subsubsection{Levantamentos Geodésicos}

Os levantamentos geodésicos são similares aos topográficos, porém destinados a levantamentos de maiores extensões, onde a curvatura da Terra deve ser considerada. A determinação da localização planimétrica dos pontos pode ser feita por triangulação, poligonação ou trilateração e a altitude por meio de nivelamento geodésico. 


\subsubsection{Sensoriamento Remoto}

Imagens da superfície da Terra obtidas por sensores embarcados em aviões (aerofotogrametria) ou em satélites orbitais.

\subsubsection{Levantamentos em Campo}

Informações qualitativas e quantitativas colhidas em campo por meio de observação, amostragem, etc.

\subsubsection{GPS}

Levantamento de dados em campo com utilização de receptores GPS para coleta de coordenadas geográficas de elementos físicos na superfície terrestre.

\subsubsection{LIDAR}

Do inglês, Light Detection and Ranging é um equipamento que pode ser utilizado em solo ou embarcado em aeronave. Gera uma nuvem de pontos para criação de modelos tridimensional de relevo e de objetos na superfície.

\subsubsection{Questionários e Entrevistas}

Certas informações como renda da população, só podem ser obtidas por meio de entrevistas e questionários com a população local.

Para a correta utilização de dados geográficos de diferentes fontes em um mesmo sistema, é necessário conhecer as propriedades espaciais de cada dado utilizado, como o Sistema de Coordenadas, a Projeção Cartográfica e o Sistema de Referência, além da Escala e Precisão do levantamento.

Em relação aos dados Secundários, provenientes de outras fontes, é necessário possuir o memorial descritivo, ou o metadado (dado sobre o dado), como a fonte dos dados, a data de aquisição, a escala dos 
trabalhos, erro (precisão), e demais informações relevantes, para compatibilização com os demais dados existentes (QUINTANILHA, 2005).

\subsection{TRATAMENTO E CONVERSÃO DE DADOS}

Após a etapa de produção e aquisição dos dados, alguns procedimentos devem ser realizados de forma a permitir sua utilização conjunta com os demais dados.

Os processos de entrada, conversão e transferência de dados tem uma forte componente tecnológica, na medida em que os aspectos tecnológicos (hardware + software) aliados ao volume e diversidade de mapas e documentos a serem manipulados, definirão os custos, prazos, acurácias e volume de informações a serem geradas (QUINTANILHA ,1996).

Conforme descrito no item anterior, são muitas as fontes de dados possíveis de serem utilizadas em um SIG. São dados em papel, em diferentes formatos digitais, com referenciais geográficos distintos, entre outras características que tornam necessário o tratamento deste material antes de sua incorporação no SIG.

A seguir são descritas algumas dessas atividades:

\subsubsection{Digitalização}

Para a digitalização de um dado em papel para o meio digital, ou seja, para a transformação das feições analógicas em objetos digitais (pontos, linhas e polígonos) podem ser utilizadas as seguintes técnicas:

a) Vetorização por software sobre imagem matricial digital (raster).

A vetorização pode ser manual, (onde um usuário desenha as feições sobre uma imagem exibida na tela do computador) ou automática (por meio de software específico). Em muitos casos, a imagem matricial digital (raster) é obtida pela varredura (feita com equipamento próprio, o scanner), ou por fotografia digital, de um mapa analógico. 
b) Digitalização por meio de uma mesa digitalizadora;

Os casos indicados para a utilização desse processo são aqueles em que é inviável o uso de scanners (pela espessura ou condições do documento, por exemplo), ou quando os originais são desenhos em formatos incomuns ou tenham muitas intersecções e/ou densidade de temas (QUINTANILHA, 1996).

\subsubsection{Georreferenciamento}

Georreferenciamento pode ser aplicado a uma imagem, um mapa ou qualquer outra forma de informação espacial, e consiste na ação de referenciar suas coordenadas a um dado sistema de referência.

Este processo inicia-se com a obtenção das coordenadas (pertencentes ao sistema no qual se pretende georreferenciar) de pontos da imagem ou do mapa a serem georreferenciados, conhecidos como pontos de controle.

Os pontos de controle são locais que oferecem uma feição física perfeitamente identificável, tais como intersecções de estradas e de rios, represas, pistas de aeroportos, edifícios proeminentes, topos de montanha, entre outros. A obtenção das coordenadas dos pontos de controle pode ser realizada em campo a partir de levantamentos topográficos, GPS ou outras imagens ou mapas (em papel ou digitais) georreferenciados (FORTES, 2007).

\subsubsection{Conversão}

Sistemas de CAD, Computer Aided Design são atualmente, o principal recurso para a criação e manipulação de informações gráficas vetoriais em computador, explicado pela disponibilidade de sistemas CAD baseada em microcomputadores, aliada à grande diminuição do preço do hardware. Um uso comum desta tecnologia é criação de entidades 
gráficas / cartográficas a partir de material não digital para uso em SIG (DAVIS JR. e FONSECA, 1994).

Apesar de seus excelentes recursos para manipulação de entidades gráficas, os sistemas CAD têm certas limitações no que diz respeito à forma de organização e armazenamento destas entidades. Estas limitações acabam por causar grandes diferenças entre a informação utilizada em um SIG e aquela que o CAD é capaz de produzir.

A utilização de sistemas CAD na conversão de dados para SIG tem levado, assim, a diversas distorções, apresentadas abaixo, e que devem ser tratadas para seu melhor aproveitamento em um SIG (DAVIS JR. e FONSECA, 1994).

Quebra de objetos em diversas partes - Um objeto único representado por varias feições;

Quebra de objetos na divisão cartográfica - Por questões de desempenho, limitação no tamanho dos arquivos, e mesmo tradição cartográfica, levantamentos CAD são entregues na forma de Cartas, dividindo objetos localizados nos limites das folhas;

Erros de codificação em níveis e atributos - Não existem, controles de simbologia no CAD ou controle que impeça a digitalização de uma entidade inconsistente, como por exemplo, um elemento de área em um nível (layer) que só deveria conter símbolos.

Refinamento cartográfico excessivo - Em muitos casos o enfoque do trabalho CAD está na formação de uma base cartográfica digital, onde a representação gráfica das entidades é importante. Para utilização em geoprocessamento, no entanto, esse refinamento como hachuras ou simbologia associada a linhas, não só não é importante, uma vez que o SIG trata a representação dos elementos, como acaba complicando e dificultando a conversão dos dados e a formação da base de dados geográfica.

Excesso de vértices - É geração de vértices em excesso, principalmente em elementos como curvas de nível. Alguns SIG 
aumentam este problema quando forçam a transformação de curvas e arcos de círculo em poligonais, gerando ainda mais vértices.

Erros de fechamento topológico - São fechamentos imperfeitos de elementos vetoriais. Este tipo de problema é difícil de detectar em CAD.

Textos gráficos divididos em várias partes - Na conversão para cartografia, os textos gráficos assumem frequentemente um papel meramente decorativo, com pouca utilidade para o SIG. Por uma questão de estética, os textos são geralmente fragmentados para que as palavras sejam uniformemente distribuídas no mapa, o que dificulta sua concatenação e aproveitamento no SIG. Sendo assim, o mais interessante é que estes textos sejam atributos adicionados posteriormente, já no SIG, como atributos associados a algum objeto.

\subsubsection{Compatibilização de Sistemas de Referencia}

\subsubsection{Datum Horizontal}

$\mathrm{Na}$ preparação de uma base cartográfica para uso em um SIG, é comum encontrar documentos cartográficos e imagens de sensoriamento remoto, referenciados a diferentes Data.

A superfície terrestre é totalmente irregular, não existindo um modelo matemático capaz de representá-la fielmente. Para permitir a representação da superfície terrestre em um plano, é feita uma simplificação sendo utilizado um modelo baseado em um elipsóide de revolução. Um Datum é um par composto por um elipsóide e um ponto de amarração deste elipsóide com a superfície da Terra (BLITZKOW et. al. 2004).

Cada país adota os Data que melhor representem seu território, isto é, melhor se aproximem da realidade na fração do superfície terrestre correspondente ao seu território. Assim existem diversos Data, para diferentes regiões da Terra. 
Com o aprimoramento dos instrumentos e técnicas de medição, são gerados modelos matemáticos mais precisos, baseados em novos Data que acabam sendo oficializados por seus países. Com isso, ao passar dos anos passam a coexistir dados produzidos em épocas diferentes sob diferentes referências espaciais. No Brasil, por exemplo, são encontrados dados nos Data Córrego Alegre, SAD69 e SIRGAS2000 (BLITZKOW et. al. 2004).

Caso a base de dados apresente Data distintos, é necessário fazer a conversão para um Datum comum,por meio de fórmulas matemáticas.

O mesmo cuidado deve ser adotado utilização de dados GPS. É comum dispositivos GPS utilizarem um Datum não oficial como o WGS84. Assim esses dados devem ser devidamente convertidos para utilização em conjunto com os outros dados.

\subsubsection{Sistema de Coordenadas e Projeções Cartográficas}

Dados Geográficos podem utilizar sistemas de coordenadas geográficas (latitude e longitude) ou planas (sistema cartesiano). Este último corresponde ao sistema de coordenadas de uma projeção cartográfica.

Para a correta sobreposição entre diferentes planos de informação, o sistema de coordenadas deve ser comum entre os planos, bem como as unidades das coordenadas que devem ser mesmas. Caso contrário, é necessário se fazer uma conversão para um sistema e uma unidade comum, por meio de fórmulas matemáticas.

Projeção cartográfica são relações matemáticas que representa a superfície terrestre sobre um plano, onde cada ponto deste plano corresponde a um ponto na superfície de referência. A representação de uma superfície curva, no caso a Terra, sobre um plano gera distorções, já que não é possível representar a superfície terrestre (ainda que ela fosse esférica ou elíptica) como uma superfície plana sem causar "extensões" ou "contrações" da superfície original. Assim todo mapa apresenta uma 
deformação ou a combinação de mais de uma dos seguintes tipos de deformação: linear, angular e superficial (BLITZKOW et. al. 2004).

Para que os planos de informação sejam corretamente sobrepostos em um SIG, é necessário que eles apresentem a mesma projeção. Caso contrário, deve ser feita a conversão para uma projeção comum.

\subsection{ANÁLISE ESPACIAL}

Segundo Câmara et. al. 2004, o que distingue um SIG de outros tipos de sistemas de informação é sua capacidade de realizar análises espaciais, baseadas em atributos espaciais (feição do objeto) e não espaciais (dados tabulares) dos elementos estudados.

Wade e Sommer (2006) definem análise espacial como:

"The process of examining the locations, attributes, and relationships of features in spatial data through overlay and other analytical techniques in order to address a question or gain useful knowledge. Spatial analysis extracts or creates new information from spatial data".

Cowen (1988) faz distinção entre SIG e outras categorias de software com os quais possui sobreposições de função - CAD, sistema de bancos de dados ou editor gráfico, ao afirmar que a sobreposição e a busca espaciais, são operações únicas a um SIG. O autor cita exemplo de critério, elaborado por Carstensen (1986 apud Cowen, 1988) na escolha de um sistema:

"He approached the selection of an automated system on the basis of each candidate system's ability to determine which parcels of land met a set of six criteria for industrial site selection. The site had to be at least five acres in size, zone commercial, vacant or for sale, not subject to flooding, not more than one mile from a heavy duty road, and have no slope over ten percent."

"The important question from the stand point of geographic data processing and the field of GIS is the determination of whether the information could be generated automatically from digital representations of the relevant maps." 
Um SIG tem a capacidade de analisar relacionamentos topológicos entre representações gráficas de elementos espaciais. Os relacionamentos topológicos estão apresentados na Figura 2.3, segundo nomenclatura proposta por Clementini et al. (1993 apud CÂMARA et. al. 2004) e são Igual a, Disjunto, Contem / Contido, Toca, Cruza e Sobrepõe.

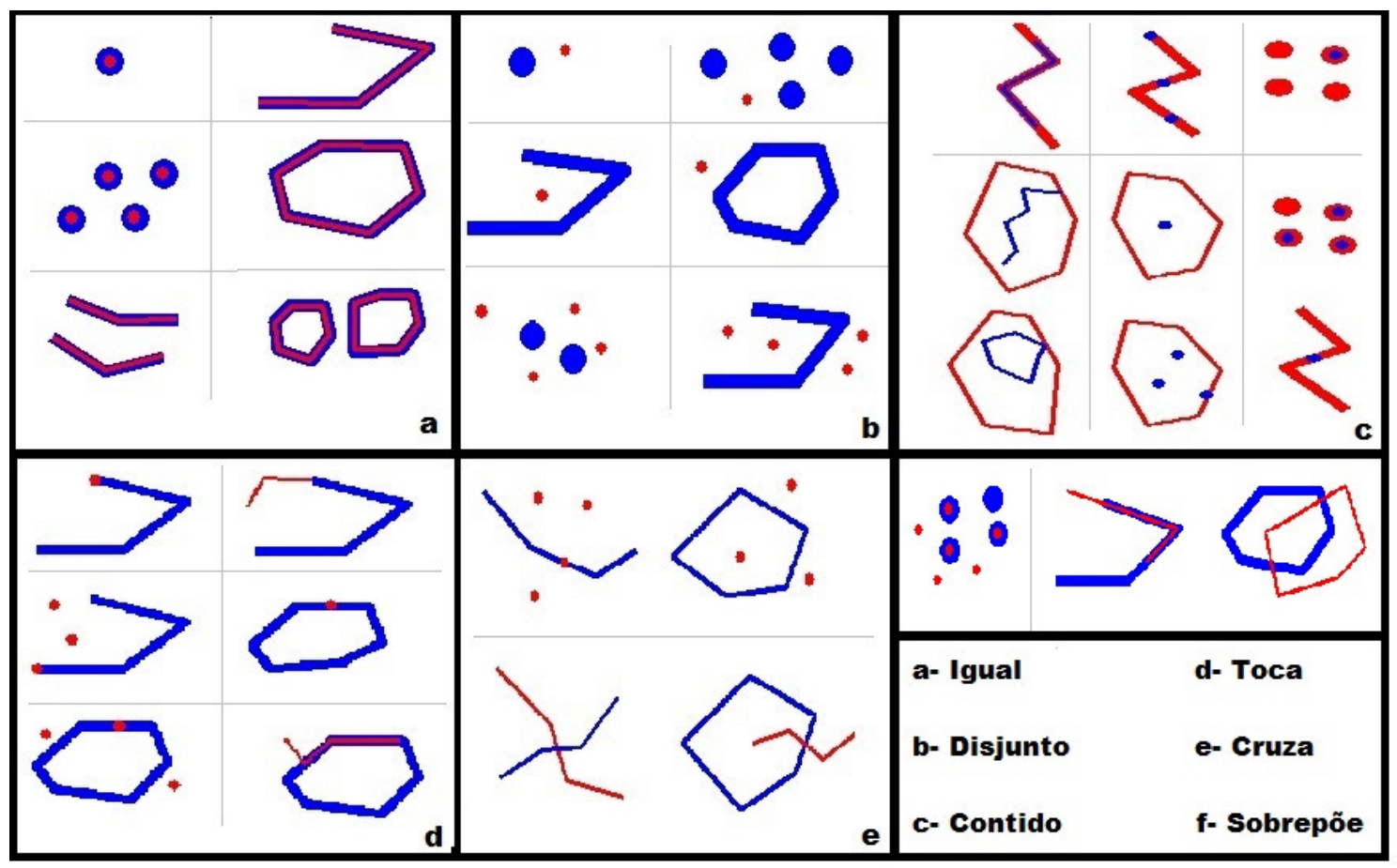

Figura 2.3 - Relações Topológicas.

Fonte: adaptado de Câmara et. al. (2004)

As análises espaciais realizadas em um SIG, segundo Câmara et. al. (2004), vão desde manipulações matemáticas e estatísticas complexas, a procedimentos extremamente simples e intuitivos, procurando examinar localizações, atributos, e relacionamentos entre feições espaciais de forma a abordar uma determinada questão ou para adquirir conhecimento sobre os dados, extraindo ou criando nova informação a cerca desses.

Algumas das principais operações de analise espacial, segundo Bolstad (2009) são:

Sobreposição Topológica (overlay) - operações aritméticas (adição, subtração, divisão e multiplicação) e lógicas (que envolve a busca de uma área 
onde um conjunto específico de condições ocorre ou não ocorre ao mesmo tempo). As operações de overlay em vetores possuem basicamente três elementos: uma camada de entrada (input), a camada de overlay e a camada de saída (output), conforme ilustrado na Figura 2.4. Da operação básica de overlay, derivam outras operações como União, Intersecção, Diferença, entre outras.

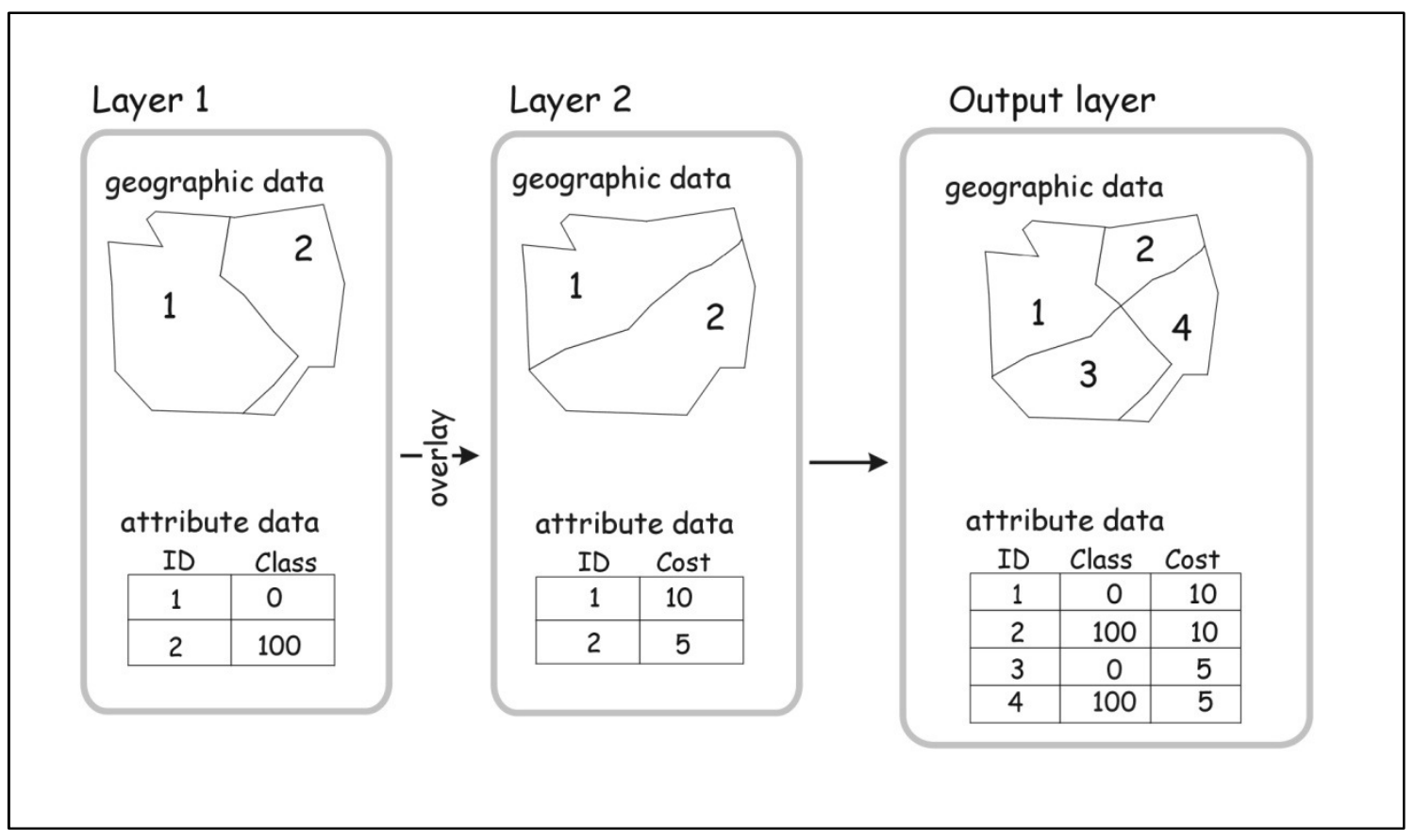

Figura 2.4 - Sobreposição Topológica (overlay).

Fonte: Bolstad (2009) 


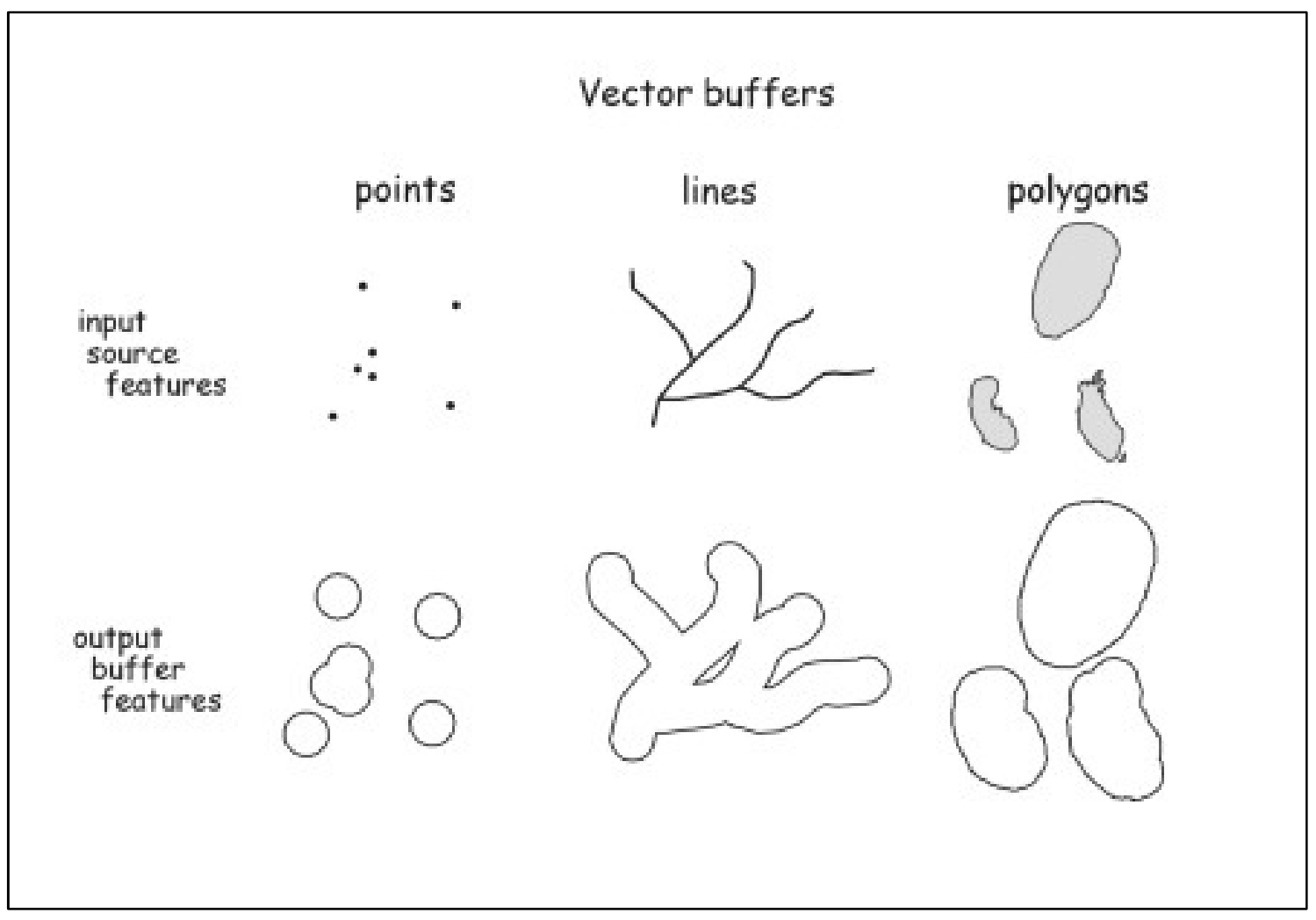

Figura 2.5 - Proximidade (buffer).

Fonte: Bolstad (2009)

Proximidade (Buffer) - É a criação de uma área em torno de um ou mais elementos espaciais (ponto, linha ou polígono), definida por uma distancia máxima especificada, conforme ilustrado na Figura 2.5. 


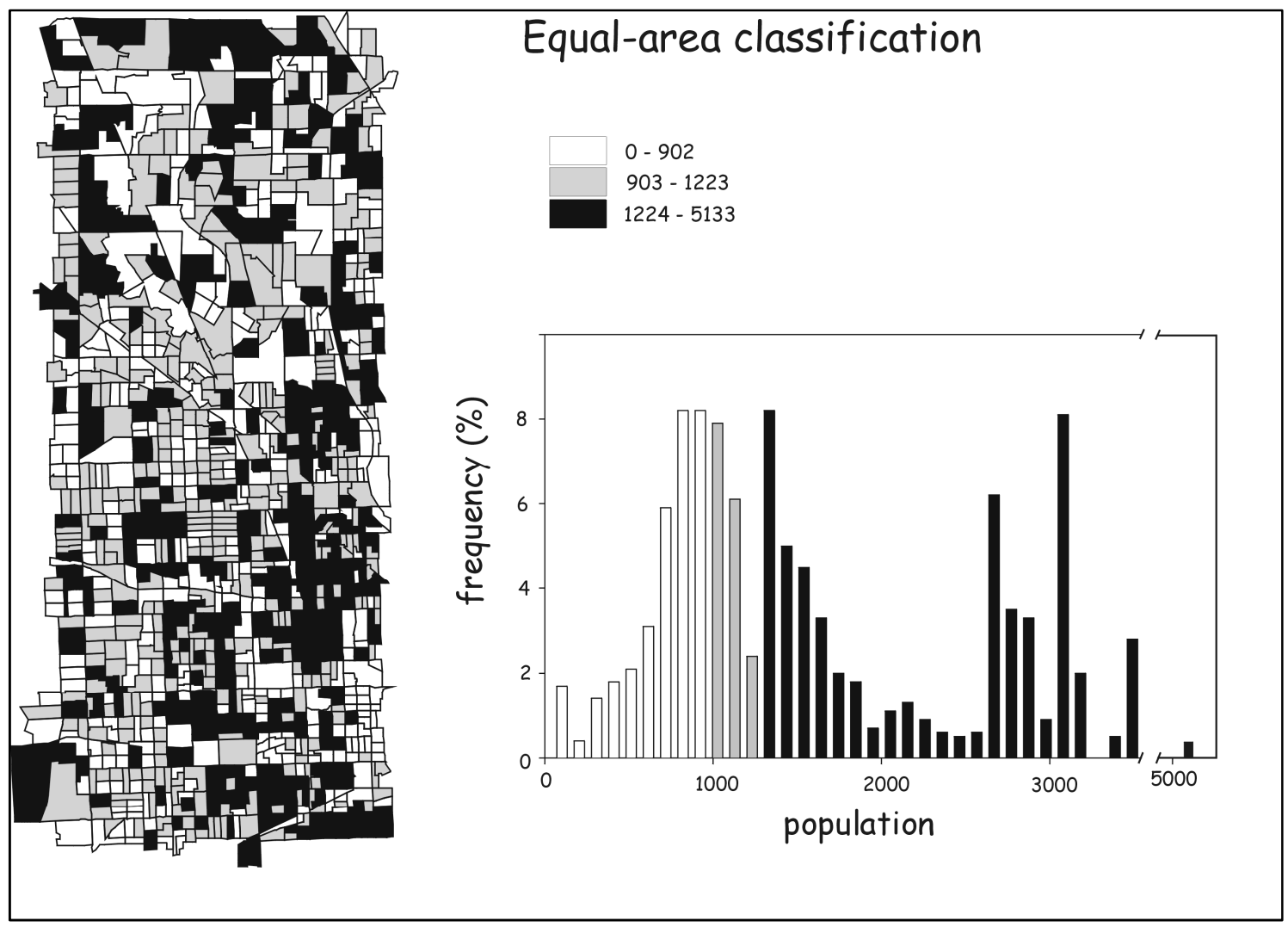

Figura 2.6 - Classificação

Fonte: Bolstad (2009)

Classificação - Procedimento de identificação de um conjunto de feições que pertencem a uma determinada classe ou padrão pré-definido. A Figura 2.6 mostra um exemplo de um mapa de quadras classificado por sua população. 


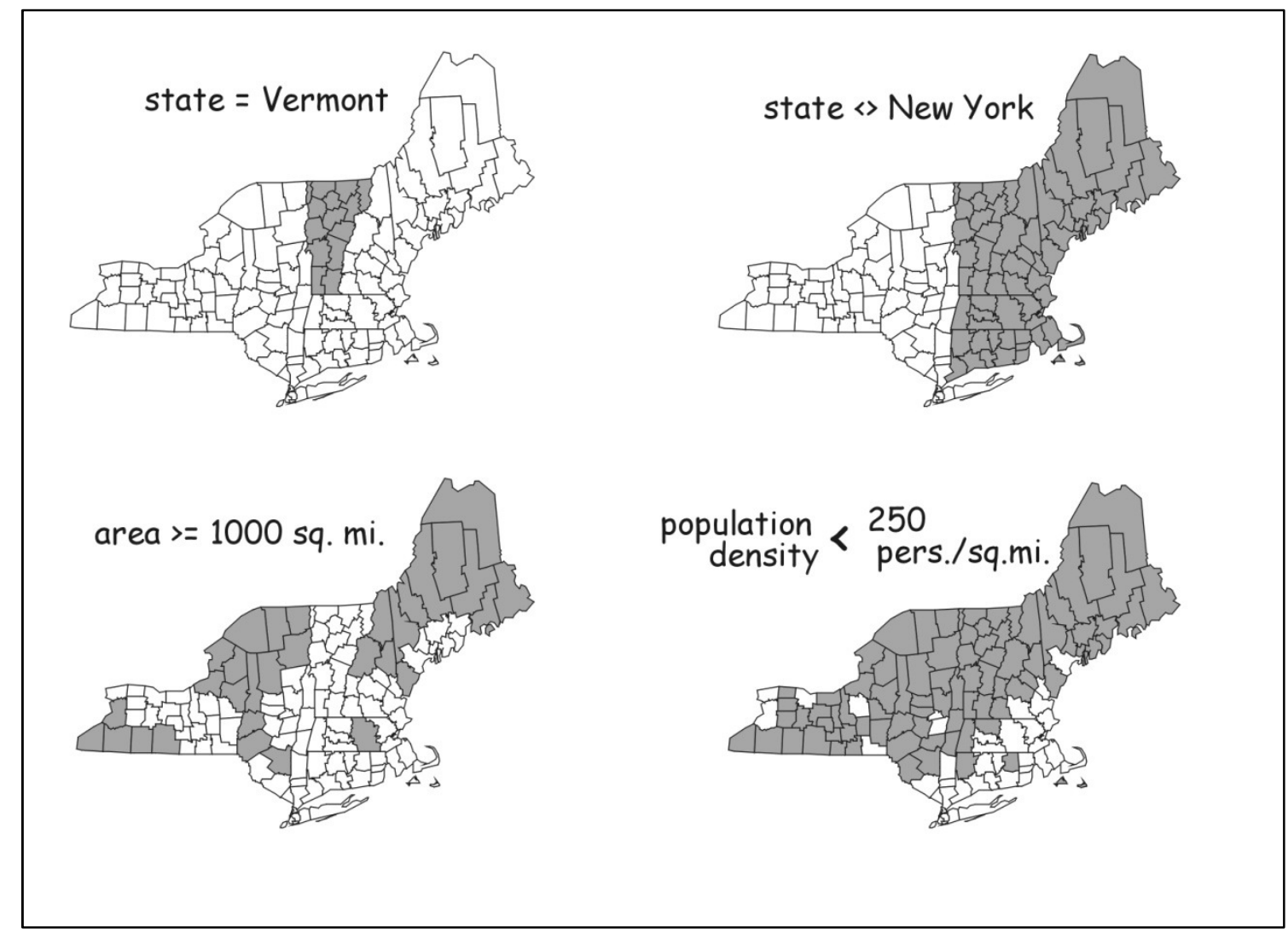

Figura 2.7 - Seleção Condicional

Fonte: Bolstad (2009)

Seleção Condicional - Recupera registros na base de dados de acordo com certos parâmetros fornecidos pelo operador, utilizando operadores condicionais: Menor que "<", Maior que ">", Igual a "=", Diferente de "<>". Exemplos deste tipo de seleção são apresentados na Figura 2.7.

Seleção Booleana - Recupera registros na base de dados de acordo com certos parâmetros fornecidos pelo operador, utilizando operadores booleanos: "E", "OU" e "NÃO", conforme ilustrado na Figura 2.8.

Seleção Espacial - Seleciona registros na base de dados de acordo com certas relações topológicas (Igual, Disjunto, Contem/Contido, Toca, Cruza, Sobrepõe) entre os elementos. No exemplo ilustrado na Figura 2.9, são selecionados todos os estados americanos que contem o Rio Mississipi ou seus afluentes. 


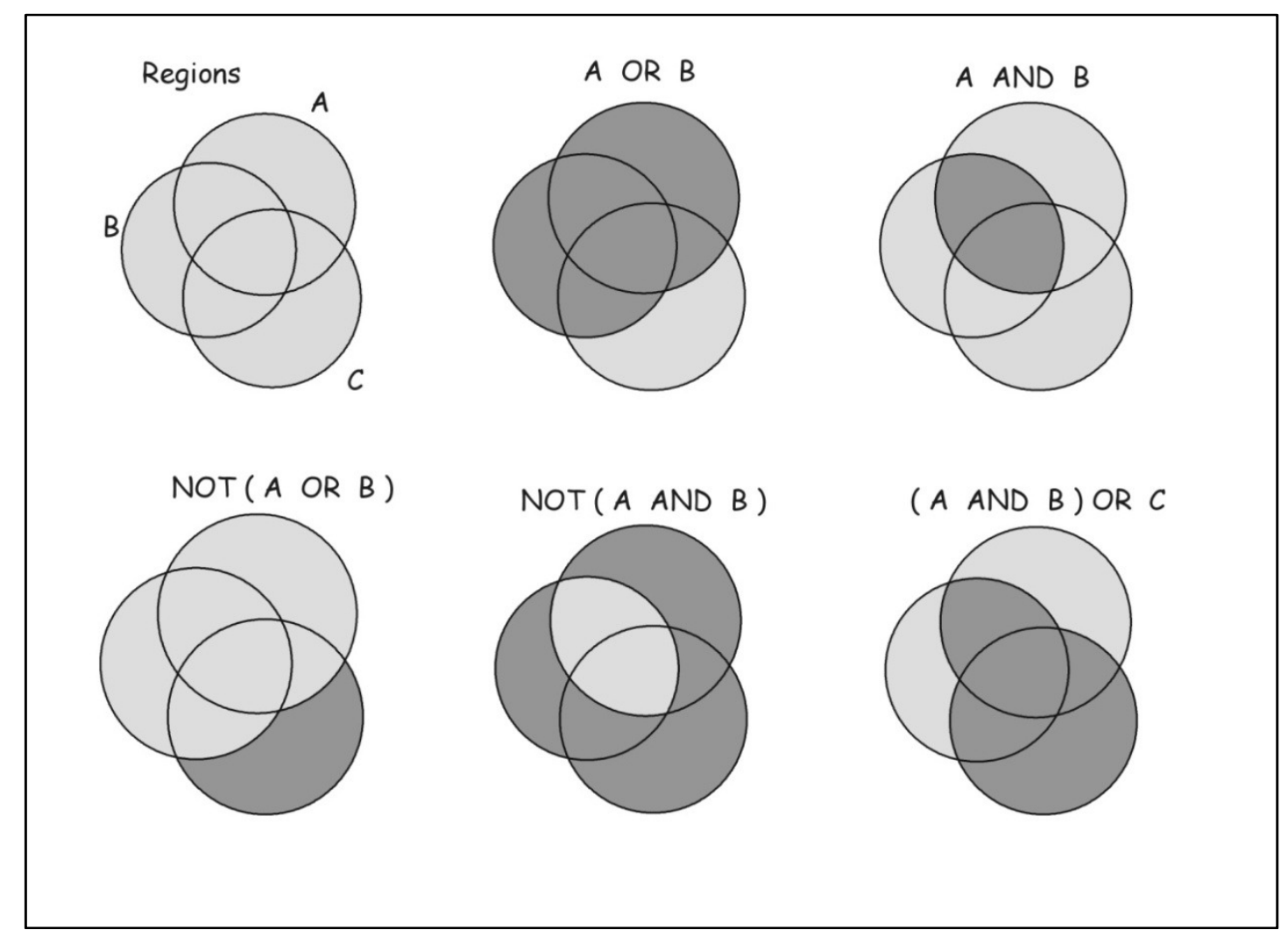

Figura 2.8 - Seleção Booleana

Fonte: Bolstad (2009)

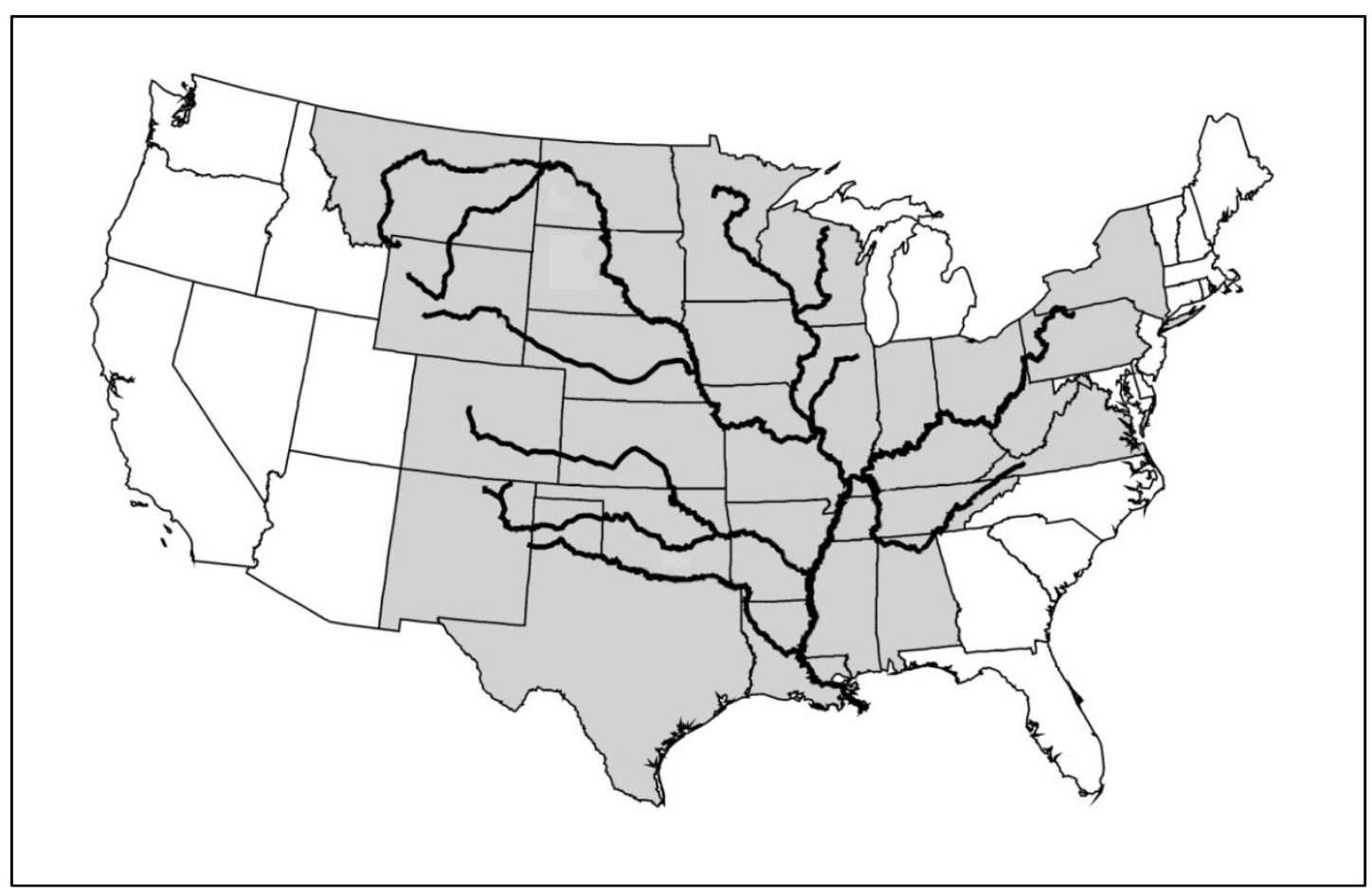

Figura 2.9 - Seleção Espacial

Fonte: Bolstad (2009) 


\section{GERENCIAMENTO DE BENS PATRIMONIAIS}

Nas ciências contábeis, ativos são os bens e direitos financeiros adquiridos pela empresa ao longo do tempo e que podem ser convertidos em valor financeiro. Essa conversão pode ser imediata (venda de um bem), ou futura como acontece no resgate de um investimento de longo ou médio prazo (CPCON, 2010).

Os Ativos, ou bens, podem ser divididos, em duas categorias:

- Bens Tangíveis ou Bens Físicos: Consistem nos bens materiais, tais como imóveis (terrenos e edificações), moveis (máquinas, veículos e equipamentos) e bens menores (computadores, mobiliário, etc.). São bens de classificação precisa e bem regulamentada, sendo facilmente mensuráveis segundo normas técnicas e regras matemáticas simples.

- Bens Intangíveis ou Bens Não-Físicos: São os bens de características não materiais, como investimentos, patentes, marcas comerciais entre outros. Ao contrário dos bens físicos, possuem classificação mais complexa e menos precisa.

Uma organização deve ter total conhecimento de seus ativos, tanto do ponto de vista contábil como do ponto de vista operacional. Acompanhar os ativos do ponto de vista contábil, conhecendo o valor original e a forma de depreciação de cada um é indispensável para sua administração financeira e fiscal. Do ponto de vista operacional, os ativos de interesse não são aqueles com relevância financeira e contábil, mas aqueles sujeitos a intervenções, ou cujo histórico de operação, inspeção e manutenção precisam ser mantidos Kindrachuck (2001).

Ainda segundo Kindrachuck, para certos bens de baixo valor e grande quantidade, nem sempre há um acompanhamento contábil individual (normalmente suas despesas estão associadas a outros bens). Entretanto, muitas vezes esses bens menores têm relevância do ponto de vista da manutenção e operação da atividade da organização. 
Neste capitulo o foco principal é dado à gestão do Patrimônio Tangível, chamado de Bens Patrimoniais, e às operações correlatas ao seu gerenciamento, como o levantamento, avaliação e registro dos bens físicos, voltados em especial às atividades de operação e manutenção.

A Gestão Patrimonial, sob esta perspectiva, consiste na coleta, processamento, análise e manutenção de informações completas sobre vários tipos de ativos, móveis e imóveis para o planejamento dos trabalhos a serem executados para a manutenção desses ativos em um nível operacional ótimo, da forma mais eficiente (LEMER, 1998).

Segundo Kindrachuck (2001), sistemas de Gerenciamento Patrimonial normalmente trabalham com a gestão de Ordens de Serviço, ou alimentam sistemas dedicados a esta atividade.

Muitos dos sistemas de gestão de Ordens de Serviço disponíveis no mercado oferecem recursos para registro de inspeções e do histórico operacional. A partir destas informações e de critérios específicos estabelecidos, podem ser criadas automaticamente Ordens de Serviço para determinado item. Normalmente os critérios acionadores são baseados:

- Em períodos fixos desde o ultimo registro de intervenção no bem (por exemplo, "12 meses da ultima manutenção");

- Em níveis quantificados de condição do bem (por exemplo, "Nível do reservatório abaixo de 1/4 da capacidade");

- No histórico de um determinado numero de operação (por exemplo, "10.000 horas de uso").

A partir de dados obtidos em inspeções ou do histórico armazenado, o sistema pode ser capaz de identificar o tipo de trabalho a ser executado, programar e acompanhar o andamento de sua execução e, após a conclusão do serviço, salvar o novo estado do bem no sistema.

Em seu trabalho sobre o Gerenciamento Patrimonial no setor de infraestrutura, Lemer (1998) coloca que o processo de gestão deve tratar em especial de duas questões: Quais bens devem ser instalados, quais os valores 
destes, e como esses bens podem ser instalados e utilizados para se obter 0 maior retorno possível.

Segundo o autor, essas não são questões simples, pois diversas organizações têm sua infra-estrutura construída há muitos anos, com registros precários disponíveis sobre essa infra-estrutura ou com um conhecimento parcial do real estado dos bens. Mesmo quando uma empresa possui um registro detalhado de seu acervo, com as características físicas e condições de cada bem atualizados, essas informações não estão relacionadas com a região servida pelo equipamento. Esse é um dos principais motivadores na adoção do Geoprocessamento nas atividades de Gestão Patrimonial.

\subsection{O USO DE SISTEMAS DE INFORMAÇÃO GEOGRÁFICA NO GERENCIAMENTO DE BENS PATRIMONIAIS}

A aquisição e a análise de dados é uma tarefa básica para qualquer sistema de gerenciamento. Os avanços da indústria da informática e eletrônica nas ultimas décadas, com o aumento do desempenho e da capacidade de armazenamento dos computadores e dos dispositivos de coleta de dados, associados à queda nos custos desses equipamentos, tornou viável a adoção de Sistemas de Informação Geográfica para fins de gestão patrimonial (LEMER, 1998).

Uma gestão patrimonial eficiente demanda um sistema de informação capaz de combinar e gerir dados, de tipos e fontes as mais diversas, como mapas, plantas, croquis, tabelas, fotografias, entre outros, num sistema cadastral centralizado, garantindo a uniformidade de tratamento dos dados, e sua fácil disseminação dentro das organizações.

Essa tarefa pode ser mais facilmente manejada com o uso de um SIG, onde os dados tabulares são combinados com as feições georreferenciados dos bens, representados sobre a forma de um mapa.

A integração desses vários tipos de cadastro, numa mesma base de dados cartográfica, proporciona uma poderosa ferramenta para manipulação e a análise das informações pertinentes a este sistema. O conhecimento da 
localização e da disposição destes bens é de grande valia para o controle do patrimônio.

O conhecimento e a representação de como estes elementos estão distribuídos ao longo do território, permite uma serie de analises que, se não impraticáveis, seriam muito mais difíceis de serem realizadas sem este recurso. A representação espacial dos elementos fornece a exata noção de sua abrangência territorial, de sua distribuição espacial, de como os elementos se relacionam entre si e das interferências de tais elementos com o meio físico.

Um sistema bem projetado de gestão patrimonial com um banco de dados detalhado pode fornecer informações para o acompanhamento de todo o ciclo de vida de um ativo, ou seja, cobrir desde a fase de projeto, construção, reparo, reconstrução, substituição e baixa, dando suporte às atividades de controle de custos (estimados e reais), as atividades de manutenção, a gestão orçamentária, a resposta a emergências entre outras (RAMLAL, 2005).

Garvey (2003) resume os principais benefícios do SIG na Gestão Patrimonial:

- Integração de dados: com um SIG é possível combinar e analisar de forma integrada, diferentes tipos de dados das mais diferentes fontes;

- Analise dos dados: além das analises inerentes a qualquer sistema de informação, um SIG permite a realização de análises espaciais e topológicas;

- Visualização dos dados: um SIG permite a visualização dos dados e dos resultados de consultas e analises de forma gráfica, melhorando a compreensão e comunicação da informação.

- Padrões e conceitos, quando envolvem um conjunto complexo e volumoso de informações, são muito mais fáceis de serem compreendidos quando apresentados de forma gráfica. A representação visual de cenários complexos, na forma de mapas, como o SIG apresenta, permite o reconhecimento de padrões e a identificação de tendências, facilitando e tornando intuitiva a tarefa de analise e de tomada de decisões sobre esse conjunto de dados, tarefa essa que 
seria muito mais complexa analisando apenas dados tabulares ou gráficos (RICH e DAVIS, 2010).

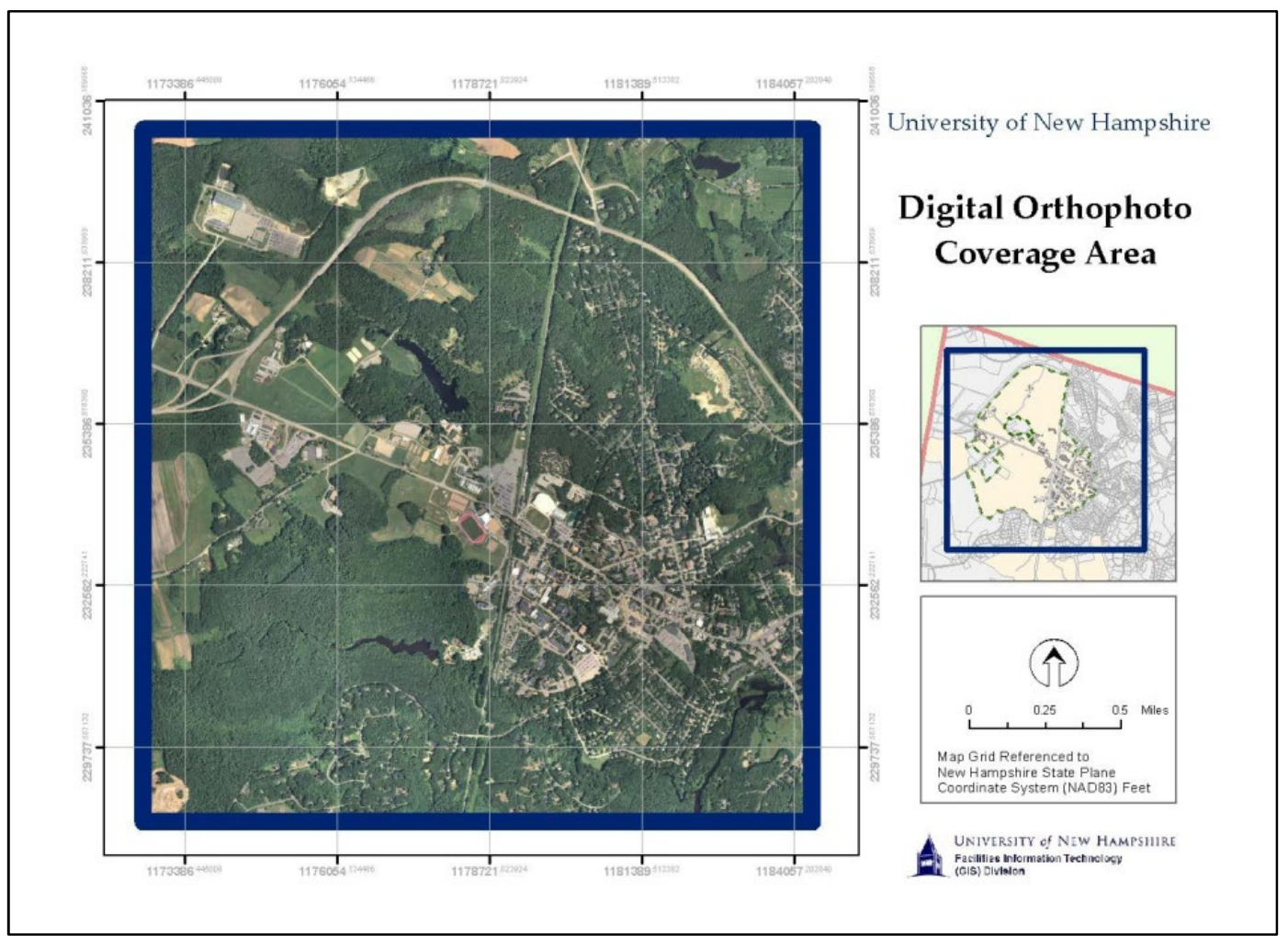

Figura 3.1 - Fotografia orbital do campus da Universidade de New Hampshire Fonte: Tardie et. al. (2003)

A Figura 3.1 apresenta um exemplo um mapa SIG elaborado a partir de uma imagem de satélite ortorretificada do campus da Universidade de New Hampshire. 


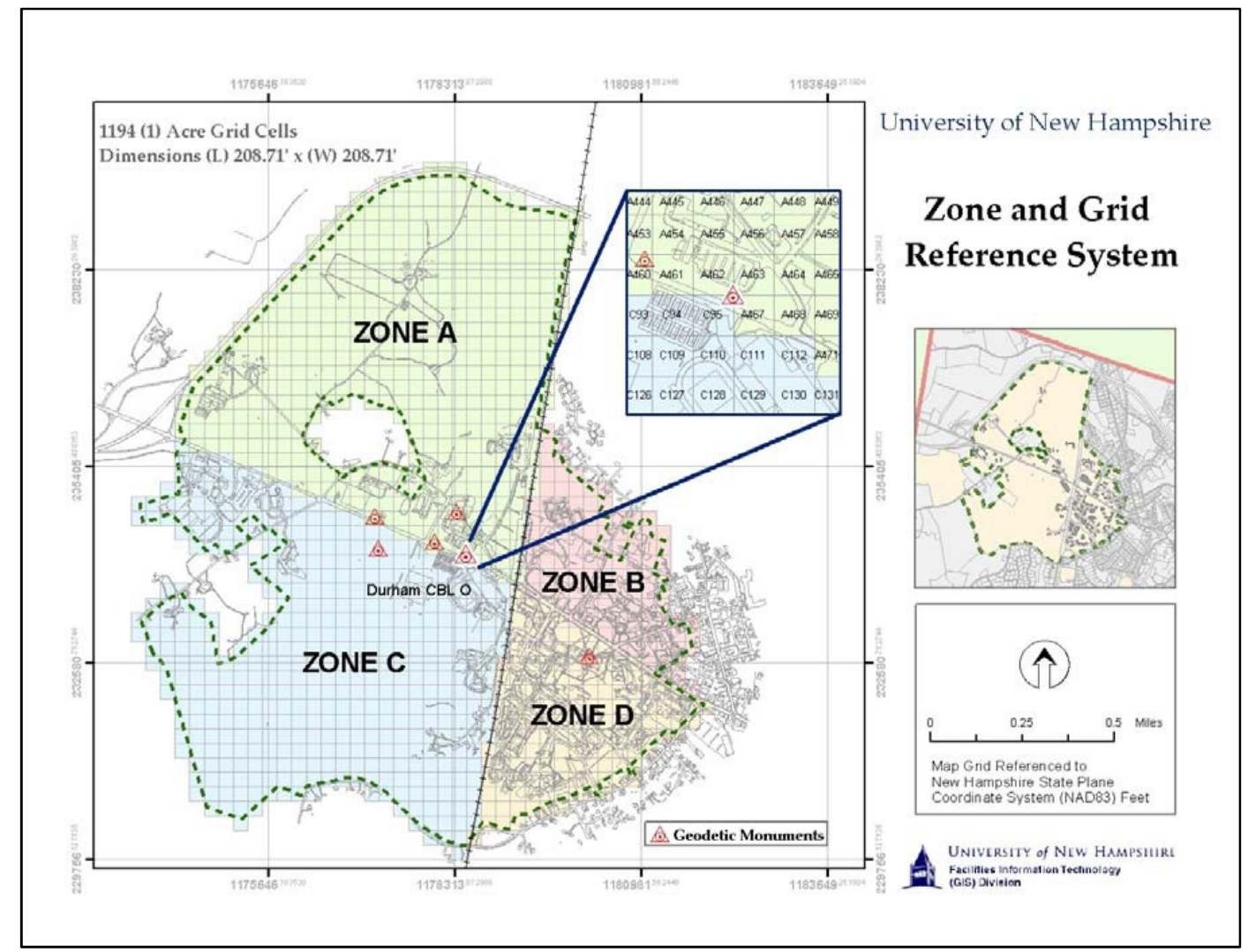

Figura 3.2 - Mapa vetorial do campus da Universidade de New Hampshire Fonte: Tardie et. al. (2003)

A Figura 3.2 apresenta um mapa vetorial com a mesma abrangência do mapa apresentado na figura 3.1. Mapas vetoriais são produzidos por restituição de imagens ortorretificadas (quando as feições presentes na imagem são identificadas, interpretadas e desenhadas vetorialmente em sua respectiva camada), ou por meio de levantamentos topográficos, com a utilização de teodolitos e/ou dispositivos de posicionamento por satélites (GPS). 


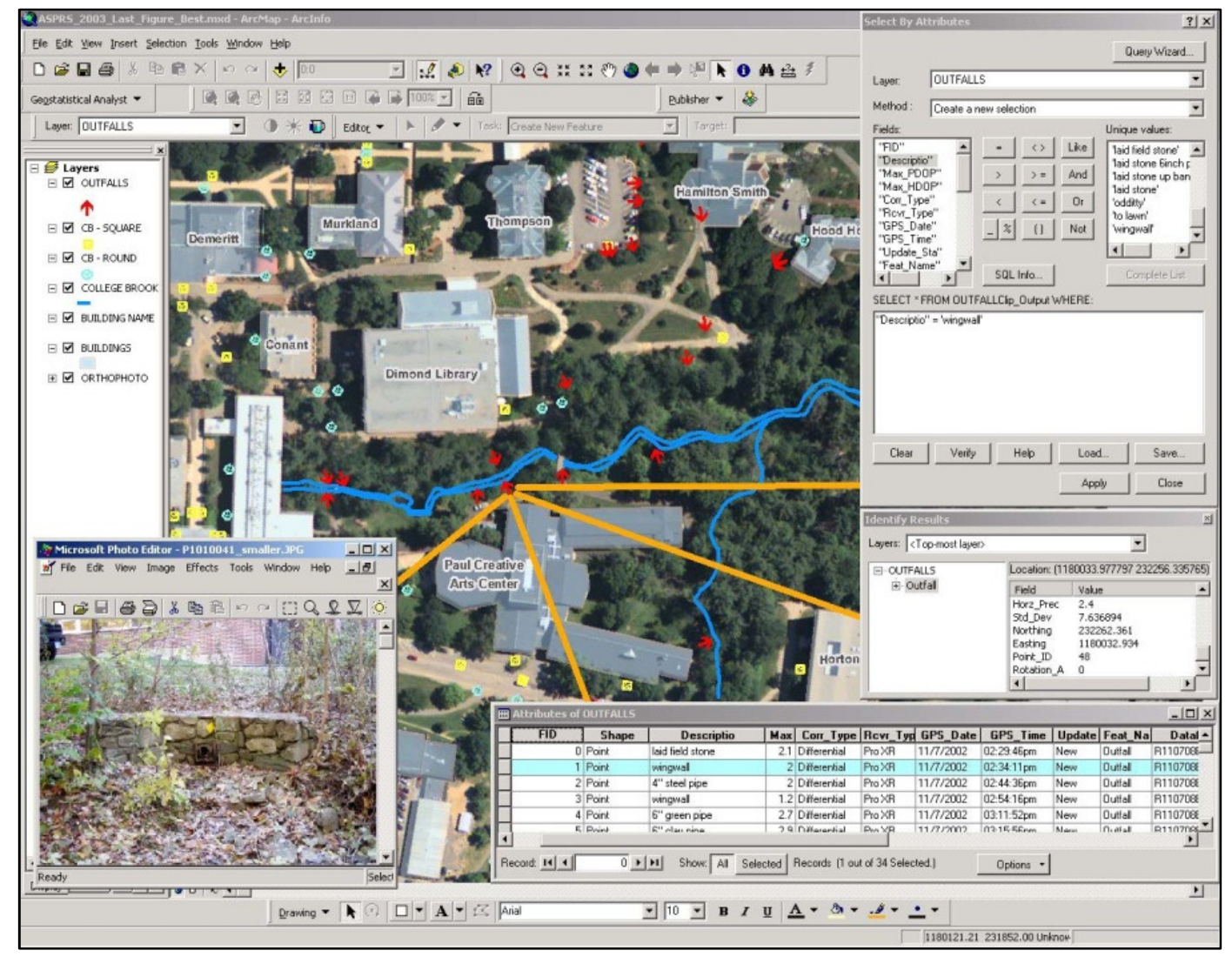

Figura 3.3 - Consulta sobre mapa em SIG

Fonte: Tardie et. al. (2003)

A Figura 3.3 exibe uma típica interface de um SIG, no caso uma das telas do sistema de gerenciamento da Universidade de New Hampshire. A esquerda da figura é possível identificar a legenda com as camadas exibidas no mapa. $O$ mapa central é uma composição de uma imagem de satélite utilizada como fundo, sobre a qual os elementos vetoriais são representados. A figura exibe ainda ferramentas de filtragem e exibição de resultados, e no destaque, um dos registros selecionados (em azul) e uma fotografia associada a esse registro. 


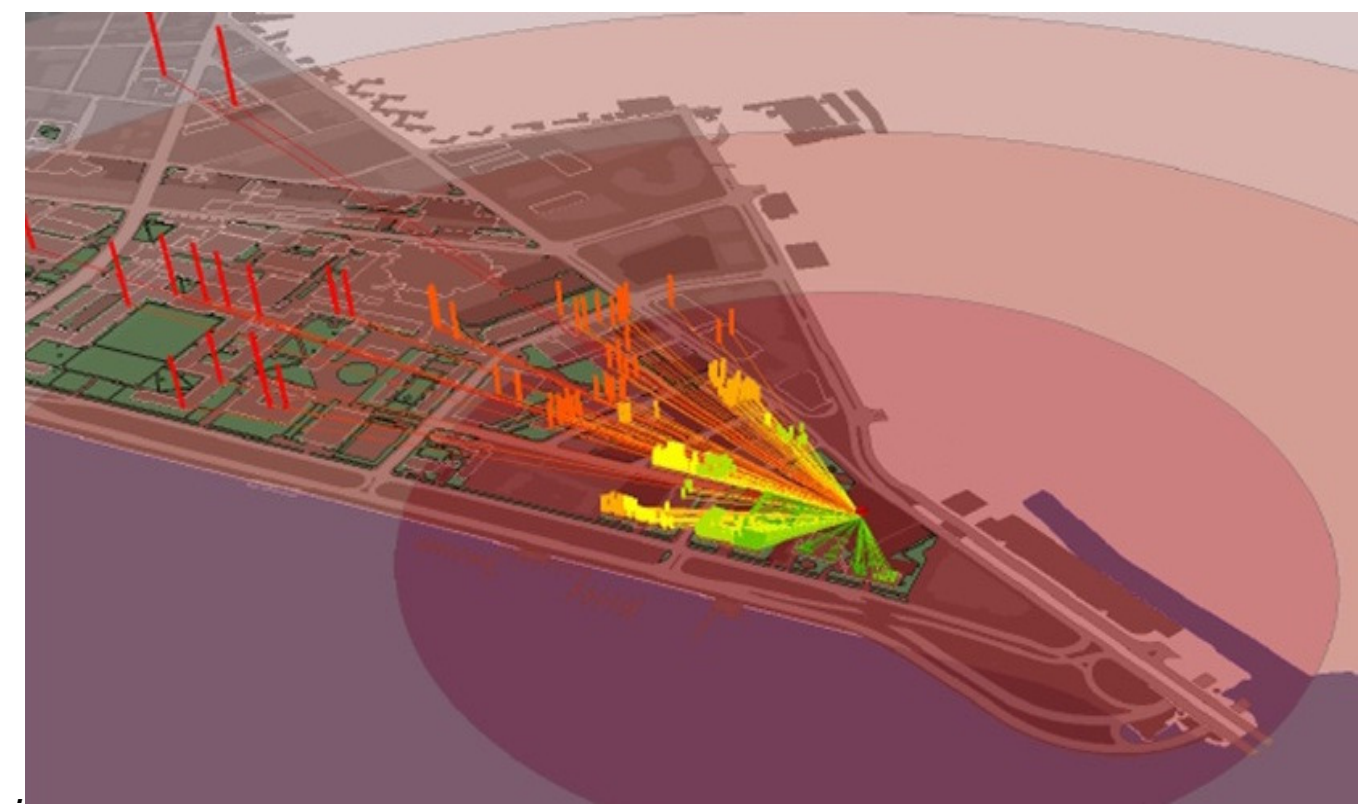

Figura 3.4 - Analise de distância e tempo de deslocamento.

Fonte: RICH e DAVIS (2010).

A Figura 3.4 exibe, de forma gráfica, o resultado de uma análise espacial. A partir de um ponto inicial (local de estacionamento) foram calculados e mapeados os caminhos até os diferentes edifícios e o tempo de deslocamento de cada rota foi representado por diferentes cores no mapa.

Um SIG em sua essência não é capaz de prover todas as ferramentas necessárias para um Gerenciamento Patrimonial efetivo. Entretanto, como uma peça de software, este pode ser estendido e personalizado para atender a demandas especificas, ou ainda pode ser associado a outras ferramentas dedicadas (LEMER, 1998).

\subsubsection{Levantamento de Dados para um SIG Patrimonial}

Um aspecto crítico da utilização do SIG no gerenciamento Patrimonial, segundo Ramlal (2005), diz respeito ao custo do levantamento e carga dos dados espaciais e tabulares para o sistema de gestão. Esses custos podem ser muito elevados, dependendo dos tipos de bens que estão sendo mapeados. Dependendo do tipo de elemento levantado, da disponibilidade de informação previamente existente, da 
técnica empregada no levantamento e na subsequente necessidade de tratamento para carga desses dados no sistema, o tempo de coleta e carga pode ser longo e demandar grande alocação de mão de obra para as atividades, encarecendo o processo.

Garvey (2003) propõe os seguintes procedimentos para a padronização do processo de levantamento de elementos em campo para alimentação de um SIG Patrimonial:

a) Identificação do conjunto de Bens a serem levantados

- Definição dos atributos relevantes para cada tipo de bem;

b) Pesquisa do acervo existente

- Localização e avaliação de fontes existentes de dados, tanto no formato digital como analógico;

c) Planejamento das atividades

- Construção de um dicionário de dados,

- Treinamento de pessoal,

- Cronograma de levantamentos;

d) Levantamento dos dados

- Suporte a questões de campo (duvidas de classificação);

e) Transferência de dados

- Armazenamento dos dados levantados,

- Armazenamento de fotografias (controle de nomenclatura),

- Copias de segurança (backups); 
f) Verificação dos dados

- Garantir a precisão espacial,

- Revisão dos atributos levantados

i. Atributos incompletos,

ii. Atributos inconsistentes,

iii. Comparação dos atributos com as fotografias;

g) Exportação dos dados

- Integração com bancos de dados existentes;

- Exportação em formato GIS

i. Definição de atributos a serem exportados,

- Exportação em formato CAD

i. Definição de camadas de informação (layers) e simbologias;

ii. Definição da forma de preservação dos atributos Como texto ou como blocos de atributos;

h) Controle de Qualidade

- Identificação de lacunas e sobreposições

i. Dados faltando ou duplicados;

- Precisão Espacial

i. Comparação com ortofotos existentes;

ii. Comparação com bases existentes,

- Precisão dos atributos

i. Completos e corretos;

- Conferencia em campo por amostragem; 
i) Integração de dados

- Integração dos dados levantados com dados espaciais existentes;

- Compatibilização e ajustes nos dados existentes sob a realidade dos dados levantados (por exemplo, ajustar um mapa esquemático de redes a partir de pontos da rede levantadas em campo por GPS).

\subsection{EXEMPLO DE USO DE SIG NO GERENCIAMENTO DE BENS PATRIMONIAIS}

A seguir é apresentado um relato do Projeto PET-70 "Inventário Físico e Rearrolamento dos Bens Patrimoniais do Sistema de Trens Urbanos do Governo do Estado do Rio de Janeiro", realizado entre os anos de 2004 e 2008 para a Companhia Estadual de Engenharia de Transportes e Logística - CENTRAL, transcrito de Couto et. al.(2011).

O projeto foi financiado pelo Banco Mundial - BIRD, para a realização do Inventário Físico e Rearrolamento dos ativos físicos do Sistema de Trens Urbanos e também para o desenvolvimento de um Sistema de Informação Geográfica (SIG) para apoiar o inventário e controle desses ativos a partir de então.

\subsubsection{Breve histórico da formação do sistema ferroviário}

\section{Fluminense}

Rodriguez (2004) faz um relato detalhado da formação das estradas de ferro no Rio de Janeiro, o qual é resumido a seguir.

Em 1854 inaugurou-se a primeira ferrovia brasileira, a Estrada de Ferro Mauá, construída e operada de forma privada pelo Barão de Mauá, cobrindo parte do que é hoje o Município de Magé, região Norte Fluminense.

Em 1858 foi inaugurada a Ferrovia Dom Pedro II, construída e operada pelo Governo Central, servindo à região Centro-Oeste 
Fluminense, expandida em 1879, para a região Sudoeste, conforme ilustra a Figura 3.5. Em 1889, com a Proclamação da Republica, e a deposição de Dom Pedro II, a ferrovia que levava seu nome foi rebatizada para Ferrovia Central do Brasil.

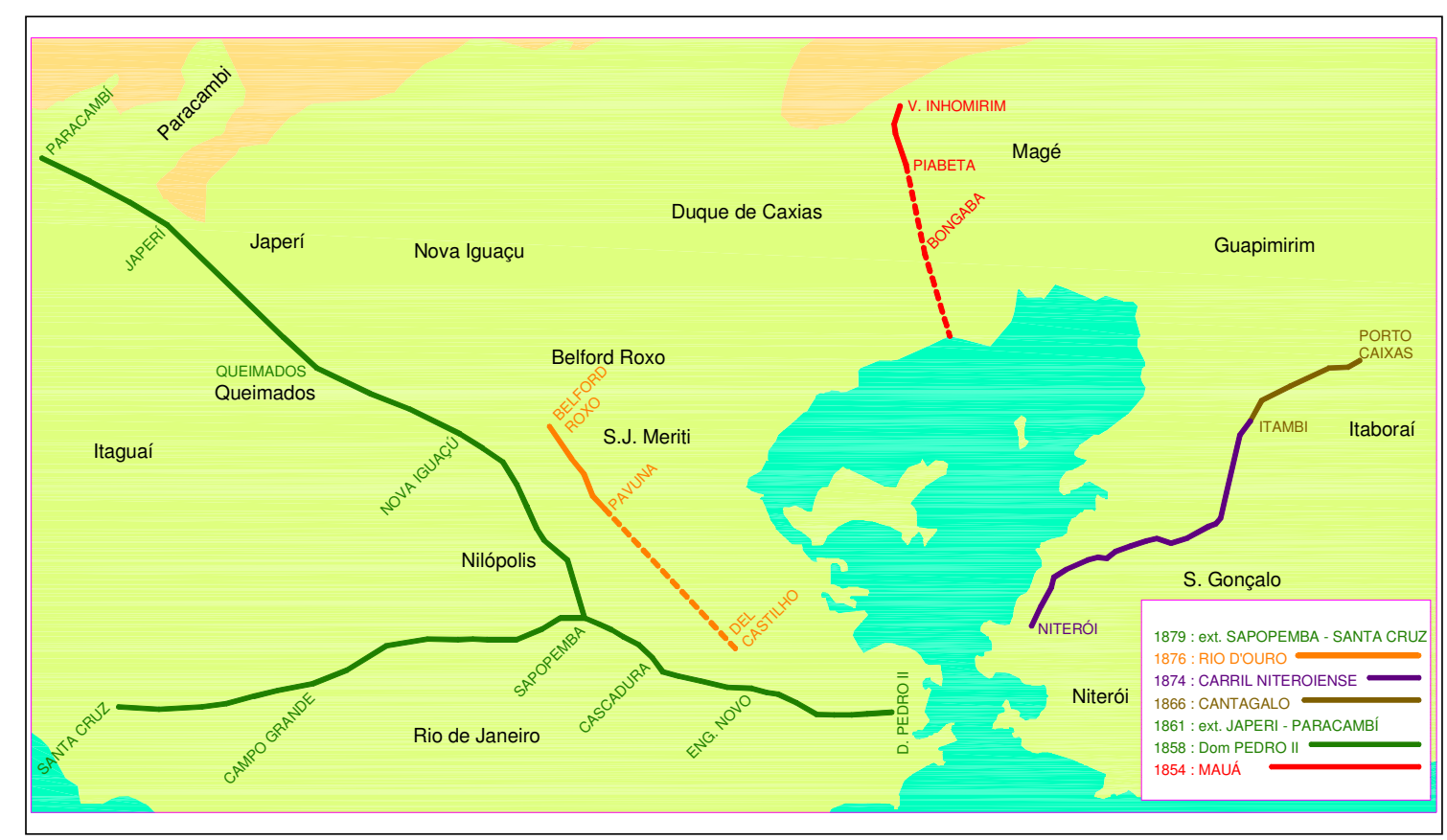

Figura 3.5 - Sistema Ferroviário na área da Baía de Guanabara (1854 1879)

Fonte: Couto et. al. (2011), a partir de uma figura de Rodriguez (2004)

Nos anos seguintes à construção das ferrovias Mauá e Dom Pedro II, outras ferrovias foram construídas, onde hoje é o estado do Rio de Janeiro, sendo em tempos diferentes incorporadas a outras ferrovias, ou desconstruídas, como a Ferrovia do Cantagalo de 1866, a Ferrovia Carril Niteroiense de 1874, a Ferrovia Rio D'Ouro de 1876, a Ferrovia do Norte de 1888, a Ferrovia Teresópolis de 1895, a Ferrovia Melhoramentos do Brasil de 1902.

Em 1897 a Ferrovia Leopoldina que já havia incorporado outras tantas ferrovias vai à falência e passa ao controle de seus credores ingleses, sendo rebatizada de Leopoldina Railway Co. 
A Estrada de Ferro Central do Brasil permaneceu sob gestão Federal ao longo de sua existência e a Leopoldina Railway manteve-se como uma empresa privada até idos da década de 50, quando foi estatizada.

Em 1957, ambas as ferrovias, juntamente com outras em todo território brasileiro, deram origem à Rede Ferroviária Federal S.A. - RFFSA, uma empresa de economia mista sob controle do Governo Federal.

Em 1984 foi criada a Companhia Brasileira de Trens Urbanos CBTU, subsidiária da RFFSA, destinada exclusivamente à prestação dos serviços de transporte ferroviário de passageiros em áreas urbanas.

Em 1994, seguindo uma norma aprovada pela Constituição de 1988, o transporte de passageiros sob trilhos passou para a alçada estadual, sendo fundada a Companhia Fluminense de Trens Urbanos - FLUMITRENS.

Em maio de 2001, foi criada a Companhia Estadual de Engenharia de Transportes e Logística - CENTRAL, que, sucessora da FLUMITRENS, absorveu parte dos seus ativos.

Em 1998, o Governo do Estado do Rio de Janeiro concedeu ao Consórcio Supervia Concessionária de Transporte Ferroviário S.A. - SUPERVIA, a maior parte da rede de prestação dos serviços de transporte de passageiros, por 25 anos, prorrogáveis por mais 25 anos. Ao fim do contrato os bens físicos usados (ou seu equivalente financeiro) devem retornar ao Governo do Estado do Rio de Janeiro para continuidade da operação. A Figura 3.6 ilustra a situação a partir de 2001. 


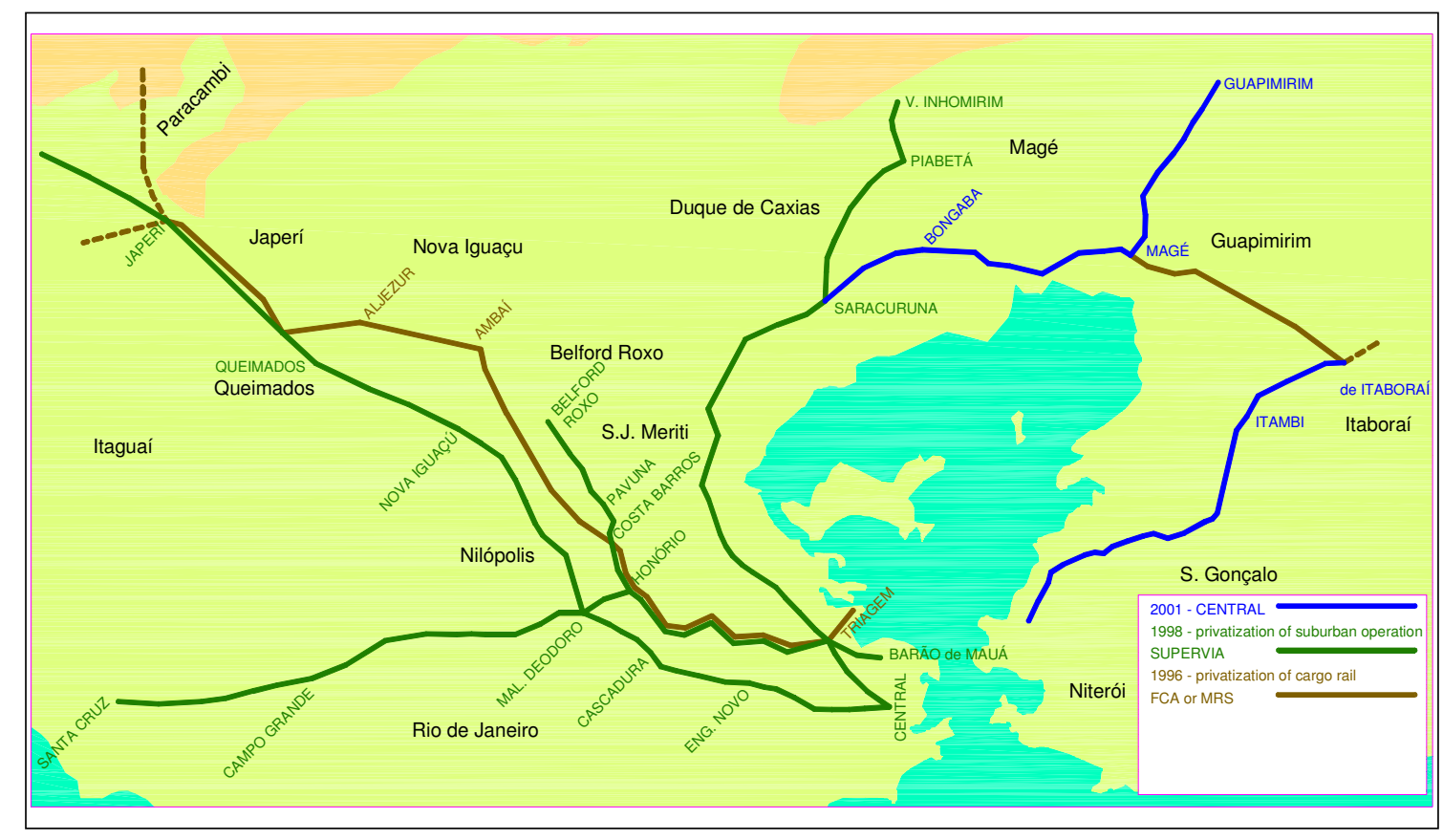

Figura 3.6 - Sistema Ferroviário na área da Baía de Guanabara (2001)

Fonte: Couto et. al. (2011), a partir de uma figura de Rodriguez (2004)

\subsubsection{A necessidade de um inventário físico}

Em 2002, o patrimônio imobiliário da CENTRAL era estimado em cerca de 1000 bens, entre bens operacionais, sob a guarda da SUPERVIA, e outros, operacionais e não operacionais, em poder da própria CENTRAL e da FLUMITRENS, ai inclusos estações, oficinas, residências, terrenos, faixas de servidão e outros localizados ao longo dos 15 municípios da Região Metropolitana do Rio de Janeiro, cruzados pelas linhas férreas do sistema.

Além dos imóveis eram estimados cerca de 9.000 bens móveis de grande porte, predominantemente material rodante (carros de passageiros, locomotivas e vagões) e aproximadamente 23.000 itens de pequeno porte, referentes a máquinas, equipamentos e utensílios diversos. Por fim existiam os bens de sistemas, ai inclusos $400 \mathrm{~km}$ lineares de via permanente, os componentes do sistema de alimentação elétrica, de sinalização, comunicações e bilhetagem.

A freqüência e a velocidade das alterações institucionais a que foi submetido o sistema de trens urbanos do Rio de Janeiro, com a mudança 
de titularidade do acervo imobiliário e demais bens dificultou o controle, a avaliação e a documentação legal dos bens constituintes do sistema.

O uso compartilhado de linhas para transporte de passageiros e cargas, alem de instalações, como oficinas, estações e pátios, utilizados por diferentes operadores, contribuiram para aumentar o problema, dificultando ainda mais o processo de regularização do patrimônio imobiliário e dos sistemas ferroviários.

Durante as sucessivas mudanças de titularidade, edifícios foram construídos e demolidos, imóveis foram vendidos, alugados, ou invadidos. Parte significativa dos bens móveis também sofreu as consequências do descontrole deste período, acarretando no extravio e sucateamento de parte dos bens.

Dada à complexidade da situação descrita, com a inconsistência entre a situação legal e cadastral dos bens e sua realidade, ficou explicita a necessidade de um recadastramento e arrolamento, bem como a adoção de ferramentas capazes de fornecer informações rápidas e precisas com relação à situação legal, à integridade física e demais detalhes relevantes que caracterizam os bens pertencentes ao Estado.

\subsubsection{O projeto PET-70}

Atendendo a uma condição do Banco Mundial - BIRD, para ter acesso a novos empréstimos, foi incluída no Programa Estadual de Transporte - PET, a contratação de serviços de consultoria para a realização de um Inventário Físico e Rearrolamento dos ativos físicos do Sistema de Trens Urbanos Estadual e também para o desenvolvimento de um Sistema de Informação Geográfica (SIG) para apoiar o inventário e controle desses ativos a partir de então.

Uma licitação internacional levou à contratação do Consorcio DPS (DE-Consult / Praxis / Sysfer) em 2004. O desenvolvimento e a implementação do SIG, denominado SISPAT, foi entregue ao LabArq, um grupo de pesquisa especializado em informatização de acervos, da Faculdade de Arquitetura e Urbanismo da Universidade de São Paulo, 
com experiência prévia no desenvolvimento de sistemas semelhantes para o Governo do Estado de São Paulo.

O projeto visou à realização do inventário de todos os bens patrimoniais de propriedade da CENTRAL, incluindo aqueles sob a guarda da Concessionária (SUPERVIA), além daqueles que ainda permaneciam sob a posse da FLUMITRENS.

Em relação aos bens imóveis, o projeto teve ainda como objetivo identificar a situação legal de cada um (área, limites, confrontantes, valor etc.), apontar os erros jurídicos e as incorreções, indicar os procedimentos judiciais de regularização e sugerir os procedimentos administrativos de regularização junto aos Cartórios Imobiliários e às Prefeituras.

No ano de 2004, teve inicio as atividades do PET-70 - "Inventário Físico e Rearrolamento dos Bens Patrimoniais do Sistema de Trens Urbanos do Governo do Estado do Rio de Janeiro", pelo consorcio DPS vencedor da licitação.

O Projeto foi dividido em três frentes de trabalho: Tratamento Técnico Patrimonial, Documentação Legal dos Imóveis e Sistema de Gestão Patrimonial em Base Georreferenciada.

\subsubsection{Tratamento Técnico Patrimonial}

Esta frente de trabalho se encarregou das atividades de levantamento, vistoria e avaliação dos bens imóveis, dos bens moveis e dos bens de sistema.

Para os bens imóveis, o trabalho consistiu no levantamento de todo documento existente nos acervos da CENTRAL e nos Registros Gerais de Imóveis como cópias das Escrituras, dos Termos de Doação e Cessão, e qualquer outra documentação relativa às áreas de terra da Companhia, levantamentos de campo, com o objetivo de verificar a existência física dos bens patrimoniais e confrontá-la com os dados do cadastro existente, preenchimento de ficha de vistoria, registro fotográfico do imóvel e 
elaboração de croqui para subsidiar o desenho ou redesenho atualizado do imóvel.

Com os dados expostos nos Laudos de Vistoria, um engenheiro avaliador estabeleceu as avaliações monetárias dos bens considerados, com base na utilização, estado, benfeitorias e obsolescência dos bens.

Para a realização do inventario dos bens denominados de bens móveis de Grande Porte (carros, locomotivas e vagões), fez-se inicialmente a analise do acervo documental da Companhia, além da confrontação dos diversos sistemas cadastrais existentes a época nas diferentes operadoras. De posse da listagem do acervo, o corpo técnico, do Consórcio DPS, realizou os levantamentos de campo, verificando a existência física dos bens patrimoniais e confrontando-os com os dados do cadastro. Divergências (inclusões/exclusões), correções e complementações nos dados foram também registradas nas Fichas de Vistoria.

Paralelamente ao inventário físico, foram produzidos os Laudos de Vistoria com o levantamento das características físicas dos bens móveis de Grande Porte, registro fotográfico de cada bem e etiquetagem dos mesmos. Com os dados expostos nos Laudos de Vistoria, o corpo de peritos engenheiros mecânicos, do Consórcio DPS, estabeleceu as avaliações monetárias dos bens.

Os procedimentos para o tratamento técnico patrimonial dos Bens de Sistema (via permanente, alimentação elétrica, sinalização, comunicações e bilhetagem) e dos Bens de Pequeno Porte (máquinas, equipamentos e utensílios) seguiram a mesma metodologia aplicada aos Bens Móveis de Grande Porte, conforme o caso, respeitando as especificidades inerentes a cada um dos sistemas tratados. Um exemplo de uma Ficha de Vistoria de um Bem Móvel de Grande Porte é ilustrado na Figura 3.7. 


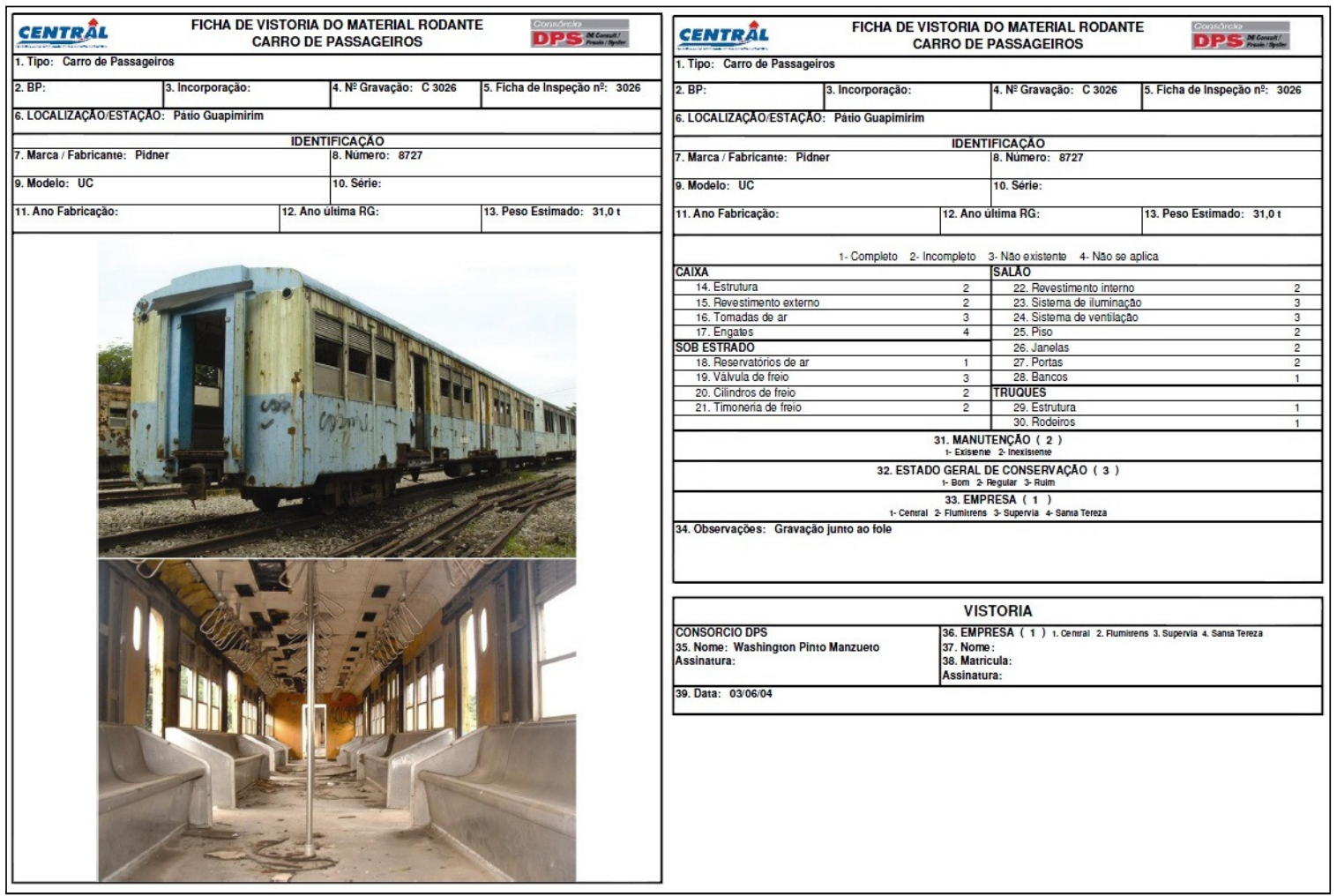

Figura 3.7 - Exemplo de Ficha de Vistoria de Material Rodante Fonte: Couto et. al. (2011)

\subsubsection{Documentação Legal dos Imóveis}

Com base nos levantamentos efetuados na fase anterior do projeto, a equipe de advogados do Consórcio DPS analisou a documentação levantada nas fichas de vistoria e avaliação e juntadas dos arquivos da CENTRAL (títulos aquisitivos, certidões do Registro Imobiliário, guias de recolhimento de tributos, contratos vigentes, entre outros), dos cartórios de Tabelionatos, do Registro Imobiliário, de prefeituras e outros órgãos públicos na forma de uma Ficha de Identificação Cadastral onde foram consolidadas as corretas informações a respeito de cada imóvel, seu histórico, e formulado um parecer jurídico com indicação de procedimentos porventura necessários à regularização de cada bem.

Todas as Fichas de Identificação Cadastral e os documentos a elas anexados foram digitalizados, para inserção no banco de dados do SISPAT, possibilitando à CENTRAL conhecer, de maneira precisa, o aspecto legal de seus imóveis. 


\subsubsection{SISPAT - Sistema de Gestão Patrimonial em Base Georreferenciada}

O Sistema Informatizado de Gestão Patrimonial em Base Georreferenciada - SISPAT foi concebido para dar suporte à gestão do acervo patrimonial da CENTRAL. Em seu Banco de Dados foram cadastrados todos os bens inventariados, com as informações provenientes das Fichas de Vistoria, Fichas de Avaliação, Fichas de Identificação Cadastral, fotografias, plantas, desenhos técnicos e demais documentos associados.

Os Bens Imóveis e os Bens de Sistema (via permanente, alimentação elétrica, sinalização, comunicações e bilhetagem) foram mapeados sobre uma Base Georreferenciada da Região Metropolitana do Rio de Janeiro. Por meio de uma interface gráfica as informações referentes a esses bens podiam ser visualizadas e consultadas espacialmente.

Em se tratando de patrimônio público, exigências legais em matéria de contabilidade exigem um tratamento diferenciado das informações. Informação sobre quaisquer ativos não podem ser substituídas, ou apagadas, possibilitando auditorias a qualquer tempo. Assim o aplicativo foi concebido sob uma ótica temporal. A mudança de qualquer dado relativo a um bem, cria uma nova entrada no Banco de Dados, ou uma "nova versão" do bem, preservando o registro do estado anterior. A cada versão cadastrada no BD é associada uma data de validade. Desta forma é possível manter um histórico de todo o patrimônio da Companhia, com o registro do estado de cada bem ao longo de toda a sua vida útil.

\subsubsection{Produção da base georreferenciada}

Para o georrefenciamento dos bens da Companhia, foi inicialmente elaborada uma base de dados de referencias urbanas e do meio físico, no entorno do sistema ferroviário e dos imóveis de interesse. As principais fontes de dados para a composição desta base foram restituições aerofotogramétricas em formato digital, da Fundação Centro de 
Informações e Dados do Estado do Rio de Janeiro - CIDE (cartas na escala 1:10.000 da Região Metropolitana) e do Instituto Pereira Passos - IPP (cartas na escala 1:2000 do município), da Prefeitura Municipal do Rio de Janeiro.

Tratava-se de levantamentos realizados para fins distintos em datas distintas (o material do IPP foi produzido no ano de 2000 para um programa de despoluição da Baia da Guanabara enquanto o material do CIDE contemplava levantamentos obtidos em diversas datas), por diferentes empresas de aerofotogrametria, sob sistemas cartográficos distintos, em escalas diferentes e com falhas na articulação das plantas.

Um grande trabalho foi requerido para o acerto e padronização da base (toda a informação relativa aos sistemas ferroviários teve de ser inserida posteriormente, por não estar representada nos levantamentos existentes). Em alguns trechos não cobertos por esses levantamentos foi realizada a restituição a partir de originais fotográficos existentes nos arquivos da CENTRAL.

Para essas atividades foram utilizados os aplicativos AutoCAD da empresa Autodesk e o pacote de geoprocessamento ArcGIS da empresa ESRI.

Essa base de dados foi preparada contemplando uma faixa mínima de 50 metros para cada lado dos limites físicos da propriedade da ferrovia, ao longo de toda sua extensão, contendo o sistema viário (com os nomes dos logradouros), edifícios públicos, morros, cursos d'água e favelas.

Sobre essa base foram inseridos os limites dos imóveis (terrenos e edificações) levantados pela equipe de campo, assim como os Bens de Sistema, cujo traçado e seus componentes (trilhos e desvios), além das faixas de servidão, foram extraídos do conjunto de 370 plantas topográficas da mapoteca da CENTRAL. 


\subsubsection{Carga das informações}

À medida que os levantamentos de campo foram sendo realizados, as informações foram cadastradas no banco de dados do SISPAT. Cada bem recebeu um numero de identificação (BP) e todas as informações levantadas nas vistorias foram inseridas. De acordo com a especificidade de cada grupo de bens (Imóveis, Sistemas, Grande Porte, Pequeno Porte, etc.) foram inseridos no Banco de Dados os anexos relevantes como registros fotográficos, desenhos em CAD, documentos legais digitalizados, laudos de avaliação, etc.

Os bens Imóveis e de Sistema, além de serem cadastrados no banco de dados tiveram suas feições georreferenciadas sobre a base espacial, em um trabalho detalhado e meticuloso.

Os bens de Sistema, ai inclusos os trechos de via férrea e seus acessórios como Aparelhos de Mudança de Via - AMV e Travessões, além dos sistemas auxiliares (Alimentação Elétrica, Sinalização e Telecomunicação) foram inventariados sobre plantas operacionais esquemáticas, onde a única referencia espacial era a quilometragem da linha. Foi necessário fazer a associação entre o traçado físico das linhas (extraído das plantas topográficas) com as referencias quilométricas oriundas das plantas esquemáticas. $O$ resultado desse trabalho, conforme ilustra a Figura 3.8, foi um mapeamento até então inédito, com a representação georreferenciada de cada segmento de Via, AMV, Travessão e Sistemas Auxiliares. 


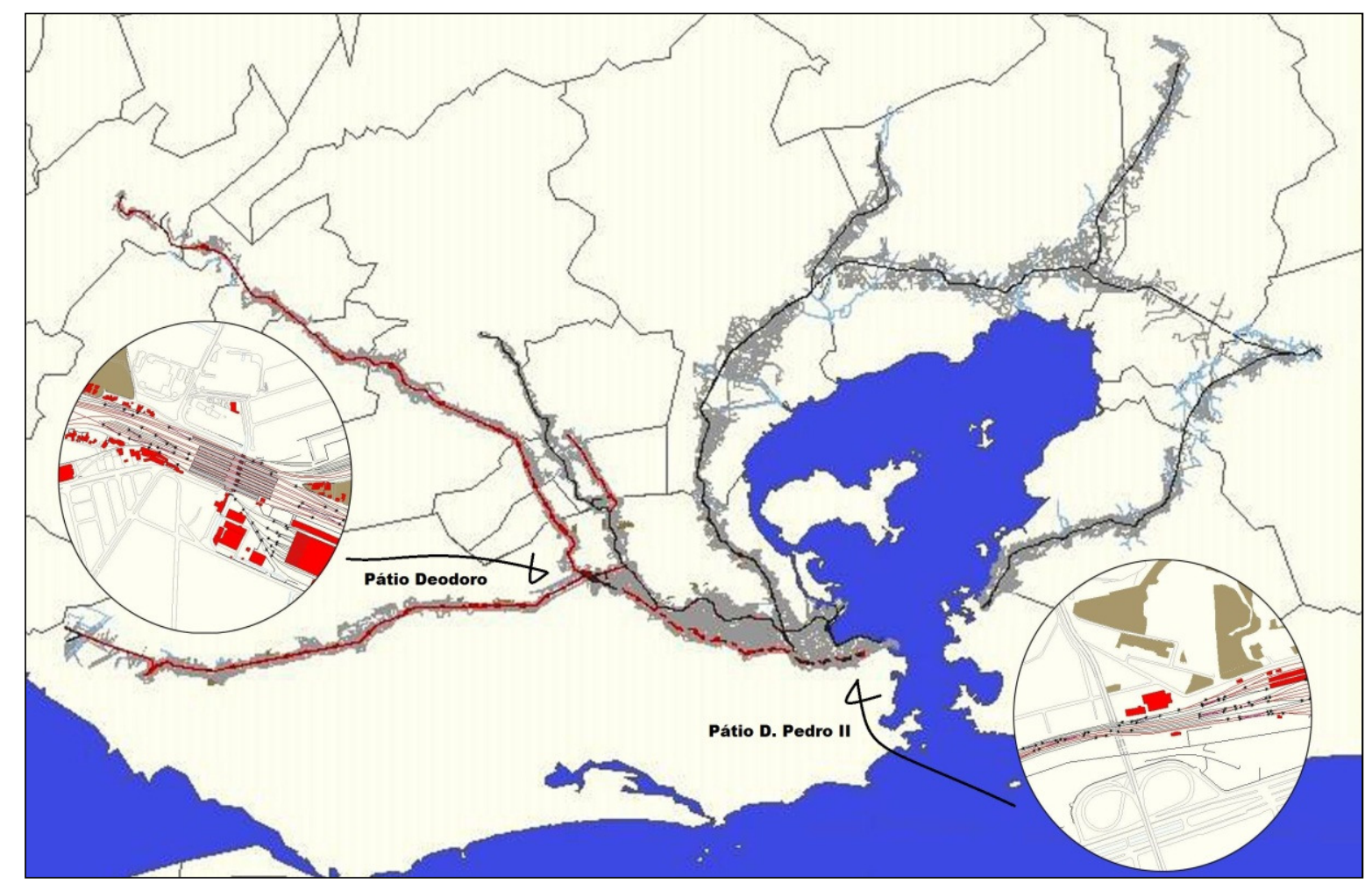

Figura 3.8 - Mapeamento produzido durante o Projeto

Fonte: Couto et. al. (2011)

Os imóveis foram carregados a partir de desenhos em CAD, produzidos na fase de levantamento. No momento do georreferenciamento desses desenhos, muitos problemas foram detectados, principalmente sobreposições de imóveis, resolvidos em novos levantamentos de campo quando necessário. Tais problemas dificilmente seriam identificados em um cadastro não espacial.

\subsubsection{Desenvolvimento do SISPAT}

O SISPAT foi concebido em uma arquitetura Cliente-Servidor baseado em Sistema Operacional Windows e Banco de Dados Microsoft SQL Server.

O aplicativo foi desenvolvido com a IDE Delphi da empresa Borland e o componente de publicação de dados espaciais MapObjects da empresa ESRI. 
A versão final do aplicativo SISPAT possui duas interfaces principais, a interface Cadastral e a interface Geográfica.

A interface Cadastral, ilustrada na Figura 3.9, permite toda a manipulação dos dados, como cadastro de novos bens, atualização de bens cadastrados, baixa de bens, buscas, exibição resultados das pesquisas, exportação de dados entre outras. A Figura 3.10 exibe a interface de manipulação dos documentos anexos a cada bem (PDF, CAD, fotografias).

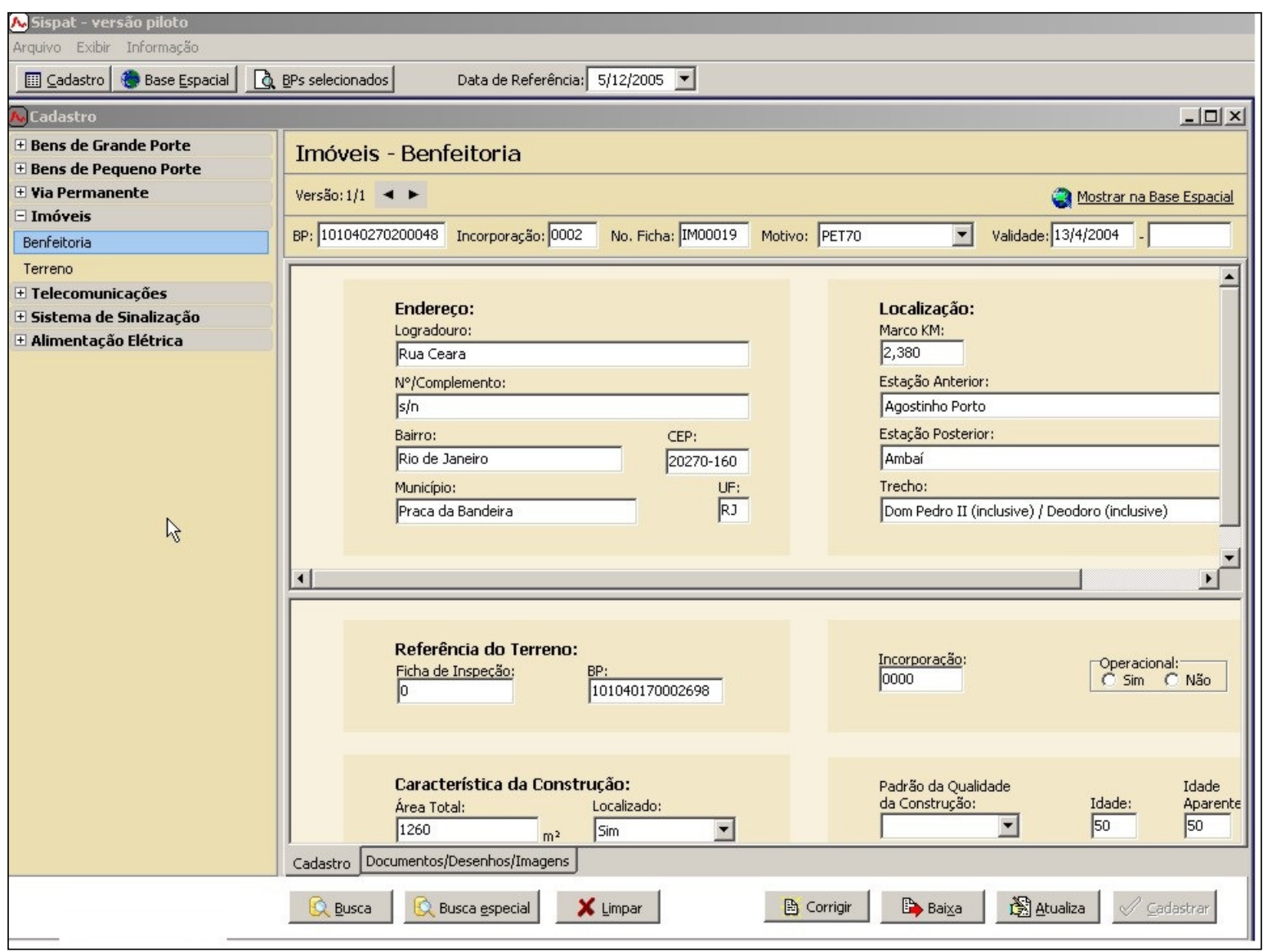

Figura 3.9 - Interface Cadastral do SISPAT

Fonte: Couto et. al. (2011) 


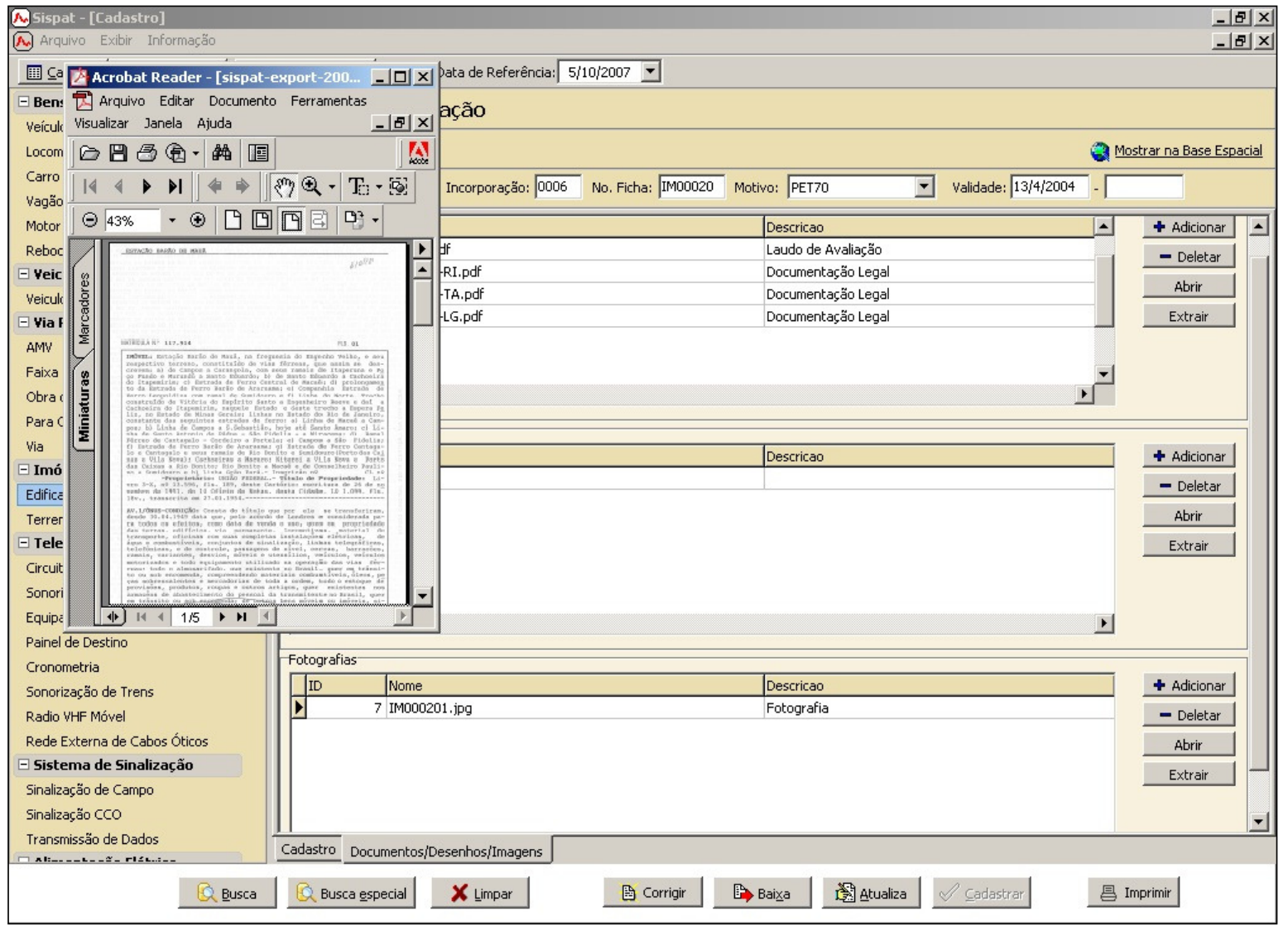

Figura 3.10 - Manipulação de Anexos no SISPAT

Fonte: Couto et. al. (2011)

A interface Geográfica, Ilustrada na Figura 3.11, possui ferramentas de visualização espacial (zoom, pan, controle de visualização de camadas), extração de coordenadas, medidas de distancia, seleção por apontamento e enquadramento, exibição gráfica de resultados de buscas do cadastro, entre outras. 


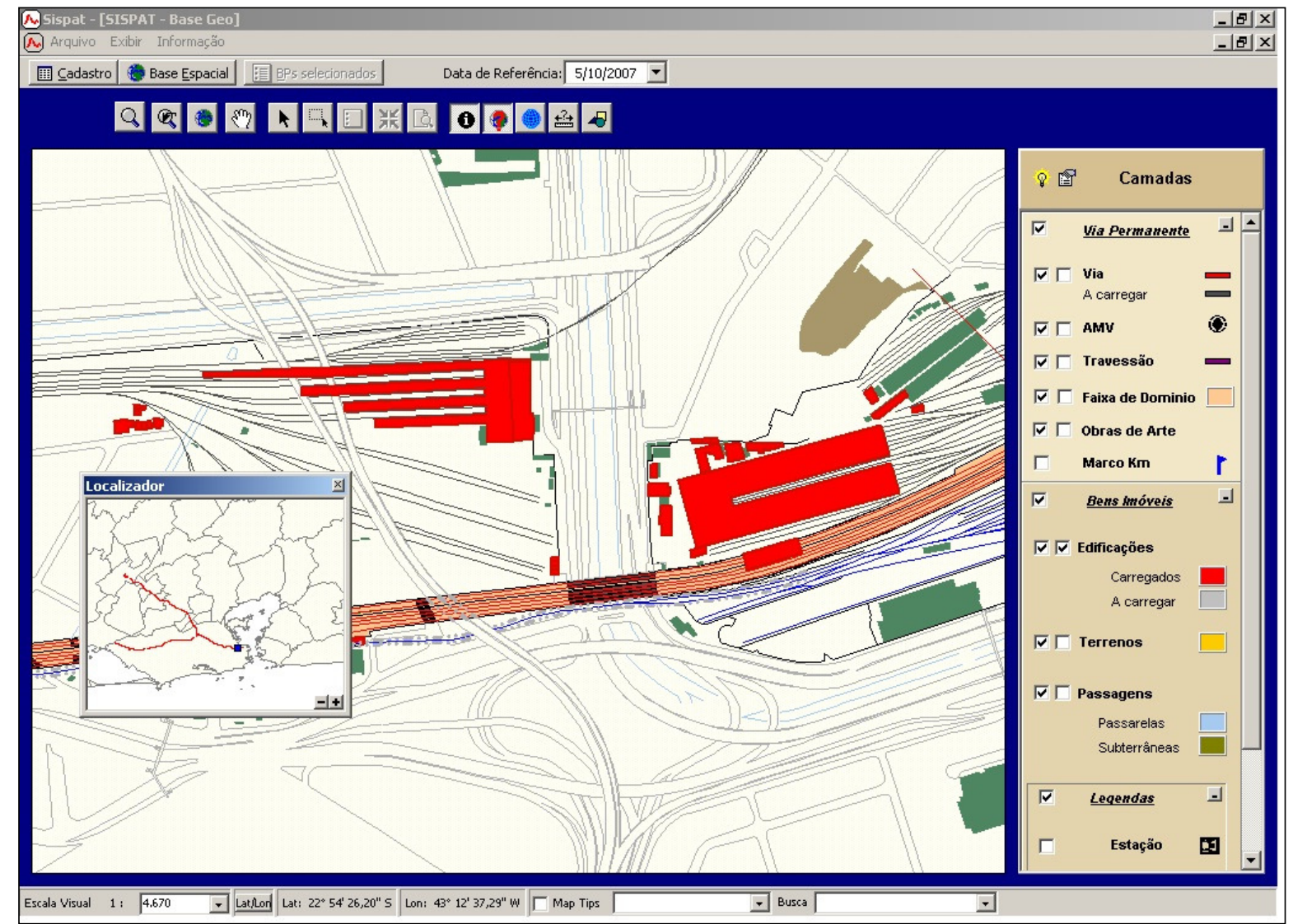

Figura 3.11 - Interface Geográfica do SISPAT

Fonte: Couto et. al. (2011)

\subsubsection{Resultados obtidos com a operação do SISPAT}

A capacidade do SISPAT de combinar e gerir dados, de tipos e fontes as mais diversas, como mapas, plantas, croquis, tabelas, fotografias, entre outros, em um sistema cadastral centralizado e georreferenciado, viabiliza a uniformização do tratamento dos dados, e sua fácil disseminação dentro da organização, sendo assim um mecanismo de suporte à tomada de decisões, em um ambiente onde é possível serem realizadas consultas, analises e atualizações sobre o inventario patrimonial da CENTRAL.

O conhecimento e a representação de como os bens pertencentes a um sistema de transporte estão distribuídos ao longo do território, permite uma serie de analises que se não impraticáveis, seriam muito mais difíceis de serem realizadas sem este recurso. A representação espacial 
dos elementos evidencia sua abrangência territorial, sua distribuição espacial, como os elementos se relacionam entre si e das interferências de tais elementos com o meio físico.

Para a CENTRAL, o diagnostico real da dimensão, estado e valor de seu patrimônio, obtido ao longo do projeto, somado a nova capacidade de controle deste ativo propiciado pelo aplicativo SISPAT, deram a companhia instrumentos para melhor cumprir suas prerrogativas institucionais.

O sucesso do SISPAT na CENTRAL fez com que ele fosse copiado e adaptado, sob o nome SISPAT RJ, para uso da Subsecretaria de Patrimônio Imobiliário, da Secretaria de Planejamento e Gestão, na modernização da gestão do patrimônio imobiliário do Estado do Rio de Janeiro (VIANA, 2010). 


\section{GERENCIAMENTO DE BENS PREDIAIS}

Entende-se por Bens Prediais o edifício construído e seus subsistemas, como o sistema estrutural, sistemas prediais (elétrico, hidráulico, segurança, dados, entre outros). Os ambientes internos da edificação são aqui também tratados como bens prediais, bem como moveis e equipamentos pertencentes à edificação.

O objetivo deste capítulo é apresentar a prática da utilização de Sistemas de Informação Geográfica - SIG na gestão de bens prediais.

São também apresentados os conceitos básicos da teoria da Gestão de Facilidades, a que se pretende, ao menos em parte, haja vista a complexidade e profundidade dos conceitos da disciplina, integrar com as tecnologias do geoprocessamento.

\subsection{GERENCIAMENTO DE FACILIDADES}

Gerenciamento de Facilidades é o termo utilizado na língua portuguesa para o Facility Managment ou FM do inglês. É o estudo multidisciplinar de atividades e áreas cujo objetivo é garantir e aperfeiçoar a integração de ambientes, pessoas, tecnologia e processos.

Segundo a International Facility Management Association - IFMA, FM pode ser definido como a atividade que abrange várias disciplinas para garantir a funcionalidade do ambiente construído, por meio da integração das pessoas, lugares, processos e tecnologia.

Antonioli (2003) define:

"Gerenciamento de Facilidades é a integração de
pessoas, espaço e tecnologia através do gerenciamento
dos processos de inter relacionamento destes sistemas,
visando à satisfação dos objetivos corporativos da
organização que os contêm."

E reforça esta definição por meio do esquema exibido na Figura 4.1. 


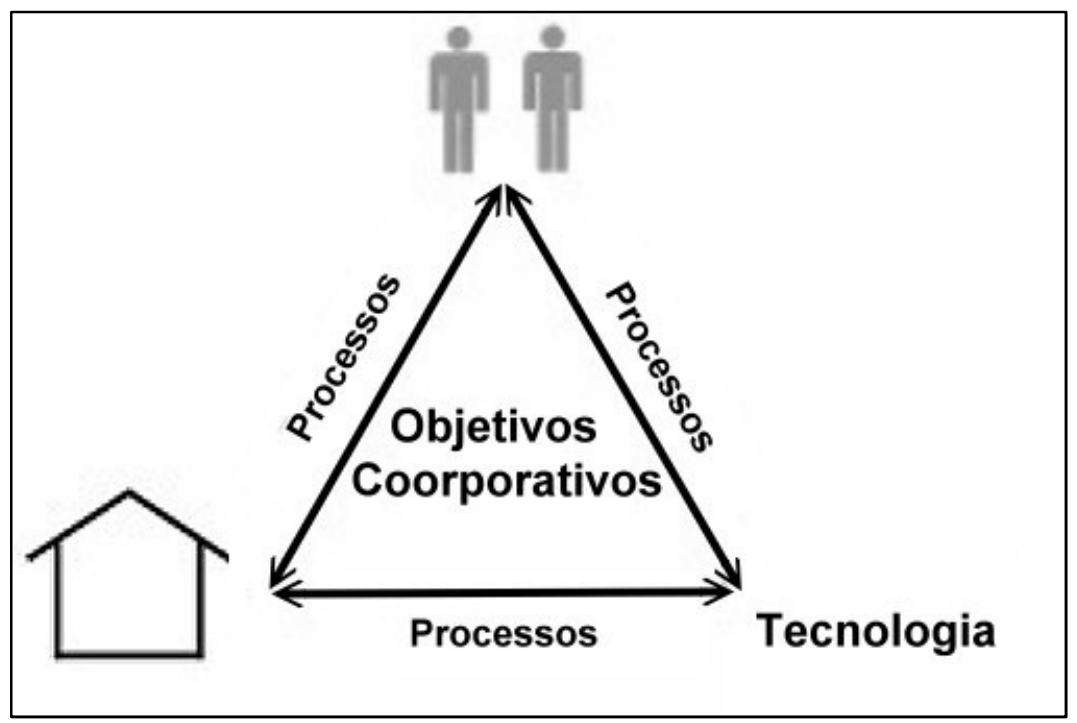

Figura 4.1 - Gerenciamento de Facilidades

Fonte: Antonioli (2003)

Segundo Antonioli (2003), o gerenciamento específico das pessoas que utilizam os espaços corporativos está normalmente subordinado ao Departamento de Recursos Humanos da organização. A Tecnologia é gerenciada por especialistas no assunto. Compete ao Gerenciamento de Facilidades administrar os processos de inter-relacionamento desses sistemas entre si e com o edifício, em conjunto com o gerenciamento do ambiente construído e tudo nele contido, como moveis e equipamentos.

Ainda segundo Antonioli (2003), os elementos presentes em um edifício podem ser divididos nos seguintes sistemas:

- Pessoas, inclusive portadoras de deficiências físicas;

- Sistemas Prediais, sistemas provedores de serviços e insumos;

- Utensílios, ativos móveis, tais como mobiliário e equipamentos;

- Tecnologia, composta por componentes tangíveis e intangíveis, como por exemplo, software, hardware e conhecimento.

O Gerenciamento de Facilidades consiste na administração de todos estes elementos, tanto na operação do edifício e de seus sistemas prediais, como também na sua manutenção, e de todos os elementos contidos em seu ambiente. É ainda prerrogativa do Gerenciamento de Facilidades intervenções 
de modernização, sejam estas de reformas ou construções novas, de maneira a permitir o contínuo fornecimento do suporte necessário ao atendimento das necessidades dos usuários, de maneira que estes possam desenvolver as tarefas previstas para atingir os objetivos estratégicos da organização.

A seguinte estrutura é derivada do trabalho Antonioli e Graça (2004):

\subsubsection{Abrangência do Gerenciamento de Facilidades}

Segundo Varcoe (2000, apud ANTONIOLI e GRAÇA 2004), O gerenciamento de facilidades está dividido em diferentes níveis de atividade. No mais primário deles, encontram-se a manutenção e a operação do edifício, e de seus sistemas prediais.

No nível mais alto, em conjunto com estas atividades, está o gerenciamento de todo o ambiente de trabalho, de forma a atender os objetivos estratégicos da empresa. A Figura 4.2 esquematiza as diferenças entre o uso do edifício e a provisão de propriedade e evidencia a separação de ambiente de trabalho e seu gerenciamento.

O gerenciamento de facilidades está inserido entre a entrega do ambiente de trabalho e seu gerenciamento, servindo como interface integradora entre estas duas atividades, onde se situa atividades como a gestão de espaços, de projetos de propriedades e aquisições.

Sobre esta camada, estão os níveis mais elevados do gerenciamento de facilidades que são: o gerenciamento de ativos seguido do gerenciamento de todo o ambiente de trabalho, e finalmente 0 gerenciamento estratégico de toda a organização. Para tanto, é imperativo a integração de todos os recursos corporativos (RC), envolvendo recursos humanos $(\mathrm{RH})$, tecnologia da informação $(\mathrm{TI})$, finanças e assessoria jurídica. 


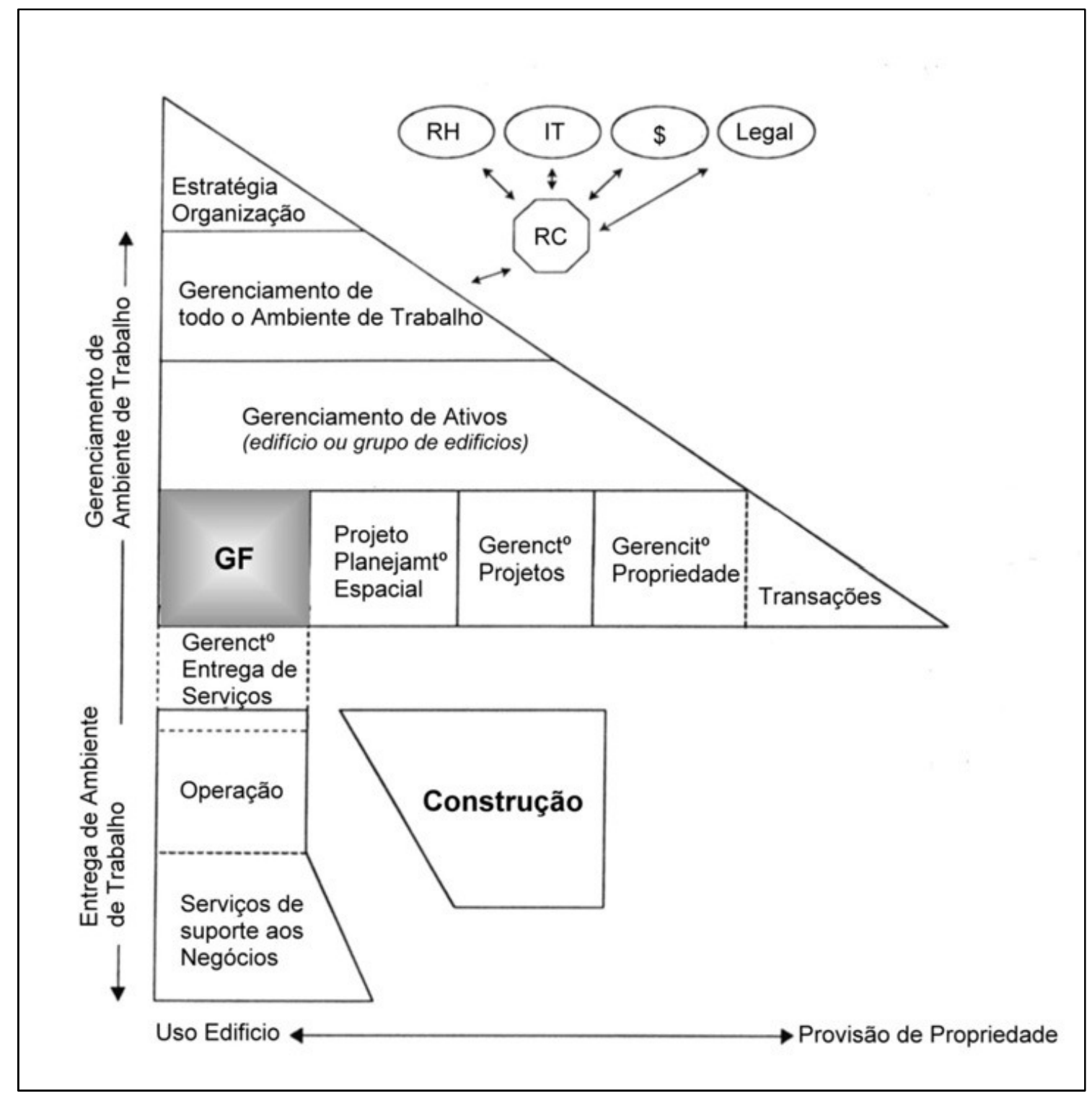

Figura 4.2 - Abrangência do Gerenciamento de Facilidades Fonte: VARCOE (2000 apud ANTONOLI; GRAÇA 2004)

\subsubsection{Variáveis que influenciam o Gerenciamento de Facilidades}

Segundo Barret (1995, apud ANTONIOLI e GRAÇA 2004) a maneira como o Gerenciamento de Facilidades é executado depende de muitas variáveis especificas de cada organização: 


\subsubsection{Tamanho e localização dos edifícios}

Quanto maior for o edifício ou portfólio de propriedades, maior será a estrutura necessária para o seu gerenciamento. A localização geográfica é uma variável importante, já que a localização dos imóveis em diferentes regiões traz complexidades adicionais de legislação, padrões éticos e culturais ao gerenciamento.

\subsubsection{Cultura organizacional}

A ênfase gerencial dentro de uma organização é reflexo direto do tipo da organização, que pode ser enquadrada nos seguintes grupos:

- Setor Público - caracterizado pelo excesso de burocracia e dependência de regulamentação;

- Setor Educacional - tendem a seguir a estrutura do setor público, e os processos decisórios passam por extensas discussões e negociações;

- Setor Privado - mais flexível e aberto a mudanças, mas sujeito a pressões por corte de gastos. Além disso, a execução dos planejamentos está sujeita a flutuações dos negócios.

\subsubsection{Objetivos do Gerenciamento de Facilidades}

Todo esforço empreendido com o Gerenciamento de Facilidades visa a obter a elevação do desempenho do edifício, como um todo. Para tanto, é necessário que o Gerenciamento de Facilidades objetive em seus processos a eficiência, a efetividade e a eficácia.

- Eficiência (fazer certo as coisas) $\rightarrow$ produtividade

- Efetividade (fazer as coisas certas) $\rightarrow$ desempenho

- Eficácia (fazer bem as coisas relevantes) $\rightarrow$ qualidade 
O sistema de Gerenciamento de Facilidades deve objetivar que os sistemas prediais apresentem, individualmente, as seguintes características, definidas por Gonçalves (1999, apud ANTONIOLI; GRAÇA 2004):

- Flexibilidade: capacidade de adaptação às evoluções funcionais e tecnológicas que ocorrem durante toda a vida útil do edifício;

- Confiabilidade: capacidade de permanecer em operação adequadamente. $\mathrm{O}$ aumento de confiabilidade advém do correto gerenciamento dos sistemas prediais envolvendo rotinas de testes, medições, manutenção adequada e existência de planos de contingência, bem como da qualidade dos equipamentos e materiais utilizados;

- Gerenciabilidade: capacidade organizacional de gerir informações que permitam atuar efetivamente sobre o sistema.

Além das características individuais, estes sistemas devem contribuir para que todo 0 edifício apresente as seguintes características emergentes, dadas por WBDG (2002, apud ANTONIOLI e GRAÇA 2004):

- Sustentabilidade Oferecer um ambiente construído habitável, confortável, seguro e produtivo, com uma diminuição do uso de recursos energéticos, de consumo de água e de matérias primas, minimizando e controlando os impactos ambientais causadas pelos edifícios ao longo de toda sua vida útil;

- Acessibilidade Deve promover o uso igualitário do ambiente construído para todos os seus usuários, favorecendo, segundo a NBR 9050 (1994), o acesso e a utilização do edifício a portadores de Deficiência Ambulatorial, Deficiência Visual e Deficiência Auditiva;

- Segurança Garantir a vida e a integridade física dos ocupantes do edifício (segurança pessoal), bem como preservar a 
integridade do edifício e de todos os seus elementos (segurança patrimonial);

- Custo efetivo operacional Quantificação de todos os custos significativos verificados durante a vida útil de um ativo, tais como: custos iniciais de aquisição, projeto, instalação, custos de operação, manutenção e valor residual ou disposição, visando obter efetividade de custos operacionais;

- Produtividade Oferecer um ambiente de trabalho Flexível, com Suporte Tecnológico, Confiável e com condições de Saúde e Conforto para que usuários possam desempenhar eficientemente suas tarefas.

\subsubsection{Planejamento}

Segundo Antonioli (2003), o planejamento é parte essencial do Gerenciamento de Facilidades, e contribui para que a organização esteja preparada para os desafios e incertezas do futuro. Ainda segundo o autor, o planejamento das ações e procedimentos gerenciais pode ser reunido em dois grupos, o planejamento Estratégico que lida com questões de longo prazo e o planejamento Tático relacionado às ações operacionais de curto prazo.

\subsubsection{Planejamento Estratégico}

Para Goffigon (2001), a resolução dos problemas certos tem precedência à resolução certa de problemas, ou a eficácia deve preceder a eficiência. Segundo o autor, o planejamento estratégico é um processo, uma maneira de pensar e traçar o caminho para alcançar os objetivos, e se baseia em três fundamentos básicos: contexto, visão e busca do ótimo.

O Planejamento Estratégico começa pela definição do que se busca alcançar e do por quê. 
Para Antonioli e Graça (2004), algumas das questões estratégicas mais abrangentes do gerenciamento de facilidades são:

- Gerenciamento de Valores - para o Gerenciamento de Facilidades, o valor de um serviço não está diretamente relacionado ao seu custo, mas sim a um contexto maior, onde objetivos não financeiros da organização, como a estratégia do negocio e da imagem da organização devem ser observados. Questões como, o nível de desempenho, a confiabilidade e estilo são relevantes, e devem ser contabilizadas nas avaliações de custos. Valor $=($ Função + Desempenho + Qualidade $) /$ Custo, onde o custo financeiro é apenas um componente da análise (ALEXANDER 2000, apud ANTONIOLI e GRAÇA 2004);

- Gerenciamento Ambiental - atualmente as organizações precisam demonstrar desempenho ambiental tanto na etapa de construção como na operação de seus edifícios, de forma a não agravar as condições do meio ambiente em que o edifício esta inserido. Simultaneamente, devem oferecer ambiente interno saudável e confortável aos usuários, resultando em qualidade de vida no trabalho e em produtividade;

- Gerenciamento da Qualidade - deve objetivar a satisfação das necessidades dos usuários em relação a todos os serviços providos, ao menor custo possível, identificando problemas, investigando causas e propondo e adotando soluções;

- Gerenciamento de Riscos - toda tomada de decisão envolve riscos, e uma vez que estes não podem ser eliminados, devem ser controlados, mantendo-os dentro de limites confiáveis, aceitáveis e pré-estabelecidos, por meio de:

- Manuais de operação claros, precisos e disponíveis;

- Treinamento constante e adequado;

- Dispositivos de alarme; 
- Confiabilidade operacional (redundância de sistemas críticos).

- Gerenciamento de Projetos - segundo Cotts (1999, apud ANTONIOLI e GRAÇA 2004), dentro do ciclo de vida útil de um edifício, nenhuma etapa é tão significativa às condições operacionais e de manutenção, com reflexos diretos na efetividade de custos operacionais, quanto às etapas de projeto, onde os custos de intervenções são baixos e os ganhos resultantes maiores. O maior empecilho ao sucesso de projetos é a falta de comunicação entre as diversas equipes envolvidas, bem como a falta de conhecimento sobre as reais condições operacionais a que será submetido o edifício. O encarregado do gerenciamento de projetos deve facilitar a comunicação entre os envolvidos buscando a efetividade de custos operacionais do edifício, sistemas e equipamentos projetados.

\subsubsection{Planejamento Tático}

O Planejamento Tático trata das questões operacionais, de curto prazo, definindo quando e como as ações definidas no nível estratégico devem ser executadas. Apesar dos problemas operacionais serem menos complexos do que as questões estratégicas, e suas soluções rotineiras e repetitivas, sua correta execução tem grande impacto no sucesso da gestão predial. Segundo Lewis (1999, apud ANTONIOLI e GRAÇA 2004) as ações táticas podem ser separadas em três grupos:

\section{- Manutenção}

- $\quad$ Corretiva - ações não planejadas e que requerem respostas imediatas. As ocorrências imprevistas podem ser reduzidas ou minimizadas por meio de vistorias e inspeções regulares.

- Preventiva - ações que visam evitar a deterioração ou quebra de um sistema ou equipamento por meio de inspeções periódicas. Evita ações corretivas, permitindo o 
planejamento das intervenções com ganho de produtividade e eficiência, menores custos e interferências em outros equipamentos ou atividades.

- Preditiva - monitoração das condições do equipamento que permitem avaliar precisamente seu estado por meio de de exames laboratoriais, medições de temperatura, vibração, ultra-som, entre outros;

- Operação - execução de serviços previamente planejados e programados, rotinas operacionais, rotinas de manutenção preventivas e preditivas, controle ou execução de obras de modernização, triagem e ação em ocorrências imprevistas com alocação de recursos e agendamento de execuções de serviços;

- Modernização - atualizações e inovações de sistemas e equipamentos existentes ou instalações de novos. Devem ser entendidas e gerenciadas como projetos.

\subsubsection{Informação}

Segundo Barrett (1995, apud ANTONIOLI e GRAÇA 2004), a eficiência dos processos de planejamento, tanto estratégico como operacional, depende muito mais da qualidade da informação utilizada do que dos processos empregados no planejamento em si. $O$ volume de informações necessárias para o correto desempenho do Gerenciamento de Facilidades é considerável, e raramente poderá ser gerenciado de maneira adequada, sem o emprego de sistemas de informações, que representam uma combinação de recursos humanos e tecnológicos visando ao uso efetivo e eficiente da informação.

- Informações sobre Usuários - uma das mais importantes informações necessárias para o planejamento e desempenho do Gerenciamento de Facilidades são às relacionadas aos usuários do edifício, suas exigências, necessidades e percepções de satisfação. Como se trata de informações subjetivas, sua 
obtenção requer o emprego de artifícios como questionários, entrevistas, observação, investigação e avaliação pós-ocupação;

- Informações sobre Propriedade - dados sobre o edifício, seus sistemas e equipamentos, que permitam conhecer as condições físicas dos elementos, tanto quantitativamente como qualitativamente. A obtenção desses dados pode ser feita por:

- Consulta a arquivos - documentos legais, técnicos, históricos e administrativos;

- Avaliações - procedimentos de medição, inspeção e analises para complementar, atualizar ou suprir informações sobre ativos;

- Auditorias - avaliações mais complexas. Diferem das avaliações pela necessidade de estudos mais aprofundados executados por especialistas.

- Informações sobre Processos - informações relativas aos processos desenvolvidos no âmbito da Gestão de Facilidades.

\subsubsection{Tecnologias do Gerenciamento de Facilidades}

A primeira e mais importante ferramenta tecnológica empregada no Gerenciamento de Facilidades foi o CAD-Computer Aided Design (ANTONIOLI, 2003), que tornou possível capturar, armazenar, manipular e distribuir desenhos e informações relacionadas de forma digital, permitindo o acesso rápido e de forma segura a desenhos e esquemas necessários para as atividades de operação e manutenção.

Posteriormente, houve o desenvolvimento de sistemas CAFM - Computer Aided Facilities Management, combinando a tecnologia do CAD com outros sistemas de informação gerenciais. Os atuais sistemas de informação CAFM evoluíram e, segundo Cotts (1999, apud ANTONIOLI 2003), permitem executar de forma automatizada as seguintes funções:

- Armazenagem e manipulação de desenhos (CAD); 
- Planejamento espacial, normalmente relacionado a sistemas CAD;

- Gerenciamento de projetos, construção e de mudanças;

- Gerenciamento de manutenções e ordens de serviço;

- Controle operacional do edifício e gerenciamento de energia;

- Gerenciamento de ativos (inventário e localização);

- Gerenciamento de comunicações e dados;

- Controle financeiro de Gerenciamento de Facilidades.

Pela necessidade e pelas circunstancias tecnológicas de sua época, os aplicativos de software de Gerenciamento de Facilidades adotaram plantas arquitetônicas em formato CAD como o denominador comum para a visualização do ambiente construído, uma vez que essa informação (plantas baixas em formato $\mathrm{CAD}$ ) era o único meio disponível para se compreender e interagir com os edifícios e seus componentes, bem como os fluxos de trabalho associados a estas edificações (RICH e DAVIS 2010).

Ainda segundo Rich e Davis (2010), estamos em um processo de evolução que parte de plantas desenhadas, à mão, representando um pavimento isolado de uma edificação, para desenhos CAD e, mais recentemente, para Modelos de Edifícios na forma de BIM - Building Information Models, com uma visão do edifício como um todo.

Para Wyatt e Ralphs (2003), o próximo passo na evolução tecnológica é a capacidade de gerir ativos e fluxos de trabalhos em um contexto geográfico, isto é, em uma escala local, regional ou mesmo global. Assim inserem-se os Sistemas de Informação Geográficos na Gestão de Facilidades 


\subsection{O USO DE SISTEMAS DE INFORMAÇÃO GEOGRÁFICA NO GERENCIAMENTO DE BENS PREDIAIS}

Os Sistemas de Informação Geográfica (SIG) permitem realizar análises complexas, ao integrar dados de diversas fontes e ao criar bancos de dados georreferenciados, oferecendo mecanismos para combinar as várias informações, por meio de algoritmos de manipulação e análise e para consultar, recuperar, visualizar e plotar o conteúdo da base de dados geocodificados (CÂMARA, 1995).

A utilização histórica do SIG se dá em diversos setores da economia como Governo, Planejamento Urbano e Regional, no setor de Infraestrutura, Transporte, Meio-Ambiente, Agricultura, entre outros, onde os elementos tratados estão distribuídos em grandes extensões territoriais. A capacidade do SIG de integrar vários tipos de cadastro numa mesma base de dados cartográfica proporciona uma poderosa ferramenta para manipulação e a análise das informações pertinentes, com o conhecimento da localização e da disposição desses elementos.

Segundo Rich e Davis (2010), as principais fontes de dados utilizadas em SIG, como levantamentos topográficos ou por GPS, restituições fotográficas de levantamentos aerofotogramétricos ou de imageamento por satélite, são incapazes de tratar o interior dos edifícios, limitando-se a mapear a projeção da edificação, sem seus detalhes internos, inviabilizando o uso do SIG para aplicações de Gerenciamento Facilidades.

Por muitos anos perdurou dentro da indústria e mesmo entre a comunidade de usuários um dogma de que ferramentas SIG não se prestavam a utilização em ambientes internos de edificações. Gerenciamentos prediais deveriam ficar a cargo de ferramentas baseadas em CAD, limitando a utilização do SIG aos ambientes externos a edificação (JORDANI e GONDECKBECKER, 2001; SRIVASTAVA e WELLINGTON, 2005).

O CAD e mais recentemente o BIM - Building Information Modeling foram concebidos como um conjunto de ferramentas e aplicações para projeto e construção. Os SIG foram concebidos e desenvolvidos como uma tecnologia 
de gestão da informação relacionada a entidades distribuídas geograficamente em grandes extensões territoriais.

Entretanto, novas tecnologias e técnicas vêm sendo utilizadas para incorporar dados de edificações, incluindo seus detalhes internos, provenientes de plantas CAD ou modelos BIM, com dados geográficos, em um mesmo ambiente computacional, aproveitando as ferramentas de analise espacial do SIG, no contexto das edificações, permitindo analises em seus ambientes internos (YOUNG e DRAKE 2008).

Para Rich e Davis (2010), a proposta da utilização do SIG na Gestão de Facilidades não é de substituição das ferramentas CAD, e suas derivadas como o CAFM, ou BIM. O verdadeiro valor de SIG para Gestão de Facilidades é como uma tecnologia complementar, capaz de integrar as inúmeras aplicações e tecnologias já em uso de Gestão de Facilidades, proporcionando benefícios nesta capacidade integradora.

Sistemas de informação geográfica é uma tecnologia com muitos usos práticos na Gestão de Facilidades. Segundo Rich e Davis (2010) um SIG é um sistema que permite visualizar, entender, questionar e interpretar dados de muitas formas que revelam relacionamentos, padrões e tendências, mormente de forma gráfica. Um SIG pode ser utilizado no âmbito da Gestão de Facilidades para a gestão de espaços, visualizações, planejamento de operação e manutenção, segurança, resposta a emergências entre outras aplicações.

O uso do SIG, dentro do conceito de Gestão de Facilidades, visa integrar informações extremamente detalhadas de engenharia e construção presentes em projetos CAD e BIM, com a capacidade do SIG de efetuar análises espaciais.

\subsubsection{Avanços tecnológicos}

A incorporação dos ambientes internos das construções em um ambiente SIG, foi possível graças aos avanços dos Sistemas de Informação, tanto em hardware, como em software. A armazenagem dos dados dentro de um SIG deixou de ser baseada em arquivos individuais e 
passou a ser administrada em bancos de dados espaciais conhecidos por Geodatabases.

Um dos componentes mais importantes de um SIG, diferenciando-o de outros sistemas de informação, é a sua capacidade para gerenciar dados espaciais em um sistema de projeção de coordenadas. Isso permite ao SIG tratar espacialmente de forma conjunta, elementos de diferentes escalas, além de permitir que dados criados em diferentes partes do mundo e em diferentes sistemas de coordenadas sejam adequadamente relacionados uns aos outros (ESRI, 2010).

Até poucos anos, os sistemas SIG armazenavam seus dados espaciais em formatos proprietários, na forma de arquivos individuais e locais (na própria maquina onde seriam utilizados). Uma primeira evolução tornou possível o armazenamento dos dados espaciais em plataformas comuns de bancos de dados relacionais como Oracle, MS SQL Server, DB2 ou PostgreSQL, por meio de uma camada de software que fazia a integração entre o banco de dados e o aplicativo SIG. Mais recentemente, com o crescimento da utilização do SIG, os próprios pacotes comerciais de banco de dados incorporaram o suporte a dados espaciais, como o Oracle Spatial, o PostGIS e o MS SQL Server a partir da versão 2008 .

Com a utilização de sistemas de banco de dados corporativos, a implantação de um SIG se beneficia da estrutura já existente de Tecnologia da Informação (TI) da organização, podendo utilizar os mesmos padrões de autenticação e comunicação além do suporte técnico existente.

Nos últimos anos, a precisão dos sistemas de coordenadas utilizadas nos SIG aumentou muito, graças às novas tecnologias computacionais disponíveis. A disseminação de computadores pessoais com capacidade de processamento cada vez maiores, maior quantidade de memoria RAM e espaço em disco, bem como a utilização de Geodatabases permitem hoje armazenar elementos espaciais com precisão posicional sub-centimétrica, em um sistema de coordenadas 
global, reflexo do aumento do número de casas decimais utilizadas no armazenamento das coordenadas $(\mathrm{RICH}, 2009)$.

Edifícios mais antigos muitas vezes possuem levantamentos desatualizados ou mesmo inexistentes, inviabilizando sua incorporação em um sistema de gestão predial. Novas tecnologias vêm sendo desenvolvidas para permitir o levantamento dessas edificações, criando plantas as-built e modelos tridimensionais de forma rápida, utilizando dispositivos moveis, com tecnologia LiDAR (Light Detection and Ranging) conforme ilustrado na Figura 4.3. Esses dispositivos geram nuvens de pontos tridimensionais do interior do edifício, sendo posteriormente processadas para a criação de plantas CAD ou modelos BIM. Paralelamente, os operadores humanos do dispositivo móvel recolhem informação georreferenciadas sobre o tipo de uso dos espaços, ocupação, avaliação do estado, ativos e muitos outros tipos de dados (RICH e DAVIS, 2010).

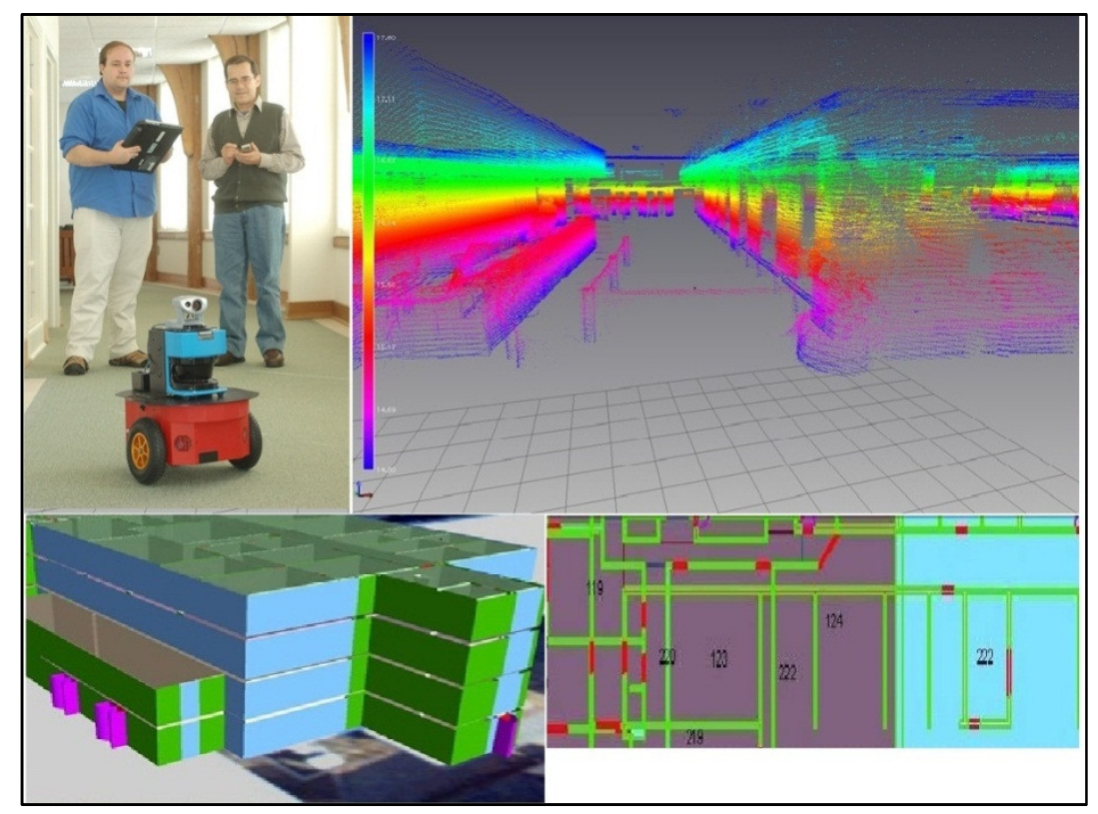

Figura 4.3 - Dispositivo móvel de levantamento, Nuvem de pontos LiDAR, planta CAD e modelo BIM gerados por processados

Fonte: PENBAY MEDIA (www.penbaymedia.com) 


\subsubsection{Modelo de dados}

Conforme exposto anteriormente, o uso tradicional do SIG, embora abrangente, sempre se deu fora do ambiente construído, tratando de elementos distribuídos ao longo de grandes extensões territoriais. Movidos pela necessidade e pelos avanços tecnológicos disponíveis, usuários pioneiros, de forma isolada, já há alguns anos vinham utilizando o SIG no gerenciamento predial. Houve uma percepção na indústria da geotecnologia de que essa era uma demanda importante de mercado e surgiram iniciativas no sentido de formalizar um modelo que atendesse a essas demandas (YOUNG e DRAKE, 2008).

No ano de 2007 é formada uma organização sem fins lucrativos com o objetivo promover o uso do SIG para o gerenciamento predial, promovendo melhores praticas, estudos de caso e um modelo de dados para servir como alicerce para iniciativas de projetos na área.

O BISDM, sigla para Building Information Spatial Data Model, é um comitê independente, formado por representantes de organizações de padrões existentes, universidades, desenvolvedores e usuários de SIG, gestores de facilidades com o objetivo de criar e disseminar um Modelo de Dados para ambientes internos para uso em Sistemas de Informação Geográfica.

O modelo de dados proposto pelo comitê, não visa à criação de um novo padrão de dados geográfico para edificações. Sua meta é permitir que os dados relativos às edificações e seus ambientes internos, sejam armazenados dentro de Geodatabases, em formato nativo SIG, e compartilhados e integrados com dados provenientes de outros sistemas em diferentes padrões já existentes como IFC, CityGML e OSCRE, com dados de classificação dos espaços, o COBIE com dados de operação do edifício e BOMA/FICM com definições e dados dos espaços (BISDM, 2010).

O modelo de dados proposto pelo BISDM visa além da implantação de projetos de Gerenciamento de Facilidades (Facility Management), projetos nas áreas de Gerenciamento Imobiliário (Real-Estate 
Management) e de Gerenciamento de Ativos (Asset Management) (ESRI 2008).

A Figura 4.4 mostra o esquema básico do primeiro modelo de dados apresentado pelo BISDM:

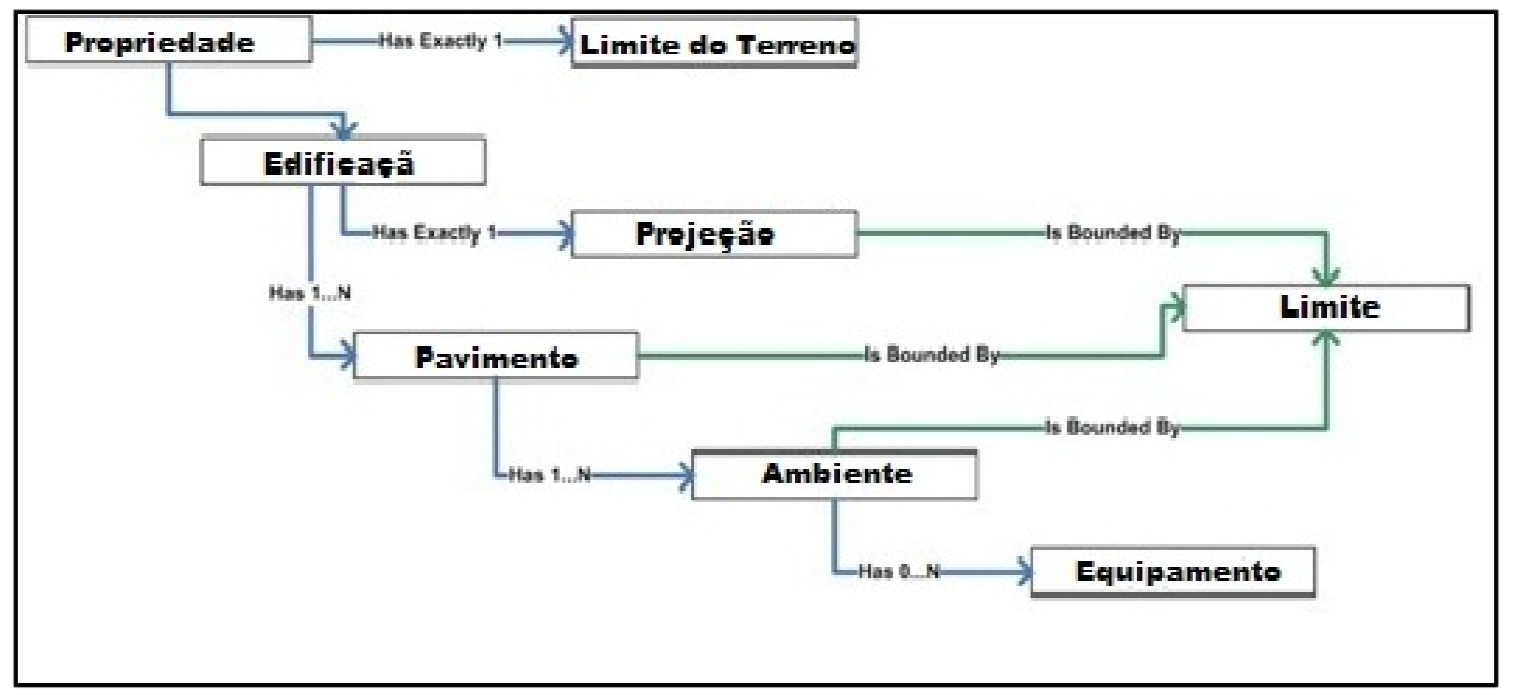

Figura 4.4 - Modelo Conceitual do BISDM v.1.

Fonte: Rich e Davis (2010).

No documento Building Information Spatial Data Model Framework (ESRI, 2008) são apresentadas algumas diretrizes para 0 desenvolvimento de projetos SIG baseados no modelo:

- Descentralização - esta é uma tendência na área de TI, que procura a integração com sistemas corporativos já existentes, e não a sua substituição, evitando a necessidade de centralizar todos os dados e todos os processamentos, dividindo as informações e a lógica ao longo das linhas naturais de responsabilidade. Há inúmeros sistemas especializados em uso dentro das instituições que não precisam ser substituídos em um SIG, bastando apenas garantir sua integração, sem a necessidade de duplicação de dados, ou a tentativa de replicar funcionalidades já existentes; 
- Uso criterioso de dados - toda a informação incorporada a um sistema tem um custo associado, relacionado ao seu levantamento, tratamento, transformação, revisão e manutenção. Mesmo um simples atributo de um elemento qualquer tem um custo associado a sua digitação, verificação e importação. Dados desatualizados comprometem 0 funcionamento e a credibilidade do sistema. É recomendável que se utilize um modelo de dados enxuto, com a menor quantidade possível de elementos e atributos associados, suficientes para permitir o desenvolvimento de soluções práticas e realísticas de curto prazo, ao invés de conjuntos enormes de dados que dificilmente serão adequadamente mantidos, visando metas grandiosas;

- Foco nas características do SIG - a utilização do SIG para gestão predial se justifica nos casos em que esta utilização é de fato beneficiada com as características próprias do SIG como:

- Necessidade de escalabilidade - evolução do sistema ao longo do tempo em relação a sua abrangência territorial, volume de dados, incorporação de novos tipos de dados, e de novas funcionalidades;

- Necessidade de análises conjuntas e de relacionamentos com diferentes tipos de dados;

- Demandam análises espaciais;

- Análises que envolvam associações espaciais entre elementos do edifício e de infra-estrutura urbana, entre edifícios ou do edifício e do seu entorno.

\subsubsection{Análises espaciais}

A capacidade de realizar análises espaciais pode, segundo Rich e Davis (2010), ser de grande valia para o gerenciamento de facilidades, 
auxiliando na solução de problemas que seriam difíceis de serem solucionados sem o SIG.

Para Rich e Davis (2010), algumas das principais operações de analise espacial com aplicações potenciais no gerenciamento de facilidades são:

- Consulta a Atributos - Consulta e edição de atributos armazenados na base de dados associados a elementos espaciais a partir de sua representação gráfica.

- "Qual uso esta associado ao ambiente X."

- "Numero do Equipamento Y."

- Seleção Espacial - Seleção de elementos baseados em sua localização ou na sua relação com a localização de outros elementos.

- "Todos os extintores instalados no edifício X".

- "Listagem dos ocupantes do edifício anexo ao edifício Y".

- Classificação - Produção de mapas temáticos baseados em uma determinada classe ou padrão pré-definido dos atributos de determinado(s) tipo(s) de elementos ou ambientes do edifício;

- Medição - Funções que incluem a medição de distancia entre pontos, comprimento de linhas, perímetros e áreas de um polígono;

- Proximidade - Avaliação de distancias entre dois ou mais elementos espaciais;

- "Quais os dois extintores Classe $A$ mais próximos ao equipamento $X^{\prime \prime}$.

- "Qual a saída de emergência mais próxima à sala Y". 
- Buffer - É a criação de uma área em torno de um ou mais elementos espaciais (ponto, linha ou polígono) definida por uma distancia máxima especificada. Um buffer é útil para a análise de proximidade entre elementos.

- "Quantos locais de estacionamento estão a X metros do edifício $Y^{\prime \prime}$.

- "Qual o tempo de deslocamento entre o local de estacionamento e as estradas de cada edifício".

- Sobreposição - Avalia a sobreposição de dois ou mais elementos espaciais, de acordo com a relação topológica entre eles. Permite a realização de operações aritméticas (adição, subtração, divisão e intersecção) e logicas (que avalia se um conjunto específico de condições ocorre ou não ocorre ao mesmo tempo);

- "Quais edifícios estão no terreno X".

- "Quais imóveis estão dentro da zona de restrição de circulação da cidade."

- Geocodificação - É o processo de associar a um atributo de entrada como, por exemplo, endereço ou CEP um par de coordenadas geográficas, tornando possível o mapeamento do elemento.

- "Onde fica o endereço X".

- "Onde fica a linha de telefone numero $Y$ ".

- Densidade - É a representação da distribuição de um dado elemento em uma dada área.

- "Onde se da maior concentração de usuários as X horas".

- "Onde esta a maior concentração de reclamações".

- Roteamento - É o calculo do caminho mais curto ou mais rápido entre dois pontos, em uma rede definida. Esta rede pode ter vários modais, (linhas de ônibus/metro, carro, a pé), além de 
restrições (barreiras para cadeirantes, acesso restrito, horário de funcionamento, etc.).

- "Qual o caminho mais curto entre a sala $X$ e a sala $Y$, para uma pessoa com mobilidade reduzida".

- "Qual o tempo para evacuar o edifício se a escada X estiver bloqueada".

- Temporalidade - Mostra a relação temporal de eventos sobre uma dada localidade.

- "Distribuição das reclamações realizadas antes e depois da iniciativa $X^{\prime \prime}$.

- "Concentração de pessoas no edifício $X$ ao longo da semana".

\subsubsection{Visualização}

Padrões e conceitos, quando envolvem um conjunto complexo e volumoso de informações, são muito mais fáceis de serem compreendidos quando apresentados de forma gráfica. A representação visual de cenários complexos, na forma de mapas, como o SIG apresenta, permite o reconhecimento de padrões e a identificação de tendências, facilitando e tornando intuitiva a tarefa de analise e de tomada de decisões sobre esse conjunto de dados, tarefa essa que seria muito mais complexa analisando apenas dados tabulares ou gráficos ( $\mathrm{RICH}$ e DAVIS, 2010). 


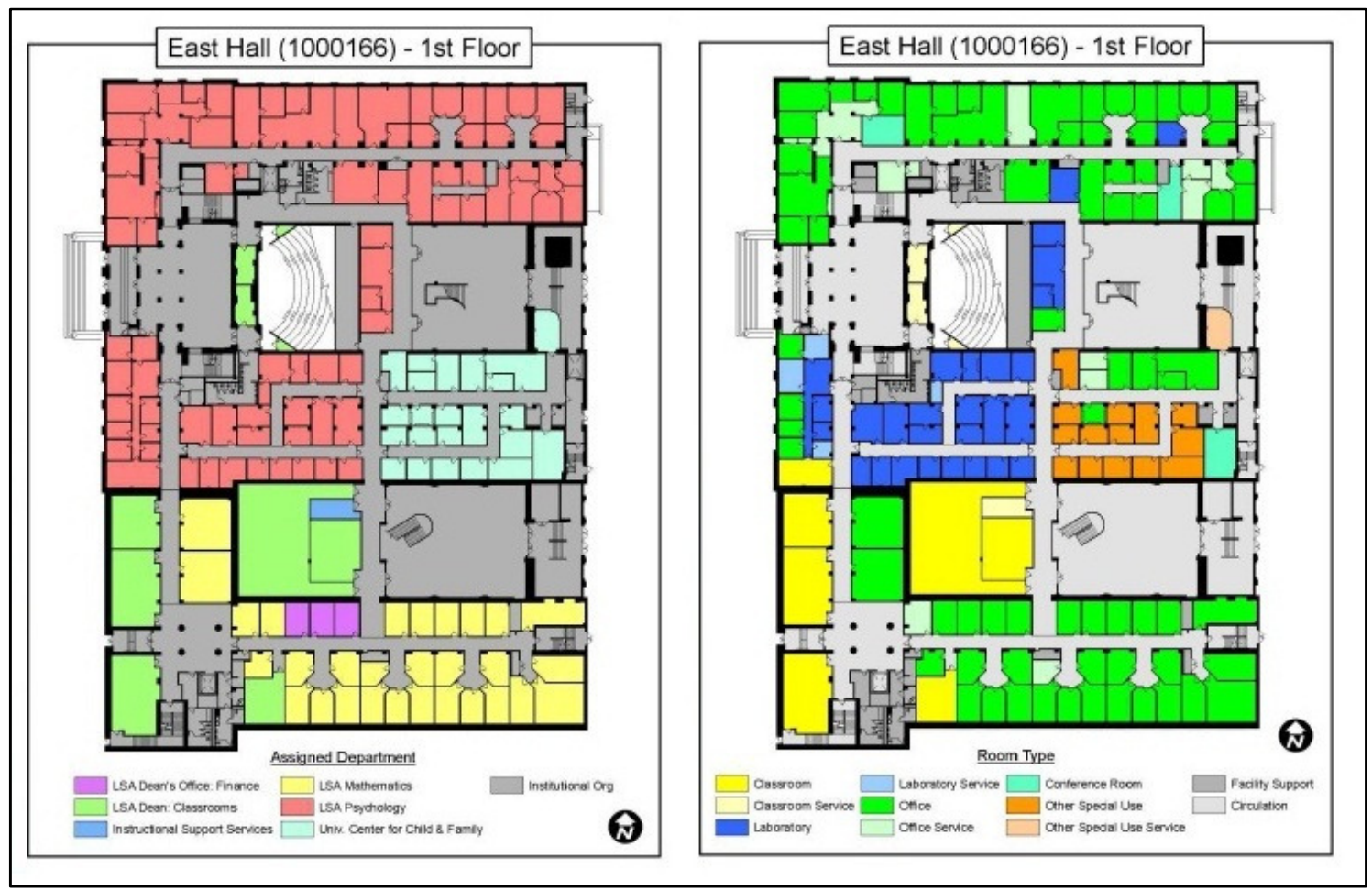

Figura 4.5 - Classificação de ambientes - esq. por Departamento; dir. por tipo Fonte: Universidade de Michigan.

A figura 4.5 exemplifica o conceito de mapas temáticos. A figura apresenta na forma de mapas, a classificação dos ambientes internos de um mesmo edifício da Universidade de Michigan, segundo dois critérios distintos.

$\mathrm{Na}$ imagem da esquerda os ambientes foram classificados conforme seus respectivos departamentos acadêmicos. A imagem da direita mostra os mesmos ambientes, classificados por tipo (sala de aula, laboratório, administração, circulação, auditórios, etc.). 


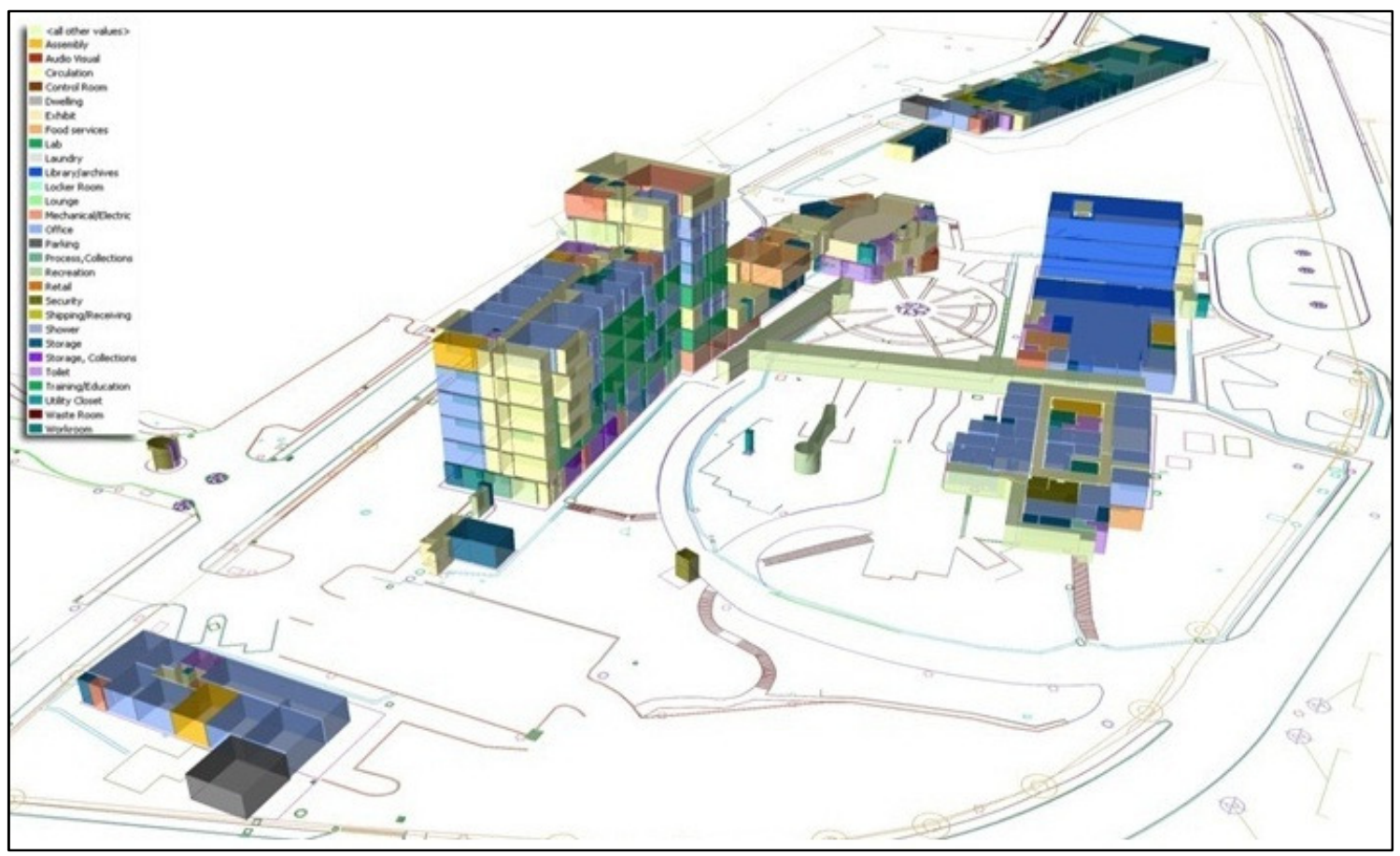

Figura 4.6 - Classificação de ambientes por uso, em 3D Fonte: Rich e Davis (2010).

A figura 4.6 apresenta o mesmo conceito de mapa temático, classificando o uso de cada ambiente porem com uma visualização em 3D do mapa. 


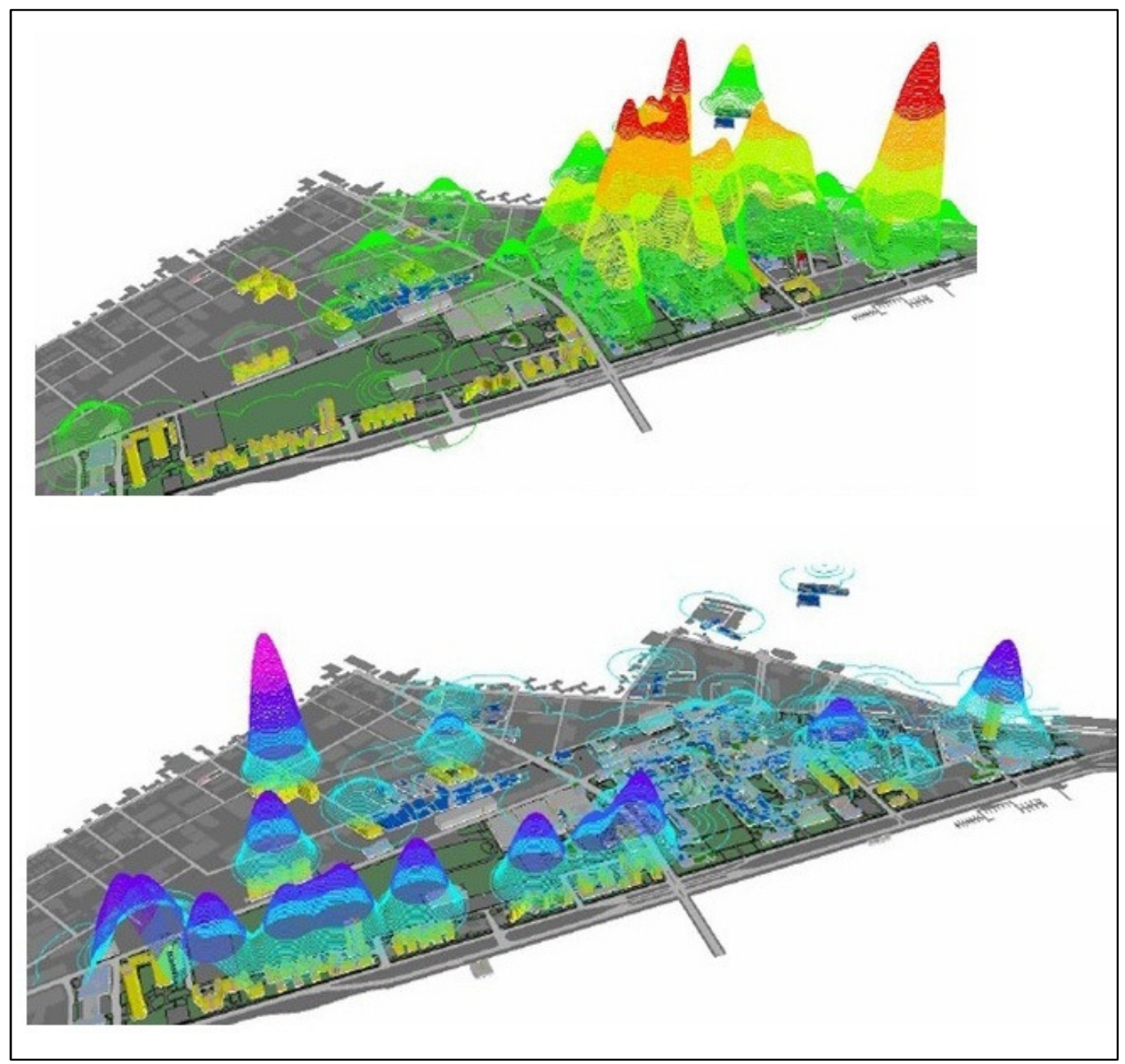

Figura 4.7 - População diurna e noturna em campus.

Fonte: Rich e Davis (2010)

A figura 4.7 apresenta um exemplo de uma visualização temporal, com a representação da relação de eventos sobre uma dada localidade ao longo do tempo, no caso a variação da população circulante nos diferentes edifícios do campus, no período diurno e noturno. 


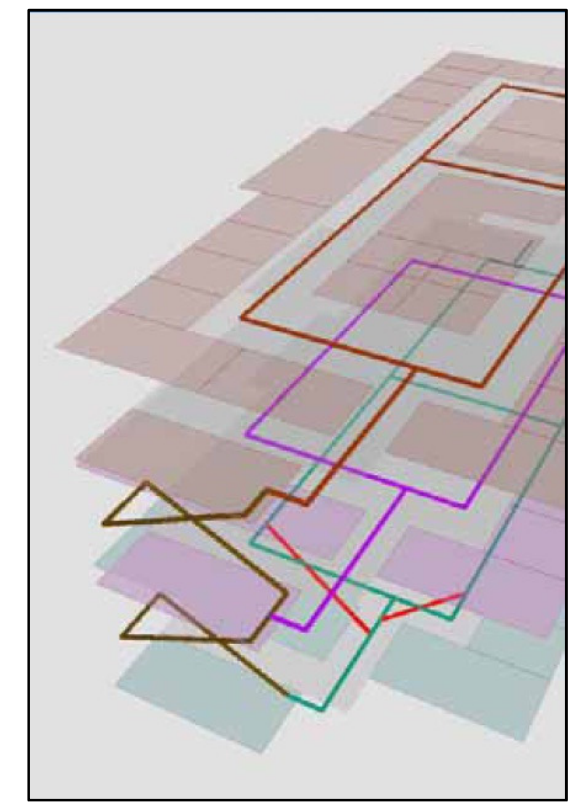

Figura 4.8 - Rede de transporte dentro de uma edificação Fonte: Olimpio e Smith (2009).

A figura 4.8 apresenta, de forma gráfica, a rede de transporte interna de uma edificação, utilizada para a elaboração de rotas e outras análises espaciais. Os mesmos princípios de uma rede de transporte tradicional podem ser aplicados no interior das edificações.

\subsubsection{Aplicações}

As características que fizeram o SIG uma ferramenta amplamente utilizada nas mais diferentes áreas de aplicação, com suas poderosas ferramentas de analise espacial e visualizações, se aplicam a muitas questões do gerenciamento interno dos edifícios. Entretanto apenas recentemente, questões técnicas foram resolvidas principalmente na integração de formatos de arquivo e na adequação de sistemas de coordenadas, capazes de suportar as escalas necessárias para 0 tratamento em um mesmo plano geográfico do detalhe da edificação a uma abrangência global (Rich e Davis, 2010).

Ainda segundo Rich e Davis, nos últimos anos, enormes esforços foram empregados pelos maiores desenvolvedores de software, para a solução desses entraves tecnológicos. As plataformas SIG modernas 
suportam hoje sistemas de coordenadas capazes de registrar um elemento com precisão sub-centimétrica em escala global. Há hoje também, maior integração entre os diferentes formatos proprietários de arquivos utilizados em projetos de edificação, como o CAD e o BIM com os formatos utilizados em SIG, com ferramentas disponíveis para a conversão entre os diferentes padrões.

Uma vez superadas as barreiras técnicas, que dificultavam a uso do SIG em sistemas de gerenciamento predial, e com o barateamento dos processos de aquisição, manutenção e manejo de informações do interior dos edifícios, uma serie de aplicações começam a ser desenvolvidas por usuários (OLIMPIO e SMITH, 2009). Algumas dessas aplicações, segundo os autores, são:

- Planejamento - o SIG é, por definição, uma ferramenta de planejamento e de auxilio a tomada de decisões;

- Gerenciamento de espaços - levantamento e classificação dos espaços baseado em levantamentos de capacidade, ocupação, forma, função, designação, estado de conservação, etc.;

- Planejamento e Adequação de espaços - maior eficiência do uso dos espaços internos, com análises simultâneas em múltiplos edifícios;

- Inventario - identificação, classificação e localização dos bens dispostos dentro das construções;

- Gerenciamento imobiliário - gestão de propriedades, custos associados, contratos, documentos, etc.;

- Manutenção e operação - suporte à manutenção e operação de edifícios de forma autônoma, ou integrada a outros sistemas especializados;

- Gerenciamento de infra-estrutura - integração do cadastro dos sistemas prediais com as redes externas de serviço e infraestrutura; 
- Segurança e resposta a emergências - avaliação de riscos, planejamento de ações emergenciais;

- Roteamentos - traçado de rotas dentro de edifícios, entre edifícios e no entorno dos edifícios. 


\section{GERENCIAMENTO INTEGRADO DE BENS PATRIMONIAIS E PREDIAIS}

\subsection{HISTÓRICO}

Historicamente sempre houve uma diferenciação nas tecnologias empregadas no gerenciamento de bens patrimoniais e no gerenciamento de bens prediais, com uma delimitação muito clara das tecnologias empregadas no gerenciamento das informações relativas a construções e as relacionadas aos dados geográficos em geral (YOUNG e DRAKE, 2008).

Os Sistemas de Informações Geográficas - SIG são utilizados há muitos anos no gerenciamento de bens patrimoniais, em especial no setor de infraestrutura (saneamento, telecomunicações, eletricidade e transporte), setor este que tem seus bens distribuídos ao longo de grandes extensões territoriais, dando suporte a operações de projeto, construção, operação e manutenção deste patrimônio.

Nessa utilização tradicional do SIG, que combina em um mesmo ambiente diferentes tipos de dados geográficos como informações cartográficas, dados de clima, hidrografia, transporte, redes de distribuição de energia, saneamento, gás e telecomunicações, limites políticos, administrativos e sócio-econômicos, entre outros, o último nível de informação é normalmente o da edificação, representada por simples pontos, ou polígonos no mapa, aos quais são associados dados da edificação como um todo, como ano de construção, proprietário, ocupante, numero de pavimentos, área útil, entre outros.

Os sistemas prediais por sua vez tiveram seu gerenciamento baseado em ferramentas CAD - Computer Aided Design - ou por sistemas derivados deste, como o CAFM - Computer Aided Facility Management (JORDANI e BECKER, 2001).

Segundo Srivastava e Wellington (2005) e Jordani e Becker (2001), disseminou-se entre os profissionais ligados ao gerenciamento dessas duas áreas (patrimonial e predial) que a utilização do SIG deveria se restringir apenas no gerenciamento do espaço exterior à edificação, e as ferramentas baseadas em CAD apenas no interior dos ambientes construídos. Essa visão 
perdurou por anos, entre usuários e desenvolvedores de sistemas, estabelecendo um padrão de atuação dos respectivos setores.

Os autores colocam que, ainda que algumas limitações técnicas e dificuldades de integração entre plataformas CAD e SIG favorecessem este cenário, as questões culturais e comerciais eram a principal razão do tratamento isolado e dissociado do patrimônio predial e do patrimônio externo às edificações.

As figuras 5.1 e 5.2 ilustram a fronteira histórica entre os domínios das ferramentas SIG e CAD.

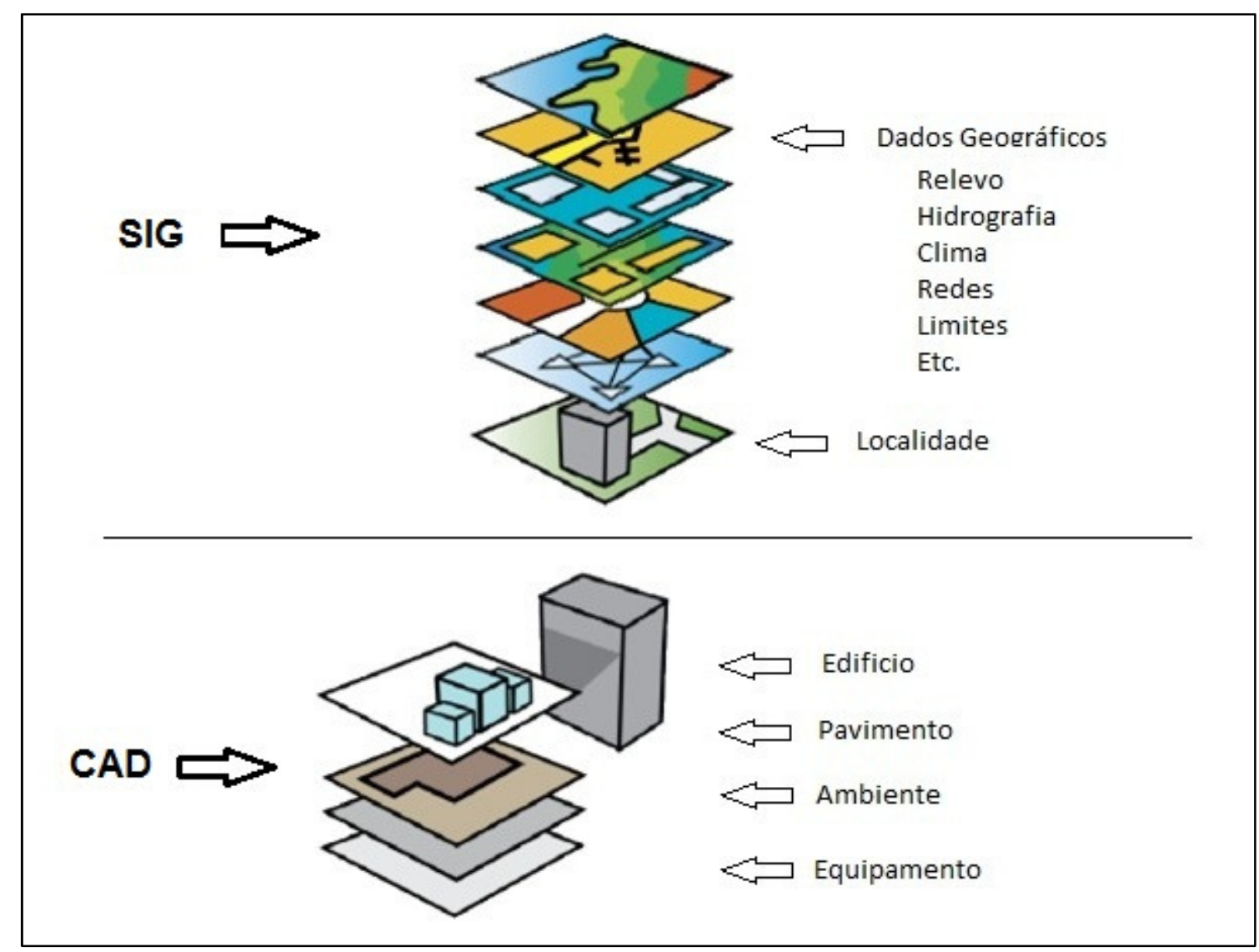

Figura 5.1 - Divisão histórica entre o domínio do SIG e do CAD - I Fonte: adaptado de Young (2008) 


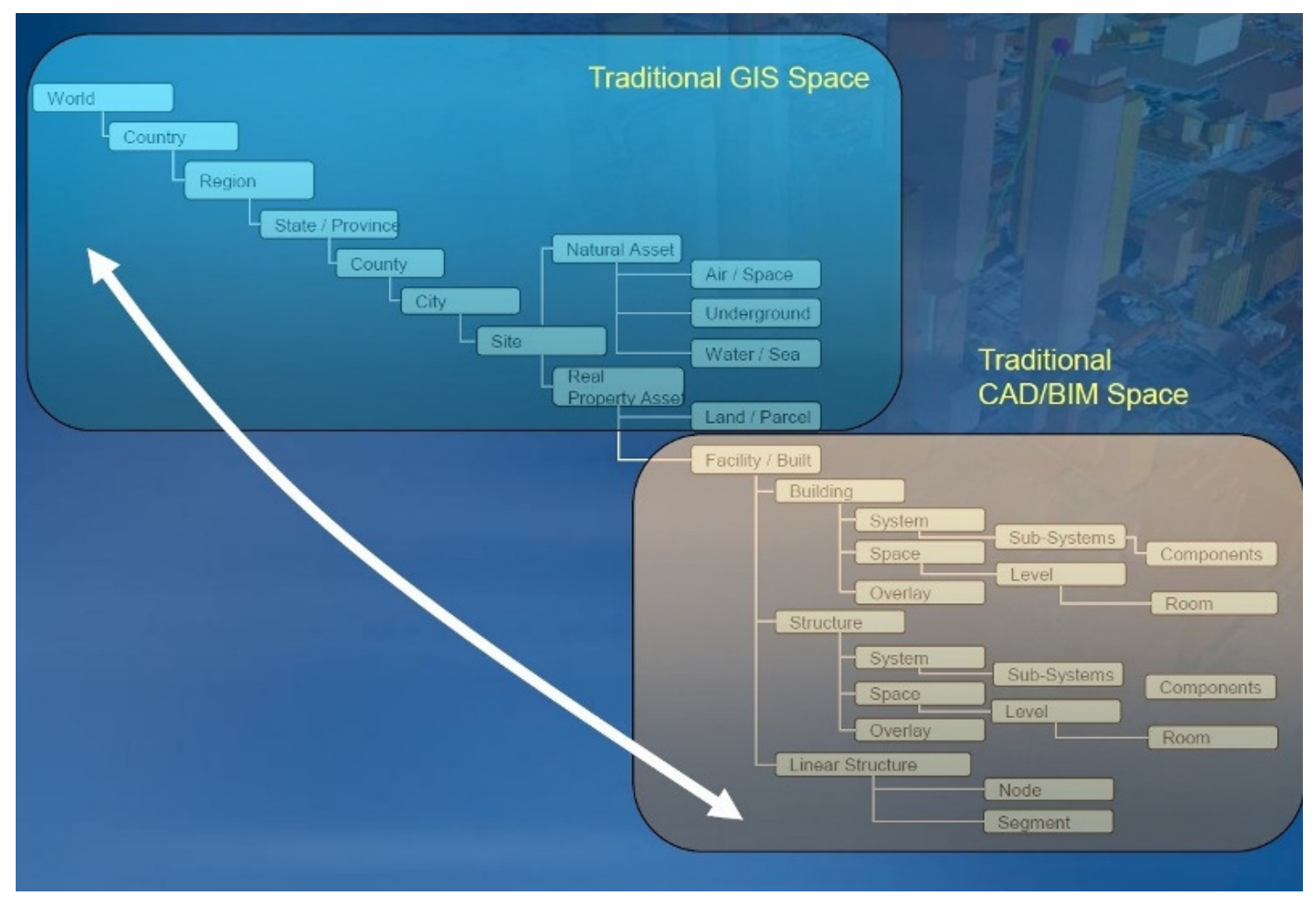

Figura 5.2 - Divisão histórica entre o domínio do SIG e do CAD - II Fonte: Young (2008)

Esse cenário começou a mudar em certos setores (tradicionais usuários de ferramentas CAD e SIG para a gestão predial e patrimonial respectivamente) cuja administração predial e patrimonial está sob responsabilidade de um mesmo gestor. São exemplos de instituições pioneiras universidades, instalações militares, hospitais, aeroportos, grandes corporações, órgãos públicos entre outros, que por iniciativa de seus profissionais avançou a fronteira tradicional da utilização do SIG, na busca por soluções integradas para a gestão de todo o seu patrimônio (YOUNG, 2008).

Esses órgãos ou instituições estão muitas vezes sediados ao longo de grandes extensões territoriais, ou costumam ter instalações em diferentes localidades, servindo a uma grande população de usuários, com uma infraestrutura de porte urbana e com um grande acervo predial.

Muitos desses primeiros usuários, de forma independente, passaram a utilizar o SIG de forma mais abrangente, incorporando o mapeamento dos ambientes internos das edificações em seus sistemas, de forma análoga à 
utilizada no mapeamento do espaço exterior, beneficiando-se das ferramentas de visualização e de analises espaciais, próprias do SIG, de forma combinada, tanto dentro dos ambientes construídos como no seu exterior (YOUNG e DRAKE 2008).

Essas iniciativas pioneiras foram percebidas pelas empresas de software que passaram a desenvolver aplicações de suporte à integração entre sistemas CAD/CAFM e SIG (RICH, 2009).

\subsection{JUSTIFICATIVA}

Um SIG é um sistema capaz de integrar dados de diferentes formatos e origens, permitindo uma serie de visualizações e analises espaciais sobre esse conjunto de dados. Não se trata de uma ferramenta de desenho ou projeto, mas um integrador de informações produzidas em outros sistemas, sendo uma poderosa ferramenta de planejamento e gerenciamento.

As ferramentas de CAFM baseadas em CAD, consolidadas no mercado de Gerenciamento de Facilidades, são eficazes no gerenciamento de edificações isoladas. Entretanto, quando uma organização passa a ter um grande numero de edificações, dispostas em grandes extensões territoriais, ou diferentes localidades, a utilização isolada de um sistema CAFM pode não ser suficiente para atender às demandas dessa organização.

Um SIG, por outro lado, permite tratar de forma integrada tanto a informação predial como a do meio externo aos edifícios. Nesse cenário, a utilização do SIG para o gerenciamento de facilidades se torna uma alternativa de grande potencial (RICH e DAVIS, 2010). A recém incorporação dos ambientes construídos em SIG foi possibilitada pelos avanços tecnológicos em software e hardware.

A armazenagem dos dados deixou de ser baseada em arquivos individuais e passou a ser administrada em sistemas de bancos de dados espaciais (geodatabases). $\mathrm{O}$ uso da tecnologia de bancos de dados facilita a armazenagem e o gerenciamento de grandes quantidades de dados. 
Outro importante avanço foi o aumento da precisão dos sistemas de referencia espacial. Esse aumento na precisão é reflexo do aumento do numero de casas decimais no armazenamento das coordenadas. Esse aumento na precisão, somado à capacidade do SIG de manipular elementos em diferentes sistemas de coordenadas, permite combinar em um mesmo modelo (mapa), elementos com precisão sub-centimétrica distribuídos em grandes extensões territoriais ( $\mathrm{RICH}, 2009)$.

A aplicação do SIG pode ser estendida desde um ambiente interno de uma edificação, a propriedades, instalações e infra-estruturas distribuídas em grandes extensões territoriais, conforme ilustrado na Figura 5.3. Em uma situação como essa, a integração em um mesmo ambiente gerencial pode ser de grande valia para o gestor, dado a potencial inter-relação entre os elementos tratados.

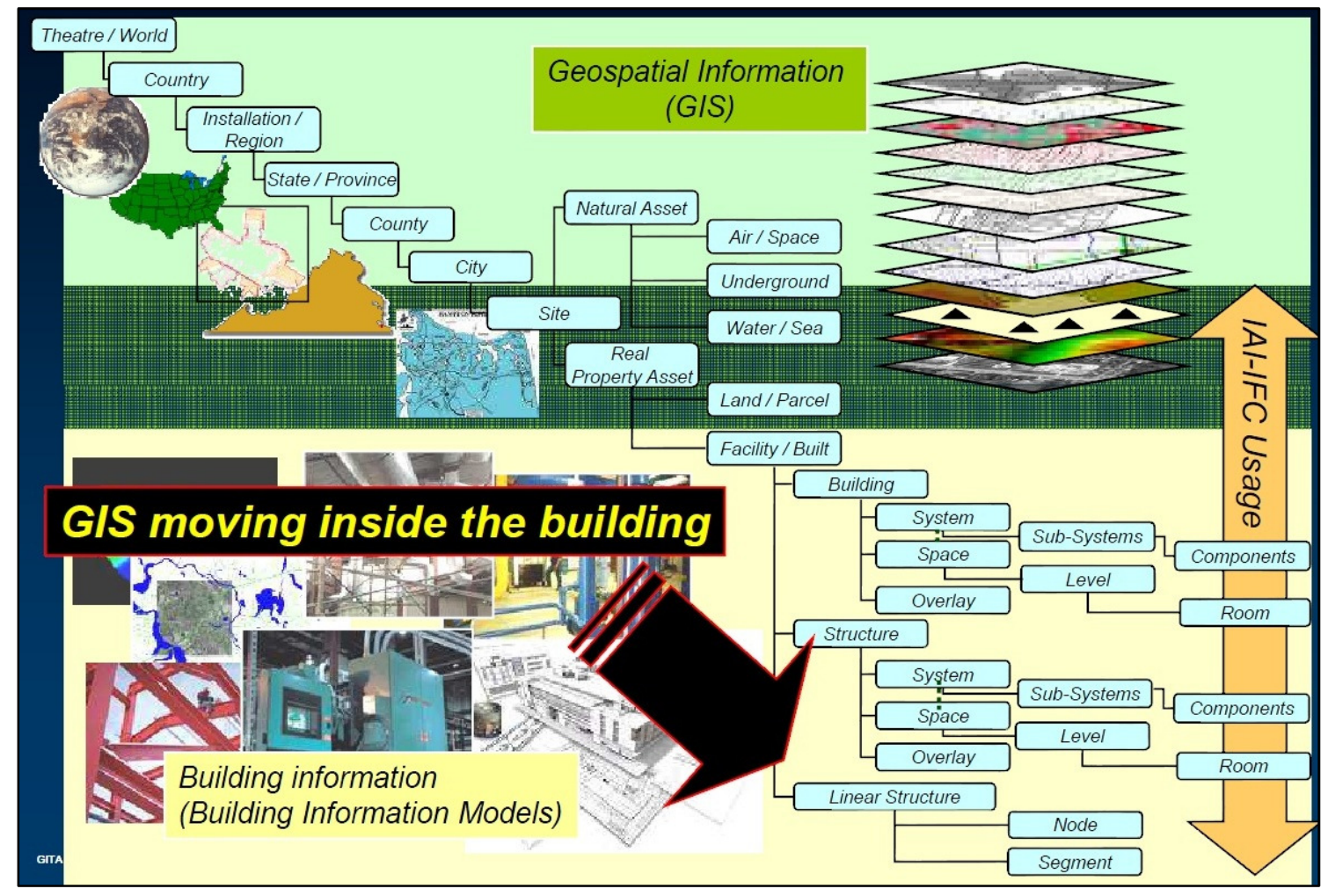

Figura 5.3 - Potencial de abrangência de um SIG Fonte: Young e Drake (2008) 
Segundo Wyatt e Ralphs (2003), um SIG oferece vantagens em relação a sistemas baseados em CAD e a sistemas CAFM, devido à sua capacidade de realizar análises espaciais complexas e à sua interface gráfica na forma de mapa, que facilita a visualização de conjuntos complexos e volumosos de informações, além da capacidade de combinar dados de diferentes tipos e origens num mesmo ambiente permitindo a análise conjunta destes dados.

A informação a respeito do conjunto dos bens de uma organização pode ser utilizada em uma serie de processos gerenciais como planejamento, operação e manutenção, gestão de propriedade (aquisição, alienação, renovação e requalificação), recursos humanos, inventário e serviços de informação.

Ainda segundo os autores, um SIG oferece a oportunidade de integrar a gestão de infra-estrutura com dados referentes a detalhes internos das edificações. Isso não é possível com sistemas tradicionais baseados em CAD. A interface na forma de mapa e a estrutura topológica dos dados em SIG oferecem um meio poderoso e flexível de organizar, analisar e apresentar informações de instalações e infra-estrutura em todos os níveis do acervo patrimonial de uma organização.

Segundo Olimpio e Smith (2009), a utilização do SIG no gerenciamento integrado de todo o patrimônio de uma organização, em todos os seus níveis, confere a esta operação um contexto geográfico ate então inédito. O local passa a ser um atributo critico em todos os níveis de operação. Bens até então tratados individualmente, de forma estanque, passam a interagir com outros, em um contexto geográfico. A Figura 5.4 indica diferentes escalas geográficas possíveis de serem tratadas em um SIG em suporte à integração de todo o patrimônio de uma organização. 


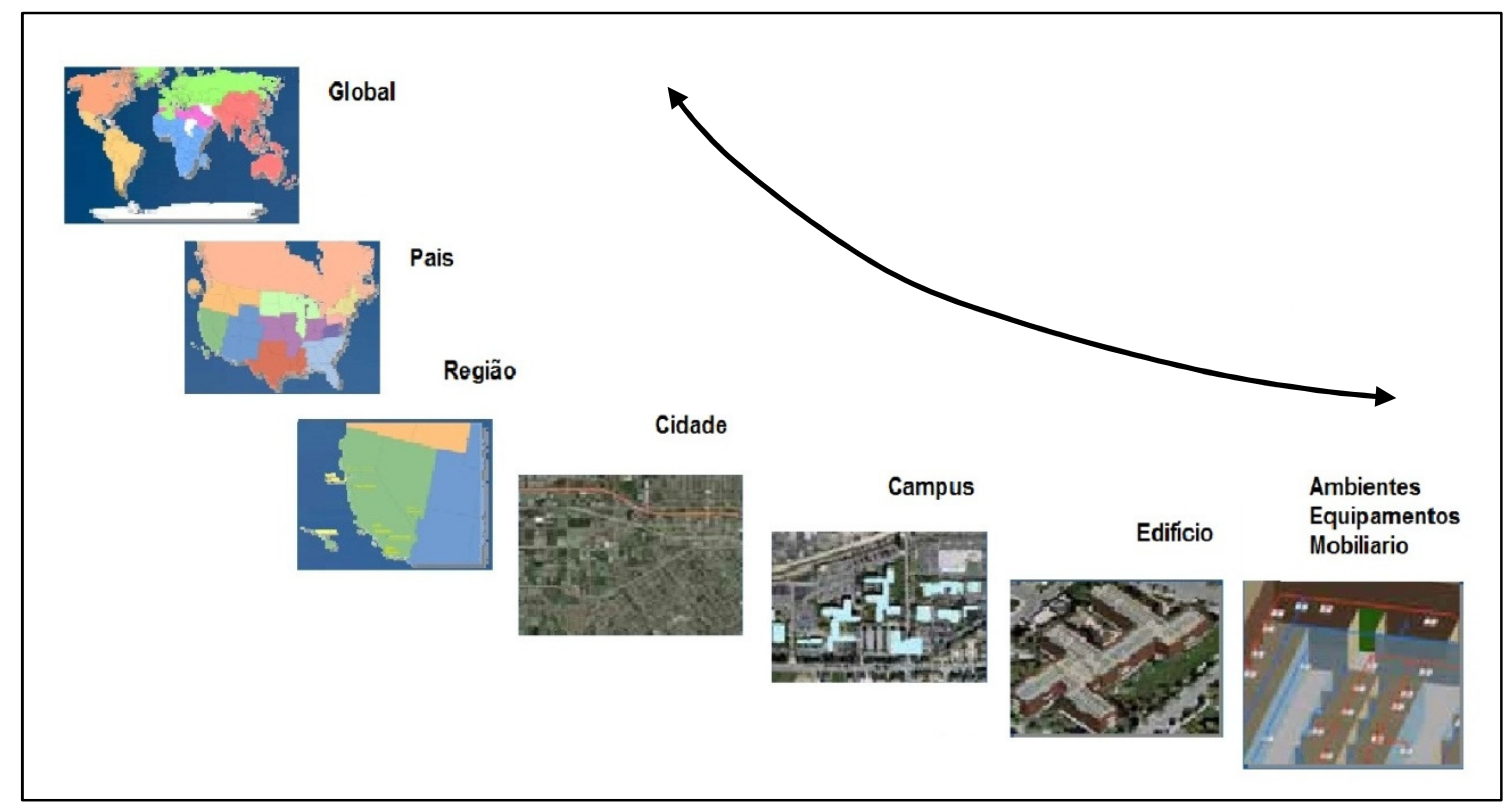

Figura 5.4 - Contexto Geográfico do Patrimônio Fonte: Adaptado de Olimpio e Smith (2009).

O SIG é por definição um sistema de suporte à decisão. Sua capacidade de integrar dados dispersos, de realizar análises espaciais sobre esses dados, possibilita novas abordagens no gerenciamento patrimonial. A apresentação visual, tanto do conjunto do patrimônio, como do resultado dessas análises tem um impacto muito forte entre todos os envolvidos nos processos gerenciais (OLIMPIO e SMITH, 2009).

\subsection{APLICAÇÃO}

Assim como o SIG no gerenciamento de facilidades não visa à substituição de ferramentas CAD e CAFM, a sua utilização mais abrangente, apresentada aqui, do uso integrado do SIG na gestão predial e patrimonial segue o mesmo principio.

Podem coexistir dentro de uma organização, inúmeros sistemas já estabelecidos e consolidados, com atribuições especificas como sistemas contábeis, de administração de pessoal, de gestão de ordens de serviço, de inventario, entre outros. Esses sistemas dedicados, não necessitam nem devem ser replicados em um novo sistema gerencial baseado em SIG. O verdadeiro valor de SIG esta na sua capacidade de integrar segundo um 
referencial geográfico, diferentes aplicações e tecnologias já estabelecidas dentro de uma organização (RICH e DAVIS, 2010).

O mesmo principio vale para a integração de dados de diferentes fontes um SIG não precisa replicar bancos de dados previamente existentes em seu próprio banco. A Figura 5.5 ilustra a possível integração de diferentes bancos de dados de uma organização com dados espaciais, por meio da associação entre chave estrangeira e chave primária de suas tabelas.

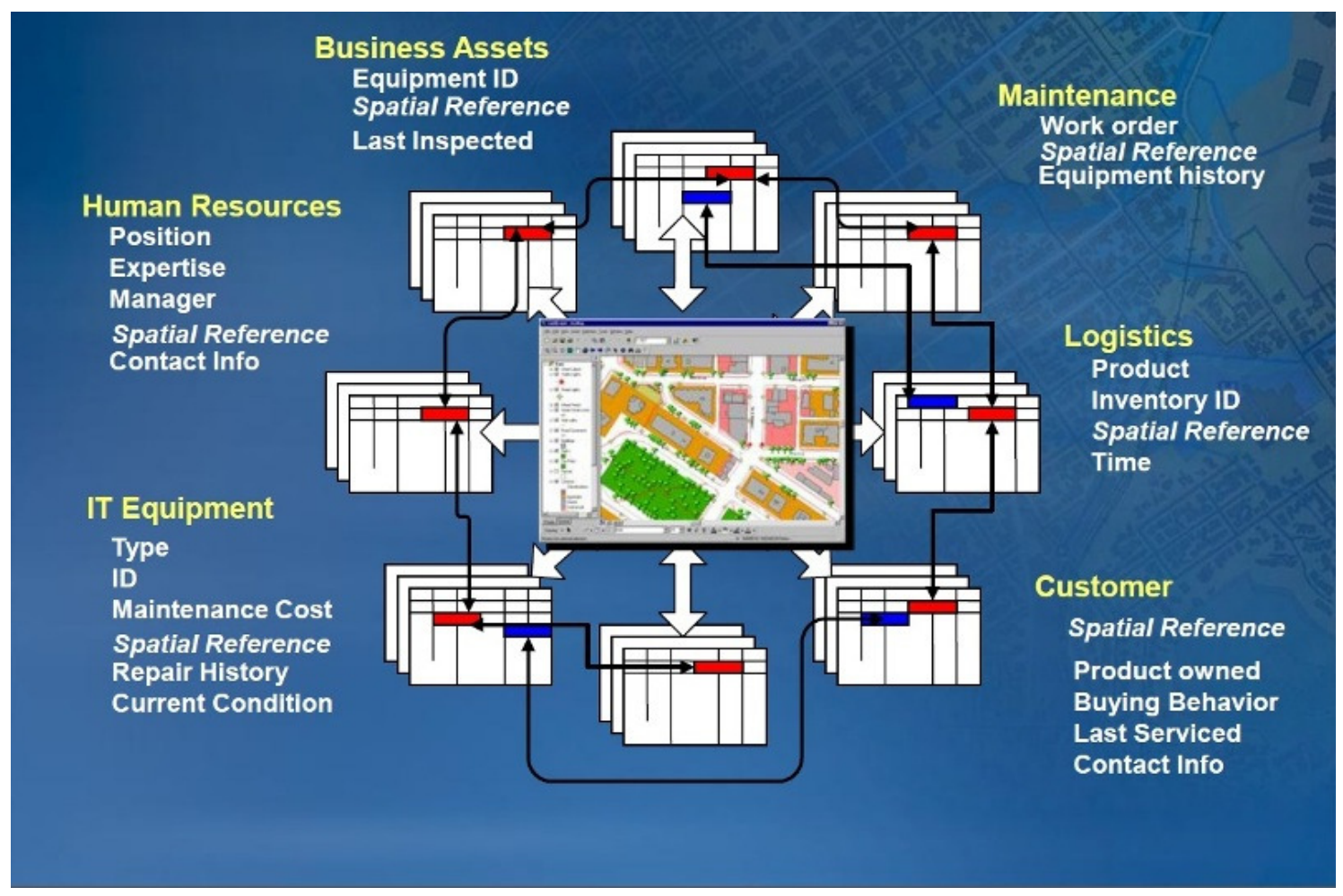

Figura 5.5 - Exemplo da integração de diferentes bancos de dados.

Fonte: Olimpio e Smith (2009)

O uso do SIG, numa gestão integrada de bens patrimoniais e prediais visa combinar o gerenciamento de facilidades com o gerenciamento patrimonial de bens dispostos geograficamente. O SIG pode ser uma ferramenta de suporte as atividades de planejamento, projeto $\mathrm{e}$ manutenção/operação, de gestão de infra-estrutura, gestão de energia, resposta a emergências, gestão imobiliária, entre outras. A Figura 5.6 ilustra o potencial integrador de um SIG em tal contexto. 


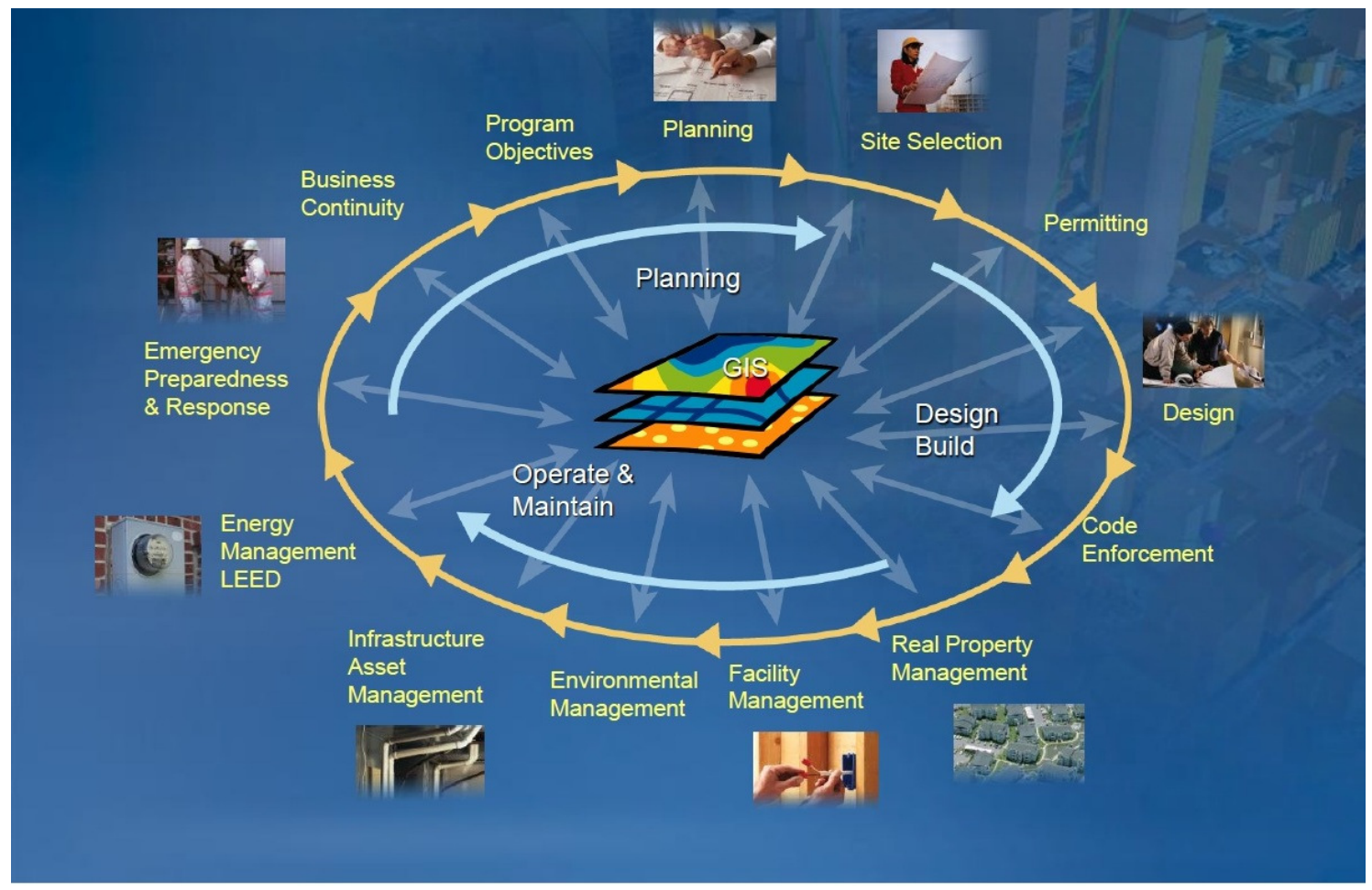

Figura 5.6 - SIG como ferramenta integradora.

Fonte: Olimpio e Smith (2009)

Conforme exposto anteriormente, os pioneiros da utilização do SIG na gestão patrimonial integrada foram instituições como universidades, órgãos militares, grandes complexos hospitalares, aeroportos, portos, grandes corporações e órgãos públicos, que costumam ter instalações em diferentes localidades ou ao longo de grandes extensões territoriais, servindo a um grande número de usuários, com uma infra-estrutura de porte urbana e com um grande acervo predial.

Segundo Young e Drake (2008), os SIG vêm sendo utilizados nessas organizações nas seguintes atividades:

- $\quad$ Planejamento - Um SIG é por definição uma ferramenta de suporte ao planejamento e à tomada de decisões. É um sistema capaz de gerir, organizar e combinar grandes volumes de diferentes tipos de dados, permitindo a realização de diversas análises sobre esse conjunto de dados. Sua interface gráfica facilita a disseminação de informações normalmente restritas, dentro de uma organização; 
- Gestão de Espaços - Analise e visualização de ambientes, pavimentos, edifícios e espaços, em todos os níveis da organização (instalações isoladas, campus, cidade, região, etc.). Gerenciamento e adequação dos espaços, planejamento de mudanças e de melhores usos, analisando o conjunto patrimonial da organização;

- Gestão Imobiliária - Gestão de propriedades, custos associados, contratos, documentos, etc.;

- Gestão de ativos - Avaliação de valor e condição dos ativos, com identificação, classificação e localização dos bens dispostos dentro e fora das construções;

- Segurança - Gerenciamento e análise do desempenho e dos custos das atividades de segurança, dentro e fora das edificações. Estudo de posicionamento de vigilantes e/ou câmeras de segurança com base em campos de visão, rotas de fuga, etc.;

- Gestão de Resíduos - Gerenciamento de resíduos e materiais perigosos e sua disposição;

- Planejamento de Transportes e Roteamento - Logística de transporte e traçado de rotas dentro de edifícios, entre edifícios e instalações da organização;

- Prevenção e Resposta a Emergências - Avaliação de riscos e planejamento de ações emergenciais utilizando-se de dados internos e externos das edificações;

- Gestão de Infra-estrutura - Integração do cadastro dos sistemas prediais com as redes externas de serviço e infra-estrutura. 


\subsection{EXEMPLOS}

A seguir serão apresentados exemplos da literatura sobre a gestão patrimonial integrada com a utilização do SIG:

\subsubsection{Sky Harbor International Airport}

Entre os anos de 2006 e 2010, o governo municipal de Phoenix, Arizona, desenvolveu um SIG para o aeroporto Sky Harbor International, o nono em movimento nos Estados Unidos. O objetivo era disponibilizar a todos os envolvidos na gestão e operação do aeroporto, dados sobre o conjunto patrimonial da instituição combinado a informações provenientes de diferentes sistemas gerenciais em uma interface única e intuitiva para os diferentes perfis de usuários (RICH e DAVIS, 2010; ESRI, 2010).

Até a execução do projeto, não havia um sistema integrado de planejamento e operação dos bens prediais e externos. Não havia um inventario atualizado das instalações e equipamentos, nem uma política de manutenção dessas informações.

Inicialmente foram levantadas, ou convertidas de levantamentos existentes (em outros formatos), para o SIG, informações de todos os elementos relacionados à operação do aeroporto, incluindo dados prediais e dados de elementos externos acima do solo, na superfície, no subsolo e no entorno do aeroporto. A Figura 5.7 mostra uma vista geral do mapeamento produzido. 


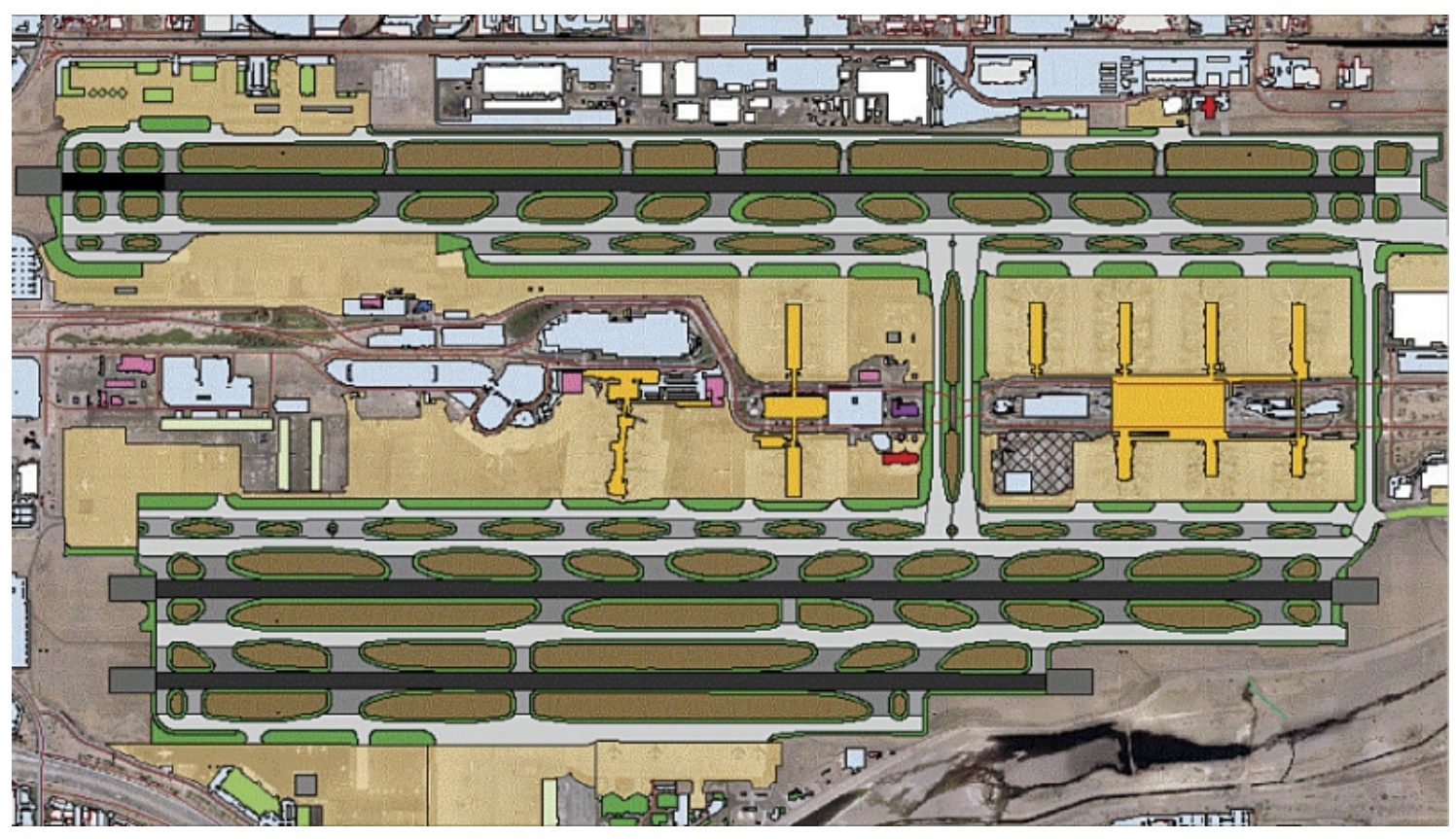

Figura 5.7 - Mapeamento do aeroporto de Phoenix - vista geral Fonte: ESRI (2010).

Em seguida, esses dados foram integrados com os demais sistemas gerenciais em uso no aeroporto, em especial o de ERP (Enterprise Resource Planning), permitindo acesso a informações mantidas por aquele sistema a partir dos elementos mapeados.

A introdução do SIG permitiu a disponibilização de uma enorme quantidade de dados até então de difícil acesso à maioria dos seus funcionários, facilitando a colaboração entre equipes de diferentes especialidades.

O objetivo do projeto foi permitir que usuários, sem conhecimento prévio em SIG, fossem capazes de realizar operações como planejamento e revisão de ordens de serviço de manutenção, checagem de medições de ambientes internos (para verificação de contratos com terceiros), elaboração de mapas com elementos atuais (internos, externos, de superfície e enterrados) e elementos em estudo ou projeto, extração de informações para estudos, projetos e apresentações, estudos de acessibilidade e resposta a emergências (confecção de mapas de rotas de fuga) entre outras. 
A Figura 5.8 mostra parte do mapeamento dos ambientes internos de um dos terminais do aeroporto.

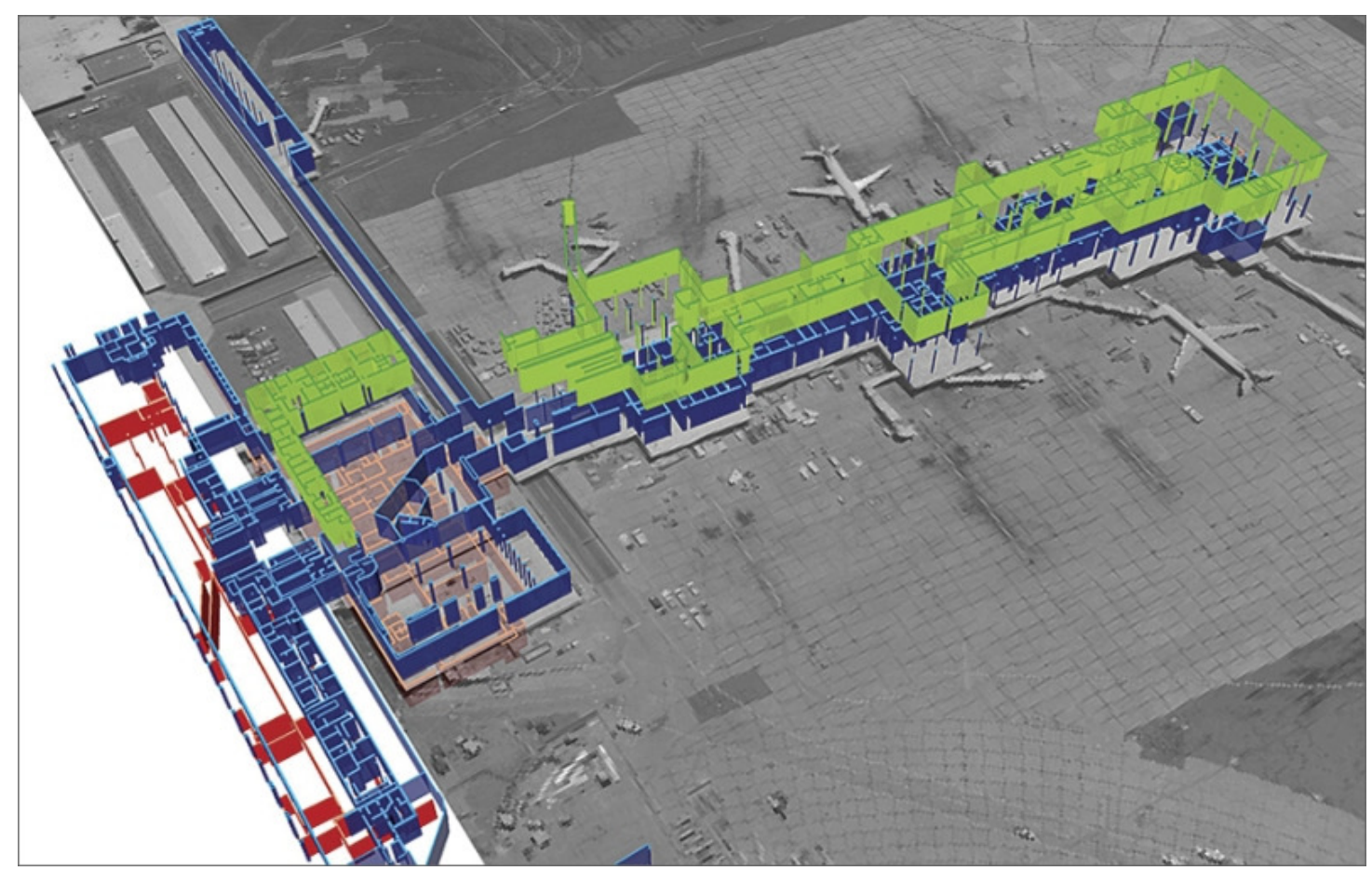

Figura 5.8 - Mapeamento do aeroporto de Phoenix - ambientes internos Fonte: ESRI (2010).

\subsubsection{LaRC / NASA}

O LaRC - Langley Research Center, Centro de pesquisas da NASA National Aeronautics and Space Administration, localizado no estado Americano da Virginia, passa periodicamente por realinhamentos e processos de ajustamento de espaços, para atender às demandas dos novos projetos da organização.

No ano de 2006, teve inicio o desenvolvimento de um projeto para a otimização da utilização da capacidade instalada do LaRC, coordenado pela equipe de SIG da NASA (NASA, 2007; ESRI, 2009).

As instalações do LaRC estão distribuídas em uma área de pouco mais de três milhões de metros quadrados, com um acervo predial de aproximadamente 400 edificações, totalizando mais de 340 mil metros 
quadrados de área construída. Essas instalações possuem 6.700 salas e laboratórios, onde trabalham pouco mais de 4.000 funcionários.

Nesse centro são realizadas pesquisas nas áreas de aerodinâmica, estrutura, materiais, eletrônica e ciências atmosféricas. Devido à variedade de atividades promovidas no local, suas instalações são complexas e associadas a uma massiva infra-estrutura. As construções do centro têm mais de 50 anos, e datam do período da guerra fria, com uma arquitetura baseada em pesadas paredes de alvenaria e concreto, o que dificulta modernizações internas e adequações do espaço.

A idade e complexidade das instalações, a dinâmica do centro de pesquisa, adaptado as necessidades de cada novo projeto ou missão, a necessidade de se buscar maior sinergia entre os postos de trabalho, bem como atender às demandas por menores custos operacionais, foram os motivadores para a implantação de um sistema automatizado para a otimização do uso dos espaços do LaRC.

Os principais avanços obtidos na primeira fase do projeto foi 0 desenvolvimento de:

- Algoritmo para o aproveitamento ótimo dos espaços e planejamento de mudanças internas;

- Interface abstrata para visualização e analise de todos os ambientes do centro de pesquisa;

- Ferramenta para planejamento de adequações na infra-estrutura demandada pelo novo uso proposto ao ambiente;

- Aplicativo WEB para visualização de todos os ambientes do centro de pesquisa;

- Ferramenta de busca de caminhos ótimos (em inglês, routing) internos.

A Figura 5.9 mostra exemplos da interface desenvolvida para visualização dos ambientes internos do conjunto predial do centro de pesquisa. Por ser um conjunto muito grande de edificações, optou-se por uma interface abstrata, 
para facilitar o entendimento holístico da ocupação dos diferentes ambientes dispostos ao longo de todo o campus do centro de pesquisa.

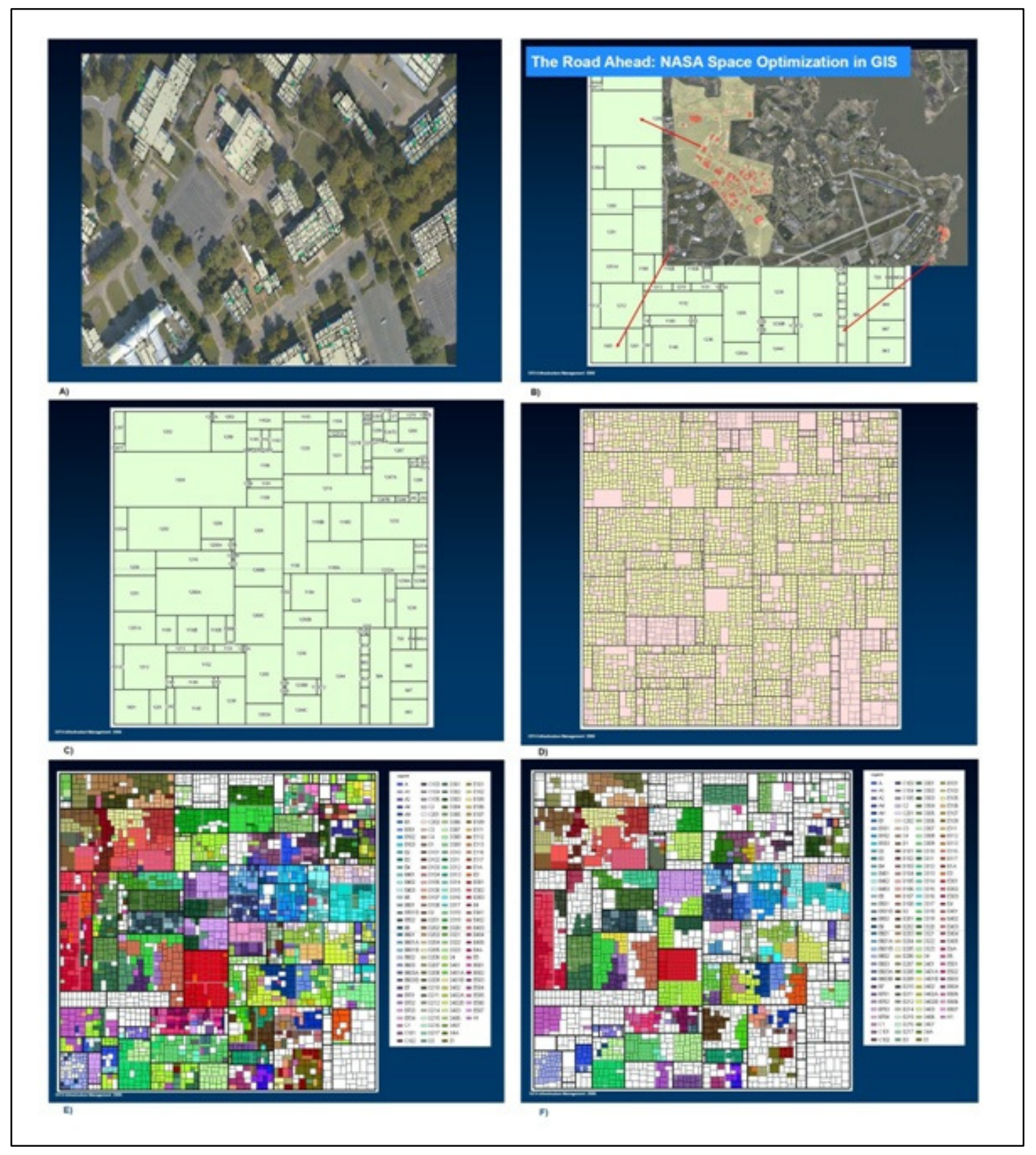

Figura 5.9 - Interface do SIG para visualização de espaços do LaRC Fonte: Adaptado de NASA (2007)

A primeira imagem (A) exibe a disposição geográfica dos diferentes edifícios. A imagem (B) mostra a transposição das edificações do mapeamento geográfico para a interface esquemática. A imagem (C) mostra o painel 
esquemático, que exibe de forma agrupada o conjunto dos edifícios para facilitar a visualização e compreensão de todo o conjunto. Na imagem (D) há o acréscimo dos ambientes internos em cada edificação. A imagem (E) mostra os ambientes classificados segundo seu uso, seguido da mesma classificação com proposta de mudança baseada no algoritmo de aproveitamento ótimo dos espaços. 


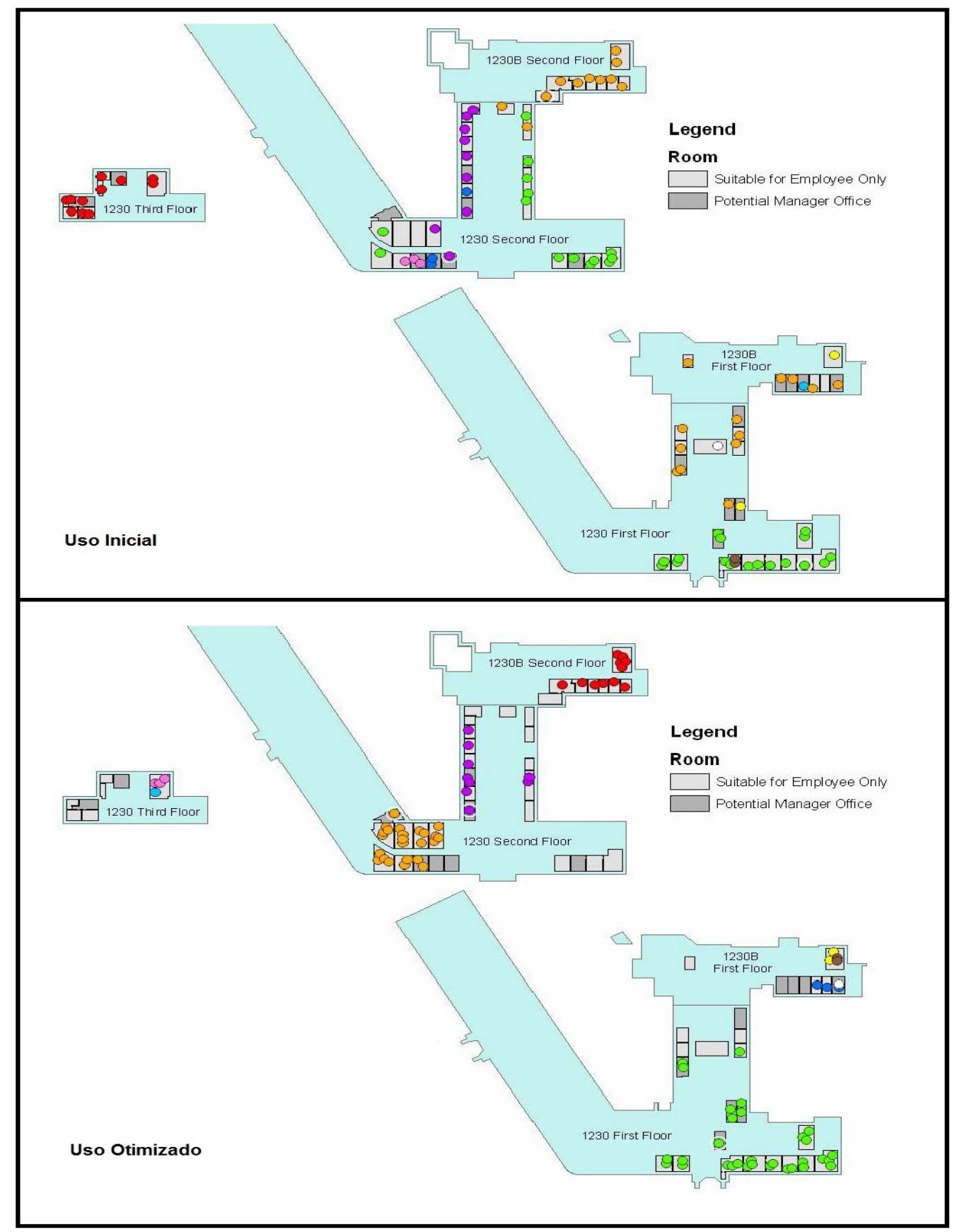

Figura 5.10 - Exemplo de otimização de espaços no LaRC. Fonte: Adaptado de NASA (2007)

Na figura 5.10 é detalhado um exemplo de busca do aproveitamento ótimo dos espaços em um dos edifícios do centro de pesquisa. $\mathrm{Na}$ imagem superior, o uso inicial dos ambientes, com certa dispersão entre os grupos. $\mathrm{Na}$ imagem inferior, após a aplicação do algoritmo, além da coesão entre os grupos, há disponibilização de espaços para novos usos. 
Segundo os autores, os trabalhos desenvolvidos pelo grupo de SIG neste projeto resultaram em escritórios melhor adequados aos diferentes perfis de profissionais, distribuição mais eqüitativa do espaço, aumento na sinergia organizacional e duplicação do numero de salas livres para novas utilizações.

\subsubsection{Universidade de Minnesota}

A Universidade de Minnesota - U.M. atende a uma comunidade de mais de 80 mil pessoas, entre estudantes, professores e funcionários. Possui ativos estimados em mais de três bilhões de dólares, distribuídos em cinco campi principais, e outros vinte centros de pesquisa e estações experimentais, que combinados possuem área superior a 2.300 .000 metros quadrados. A universidade possui mais de 1.000 edificações, num total de 1.400 pavimentos e 56.000 ambientes (salas de aula, laboratórios, escritórios, etc.).

A U.M. foi uma das instituições pioneiras no uso do SIG para gerenciamento patrimonial (Jordani e Gondeck-Becker, 2001). O projeto de gestão do seu extenso patrimônio, denominado SPACE, teve inicio em 1998, motivado pela dificuldade de acesso e disseminação das informações disponíveis sobre o patrimônio, pressões para redução de gastos em operação e manutenção e uma crescente percepção da importância da componente geográfica na gestão de acervos do porte da U.M.

O projeto foi amplamente discutido, antes do inicio dos trabalhos, entre comissões formadas por representantes da administração, da operação e da área acadêmica da Universidade. Foram cuidadosamente analisados os requisitos necessários para o sistema gerencial, com avaliação dos procedimentos internos de gestão e operação e identificação do nível de informação necessária para execução das demandas internas.

Ficou constatado que os usuários do sistema precisavam para suas atividades, acesso as informações presentes em diferentes sistemas corporativos, como informações acadêmicas, contábeis, administrativas, de segurança, patrimonial, entre outras. Além do acesso aos dados corporativos, de forma integrada, levantou-se a necessidade do usuário utilizar dados próprios em conjunto com os dados existentes. 
Decidiu-se por integrar os diferentes sistemas e bancos de dados usando como referencia elementos espaciais, permitindo o acesso aos diferentes sistemas corporativos por meio de uma interface de navegação intuitiva, baseada em mapas. Por fim, o sistema deveria ser desenvolvido com uma tecnologia "aberta", permitindo customizações e modificações futuras.

Após a definição de requisitos, e escolha das tecnologias para 0 desenvolvimento do projeto, foi elaborado um piloto para validar as estratégias propostas. Com o sucesso do piloto foi iniciada a fase de desenvolvimento do projeto e da produção dos dados para alimentação do sistema, bem como treinamento da equipe técnica da universidade. Segundo os autores, o sistema vem sendo utilizado com grande sucesso, e é constantemente aperfeiçoado com novos dados e funcionalidades.

A seguir são apresentados alguns exemplos da utilização do sistema SPACE nas atividades gerenciais da Universidade. 


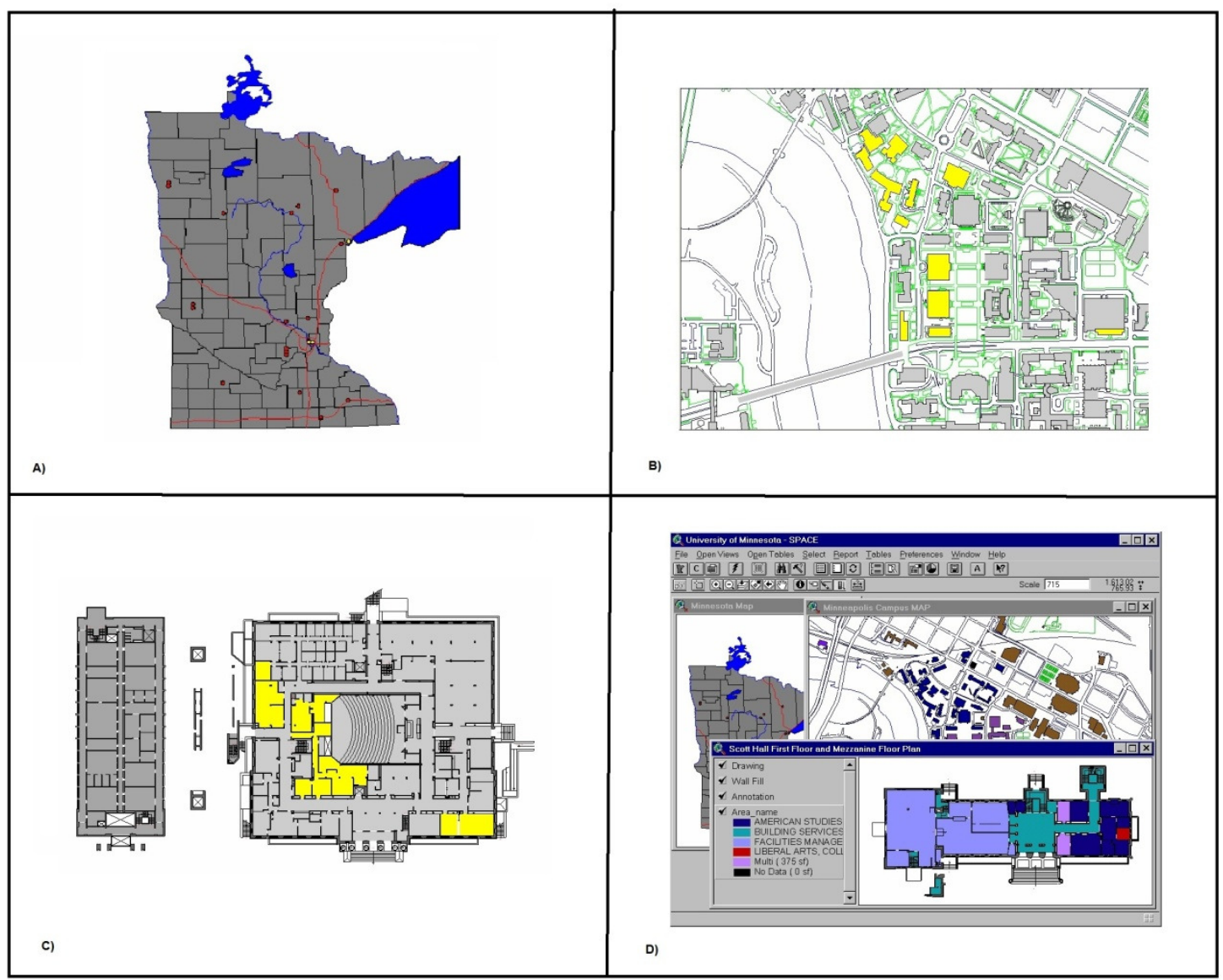

Figura 5.11 - Exemplos de diferentes níveis de exibição patrimonial na U.M. com o SPACE

Fonte: Adaptado de GONDECK-BECKER (1999)

Navegação - O sistema permite, por meio de uma interface gráfica intuitiva, visualizar e consultar informações referentes a todo o patrimônio da instituição, do detalhe de um ambiente interno de uma edificação, a distribuição dos Campi e dos centros de pesquisa espalhados pelo Estado. Na Figura 5.11, a imagem (A) mostra a distribuição dos campi sobre um mapa político do Estado, na imagem (B) o detalhe de um dos campi, na imagem (C) o detalhe de um dos edifícios e na imagem (D) a interface integrada de navegação de todos os níveis. 


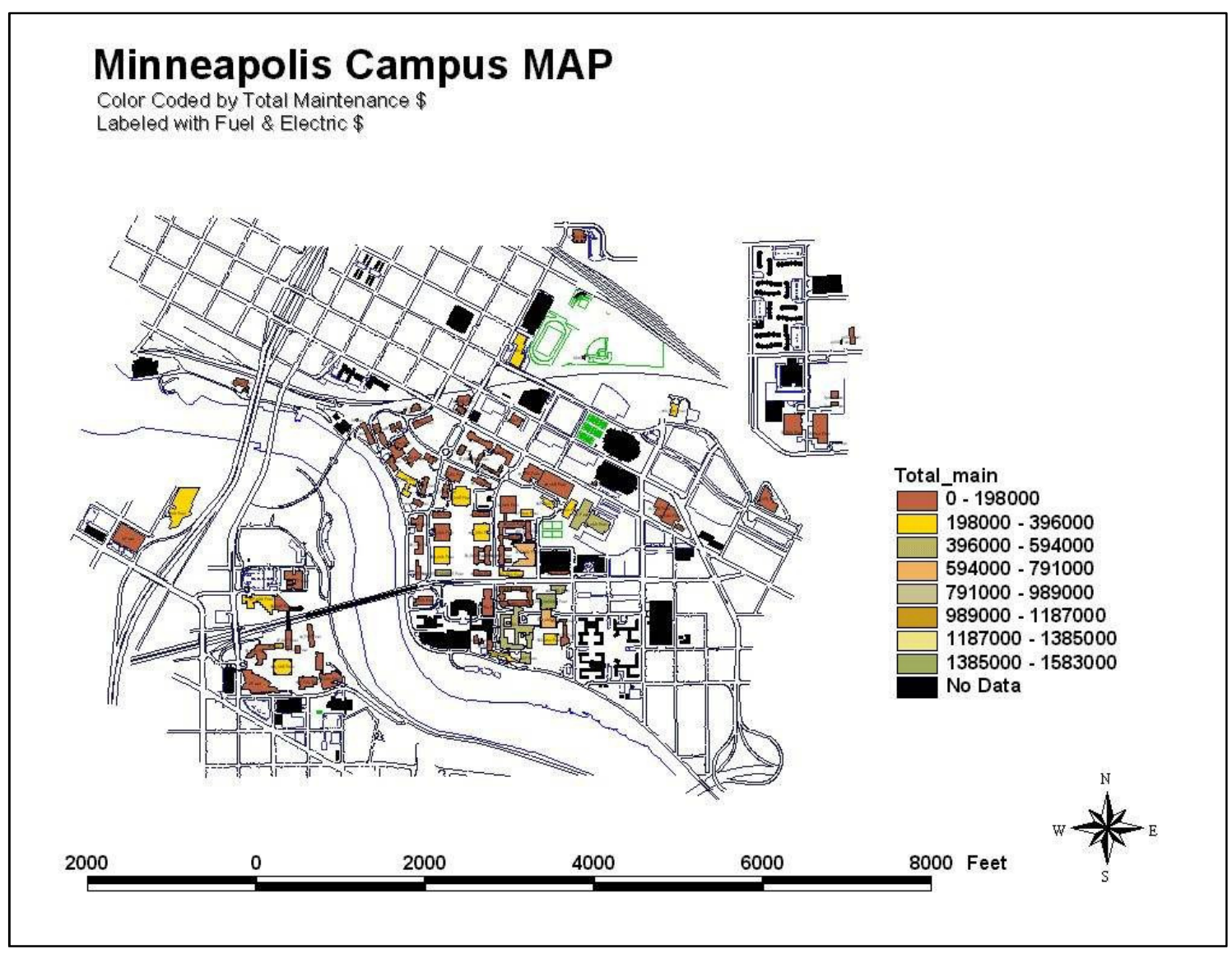

Figura 5.12 - Exemplo de classificação, por custo de manutenção na U.M. com - SPACE

Fonte: GONDECK-BECKER (1999)

Mapas temáticos - O sistema permite, por meio do cruzamento da base espacial com diferentes sistemas administrativos da universidade, a geração de mapas temáticos em todos os níveis. A Figura 5.12 mostra um exemplo de classificação dos edifícios, segundo os custos de manutenção. 


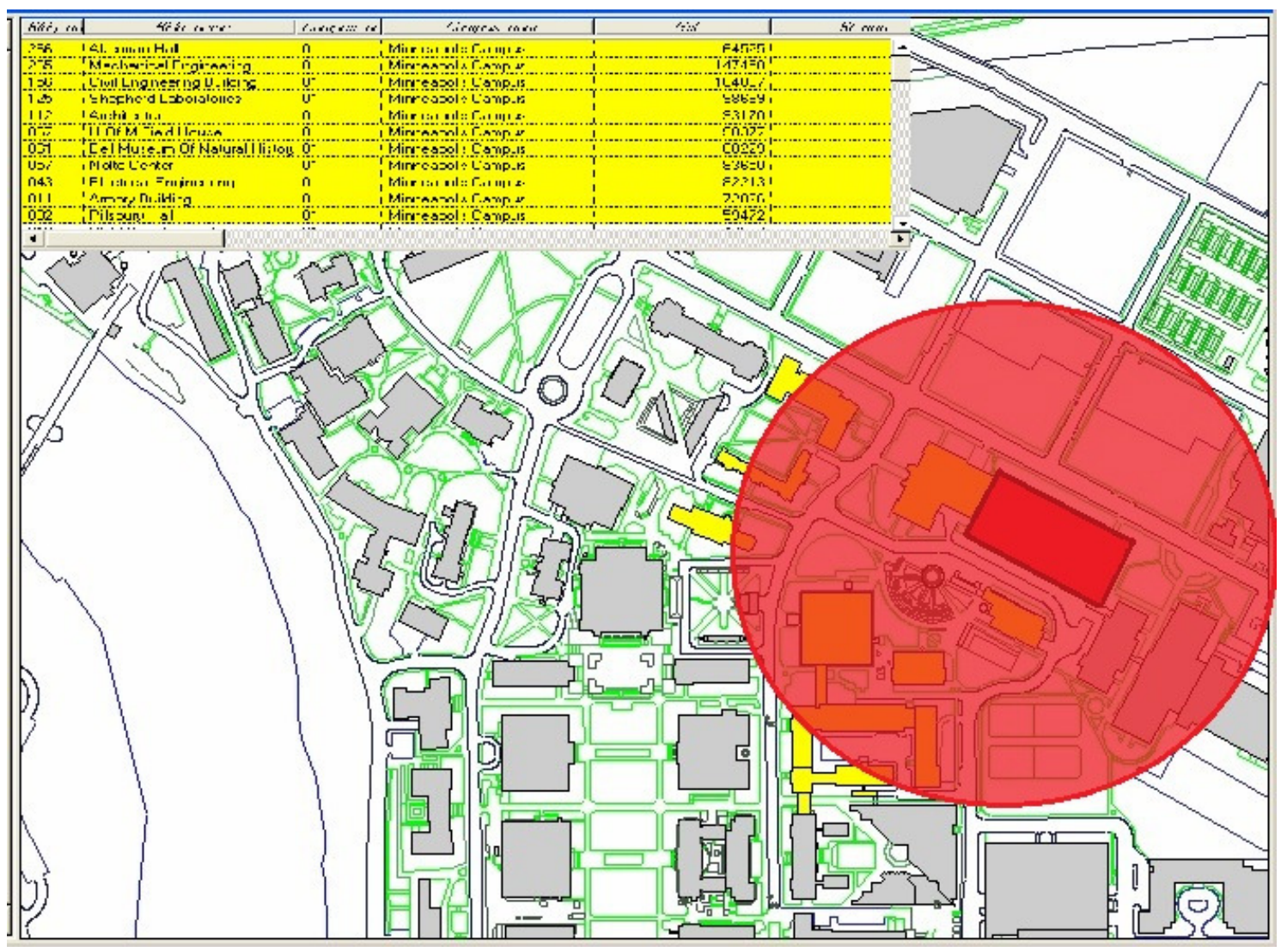

Figura 5.13 - Exemplo de análise espacial na U.M. com o SPACE Fonte: GONDECK-BECKER (1999)

Analise Espacial - Uso da capacidade do SIG em realizar análises espaciais, combinando dados geográficos com dados dos sistemas administrativos da universidade, para fins de planejamento. No exemplo da Figura 5.13, é feito uma busca da relação dos estudantes com aulas em salas situadas a menos de 300 metros de um bolsão de estacionamento, num horário especifico. 
File Open Views OpenTables Select Report Tables Preferences Window Help

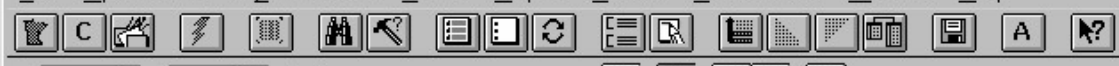

27 of 215:electec $\quad$ G

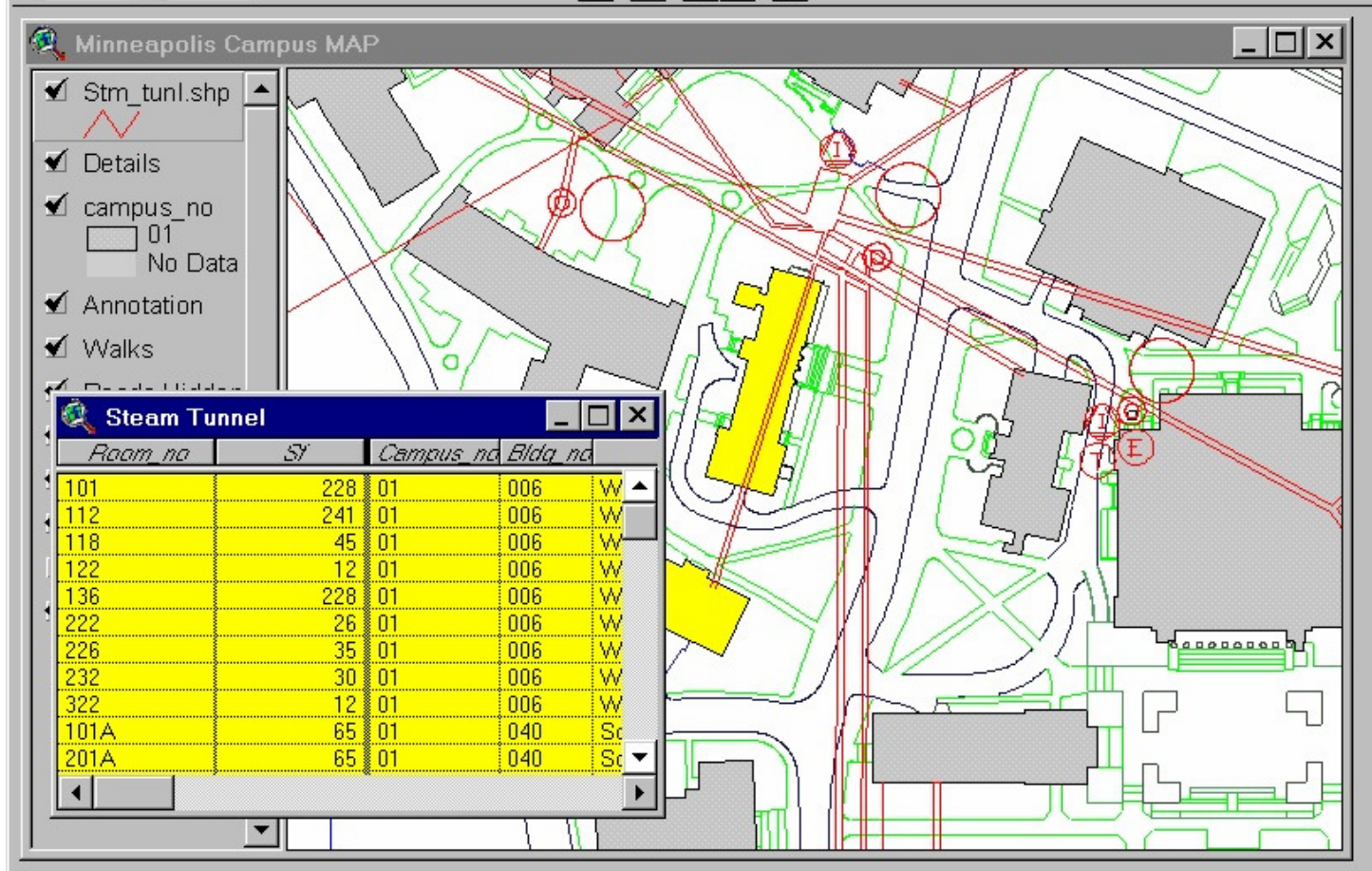

Figura 5.14 - Análise de impactos e interferências na U.M com o $S P A C E$ Fonte: GONDECK-BECKER (1999)

Analise de Impactos - Uso da capacidade do SIG em realizar análises espaciais para identificação de impactos e interferências em instalações causadas por intervenções na infra-estrutura do campus. O exemplo da Figura 5.14 mostra os ambientes internos afetados por uma interrupção na rede externa de distribuição de vapor. 


\section{ESTUDO DE CASO - PROJETO ATLAS}

O Atlas é um Sistema de Informação Geográfica - SIG, desenvolvido para a Coordenadoria do Espaço Físico-Coesf, da Universidade de São Paulo-USP, pelo Laboratório de Informatização de Acervo-LabArq, da Faculdade de Arquitetura e Urbanismo - FAU USP, com o propósito de auxiliar os órgãos gestores do patrimônio físico da Universidade nas atividades de planejamento e controle do uso dos espaços, e na manutenção do cadastro da situação atual do campus da Capital, Cidade Universitária Armando de Salles Oliveira - CUASO.

A Coesf é o órgão administrativo da USP, responsável pela organização e sistematização das atividades relacionadas ao seu espaço físico, pela análise das solicitações e propostas de ocupação dos campi, de construções novas, de ampliação e reformas de edifícios existentes, entre outras.

O Laboratório de Informatização de Acervo-Labarq, pesquisa a informatização de acervos técnicos e históricos nas áreas de Urbanismo e Arquitetura, desenvolvendo desde 1995 sistemas de gerenciamento informatizado patrimonial utilizando SIG, tendo realizado trabalhos para empresas estatais como a Companhia Paulista de Trens Metropolitanos CPTM e a Companhia Estadual de Engenharia de Transportes e Logísticas Central, que administra uma parte da malha ferroviária do Estado do Rio de Janeiro, entre outros, envolvendo acervo documental e ou patrimonial (YURGEL, 2008).

\subsection{ESCOPO}

A Universidade de São Paulo, criada no ano de 1934, é uma das mais importantes instituições de nível superior do Brasil. Possui 240 cursos de graduação, em todas as áreas do conhecimento, distribuídos em 42 unidades de ensino e pesquisa, com mais de 57 mil alunos. A pós-graduação é composta por 239 programas com 308 cursos de mestrado e 299 de doutorado, com mais de 26 mil alunos. 
O corpo docente da instituição é composto por 5.865 professores e a Universidade conta com um corpo técnico-administrativo de pouco mais de 16 mil servidores.

Além da CUASO, seu principal campus, a USP possui outras unidades distribuídas pela Capital e Interior do Estado, com unidades em Ribeirão Preto, Piracicaba, São Carlos, Pirassununga, Bauru e Lorena, e unidades de ensino, museus e centros de pesquisa situados fora desses espaços e em diferentes municípios, totalizando uma área territorial de aproximadamente 76.314.505 metros quadrados e uma área edificada aproximada de 1.757 .193 metros quadrados (USP, 2011).

Até a presente data, o projeto Atlas, apresentado neste capitulo, tratou apenas da CUASO. As demais unidades da capital, os campi do interior bem como os demais centros de pesquisa e unidades de ensino serão objeto de trabalhos futuros.

\subsubsection{CUASO}

A Cidade Universitária Armando de Salles Oliveira - CUASO, localizada no bairro do Butantã, possui área de 4.173.644 metros quadrados, onde se localizam vinte unidades de ensino e pesquisa, dois museus, três centros e institutos especializados, o Hospital Universitário, além dos órgãos centrais da Universidade. Além da USP, abriga também outras instituições: Centro Tecnológico da Marinha em São Paulo; Instituto de Pesquisas Energéticas e Nucleares - IPEN; a Fundação Prefeito Faria Lima - CEPAM; Paço das Artes; Instituto de Pesquisas Tecnológicas-IPT; Instituto Geográfico e Cartográfico - IGC e sete agências bancárias.

O CUASO foi criado a partir de duas áreas principais, inicialmente da gleba entre a adutora de Cotia e o Ribeirão Jaguaré (destacada da Fazenda Butantã) em 1941, e posteriormente da gleba desapropriada entre a nova e a velha Estrada de Itu em 1944, totalizando 4.700.000,00 metros quadrados (posteriormente algumas áreas foram cedidas ou ocupadas por terceiros). A construção da Cidade Universitária teve inicio no ano de 1951, e desde então vem sendo ampliada e modernizada. (USP, 2012a) 
De sua área total, 741.615 metros quadrados são áreas construídas, 1.300.000 metros quadrados são de área verde livre, ajardinada e de preservação, 354.651 metros quadrados constituem área de preservação permanente e 36.933 metros quadrados são de áreas verdes com equipamentos esportivos. O sistema viário da Cidade Universitária tem aproximadamente $60 \mathrm{~km}$ de vias e 14.000 vagas nos estacionamentos.

Diariamente, o Campus recebe cerca de 100 mil pessoas, entre alunos, professores, funcionários e visitantes, com um fluxo aproximado de 50 mil automóveis. (USP, 2012b)

\subsubsection{Gestão patrimonial da CUASO}

A gestão patrimonial da CUASO é realizada, em especial por três órgãos da Universidade, Coesf, COCESP e CCE, que de forma integrada são responsáveis pelo planejamento e operação de todo o patrimônio presente no Campus.

A Coordenadoria do Espaço físico da Universidade de São Paulo - Coesf tem por finalidade organizar e sistematizar todas as atividades relacionadas ao espaço físico (dos campi da USP), garantindo um uso e uma expansão física harmônica da Universidade, preservando o patrimônio existente, de modo a proporcionar o melhor suporte para as atividades fim da Universidade (USP, 2007a).

É o principal órgão de planejamento de intervenções físicas em edifícios e no território do Campus. Propõe, no âmbito predial, a construção de novas edificações e ampliações ou reformas em edificações existentes. No que tange ao território, elabora estudos e propostas sobre questões ambientais, e relativas à infraestrutura, em especial o sistema viário, redes do sistema elétrico, hidráulico, de informação, entre outros.

São atividades da Coesf (USP, 2007b):

- Elaborar planos executivos anuais e quadrienais de obras;

- Elaborar planos diretores e estudos de viabilidade física de empreendimentos; 
- Elaborar estudos de arquitetura com estimativa de custos de serviços e obras;

- Elaborar anteprojetos, projetos executivos e materiais técnicos, para licitação de obras;

- Elaborar pareceres e laudos técnicos sobre terrenos e edificações;

- Elaborar licitações e contratos;

- Fiscalizar as obras e a gestão dos contratos;

- Cadastrar plantas, áreas, índices de ocupação;

- Avaliar e aprovar projetos externos;

- Emitir e acompanhar os Termos de Compromissos.

A Coordenadoria do Campus da Capital - COCESP é responsável pela gestão de todas as áreas externas do Campus:

- Áreas verdes - serviço de poda, cortes, rastelo, combate a pragas, varrição, catação e remoção de detritos, de cerca de 1.300 .000 metros quadrados, correspondentes às áreas laterais das avenidas, aos canteiros centrais, praças, rotatórias e áreas da Reitoria, contemplando árvores, arbustos, gramados, jardins e canteiros;

- Ruas e avenidas - manutenção e conservação do arruamento do Campus (incluindo guias, sarjetas, prismas, lombadas, semáforos, sinalização horizontal e vertical), e dos passeios e caminhos de pedestres, estacionamentos, ciclovias e elementos de acessibilidade;

- Mobiliário urbano - manutenção e provimento de elementos para pontos de ônibus, placas de sinalização, totens, portas, portões e grades de proteção, pré-moldados para obras e manutenção, peças para pavimentos intertratavados, guias, mourões, lajotas, tampas de concreto e ferragens para diversas finalidades; 
- Comunicação visual - projeto, execução e acompanhamento da execução da sinalização interna e externa de edifícios;

- Infraestrutura elétrica - planejamento, manutenção, medição e controle de consumo de toda a rede de distribuição de energia (vinte e dois quilômetros de rede enterrada), das cabinas primárias e grupos geradores, além de toda a estrutura de iluminação pública;

- Infraestrutura hidráulica - manutenção das redes de micro drenagem (bocas de lobo e grelhas). Intermediação de ações de manutenção, combate a vazamentos e planejamento de abastecimento e coleta junto a concessionária SABESP.

O Centro de Computação Eletrônica - CCE coordena e executa a área de informática e comunicação de dados da Universidade. É o gestor da USPnet, a rede computacional da USP, sendo responsável pela manutenção de sua espinha dorsal (servidores e rede física de dados pelo Campus), e projetos de redes locais das Unidades. Além da rede de dados, é responsável pela telefonia do Campus, sistema este composto de doze centrais, atendendo, ao todo, aproximadamente 11.650 ramais (USP, 2012c).

\subsection{MOTIVAÇÃO}

As colocações apresentadas aqui são do autor deste trabalho, baseadas em sua participação e nas experiências vivenciadas ao longo do desenvolvimento do projeto Atlas, do qual participa desde seu inicio como pesquisador do Labarq.

A primeira dificuldade, reconhecida pela Coesf, foi a dificuldade de comunicação técnica entre os diferentes órgãos: Coesf, COSESP e CCE, somada à falta de um cadastro atualizado e integrado do Campus.

\subsubsection{Cadastro das áreas externas}

O cadastro das áreas externas, como se encontrava na época, apresentava problemas que dificultavam a sua utilização para as atividades de 
gestão patrimonial. O ultimo registro abrangente realizado na área do campus, havia sido a restituição de um levantamento aerofotogramétrico do ano de 2000.

Levantamentos baseados em fotografias aéreas necessitam de trabalhos complementares de campo, conhecidos por reambulação, para o levantamento de elementos encobertos pelas copas das árvores, quando do aerolevantamento. Essa etapa do levantamento nunca foi realizada em toda sua abrangência, de forma que muitos elementos como caixas de infraestrutura, poços de visita, elementos de drenagem, elementos de mobiliário urbano, algumas projeção de construções, entre outros nunca foram devidamente registrados nesse cadastro.

Apesar de não ser um levantamento completo, com a representação de todas as estruturas do campus, esse levantamento aerofotogramétrico do ano de 2000 , foi amplamente utilizado nos anos seguintes à sua realização, pelos diferentes órgãos da Universidade, mas de forma isolada, com pouca ou nenhuma interação.

Como cada usuário atualizava e complementava sua base de dados, coexistiam várias versões, em diferentes formatos e com diferentes conteúdos, deste mapeamento externo original, dificultando as atividades de planejamento e operação do Campus.

No intervalo de tempo entre o levantamento aerofotogramétrico de $2000 \mathrm{e}$ o levantamento topográfico de 2010 que o substituiu, vários pequenos levantamentos foram realizados para atender demandas especificas. Esses levantamentos, realizados por diferentes empresas, em momentos distintos, possuíam pouca homogeneidade entre si, com diferenças de representação e conteúdo, e com o tempo sofreram dos mesmos problemas da base aerofotogramétrica de 2000.

Pela falta de um cadastro atualizado e integrado, era comum a ocorrência de acidentes durante escavações no Campus, atingindo uma das muitas redes subterrâneas de dados, voz, água, esgoto, gás, eletricidade ou drenagem.

Outro problema recorrente, causado pela falta de um cadastro integrado, era a realização de estudos e projetos para uma mesma área, por equipes 
diferentes. Muitas vezes essas interferências só eram percebidas no momento da execução da obra, com prejuízo de tempo, trabalho e recursos empregados.

A existência de cadastros diferentes, em diferentes órgãos, acarretava problemas operacionais em alguns serviços, como na poda de grama do campus por exemplo. A COCESP, na época ainda Prefeitura do Campus, possuía um mapeamento com suas áreas de atribuição (canteiros centrais, praças, rotatórias, áreas de uso da Reitoria e uma faixa de 10 metros ao longo das laterais das avenidas).

A Coesf por sua vez, repassava às unidades, verba para que cada uma realizasse a poda do entorno de seus edifícios, segundo um mapeamento dela. Entretanto, havia aéreas gramadas que ficavam de fora de ambos os registros, e que não eram percebidas nem contabilizadas por nenhum dos órgãos no seu planejamento, mas que ficavam evidentes em campo, com áreas não podadas.

\subsubsection{Cadastro predial}

Em relação ao cadastro predial, havia muito pouca homogeneidade no acervo técnico, de responsabilidade da Coesf, com edificações em formato vetorial (CAD), outras arquivadas a partir de digitalização das plantas originais e algumas apenas em papel. Além dos diferentes formatos, os registros em sua maioria eram desatualizados, não representando a situação real das construções à época. À medida que intervenções eram realizadas em edificações, para uma reforma, por exemplo, um novo registro CAD atualizado era produzido, mas este se mostrou um processo pouco eficiente para o tamanho do acervo predial do campus, com mais de 400 construções.

Os técnicos da Coesf tinham dificuldade em administrar a grande quantidade de arquivos, tanto físicos como eletrônicos, referentes às edificações, como as plantas, projetos, estudos, tabelas gerenciais, fotografias, etc. Questões do dia a dia da Coordenadoria como a administração do repasse de verbas de manutenção predial para as unidades ou o planejamento de intervenções como reformas, ampliações e novas construções eram dificultados pela dificuldade de acesso rápido as informações. 
Questões simples como, por exemplo, definir quantas salas de aula com capacidade para 50 alunos, ou mais, pode ser disponibilizado para a realização de exames de vestibulares, eram demoradas, pois dependiam da análise individual de plantas e tabelas. Questões mais complexas, como definir o valor do repasse de manutenção predial, ou a necessidade ou não de se ampliar uma determinada unidade, eram ainda mais complexas, pois dependiam do cruzamento de informações de diferentes origens.

Para o repasse de verba de manutenção, a Coesf faz uma ponderação entre diversas variáveis, como a somatória das áreas da edificação, por tipo de uso (sala de aula, laboratório, banheiro, auditório, circulação, etc.); área de parede; número de elevadores; idade da edificação; histórico de intervenções; valor arquitetônico (tombamento); número de usuários, entre outros. Para responder à demanda de uma unidade por ampliação, por exemplo, é necessário avaliar a situação física existente (número e tamanho de salas, salas de professores, laboratórios, etc.) confrontando com dados de outros sistemas como número de alunos matriculados; número, tamanho e horário das turmas, entre outros.

\subsubsection{Diagnóstico}

Diante do quadro apresentado acima, a Coesf, definiu um programa de atualização cadastral, com a contratação de um levantamento topográfico novo para todo o Campus, e a contratação de levantamentos prediais das unidades, conforme novo padrão de representação predial definido pela Coordenadoria.

Foi montada uma comissão dentro da Coesf para definir a tecnologia a ser empregada para a gestão desse novo conjunto de dados em levantamento, somado às informações existentes.

Essa tecnologia deveria facilitar a comunicação técnica entre os diferentes atores envolvidos no gerenciamento do campus, absorver as "ilhas de conhecimento", integrar diferentes cadastros, além de permitir uma gestão centralizada dos dados, de forma a não repetir os mesmos erros cometidos em iniciativas semelhantes no passado. 
A opção pela adoção de um SIG para a gestão da CUASO foi inspirada em experiências bem sucedidas em diferentes universidades internacionais, de porte semelhante, em especial a Universidade de Minnesota, Universidade do Texas em Dallas, Universidade de Michigan e Universidade de Alicante, na Espanha.

Uma vez definido o SIG como plataforma tecnológica para o projeto Atlas, a Coesf passou a procurar alternativas comerciais para o desenvolvimento do projeto. No início do ano de 2007, o LabArq fez uma apresentação para o corpo técnico da Coesf, expondo a linha de pesquisa do Laboratório e os projetos desenvolvidos em SIG para gestão patrimonial, projetos estes alinhados com as demandas da Universidade. A experiência do Labarq, somado às vantagens da internalização do desenvolvimento de um projeto desta importância estratégica, levou à assinatura de um Convênio entre a FAU e a Coesf para o desenvolvimento do projeto Atlas.

\subsection{DESENVOLVIMENTO}

Em setembro de 2007 teve inicio os trabalhos do projeto Atlas, com o desenvolvimento de um sistema Piloto pelo Labarq, para atestar a viabilidade da plataforma proposta. O Piloto foi desenvolvido a partir do desdobramento de outro projeto realizado pelo Labarq, para a gestão patrimonial da Companhia Estadual de Engenharia de Transportes e Logísticas - Central (YURGEL, 2008; COUTO et. al., 2011).

O desenvolvimento do Piloto levou três meses, período no qual o sistema da Central foi customizado para as demandas iniciais da Coesf e sua funcionalidade estendida para manipulação e cadastro dos ambientes internos dos edifícios. No Piloto foram carregados os edifícios e o entorno da Faculdade de Filosofia, Letras e Ciências Humanas - FFLCH.

Após período de análise e validação, a solução apresentada foi aprovada e, em julho de 2008, foi assinado convênio de um ano entre a FAU e a Coesf para o desenvolvimento da primeira etapa do projeto Atlas.

No inicio do ano de 2008, a Coesf, por meio de licitação publica, contratou um levantamento topográfico para toda a área do Campus. Esse contrato foi 
rescindindo, pois não estava sendo realizado de acordo com o especificado no edital. Por questões legais e administrativas, um novo levantamento topográfico só pôde ser contratado novamente no final do ano de 2009, tendo sido entregue no final de 2010.

Dessa forma, nesta primeira etapa do projeto, a ênfase principal dos trabalhos foi no desenvolvimento do sistema de informação. Nesse mesmo período a Coesf iniciou a contratação de levantamentos prediais das unidades, que, à medida que iam sendo finalizados, eram incorporados no banco de dados do sistema. Como o novo levantamento topográfico estava em vias de contratação, não foram tratadas as áreas externas do campus, sendo utilizando o levantamento aerofotogramétrico do ano de 2000, sem maiores revisões.

Com o término da primeira etapa do projeto, em julho de 2009, o trabalho de desenvolvimento do Atlas foi interrompido, até a realização dos novos levantamentos topográficos do Campus e o levantamento predial das unidades restantes.

Em novembro de 2010, foi assinado novo convênio entre a FAU e a Coesf para a continuidade do desenvolvimento do projeto Atlas, inclusão das áreas externas e das edificações das demais unidades. Essa etapa teve duração de 14 meses, sendo finalizada em dezembro de 2011.

Ao longo das etapas do projeto, a equipe do Labarq teve diferentes configurações, mas sempre manteve a característica de multidisciplinaridade. Trabalharam no desenvolvimento do Atlas estudantes, pesquisadores e profissionais das áreas de informática, engenharia, arquitetura, geografia e biblioteconomia, entre 10 e 30 pessoas.

A seguir, são detalhadas as três principais linhas de trabalho realizadas durante o desenvolvimento do projeto.

\subsubsection{Sistema de informação}

A primeira atividade de desenvolvimento do sistema Atlas foi à realização de reuniões com as equipes técnicas dos diferentes órgãos de gestão da Universidade, para a definição dos requisitos do sistema e elaboração de casos 
de uso do sistema. A partir da definição dos casos de uso, na etapa seguinte realizada a modelagem do sistema, utilizando os padrões Unified Modeling Language - UML (Eriksson et. al., 2004) e Object-Relationship Modeling ORM (EMBLEY, 1998). O Anexo I, deste trabalho, apresenta os Casos de Uso definidos, da UML, e os Diagramas de Relacionamento dos Objetos, da ORM.

O Atlas seguiu o modelo de desenvolvimento empregado no projeto SISPAT (COUTO et. al., 2011), sendo concebido em uma arquitetura ClienteServidor baseado em Sistema Operacional Windows e Banco de Dados Microsoft SQL Server. Para o seu desenvolvimento foi utilizado a IDE Borland Delphi 2005 e o componente ESRI MapObjects, que possibilitou a exibição e interação com os mapas. A versão do banco de dados utilizado foi o Microsoft SQL Server 2005, com o módulo de banco de dados espacial ESRI ArcSDE, para armazenamento dos dados espaciais em tabelas do banco de dados relacional.

A equipe de informática do Labarq utilizou com sucesso durante o desenvolvimento do projeto técnicas de programação ágil, com programação sempre em duplas, interação constante com o usuário final (Coesf), reuniões diárias de desenvolvimento, testes automatizados, entre outras.

O sistema Atlas segue o conceito apresentado no capitulo 4 de descentralização da T.I. dentro das organizações. Segundo este conceito, o desenvolvimento de sistemas deve procurar sempre que possivel a integração com sistemas corporativos já existentes e não a sua substituição, evitando a necessidade de centralizar todos os dados e todos os processamentos, mas dividindo as informações e a lógica ao longo das linhas naturais de responsabilidade.

$\mathrm{Na}$ USP ha inúmeros sistemas especializados em uso como sistemas administrativos, de controle acadêmico, de compras, entre outros. Esses sistemas possuem uma maturidade institucional grande, com regras de negocio muito bem estabelecidas, restrição de acesso a informações entre outras particularidades. Neste tipo de cenário, a introdução de um novo sistema como no caso o SIG, deve buscar a integração com os modelos existentes e não a substituição de tecnologias, sem a necessidade de duplicação de dados, ou a tentativa de replicar funcionalidades já existentes. 
Assim, o desenvolvimento do Atlas foi concentrado na gestão do cadastro dos elementos físicos e dos espaços do campus e em ferramentas que facilitassem a integração entre esses dados cadastrais e dados de outros sistemas informatizados da Universidade.

\subsubsection{Base externa}

Conforme citado anteriormente, a falta de um mapeamento homogêneo, abrangente e atualizado das áreas externas da CUASO, era um limitador das atividades de gestão do patrimônio da Universidade. Com o objetivo de sanar esta deficiência a Coesf decidiu pela contratação de um novo levantamento planialtimétrico do campus.

No ano de 2008 foi realizada uma licitação para a contratação de um novo levantamento para toda a área do campus. Entretanto a empresa vencedora da licitação não foi capaz de cumprir os prazos nem as especificações exigidas, e o contrato foi rescindido.

$\mathrm{Na}$ tentativa de minimizar os riscos em uma nova licitação, evitando que mais tempo fosse perdido, a licitação foi dividida em quatro lotes, de 700 mil metros quadrados aproximadamente cada. Alem disso, optou-se por utilizar todos os levantamentos topográficos existentes com menos de cinco anos, excluindo o perímetro desses levantamentos da área licitada.

Essas iniciativas da Coesf contribuíram para o sucesso da nova licitação, entretanto ao final dos trabalhos a Coordenadoria possuía doze arquivos distintos, de levantamentos planialtimétricos, realizados por empresas diferentes, em momentos distintos, e sem um padrão de representação e conteúdo. A Figura 6.1 relaciona os diferentes arquivos topográficos do campus ao final da licitação (os últimos levantamentos são respectivamente os indicados pelas letras $F, G, H$ e I). 


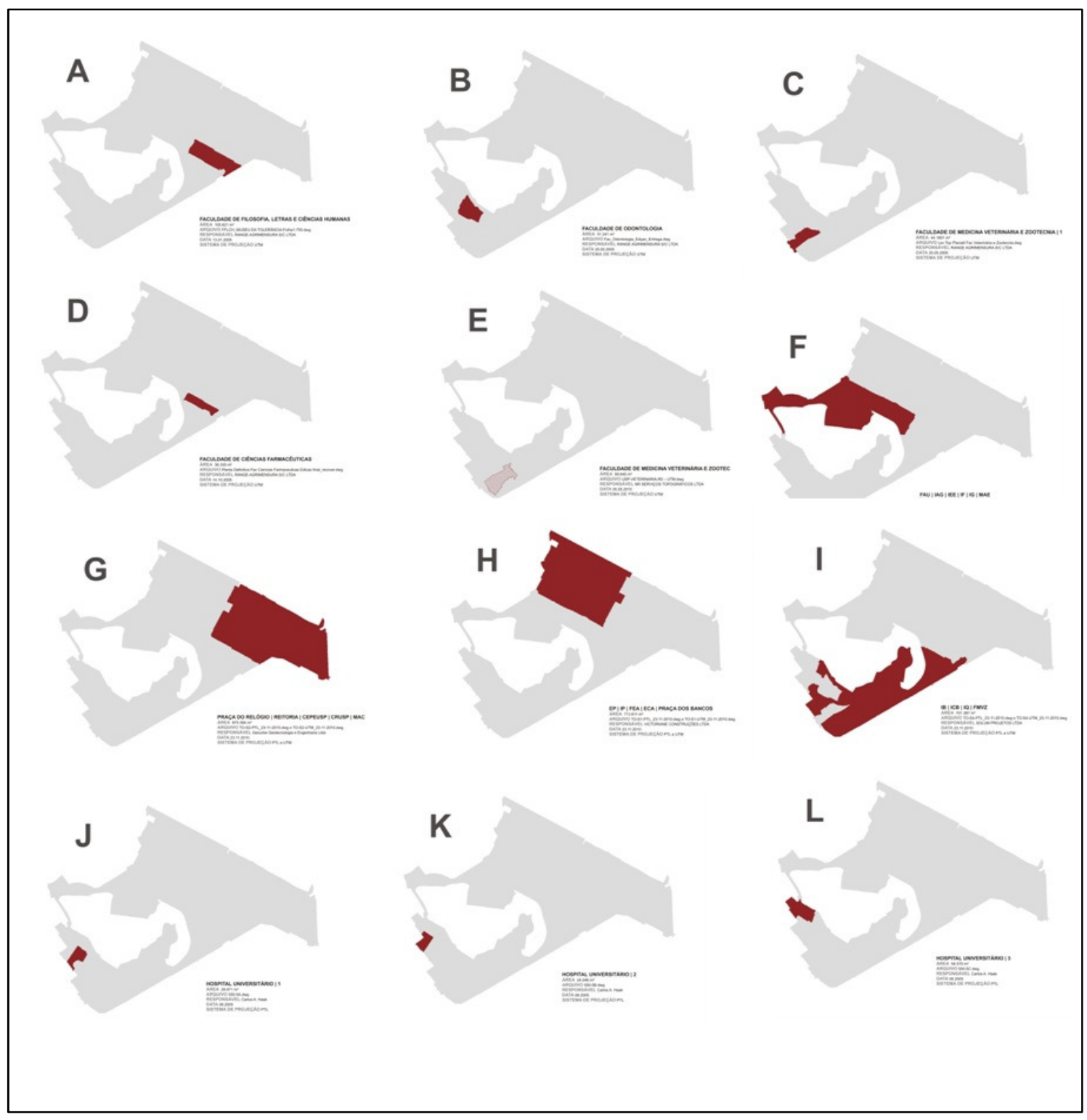

Figura 6.1 - Levantamentos planialtimétricos da CUASO, ao final de 2010.

Fonte: Labarq

Coube ao Labarq, a tarefa de consolidar esses doze arquivos CAD, em uma única base contínua, para sua posterior utilização no sistema Atlas.

Os novos levantamentos foram realizados, seguindo padronização proposta pela equipe do Labarq ainda na primeira fase do projeto, direcionado para a utilização em SIG. Este padrão de representação é composto por 145 camadas divididas em treze grupos de elementos (Edificação, Sistema Viário, Vegetação, Mobiliário Urbano, Hidrografia, Topografia, e os subgrupos de infraestrutura de Água e Incêndio, Esgoto, Drenagem, Dados e Voz, Elétrica, 
Mista e Não identificadas). A listagem completa com o padrão de camadas utilizado é apresentada no Anexo II deste trabalho.

Para facilitar a organização do trabalho de consolidação e revisão do levantamento planialtimétrico, e permitir que várias pessoas trabalhassem simultaneamente, os levantamentos foram divididos em 26 arquivos CAD menores (setores) e um arquivo geral com todo o sistema viário, conforme esquematizado na Figura 6.2.

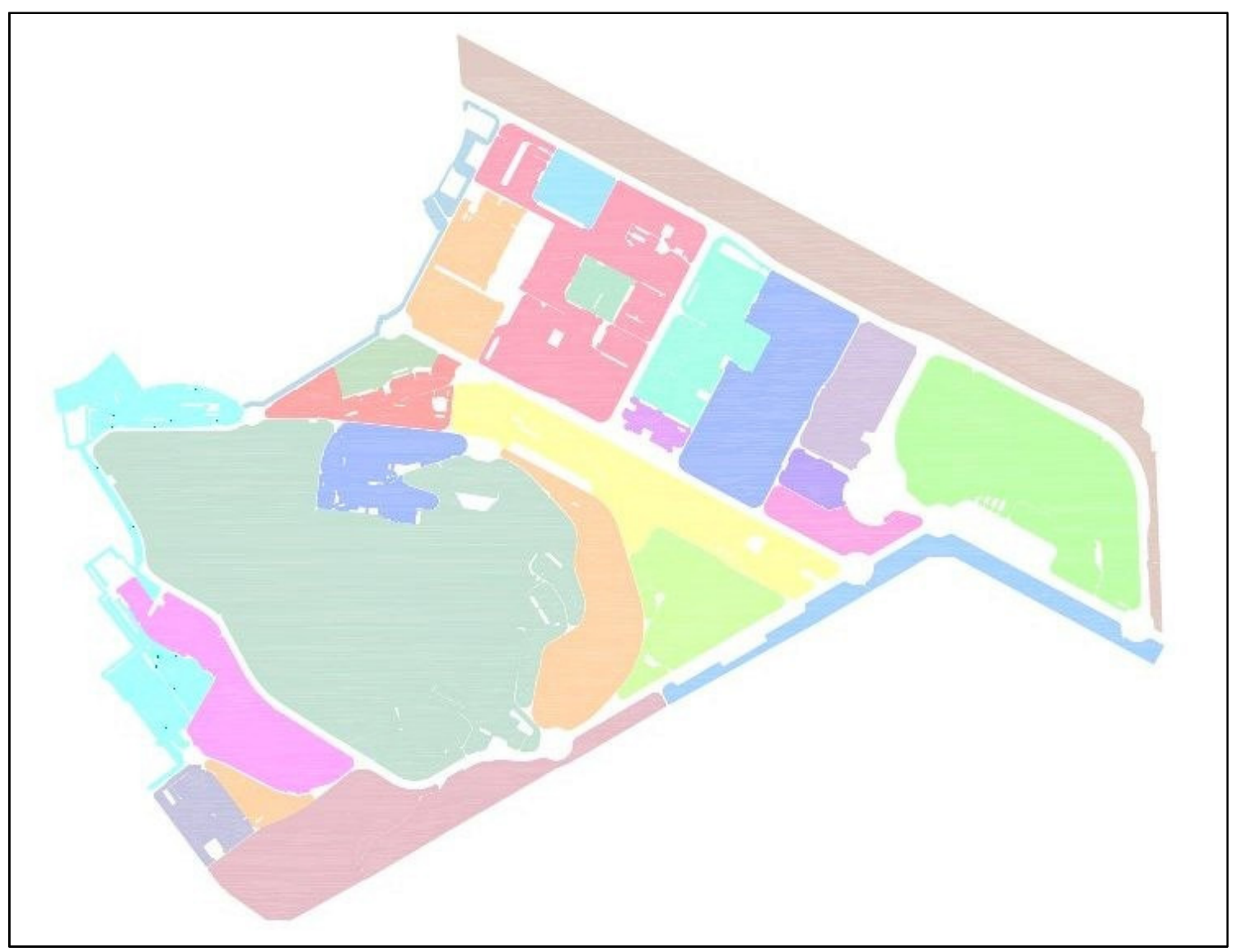

Figura 6.2 - Divisão de Trabalho dos Levantamentos (setores)

Fonte: Labarq

O tratamento dos arquivos CAD dos setores se deu em três etapas:

1- CAD Inicial - o arquivo $C A D$ de um setor era examinado, do ponto de vista estrutural, com a conferência da nomenclatura e da representação (se ponto, linha ou polígono) das camadas corrigidas, se necessário, segundo o padrão estabelecido. A seguir era realizada uma conferência e adequação de elementos 
classificados, de forma incorreta, nas camadas (elemento de guia desenhado na camada de pista, por exemplo). Elementos soltos, duplicados ou sobrepostos eram apagados ou corrigidos, e falhas (elementos descontínuos, omissões e incoerências) ou dúvidas no levantamento, eram assinaladas para conferência em campo;

2- Esclarecimentos de dúvidas em campo - uma impressão do arquivo revisto na etapa anterior era utilizada pra as conferências em campo (Figura 6.3), realizadas sempre em duplas. Nesta etapa, além da conferência das questões assinaladas na etapa anterior, a equipe de campo identificava novos erros no levantamento, incoerências no desenho e, principalmente, elementos não representados. Normalmente, os setores necessitavam de mais de uma interação entre trabalho de CAD e inspeção em campo até, a solução de todos os problemas do levantamento;

3- CAD Final - com o subsidio das informações levantadas na etapa anterior, o arquivo CAD do setor era finalizado. Atenção especial foi dada para o fechamento e continuidade dos elementos, para garantir a posterior carga dos elementos no SIG. A Figura 6.4 ilustra diferenças entre o levantamento original e após as etapas de revisão. 


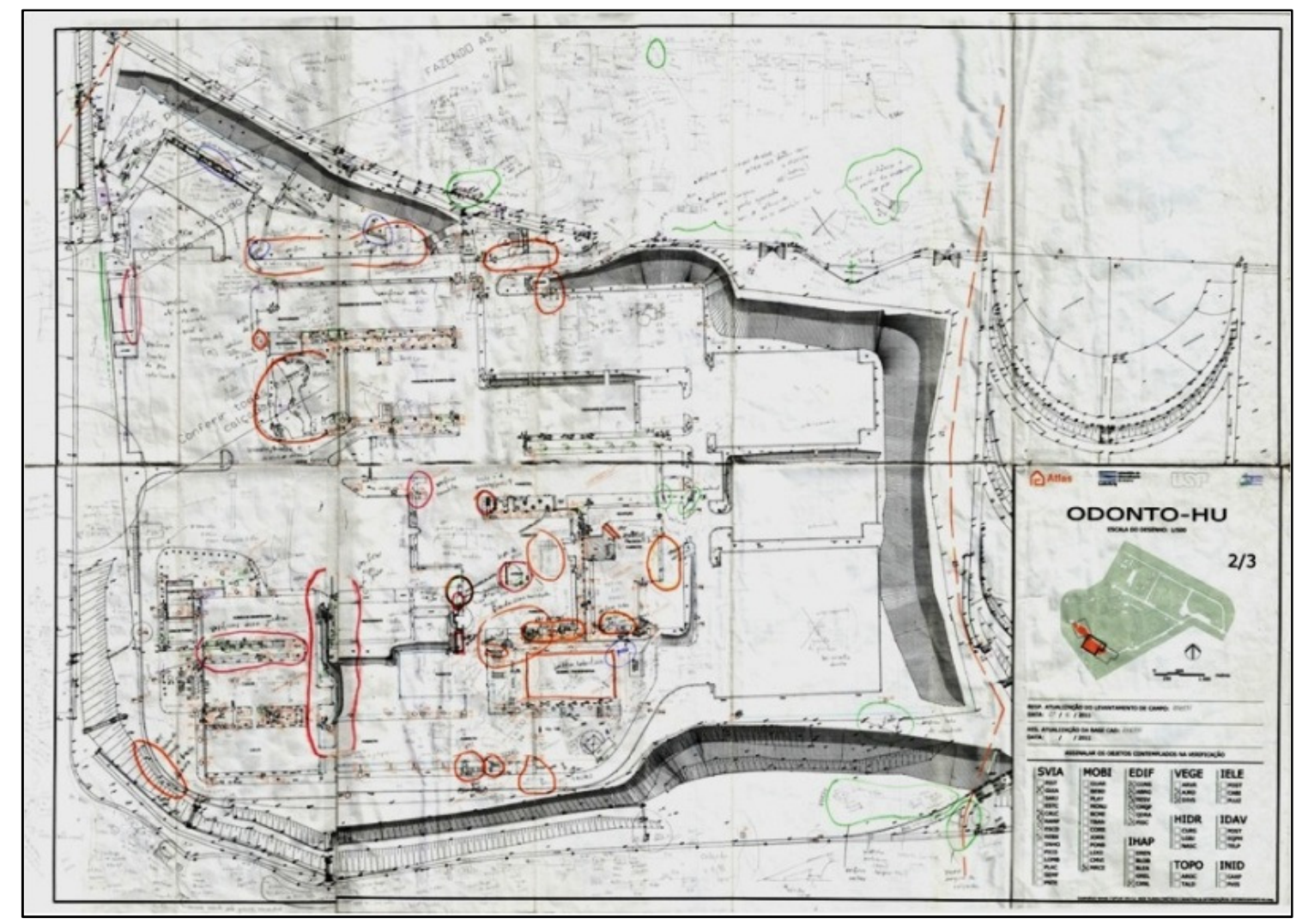

Figura 6.3 - Conferência em campo, sobre o levantamento topográfico.

Fonte: Labarq 


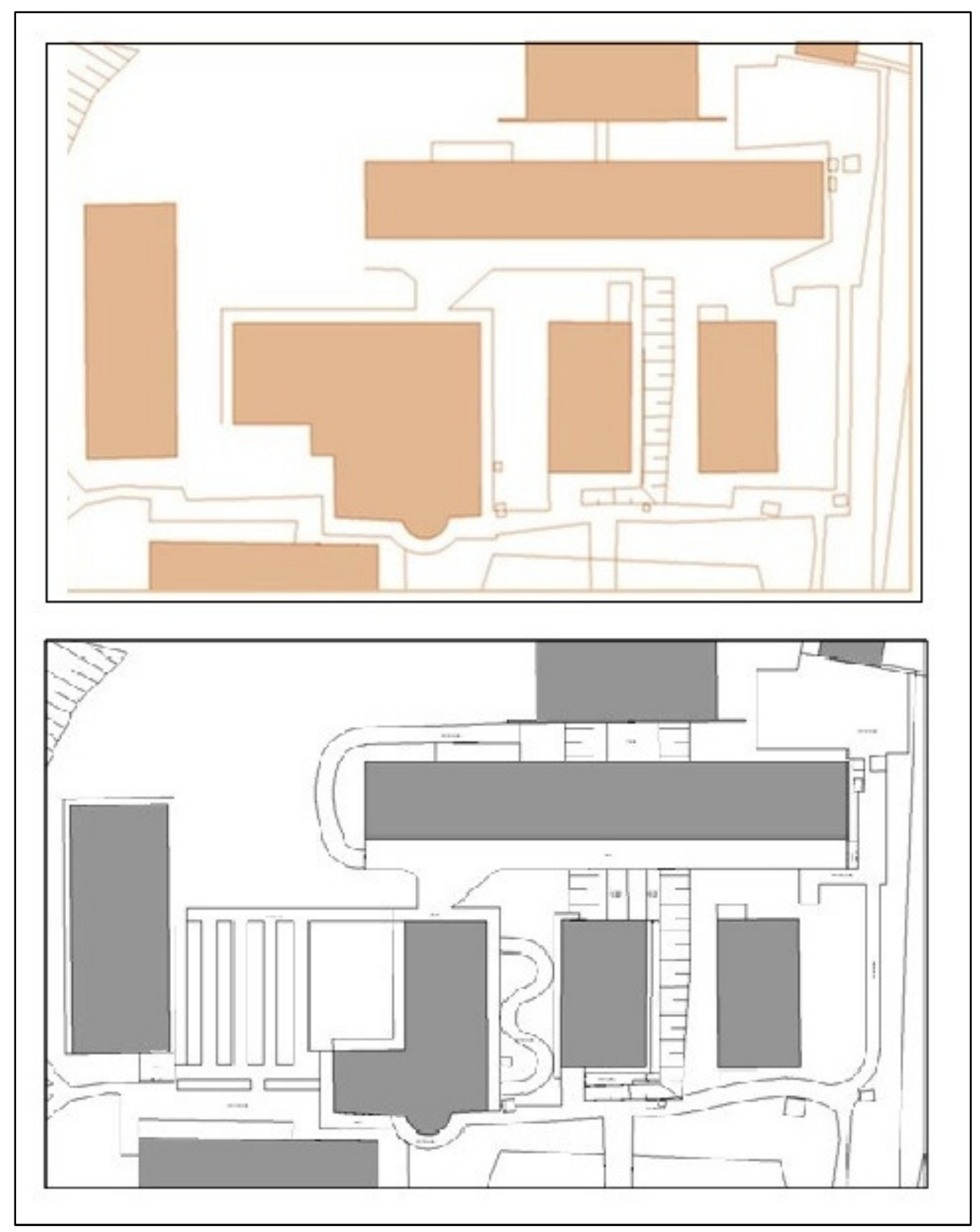

Figura 6.4 - Resultado das etapas de conferência (acima: arquivo original, abaixo: arquivo revisto) Fonte: Labarq

A revisão e unificação dos levantamentos planialtimétricos, foi uma tarefa trabalhosa e demorada, demandando grande esforço da equipe para a sua execução. Trabalharam exclusivamente para este fim, cerca de, quinze estagiários, entre estudantes de Arquitetura e Urbanismo e de Geografia, por aproximadamente um ano. Entretanto, devido aos cuidados respeitados nesta etapa do projeto, a etapa seguinte, referente a exportação dos arquivos para o 
formato (shapefile) requerido pelo SIG, para incorporação, no banco de dados do Atlas, foi extremamente facilitada.

As figuras 6.5 e 6.6 exibem o resultado da revisão e consolidação do levantamento externo do campus, já convertido para o SIG.

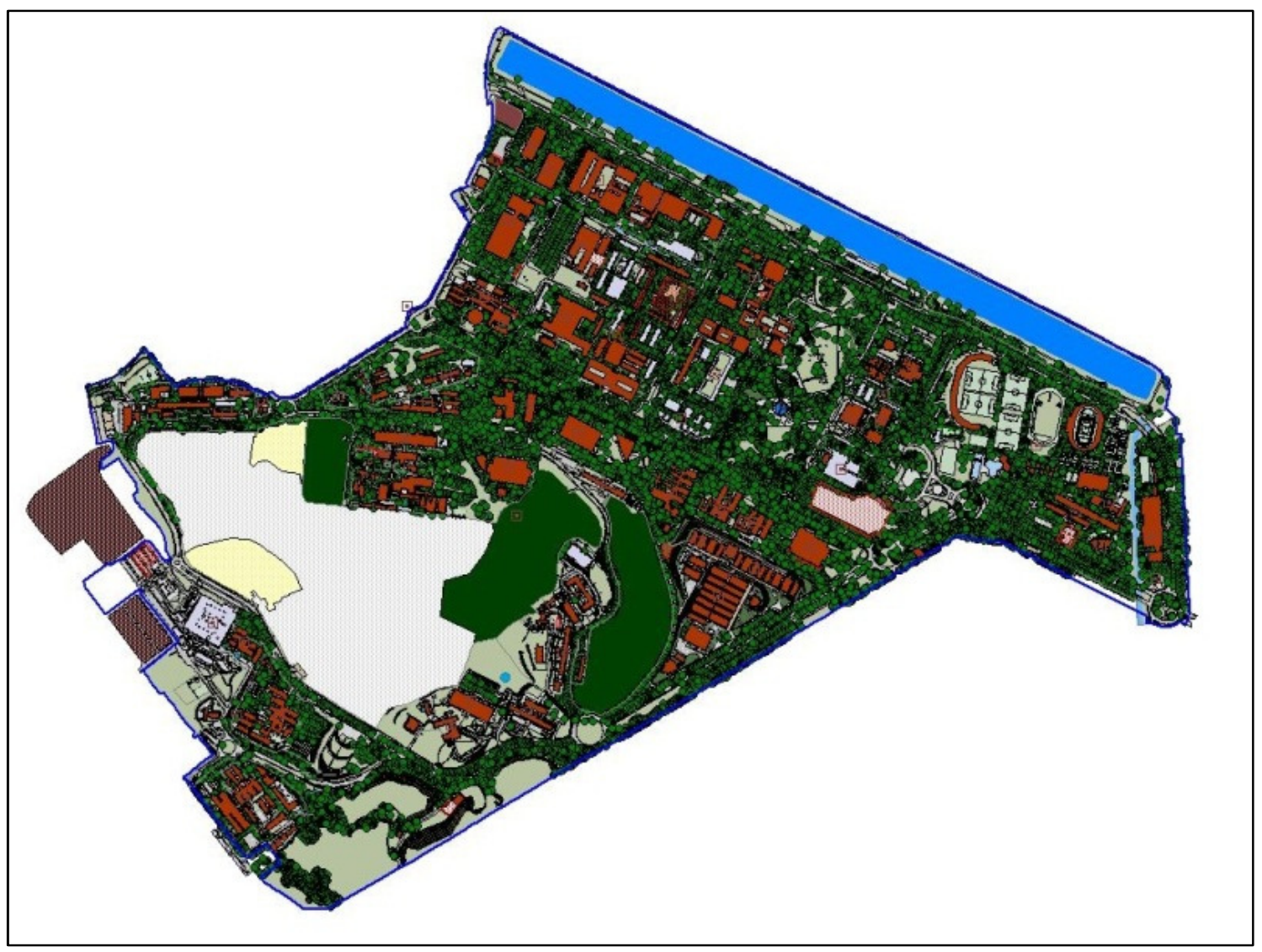

Figura 6.5 - Levantamento das áreas externas da CUASO.

Fonte: Labarq 


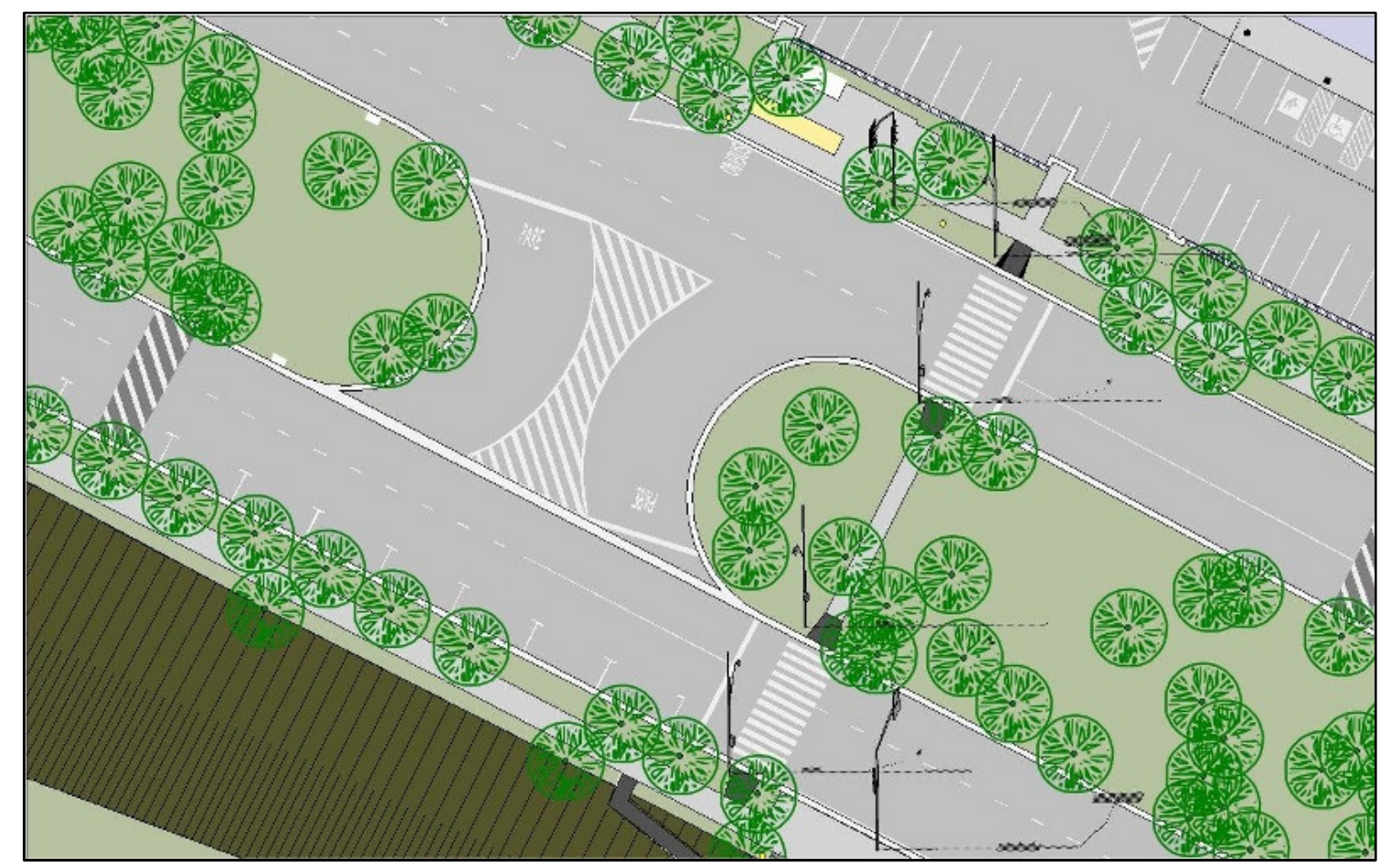

Figura 6.6 - Detalhe do Levantamento das áreas externas da CUASO.

Fonte: Labarq

\subsubsection{Cadastro predial}

O cadastro predial foi iniciado já no piloto do projeto, sendo realizado ao longo das etapas seguintes de trabalho, incorporando novas unidades à medida que os levantamentos eram finalizados.

O procedimento para a carga de um edifício do sistema também foi realizado em três etapas:

1- Tratamento CAD - um desenho antigo era inicialmente conferido in loco, e, caso necessário, atualizado. Em seguida, o desenho era simplificado, com a remoção de linhas de eixo, cotas, hachuras e outros detalhes, mantendo apenas as feições básicas da planta. Por fim, cada ambiente interno da edificação tinha seu perímetro desenhado;

2- Georreferenciamento - após o tratamento inicial, o edifício era reposicionado tendo como referencia o mapeamento externo do campus; 
3- Exportação para o SIG - o arquivo CAD era convertido para o formato (shapefile), requerido pelo SIG, e configurado para permitir sua incorporação no banco de dados do Atlas.

A Figura 6.7 ilustra as etapas descritas acima. $\mathrm{Na}$ imagem (A) a planta original da edificação em formato $C A D$, na imagem (B) a planta da edificação tratada e georreferenciada (a imagem mostra os diversos pavimentos sobrepostos)> $\mathrm{Na}$ imagem (C) o resultado da exportação de um dos pavimentos da edificação para o formato (shapefile) requerido pelo SIG. 


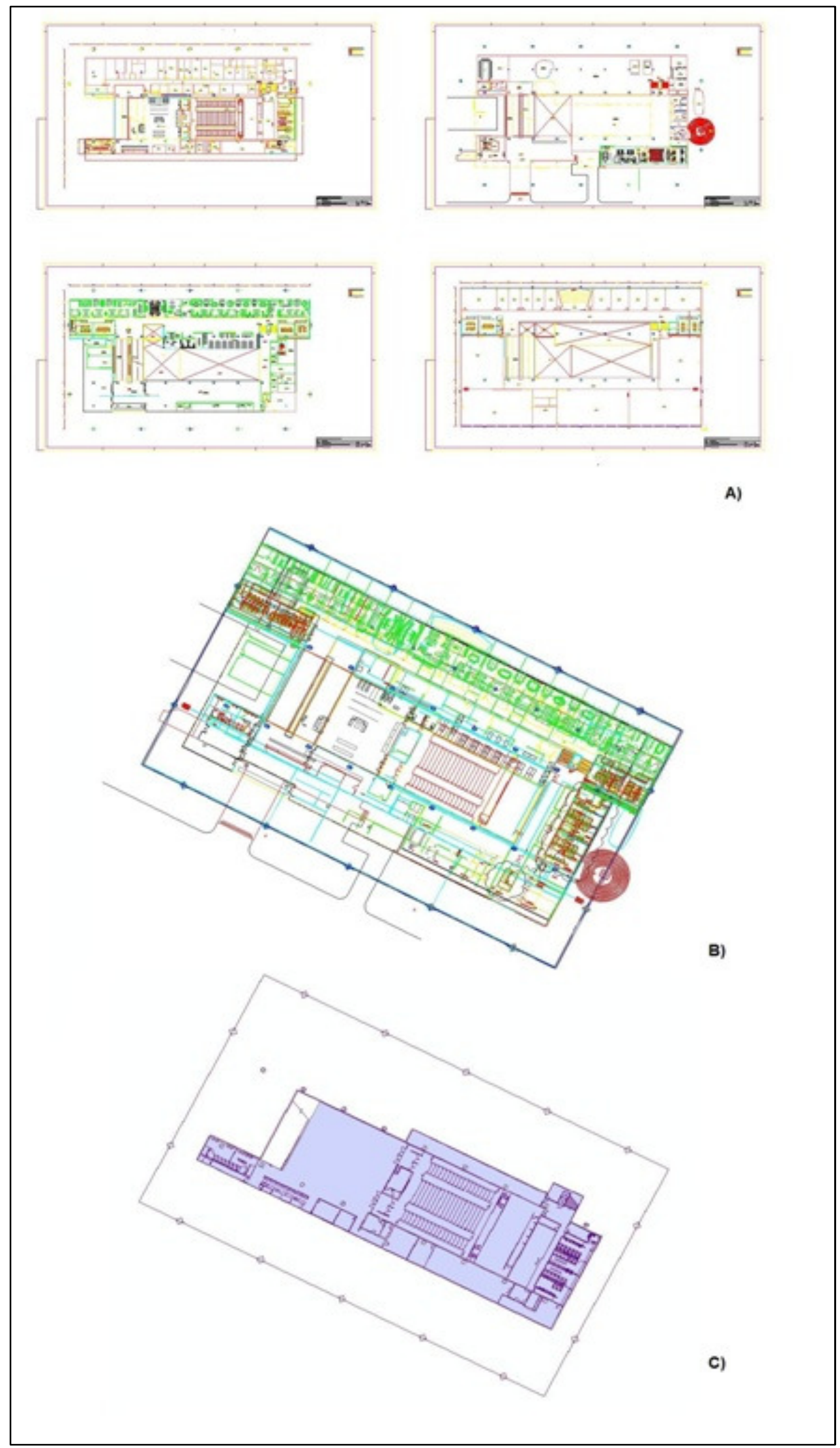

Figura 6.7 - Etapas do carregamento de desenhos de um edifício. Fonte: Labarq 
O cadastro predial se dá em dois níveis diferentes. Num primeiro nível é feito o cadastro da edificação como um todo, com dados como Nome, Uso, Endereço, Ocupante, Número de Pavimentos, Área, entre outros. No cadastro do edifício ficam associados anexos como fotografias externas, desenhos em CAD originais, planos e estudos, ou qualquer outro documento pertinente àquela construção.

A Figura 6.8 ilustra o cadastro de um edifício (Vilanova Artigas, da FAU USP), com sua representação no mapeamento externo do Campus, sua ficha de cadastro e diferentes anexos associados.

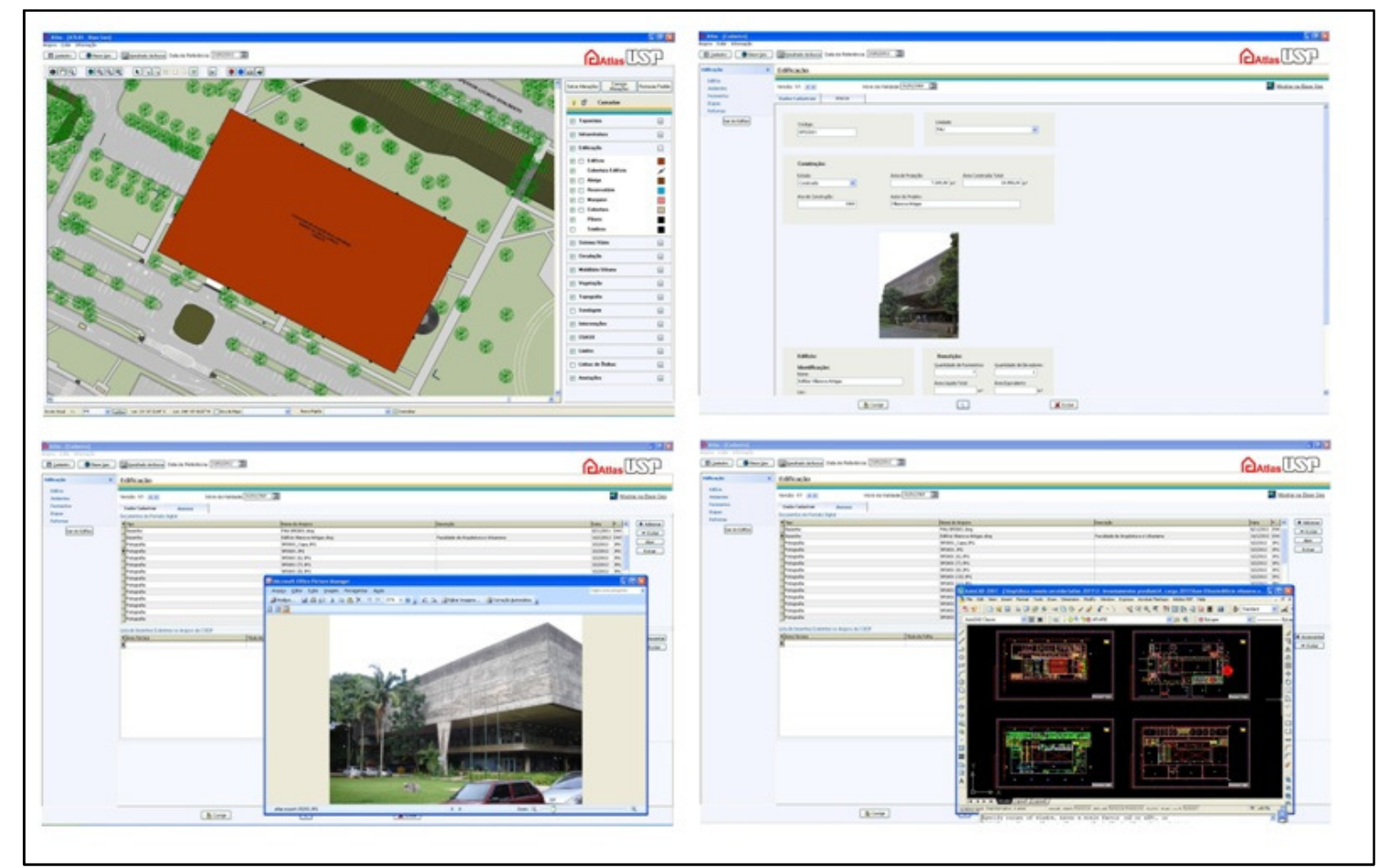

Figura 6.8 - Cadastro de um edifício no Atlas.

Fonte: Labarq

O segundo nível de cadastro predial é o dos detalhes internos das edificações, com o cadastro dos pavimentos e ambientes. O cadastro é feito individualmente, para cada ambiente interno, em uma ficha, com informações como Nome da sala, Tipo de ambiente (laboratório, sala de aula, banheiro, etc.), Uso, Área, Pé Direito, Tipo de acabamento (piso, parede e forro), mais anexos, como fotografias e outros documentos. 
A partir da representação de um edifício, no mapeamento externo do Campus, é possível acessar dados do seu interior, navegando pelos pavimentos, e pelos ambientes internos. A Figura 6.9 ilustra a navegação a partir do mapeamento externo até a ficha de cadastro de um dos ambientes internos do edifício Vilanova Artigas, da FAU USP.

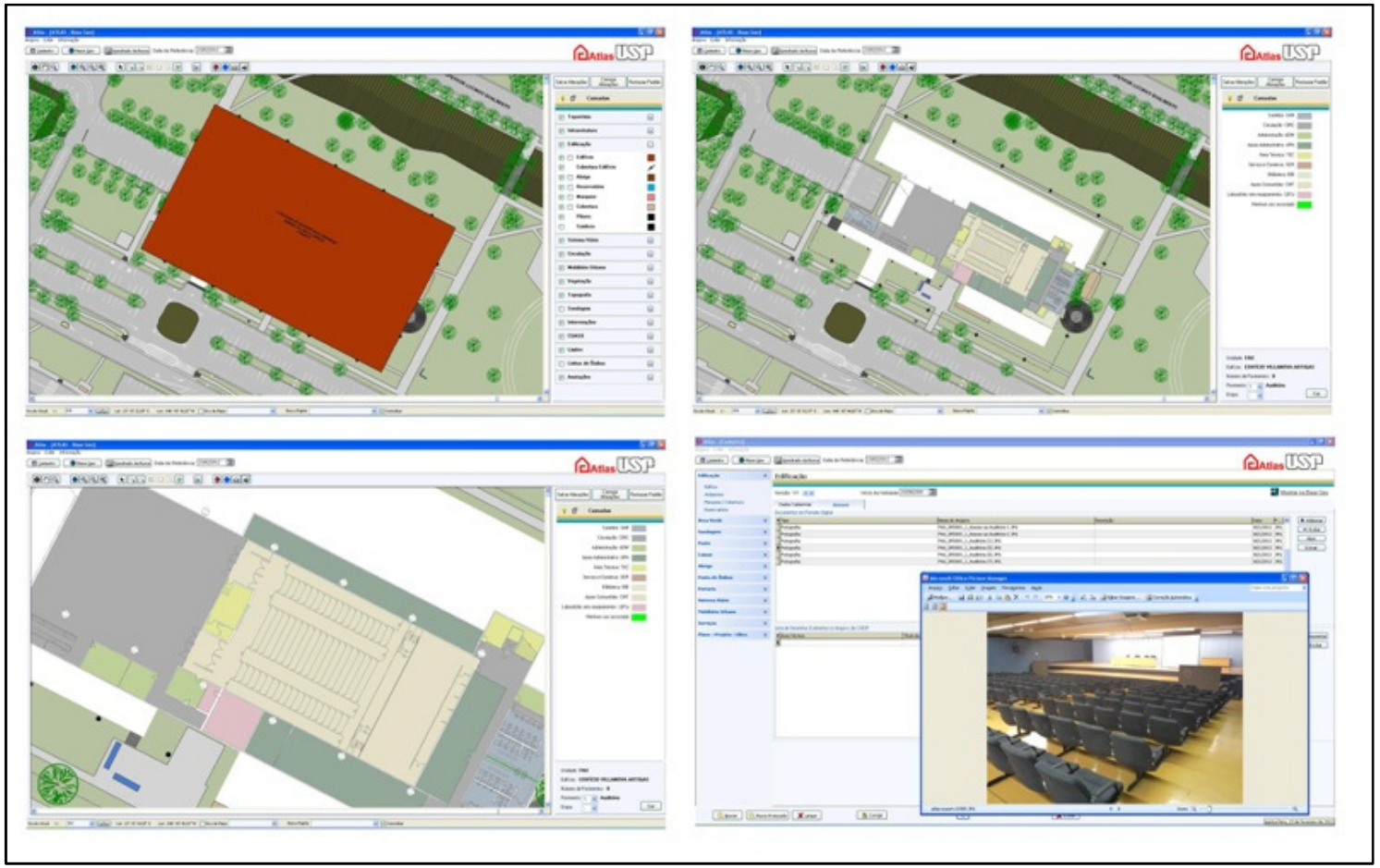

Figura 6.9 - Cadastro Interno de uma Edificação no Atlas.

Fonte: Labarq

\subsection{RESULTADOS}

Foram tratadas e cadastradas no sistema 385 Edificações (ficando de fora apenas as construções em reforma ou com projeto de demolição ou reformulação). Para tanto foram tratadas 493 plantas CAD de pavimentos, posteriormente convertidas para shapefiles e incorporadas ao sistema, permitindo o cadastro de 19.370 ambientes.

Foram anexados a este cadastro predial mais de 24 mil arquivos entre fotografias, plantas CAD e outros documentos. Esses documentos alem de consultados via interface do sistema, podem ser baixados para a maquina do 
usuário, facilitando a comunicação e a disseminação de informação entre diferentes gestores e usuários.

No mapeamento das áreas externas foi gerada uma cartografia com mais de 100 camadas de informação. Todas as superfícies do terreno (ruas, sarjetas, calçadas, gramados, jardins, escadas, rampas, estacionamentos, etc.) foram tratadas e são representadas na forma de polígonos, sem sobreposições ou vazios. Dessa forma a consulta sobre a área de qualquer um desses elementos é instantânea e exata, facilitando muito o calculo e planejamento de serviços como podas, recapeamentos, manutenção de calçadas, entre outros.

Informações que até então ficavam arquivadas, com difícil acesso estão disponíveis para consulta como todos os planos, projetos e obras do campus ou como, por exemplo, o histórico de todos os estudos de sondagem já realizados na CUASO, com o mapeamento na base de 1.261 pontos de sondagem, e os respectivos laudos e perfis digitalizados em anexos.

Com exceção das três áreas de preservação permanente do campus (bosques da Biologia, Física e Lago), todas as árvores do campus (mais de 23 mil) foram mapeadas e incorporadas ao sistema alem de receberem uma plaqueta de identificação individual. Isso facilitará o planejamento de podas, o controle de pragas e doenças, o estudo de compensações ambientais entre outras.

Um dos grandes problemas do campus esta relacionado ao risco em escavações devido ao pouco conhecimento do traçado das redes subterrâneas de infraestrutura (eletricidade, fibra ótica, gás, água, esgoto e drenagem). $\mathrm{Na}$ busca por sanar esta questão e aprimorar o cadastro existente da infraestrutura enterrada, foram levantadas todas as estruturas de superfície das redes como caixas, abrigos, poços de visita, grelhas, ralos, boca de lobos, etc. Alem do mapeamento dos mais de 15 mil elementos de superfície, estes sempre que possíveis foram abertos para o registro das informações internas e registro das ligações existentes (posição, cota, diâmetro, sentido de escoamento, quantidade de fios, etc.). Juntando essa informação do interior das caixas e poços de visita com o mapeamento externo, é possível estimar o traçado das redes (Figura 6.10). 


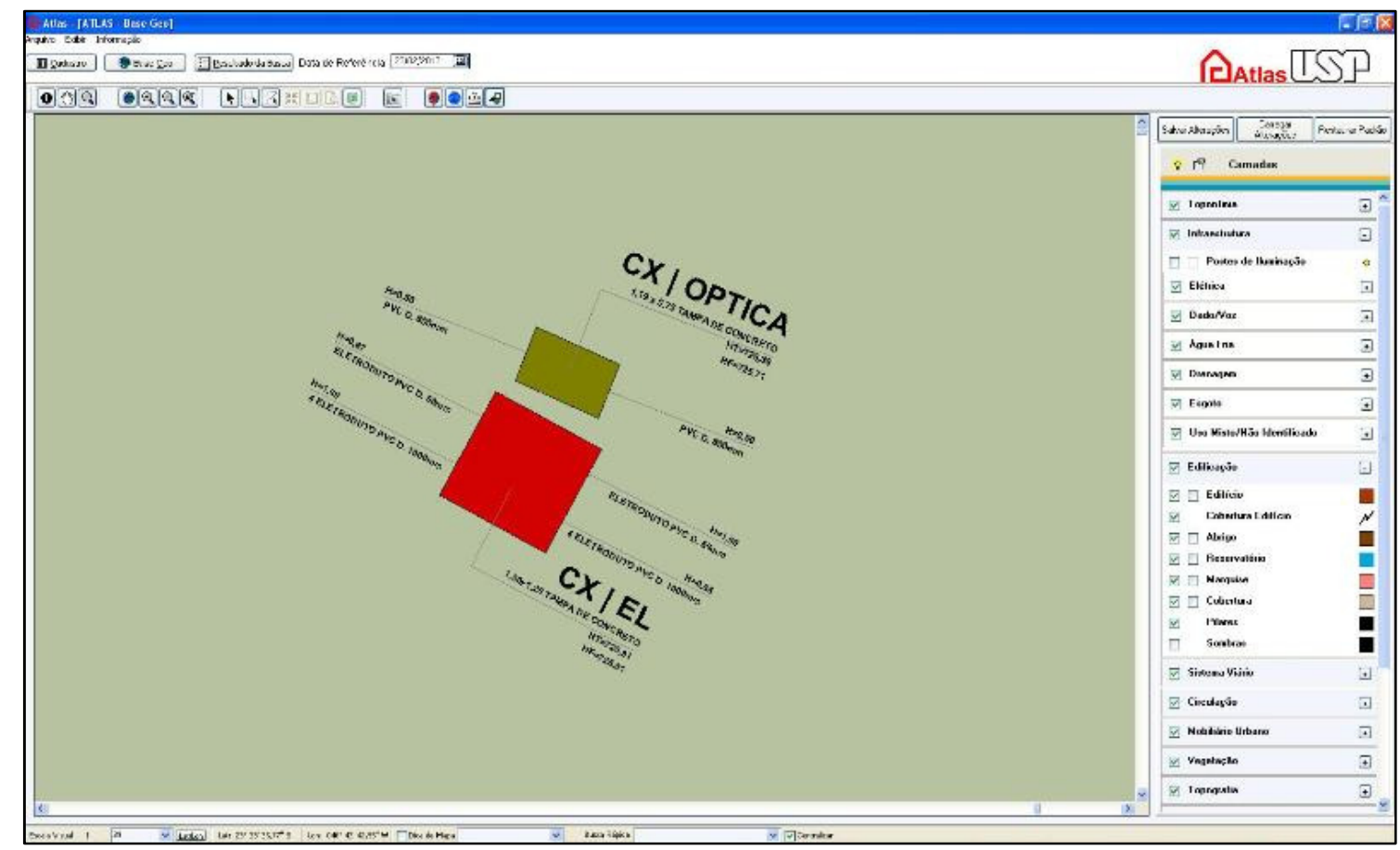

Figura 6.10 - Cadastro das Redes de Infraestrutura no Atlas.

Fonte: Labarq

O sistema já se encontra disponível para os técnicos da Coesf, COCESP e CCE e em breve será disponibilizado para o acesso pelas unidades de ensino.

As funcionalidades presentes no Atlas, combinadas com o conjunto de dados produzido da CUASO permitem o apoio as seguintes operação de gestão patrimonial:

- Planejamento - apoio no planejamento das mais variadas atividade: grandes e pequenas intervenções, ampliações, reformas, segurança, transporte, meio ambiente, entre outras;

- Gerenciamento de espaços - maior transparência e eficácia na distribuição de verbas de operação e manutenção predial baseada no diagnostico completo produzido da ocupação do campus;

- Planejamento e Adequação de espaços - maior eficiência do uso dos espaços internos, combinando dados prediais com dados de sistemas acadêmicos e de recursos humanos; 
- Inventario - identificação, classificação e localização dos bens de propriedade da Universidade;

- Manutenção e operação - suporte à manutenção e operação de edifícios e áreas externas, com integração a outros sistemas especializados;

- Gerenciamento de infra-estrutura - integração do cadastro dos sistemas prediais com as redes externas de serviço e infraestrutura; 


\section{CONSIDERAÇÕES FINAIS}

Os casos apresentados neste trabalho, tanto da bibliografia como da experiência prática do autor, evidenciaram os benefícios do uso do SIG em aplicações de gerenciamento predial e patrimonial.

O SIG é uma tecnologia consolidada no gerenciamento de bens patrimoniais, em especial no setor de infraestrutura (saneamento, telecomunicações, eletricidade, transporte), onde os bens são distribuídos ao longo de grandes extensões territoriais. O relato apresentado no Capítulo Três deste trabalho, sobre o SIG, intitulado SISPAT, desenvolvido para a Companhia Estadual de Engenharia de Transportes e Logística - CENTRAL é um exemplo deste tipo de aplicação.

A utilização dos SIG no gerenciamento predial, apesar de ser uma prática mais recente, vem se desenvolvendo há, pelo menos, uma década com diversos exemplos de aplicação e bibliografia sobre o tema.

No Capítulo Quatro foram apresentados os conceitos básicos da teoria de Gerenciamento de Facilidades, ou facility managment (FM). Esta é uma disciplina multidisciplinar, que objetiva a elevação do desempenho do edifício, como um todo, por meio da integração das pessoas aos espaços e processos da organização, envolvendo todos os recursos corporativos de uma organização como a área de recursos humanos, da tecnologia da informação, de finanças e assessoria jurídica.

A proposta de aplicação do SIG não pretende responder a todas essas demandas, mas combinar, sempre que possível, as técnicas de gestão do FM, com as ferramentas próprias do SIG, em especial sua capacidade de visualização e análise espacial, para auxiliar em atividades de planejamento, gerenciamento e adequação de espaços, inventário, manutenção e operação.

Uma vez superada as barreiras tecnológicas que dificultavam a incorporação dos ambientes construídos em um SIG, o uso desta tecnologia no gerenciamento predial vem se consolidando. As ferramentas de análise espacial e de visualizações, próprias do SIG, permitem uma abordagem nova no gerenciamento interno dos edifícios. 
A proposta apresentada neste trabalho do uso do SIG para gerenciamento predial, não busca substituir ferramentas tradicionais deste setor como o CAD ou CAFM, mas agregar o SIG e suas ferramentas exclusivas a este processo, se beneficiando do melhor de cada tecnologia.

O SIG ainda não é capaz de operar no mesmo nível de ferramentas CAD ou BIM, que modelam detalhes de elementos construtivos, equipamentos $\mathrm{e}$ instalações. Por outro lado, o SIG é capaz de gerir grandes volumes de dados, em diferentes localidades geográficas num mesmo ambiente. No estado atual da tecnologia, o atendimento a ambas as premissas, a gestão de grandes volumes de dados, distribuídos espacialmente, e que ao mesmo tempo torne acessíveis detalhes menores das edificações, requer o uso integrado dessas duas tecnologias.

O gerenciamento integrado de bens patrimoniais e prediais é uma atividade menos difundida. A bibliografia do tema é escassa, assim como o relato de experiências práticas, embora existam algumas iniciativas nesta linha conforme apresentado no Capítulo Cinco deste trabalho.

Atualmente, o setor que mais se destaca na adoção do SIG para a gestão integrada de seu patrimônio é o das universidades, instituições que muitas vezes possuem uma grande infraestrutura urbana, e um denso acervo predial. Contribui ainda o fato de nesse cenário, a administração dos dois segmentos o predial e o patrimonial - estar sob a responsabilidade do mesmo gestor, fato normalmente não encontrado em outros segmentos, e que possivelmente até dificulta sua gestão integrada.

No desenvolvimento do projeto Atlas, apresentado no Capítulo Seis, deste trabalho, se verificou muitas das ocorrências citadas em bibliografia.

Projetos dessa natureza criam muita resistência entre o corpo técnico da instituição. A perspectiva de um sistema novo, com uma tecnologia nova que 0 gestor não domina e que promete tornar transparente o acesso às informações, gera certa insegurança. Há a sensação de perda de poder e controle sobre um conjunto de dados até então restrito a seu grupo, com a possibilidade de ter seu trabalho avaliado por terceiros e de ter de se adequar a novos fluxos de trabalho. 
Outra ocorrência comum a ser contornada, é o excesso de expectativas gerado sobre um novo sistema de informação. É comum sistemas informatizados serem superestimados, imaginando que uma ferramenta possa resolver todos os problemas da organização.

Para tanto é indispensável que a fase de levantamento de requisitos do sistema, com a descrição de Casos de Uso (da UML), que sustentem a modelagem do sistema seja muito criteriosa, não se deixando levar pela tentação de "abraçar o mundo". Todos envolvidos (desenvolvedores e usuários) devem concordar formalmente com, desde o início, o que é esperado do sistema, o que ele irá efetivamente fazer.

O mesmo critério deve ser usado em relação aos dados alimentados no sistema, pois para toda informação há um custo de levantamento e tratamento associado, mas acima de tudo há o custo de manutenção dessa informação, fator muitas vezes negligenciado. Um sistema com informações desatualizadas ou incorretas gera desconfiança e perda de credibilidade entre os usuários. Apenas dados que possam ser mantidos e que se justifiquem no contexto da operação devem ser incorporados.

No caso de uma Universidade, como, por exemplo, a USP, dada sua complexidade, a responsabilidade pela manutenção das informações, num SIG, como o Atlas, é de cada usuário desse sistema. A gestão física e cadastral (no Atlas) da rede de informática da USP, no CUASO, é responsabilidade do Centro de Computação Eletrônica - CCE. A gestão das demais redes de infraestrutura e de transportes é da Coordenadoria do Campus da Capital - COCESP. A gestão predial, dos espaços físicos internos e das áreas externas é da Coordenadoria de Espaços Físicos - COESF. Sem essa divisão de competências, em fase inicial na USP, o Atlas não alcançará seu potencial de suporte à gestão.

Se o uso do Atlas for estendido para os demais Campi, os respectivos órgãos gestores dividirão as responsabilidades e os benefícios do seu uso. No caso da gestão predial, caberá a cada Unidade Administrativa da USP, o gerenciamento físico e cadastral de suas facilidades. O início desta etapa 
dependerá do sucesso da anterior, acima descrita. Também irá requerer mudanças nos procedimentos administrativos nas unidades, pelo comprometimento institucional do uso e da manutenção (dentro de sua competência) do sistema.

Outro fator crítico de sucesso é a integração do SIG com os demais sistemas administrativos informatizados da Universidade - Recursos Humanos, Graduação e Pós-Graduação, Compras, etc. No caso da USP, essa integração é realizada por meio da integração dos esquemas lógicos de seus bancos de dados, em aplicações de relatórios gerenciais. A operação desses sistemas é independente entre $\mathrm{si}$, mas os gestores têm acesso a ferramentas que Ihes permitem produzir os relatórios personalizados segundo suas necessidades, com dados oriundos de mais de um sistema. 


\section{REFERÊNCIAS BIBLIOGRÁFICAS}

ALEXANDER, K. (Ed.). Facilities management: theory and practice. London: E\&FN SPON, 1999.

ANTONIOLI, P. E.; GRAÇA, M. E. A. Subsídios conceituais para o planejamento de sistemas de gerenciamento de facilidades em edificações produtivas. São Paulo: EPUSP, 2004. 26 p. (Série Boletim Técnico da Escola Politécnica da USP, BT/PCC/358).

ANTONIOLI, P. E. Estudo crítico sobre subsídios conceituais para suporte do planejamento de sistemas de gerenciamento de facilidades em edificações produtivas. 2003. 241 p. Dissertação (Mestrado em Engenharia) - Escola Politécnica da Universidade de São Paulo, São Paulo, 2003.

ASSOCIAÇÃO BRASILEIRA DE NORMAS TÉCNICAS. NBR 9050:

Acessibilidade de pessoas portadoras de deficiências a edificações, espaço, mobiliário e equipamento urbano. Rio de Janeiro, 1994.

BARRETT, P. Facilities management: towards best practice. Oxford: Blackwell Science Ltd., 1995.

BLITZKOW, D.; NETTO, N. P.; QUINTANILHA, J. A. Fundamentos de informações espaciais. São Paulo, 2004. Notas de aula da disciplina PTR 5003, do Programa de Pós-Graduação em Engenharia de Transportes da Escola Politécnica da Universidade de São Paulo. Não publicado.

BOLSTAD, P. GIS fundamentals. 3 ed. Eider Press: White Lake, Minnesota, 2009.

CÂMARA, G. Modelos, linguagens e arquiteturas para bancos de dados geográficos, 1995. 264 p. Tese (Doutorado) - Instituto de Pesquisas Espaciais - INPE, São José dos Campos, 1995. 
CÂMARA, G; BARBOSA, C; CORDEIRO, J. P.; LOPES, E.; de FREITAS, U. M.; LUCENA, I. Álgebra de mapas. p. 8.1 - 8.30. In: CÂMARA, G.; DAVIS, C.; MONTEIRO, A. M. V. (Eds.) Introdução à ciência da geoinformação. São José dos Campos: Instituto de Pesquisas Espaciais- INPE, 2004.Disponível em: <http://mtcm12.sid.inpe.br/col/sid.inpe.br/sergio/2004/04.22.07.43/doc/publicacao.p df> Acesso em: 20 de fevereiro de 2012.

CÂMARA, G; MONTEIRO, A. M. V. Conceitos básicos em ciência da geoinformação, p. 2.1 - 2.35. In: CÂMARA, G.; DAVIS, C.; MONTEIRO, A. M. V. (Eds.) Introdução à ciência da geoinformação. São José dos Campos: Instituto de Pesquisas Espaciais- INPE, 2004.Disponível em: $<$ http://mtcm12.sid.inpe.br/col/sid.inpe.br/sergio/2004/04.22.07.43/doc/publicacao.p df> Acesso em: 20 de fevereiro de 2012.

CARSTENSEN, L. W. Regional land information systems development using relational databases and geographic information systems. Proceedings, Auto Carto, London, 1986, p. 507-516.

COUTO, R. A. S.; GIACAGLIA, M. E.; YURGEL, M. SISPAT - Sistema informatizado de gestão patrimonial em base georreferenciada. In: Congresso Brasileiro de Transporte e Trânsito, 18., 2011, Rio de Janeiro. Anais... Rio de Janeiro, 2011, p. 857-865.

COTTS, D. G. The facility management handbook. New York: Amacom, 1999.

COWEN, D. J. Gis versus CAD versus DBMS: what are the differences? Photogrametric Engineering and Remote Sensing, v. 54 n. 11 p.1551-1555, 1988.

CPCON. A gestão patrimonial e a racionalização da gestão de ativos. 2010. Disponível em: < http://www.cpcon.eng.br/gestaopatrimonial/gestao-e-financas/racionalizacao-gestao-ativos/>. Acesso em: 02 de junho de 2011. 
DAVIS, C.; CÂMARA, G. Arquitetura de sistemas de informação geográfica, p. 3.1 - 3.35. In: CÂMARA, G.; DAVIS, C.; MONTEIRO, A. M. V. (Eds.) Introdução à ciência da geoinformação. São José dos Campos: Instituto de Pesquisas Espaciais- INPE, 2004. Disponível em: $<$ http://mtcm12.sid.inpe.br/col/sid.inpe.br/sergio/2004/04.22.07.43/doc/publicacao.p df> Acesso em: 20 de fevereiro de 2012.

DAVIS JR., C. A.; FONSECA, F. T. Geração de dados em CAD para uso em GIS: precauções. In: GIS Brasil'94, Seção SIG e Conversão de Dados, 1994, Curitiba. Anais... Curitiba, 1994. p. 43-47.

EMBLEY, D. W. Object database development: concepts and principles. Reading, Massachusetts: Addison-Wesley Longman, 1998.

ERIKSSON, H-E.; PENKER, M.; LYONS, B.; FADO, D. UML 2 toolkit. Indianapolis: Wiley Publishing, 2004.

ESRI. Building interior space data model (BISDM) framework document, 2008. Disponível em: <http://bisdm.org/downloads/ESRI Building Interior Space Data Model -- Framework Document_R02_PenBayComments.htm>, Acesso em: 10 de setembro de 2010.

ESRI. Space utilization optimization,2009. Disponível em:

<http://www.esri.com/library/whitepapers/pdfs/space-utilization.pdf>, Acesso em: 20 de fevereiro de 2012.

ESRI. Enterprise GIS takes off at Phoenix Sky Harbor International, 2010. Disponível em: <http://www.esri.com/news/arcnews/spring10articles/enterprisegis.html>, Acesso em: 20 de fevereiro de 2012.

FORTES, M. Sistema de informação geográfica na gestão do cadastro urbano municipal aplicado ao município da praia, 2007. 241 p. Dissertação (Mestrado em Ciências e Sistemas de Informação Geográfica) - Instituto Superior de Estatística e Gestão de Informação da Universidade de Nova Lisboa, 2007. 
GARVEY, B. Developing asset inventory GIS databases. 2003. Trabalho apresentado ao Florida Joint Mapping Conference, Fort Lauderdale, 2003.

GOFFIGON, L. Strategic Planning. In: TEICHOLZ, E. Facility design and management handbook, New York: McGraw-Hill, 2001. p. 3.1-3.21.

GONÇALVES, O. M. Qualidade de sistemas prediais. São Paulo, 1999 Notas de aula da Disciplina PCC 5715, do Programa de Pós-Graduação em Engenharia Civil da Escola Politécnica da Universidade de São Paulo. Não publicado.

GONDECK-BECKER, D. Implementing an enterprise-wide space management system: a case study at the University of Minnesota, 1999. Trabalho apresentado ao ESRI User Conference, 19., San Diego, 1999. Disponível em:

$<$ http://proceedings.esri.com/library/userconf/proc99/proceed/papers/pap 532/p532.htm >. Acesso em: 20 de fevereiro de 2012.

JORDANI, D.; GONDECK-BECKER, D. GIS case study: space management at the University of Minnesota. In: TEICHOLZ, E. Facility design and management handbook. New York: McGraw-Hill, 2001. p. 30.1-30.14

KINDRACHUK, G. Integration of asset management and GIS. 2001. Disponível em <http://www.gisdevelopment.net/proceedings/gita/2001/tat/techgi088.shtml>, Acesso em: 20 de fevereiro de 2012.

LEMER, A. C. Progress toward integrated infrastructure-assets-management systems: GIS and beyond. In: APWA International Public Works Congress, Las Vegas, 1998. NRCC/CPWA Seminar Series: Innovations in Urban Infrastructure, Las Vegas, 1998, p. 7-24.

LEWIS, B. T. Facility manager's portable handbook. New York: McGraw-Hill, 1999.

NASA. Building data management in GIS space utilization \& optimization, 2007. Disponível em <http://bisdm.org/files/library/downloads/NASALaRC_BISDM_Kickoff.pdf>, Acesso em: 20 de fevereiro de 2012. 
OLIMPIO, J.; SMITH, D. Location, location, location - improve asset management by taking GIS inside the building, 2009. Disponível em: <http://www.esri.com/partners/alliances/ibm/pdfs/location3_ibm.pdf>, Acesso em: 8 de fevereiro de 2012.

QUINTANILHA, J. A. Sistemas de informação geográficas I. São Paulo, 2005. Notas de aula da disciplina PTR 5741 do Programa de PósGraduação em Engenharia de Transportes da Escola Politécnica da Universidade de São Paulo. Não publicado.

QUINTANILHA, J. A. Conversão e modelagem de dados espaciais. EPUSP: São Paulo, 1996. Apostila de mini-curso.

RAMLAL, B. Using GIS for asset management in Trinidad and Tobago. Journal of the Association of Professional Engineers of Trinidad and Tobago, v. 36, n. 1, p. 16-21, 2005.

$\mathrm{RICH}, \mathrm{S}$. Looking through the walls. 2009. Disponível em: < http://www.esri.com/industries/facilities-management/pdfs/stu-rich.pdf>. Acesso em: 10 de setembro de 2010.

RICH, S.; DAVIS, K.H. Geographic information systems (GIS) for facility management. 2010. Disponível em:

<http://www.ifmafoundation.org/documents/public/GIS_WP_FINAL.pdf>, Acesso em: 8 de fevereiro de 2012.

RODRIGUES, M. Geoprocessamento. 1987. 347 p. Tese (Livre docência) EPUSP - Escola Politécnica da Universidade de São Paulo, São Paulo, 1987.

RODRIGUES, M. Sistemas de informações geográficas. In: Programa de Transferência de Tecnologia GIS, v. 2, apostila e CD-rom. Convênio EPUSP /SABESP, São Paulo, 1998.

RODRIGUEZ, H. S. A formação das estradas de ferro no Rio de Janeiro: o resgate da sua memória. Rio de Janeiro: Sociedade de Pesquisa para Memória do Trem, 2004. 
SRIVASTAVA, A.; WELLINGTON B. GIS-based facility information management systems: an evolving success story. 2005. Trabalho apresentado ao ESRI User Conference, 25., San Diego, 2005.

Disponível em:

$<$ http://proceedings.esri.com/library/userconf/proc05/papers/pap1910.pdf >, Acesso em: 8 de fevereiro de 2012.

TARDIE, P. S.; FORTIER, R.W.; LISICHENKO, P. The benefits and challenges of integrating a geographic information system (GIS) into facilities management at the University of New Hampshire. 2003. Trabalho apresentado ao ASPRS Annual Conference, Anchorage, 2003.

USP. USP em números (base de dados 2010). 2011. Disponível em:

<http://www.usp.br/usp-em-numeros>, Acesso em: 22 de fevereiro de 2012.

USP. USP COESF - apresentação. 2007a. Disponível em:

$<$ http://www.coesf.usp.br/apresentacao/>, Acesso em: 22 de fevereiro de 2012.

USP. USP COESF - atividades. 2007b. Disponível em:

$<$ http://www.coesf.usp.br/atividades/>, Acesso em: 22 de fevereiro de 2012.

USP. COCESP - história. 2012a. Disponível em:

<http://www.usp.br/cocesp/index.php?p=historia>, Acesso em: 22 de fevereiro de 2012.

USP. COCESP - campus hoje. 2012b. Disponível em:

<http://www.usp.br/cocesp/index.php?p=38\&f=177>, Acesso em: 22 de fevereiro de 2012.

USP. CCE - institucional - o que fazemos. (2012c). Disponível em: <http://www.cce.usp.br/?q=node/77>, Acesso em: 22 de fevereiro de 2012. 
VARCOE, B. The disruptive impact of Web-based business on the corporate real estate and facility industry. In: CIBW70 International Symposium on Facilities Management, 2000, Brisbane. Proceedings ... Providing facilities solutions to business challenges - moving towards integrated resource management, Brisbane, 2000, p. 7-15.

VIANA, C. Modernização da gestão patrimonial imobiliária: a experiência do Estado do Rio de Janeiro, 2010. Trabalho apresentado ao Congresso de Gestão Pública do Rio Grande do Norte, 4., Natal, 2010. Disponível em: <http://www.searh.rn.gov.br/congesp/ap_palestras.asp>, Acesso em: 20 de fevereiro de 2012.

WADE, T.; SOMMER, S. A to Z GIS: an illustrated dictionary of geographic information systems. ESRI Press, Redlands, California, 2006.

WBDG. Whole building design guide. Disponível em <http://www.wbdg.org>. Acesso em: 12 de novembro de 2002.

WIKIPEDIA. Georreferenciamento. Disponível em: <http://pt.wikipedia.org/wiki/Georreferenciamento>, Acesso em: 01 de junho de 2011.

WYATT, P.; RALPHS, M. GIS applications in land and property management. London: Spon Press, 2003.

YOUNG, J. Using geographic information systems (GIS) for real property management and green building analysis, 2008. Disponível em <http://bisdm.org/downloads/FRPA_annual_conf_May08_Final.htm>, Acesso em: 12 de fevereiro de 2012.

YOUNG, J; DRAKE, R. GIS for building interior spaces and infrastructure management. 2008. Trabalho apresentado ao GITA Geospatial Infrastructure Solutions Conference, Seattle, 2008. Disponível em <http://bisdm.org/downloads/GITA2008_GIS_for_BIS_John_Young.htm> , Acesso em: 12 de fevereiro de 2012.

YURGEL, M. Laboratório de informatização de acervo (Labarq). In: Revista do Programa de Pós-Graduação em Arquitetura e Urbanismo da FAUUSP, n. 23, p. 224-232, 2008. 
Anexo I

Modelagem do Sistema 


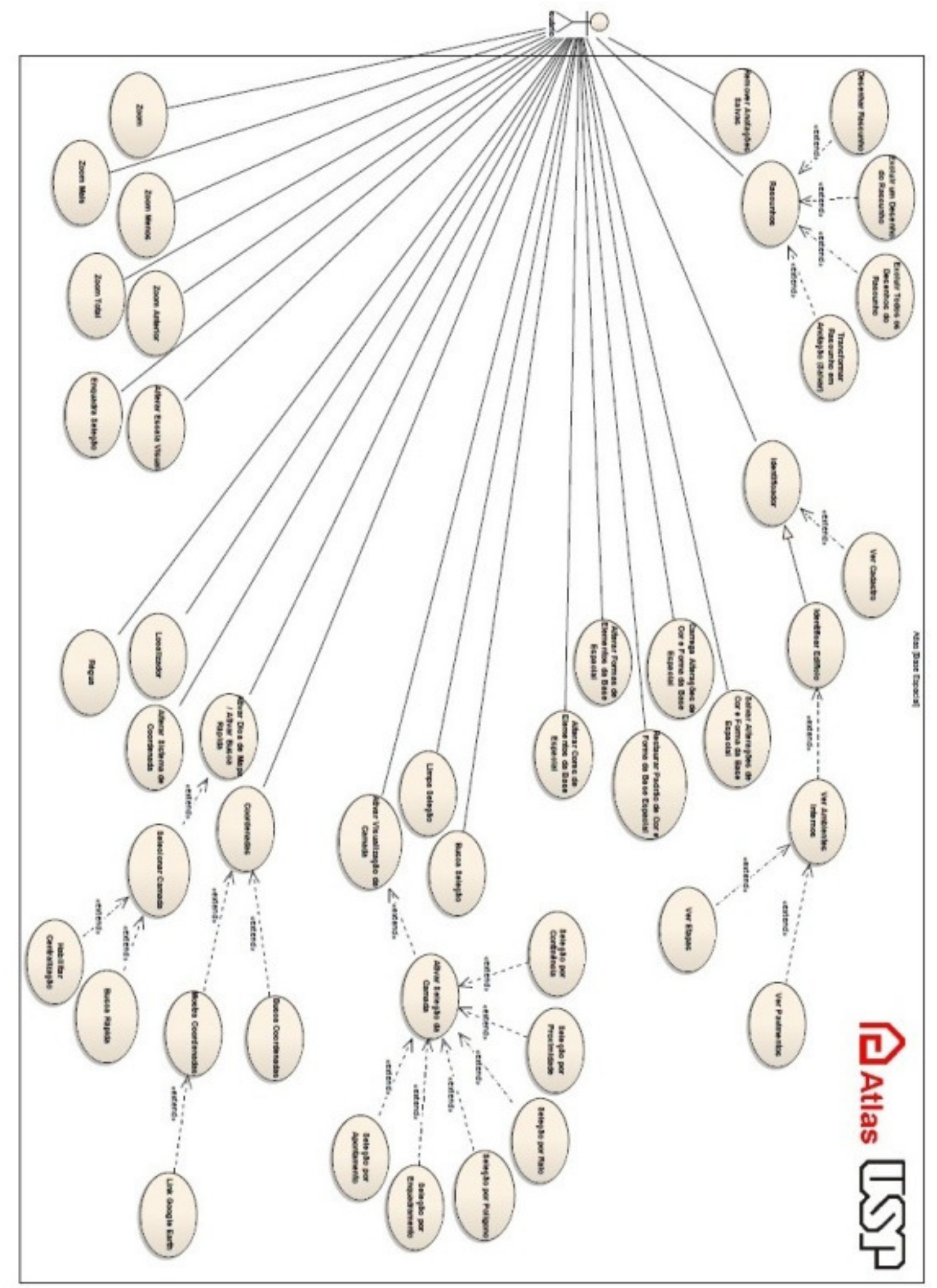

Casos de Uso da Interface Grafica 


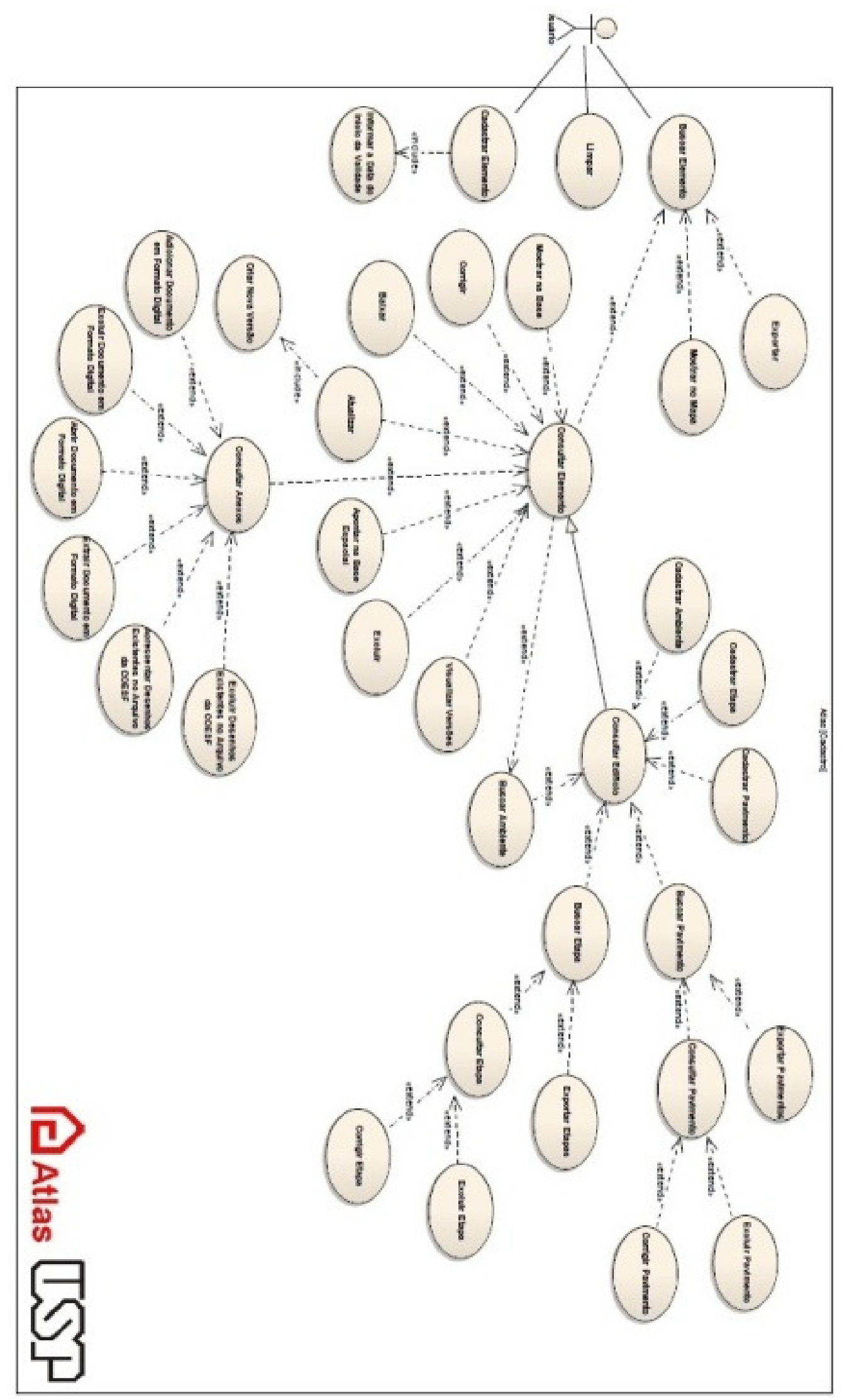

Casos de Uso da Interface de Cadastro 


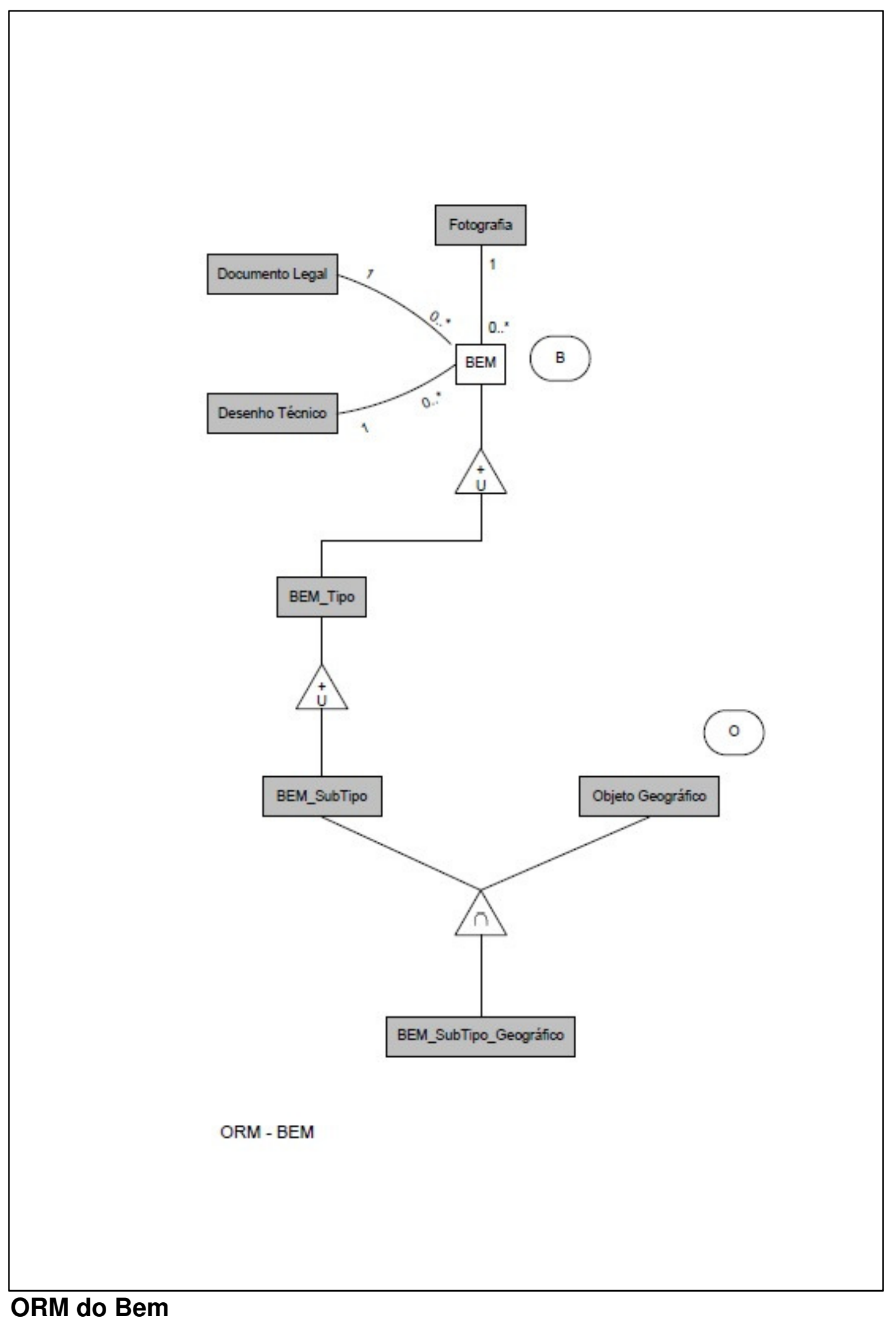




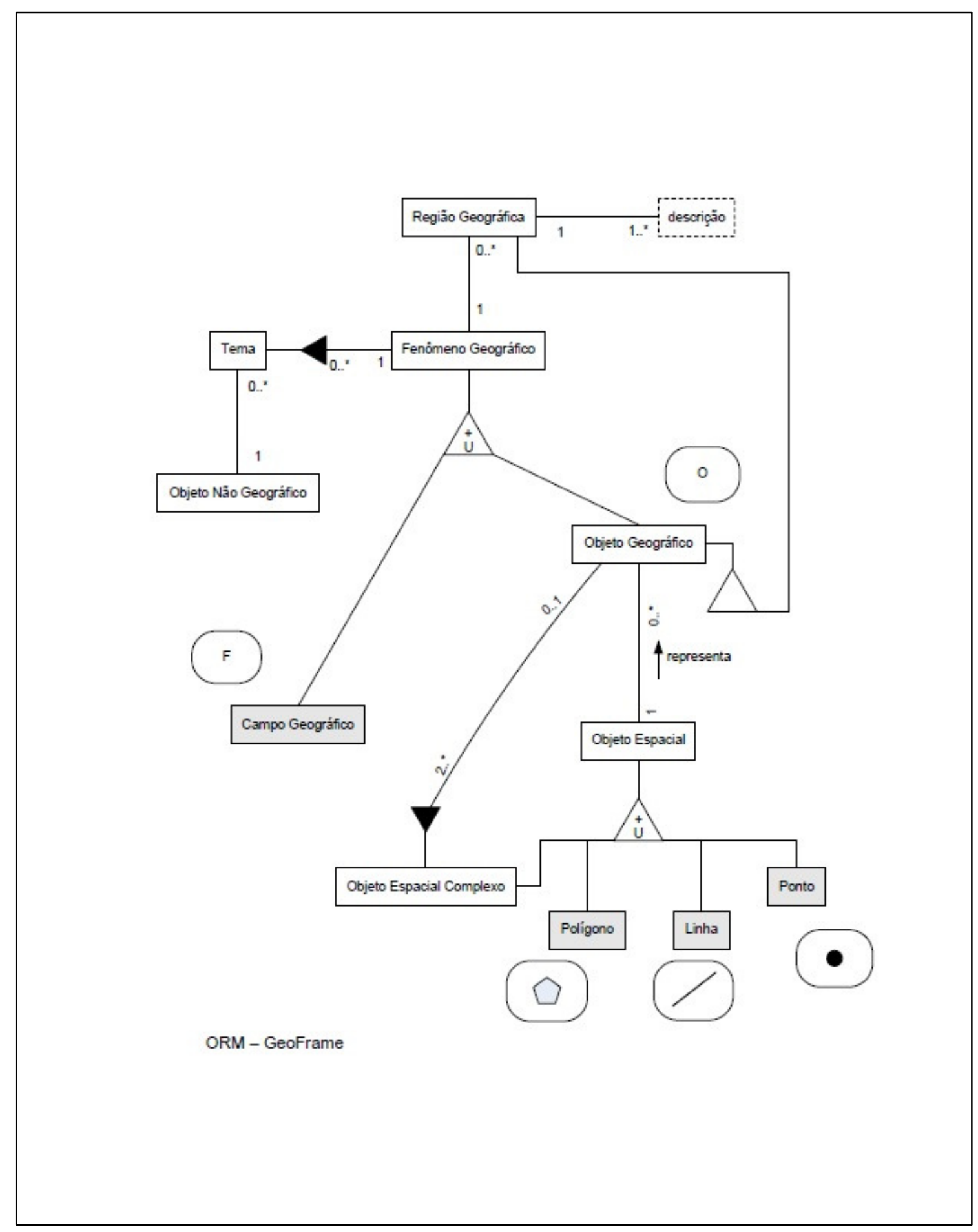

ORM dos Dados Espaciais 


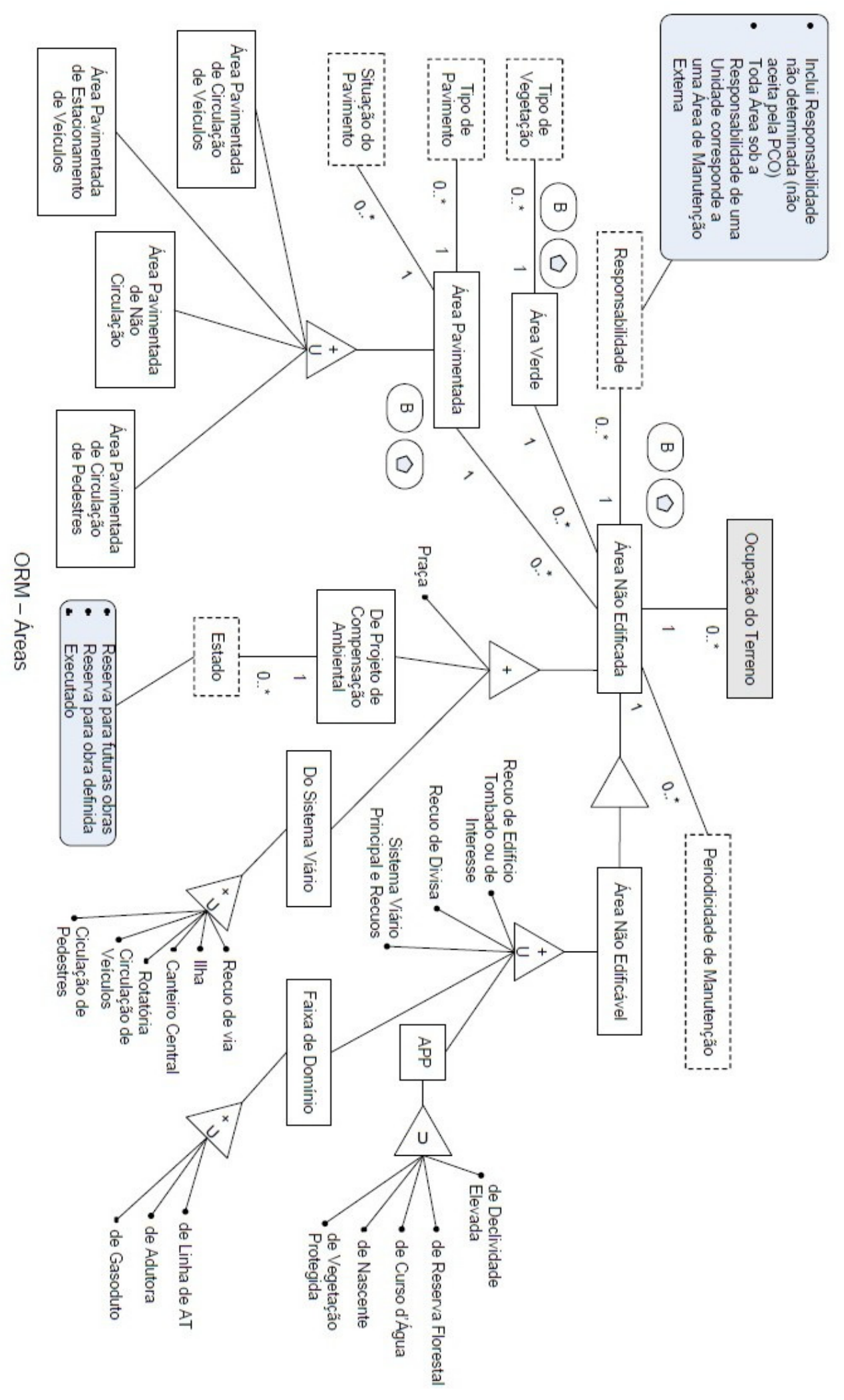

ORM de Áreas Externas 


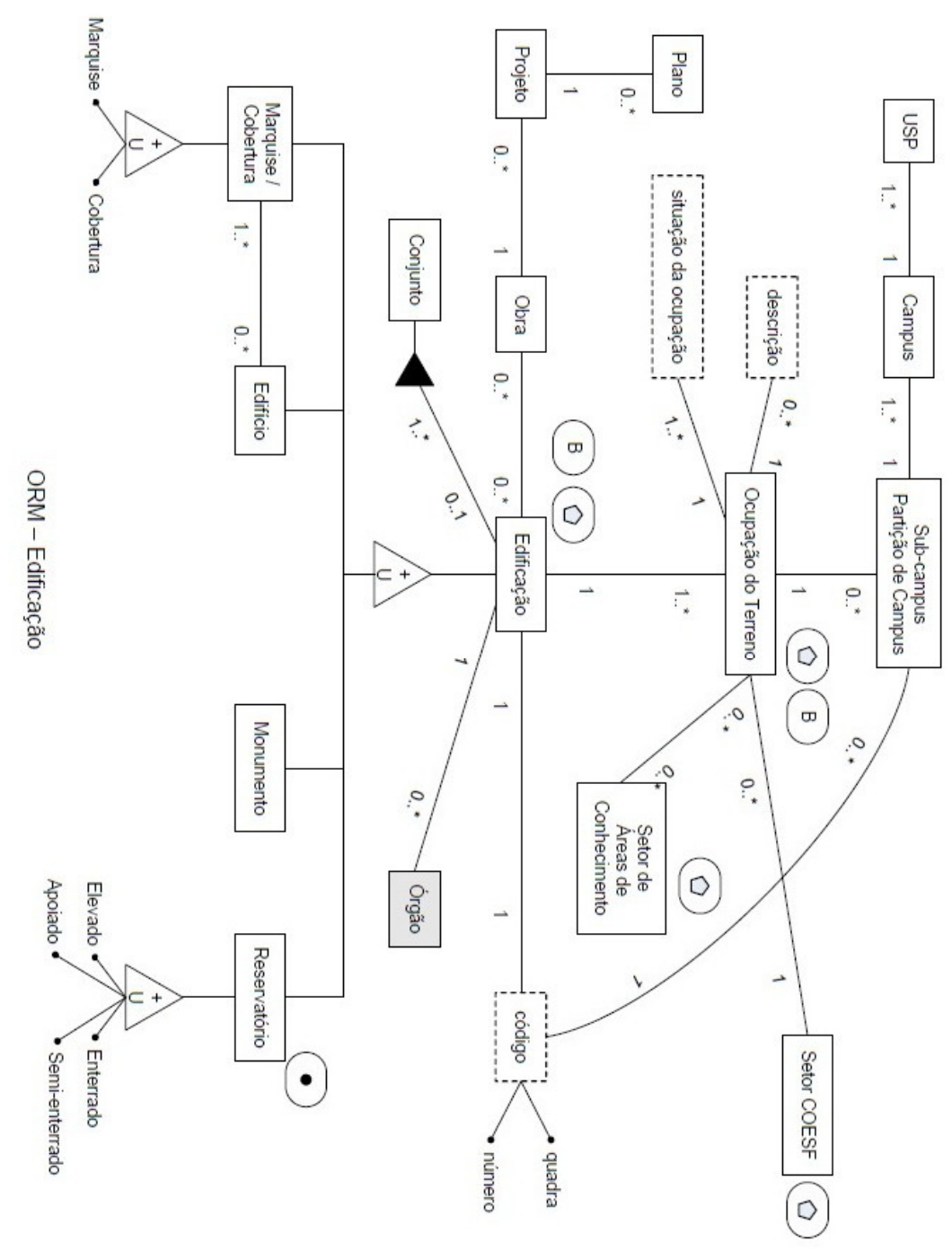

ORM da Edificação (geral) 


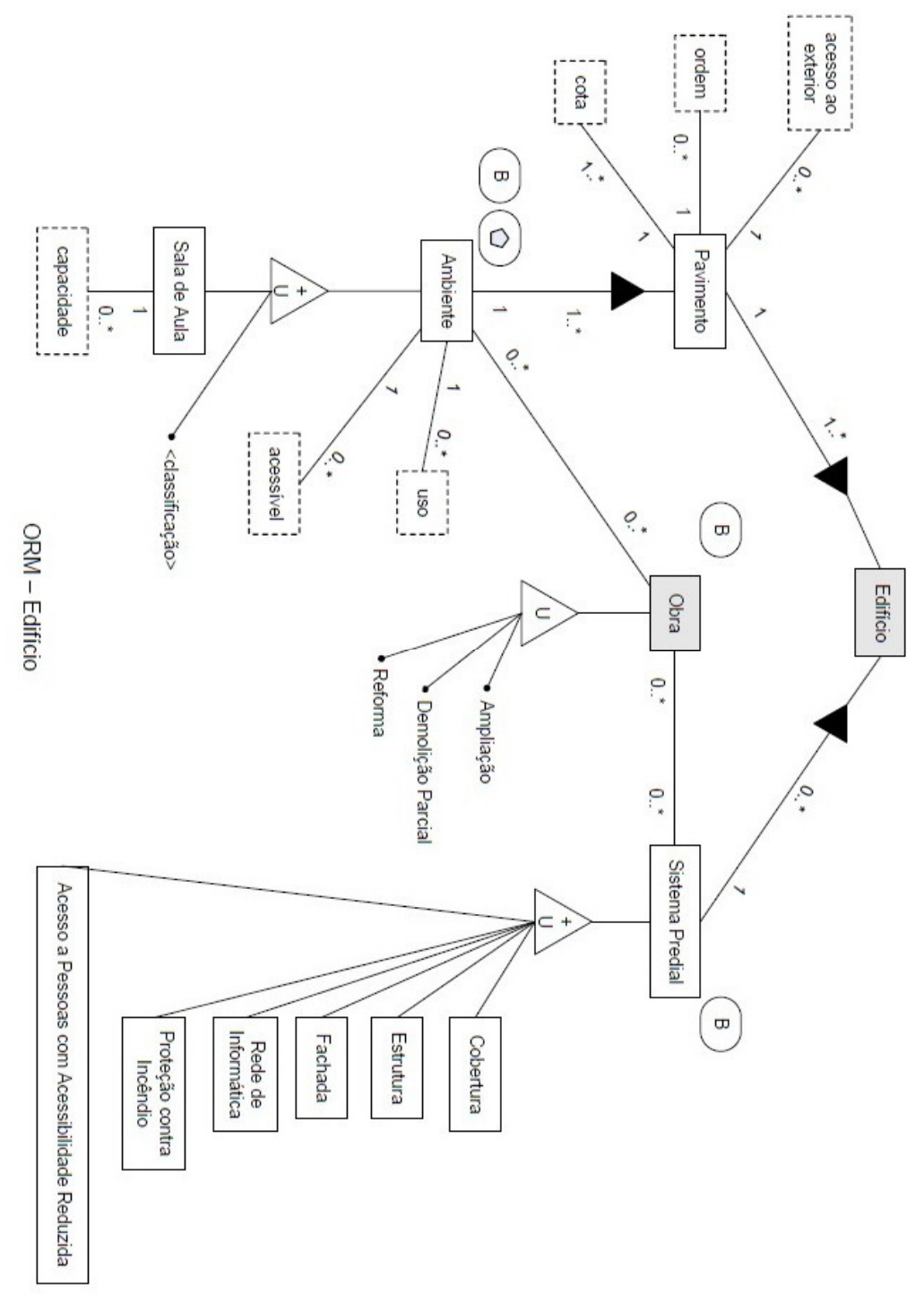

ORM do Edifício (específico) 


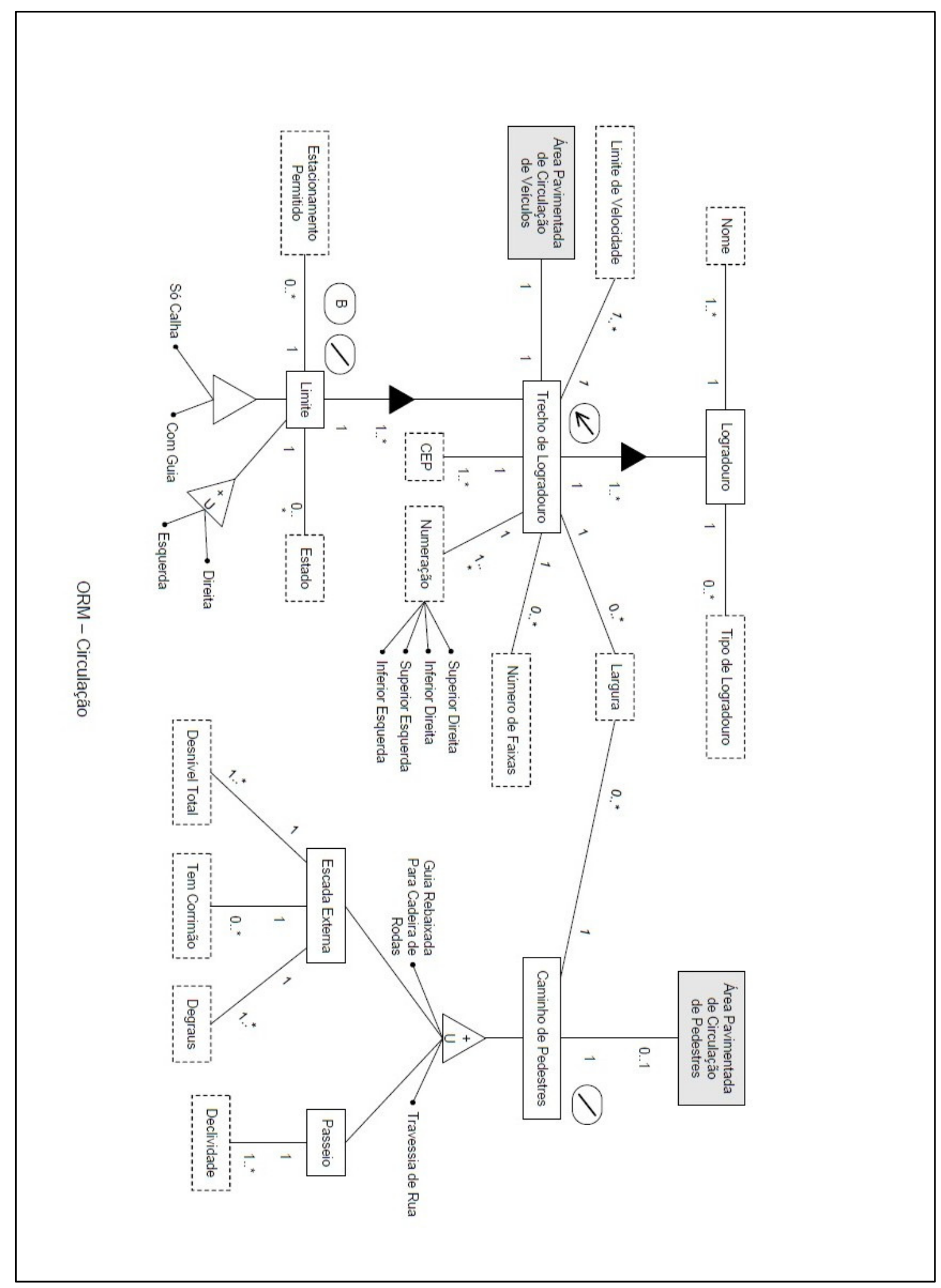

ORM dos Elementos de Circulação 


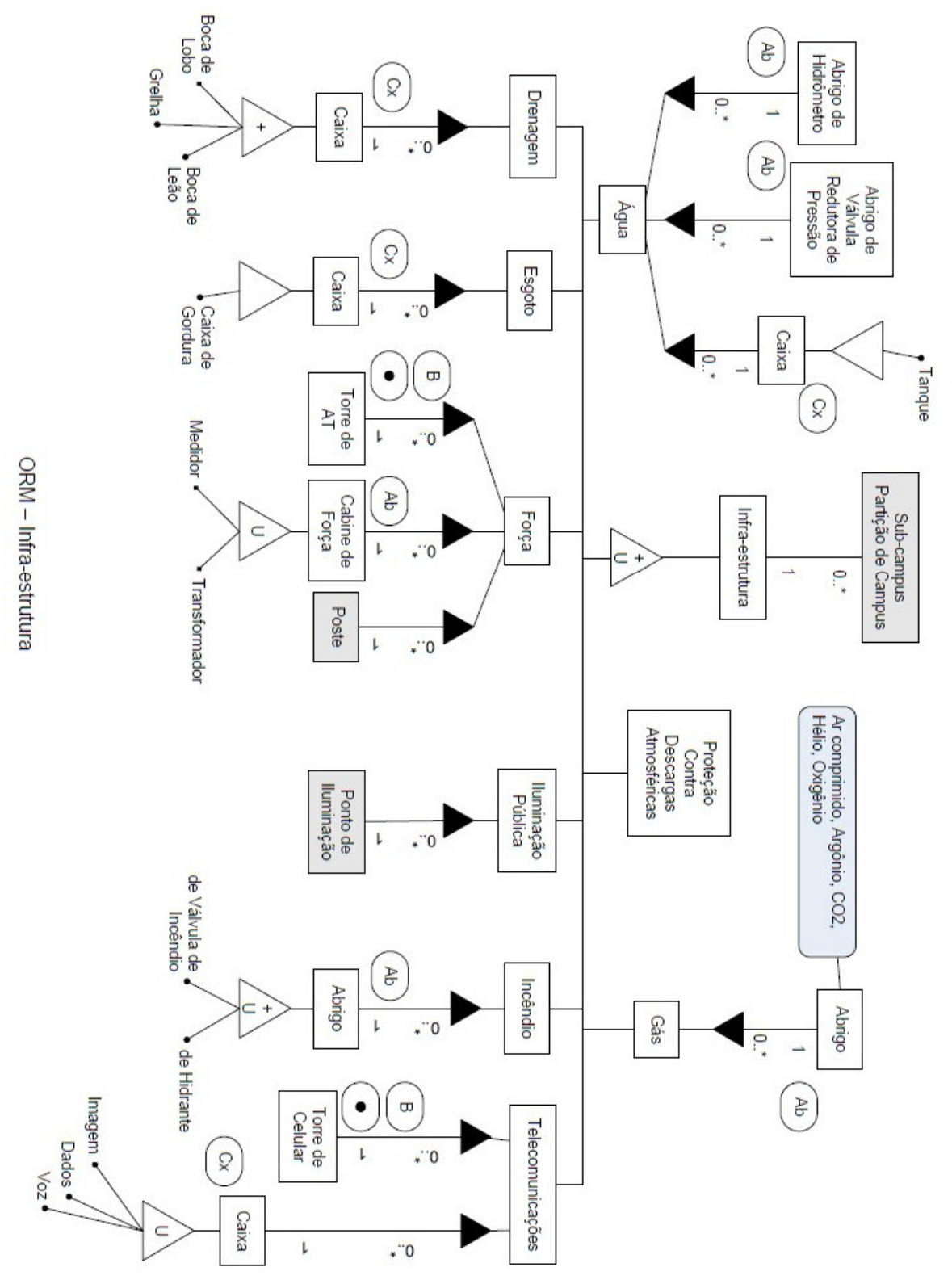

ORM dos Elementos de Infraestrutura 


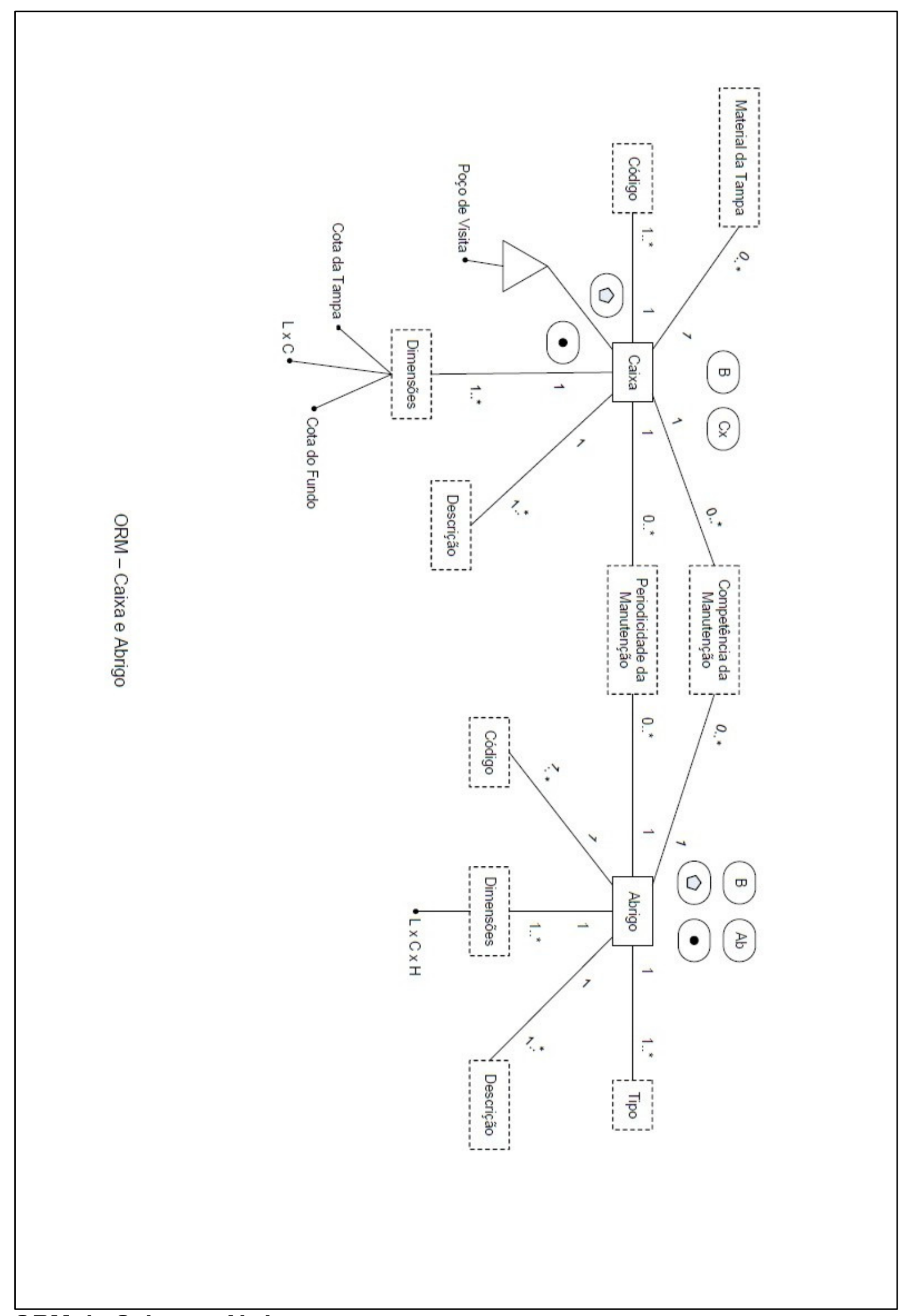

ORM de Caixas e Abrigos 


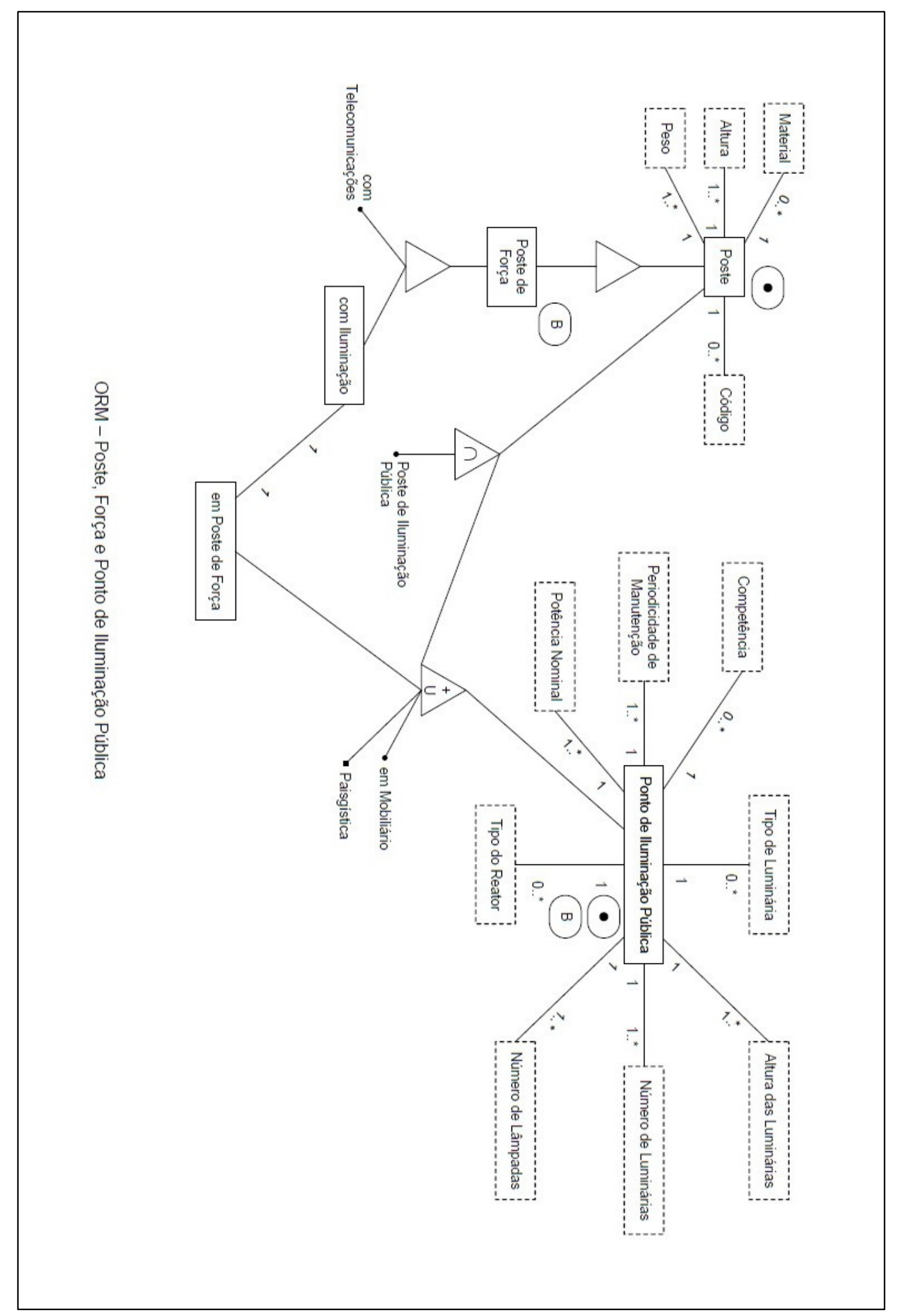

ORM de Postes de Força e de Iluminação Publica 
Anexo II

Padronização das Camadas (layers) adotadas nos levantamentos topográficos da CUASO 


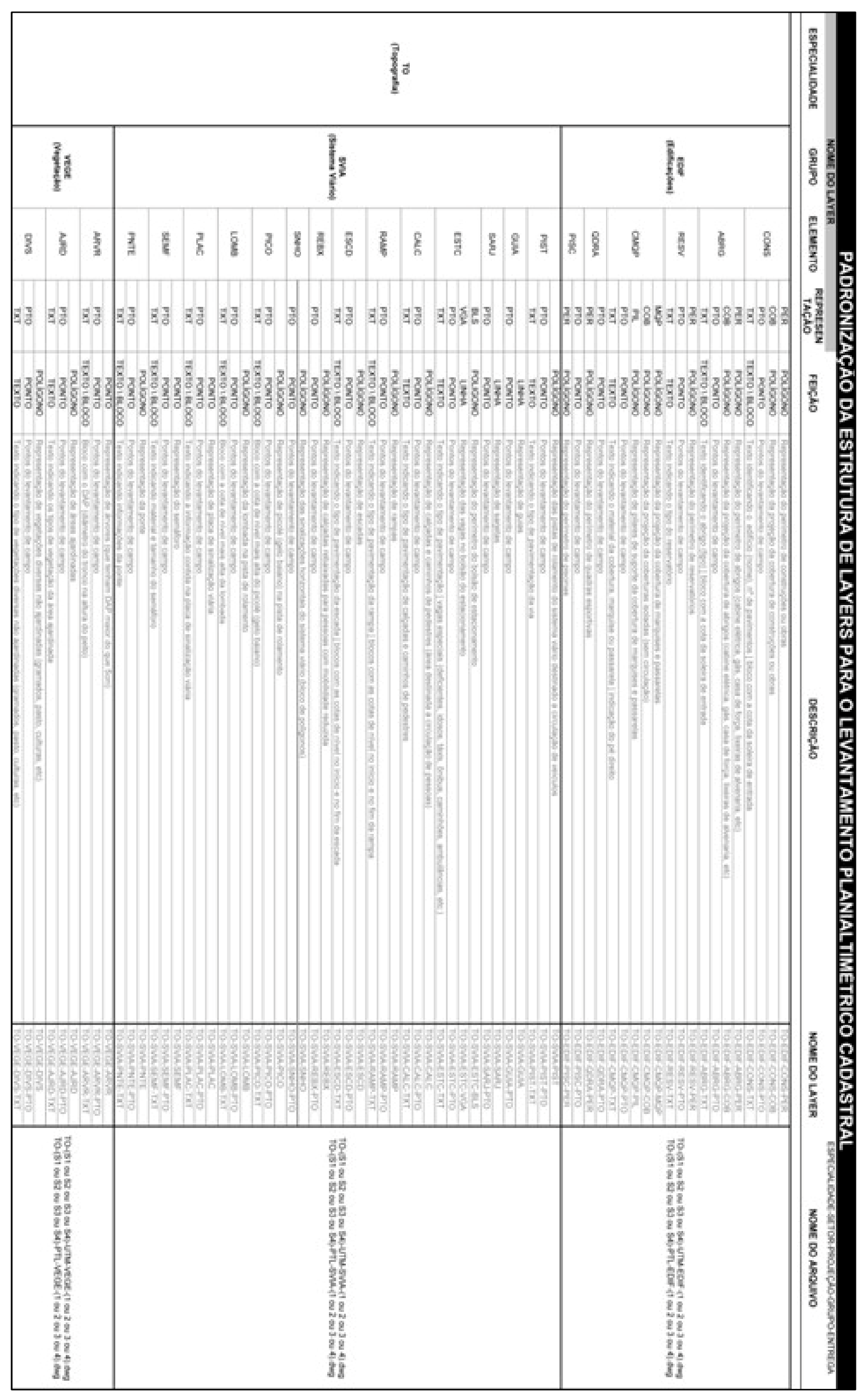




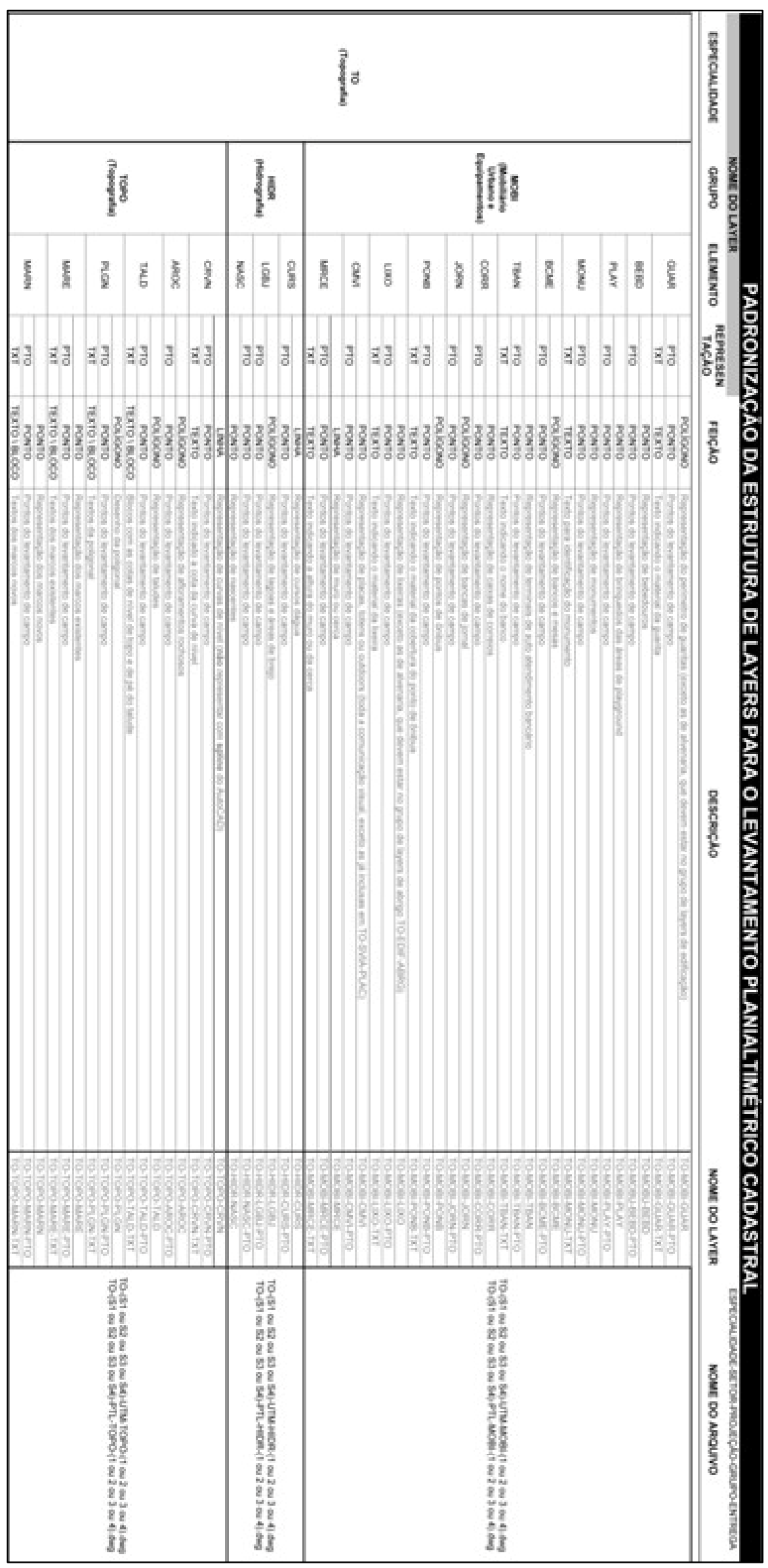




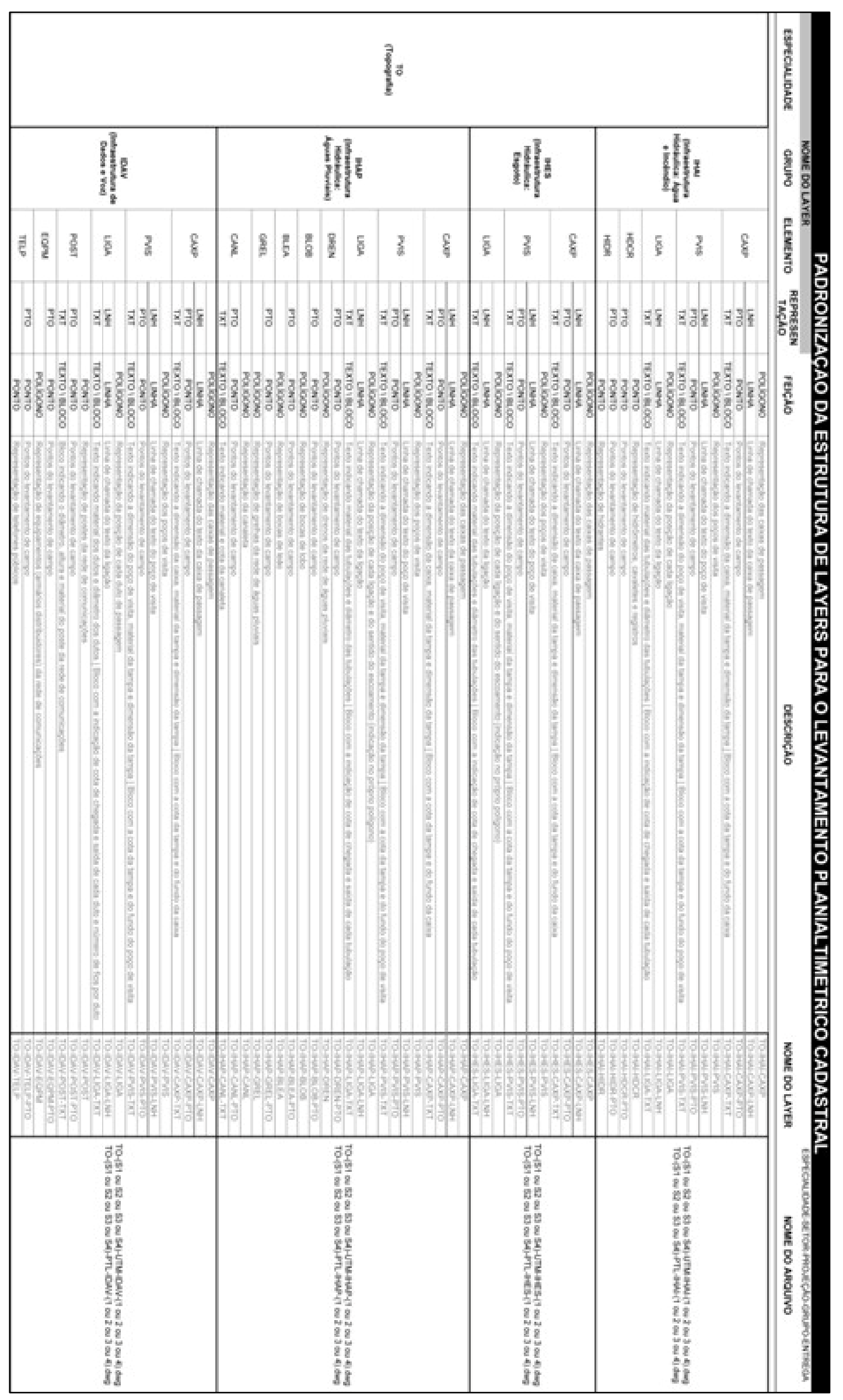




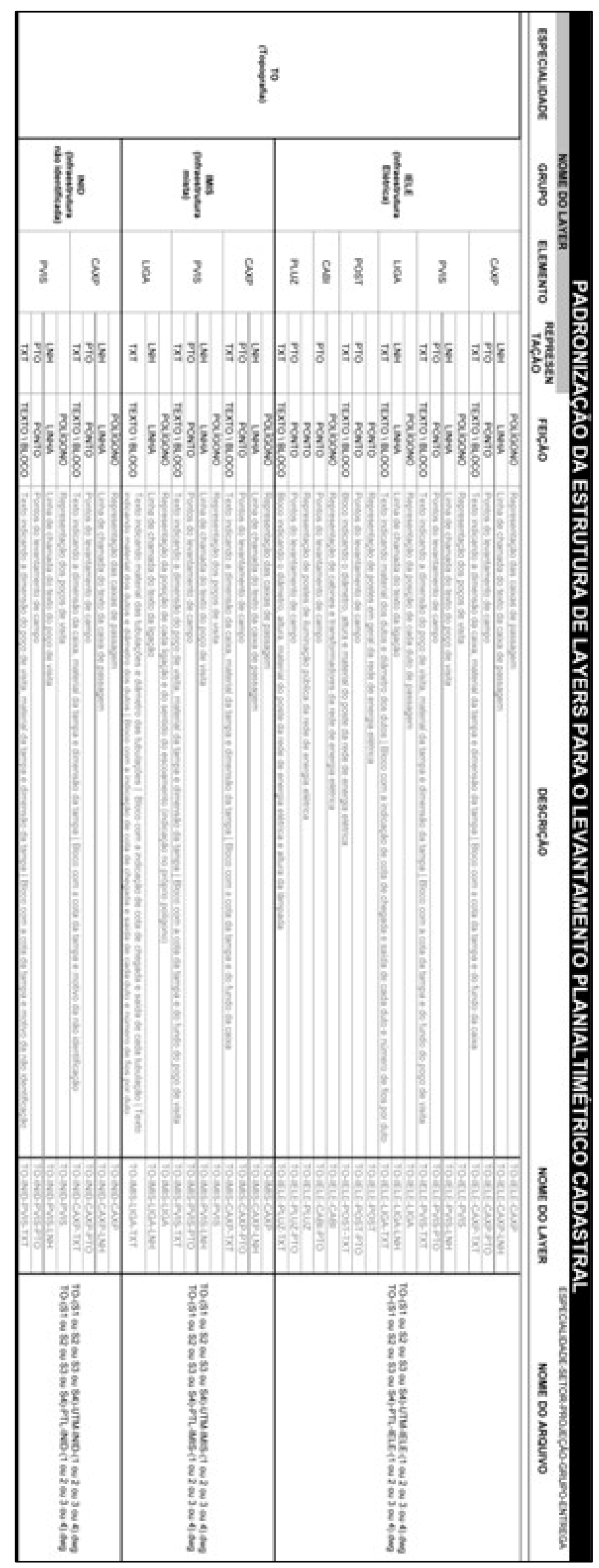

